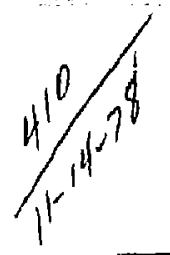

\title{
th. 721
}

UCRL. 5000\%:-77

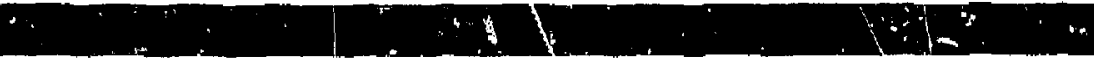

\section{MAGNETIC FUSION ENERGY ANNUAL REPORT \\ October 1976 through September 1977}

Scientific Editor: M. A. Harrison

General Editor: L. Guttlieb

- January 4, 1978

Work porlormed under the auspices of the US Depariment of

Energy by the UCLLL under contract number W.7405-EA,G-48
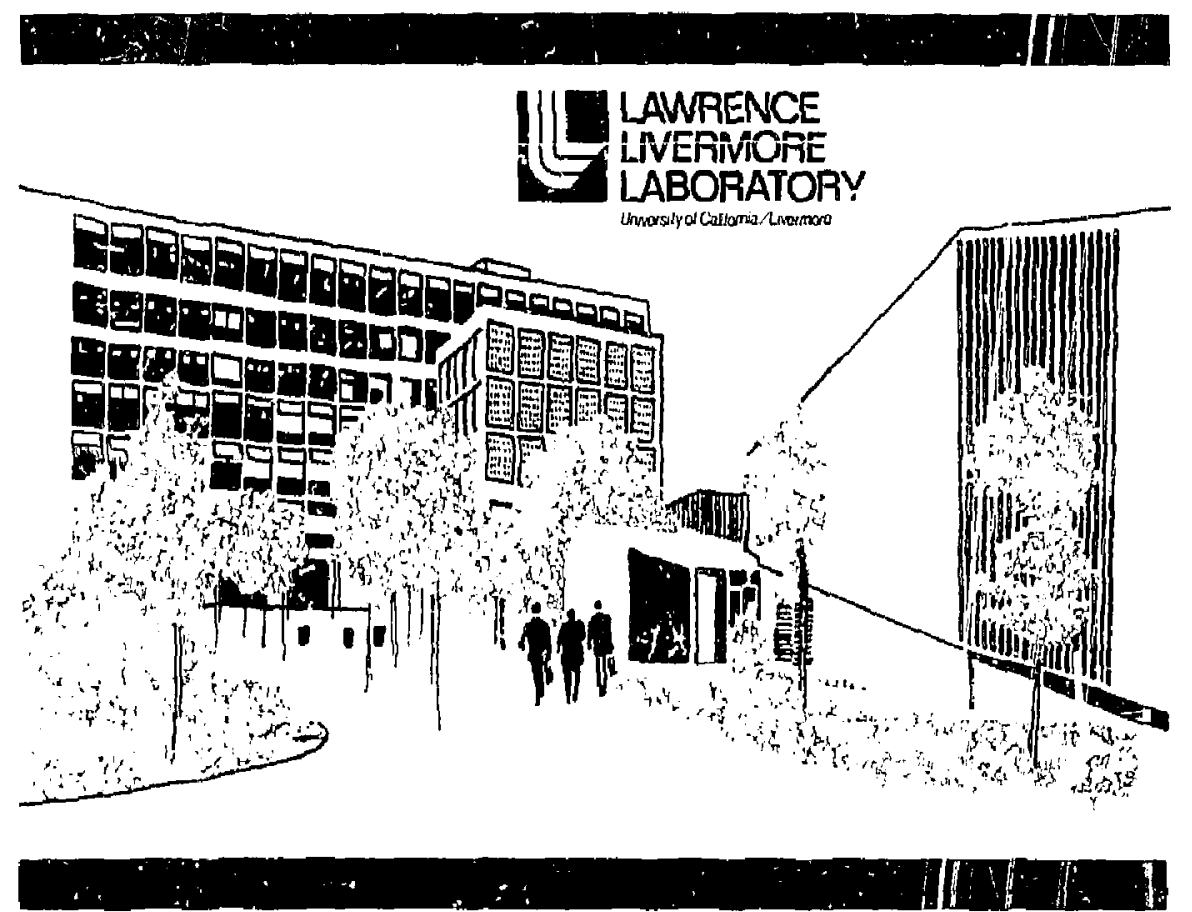


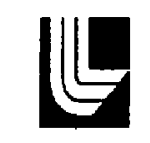

\section{IAWRENCE IIVERMORE I_ABORATORY}

UnversityolCalfornia Livermore,California 94550

\section{MAGNETIC FUSION ENERGY ANNUAL REPORT \\ October 1976 through September 1977}

Scientific Editor: M. A. Harrison

General Editor: L. Gottlieb

MS. date: January 4. 1978

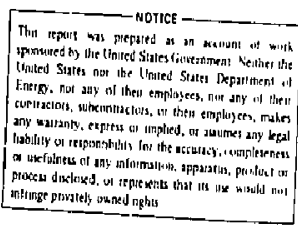




\section{CONTENTS}

Abstract $\ldots \ldots \ldots \ldots \ldots \ldots \ldots \ldots \ldots \ldots$

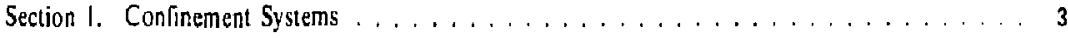

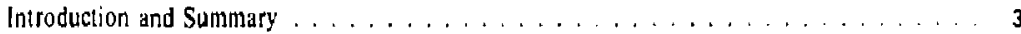

2XIIB Experiment $\ldots \ldots \ldots \ldots \ldots \ldots \ldots \ldots \ldots \ldots \ldots$

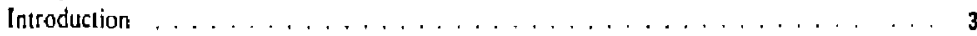

Field-Reversal Experiment . . . . . . . . . . . . . . . . . . . . . . 5

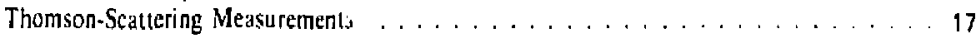

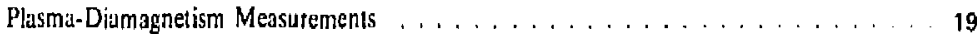

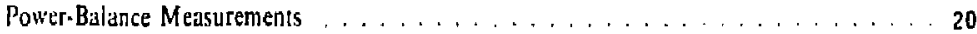

Neutron Measurements . . . . . . . . . . . . . . . . . . . 20

Zeman-Effect Magnetic-Field Diagrostic . . . . . . . . . . . . . . . . . 21

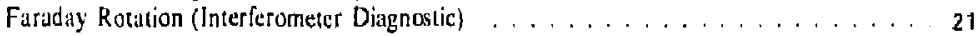

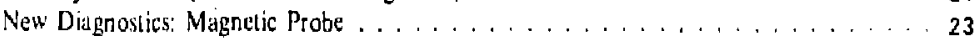

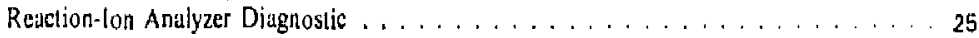

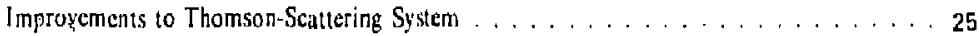

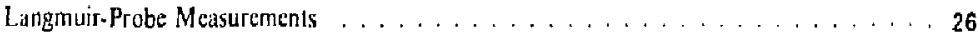

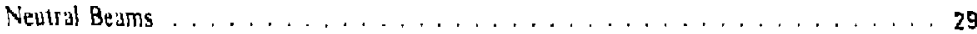

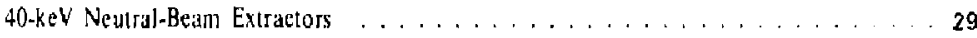

80-keV Source Design for Mirror Fusion Test Facility . . . . . . . . . . . . . 30

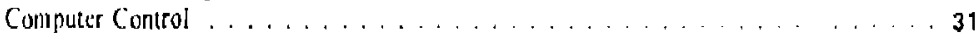

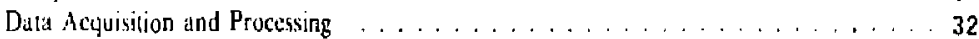

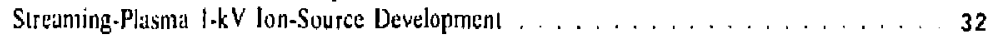

Radially Dependent Fokker-Planck Code . . . . . . . . . . . . . . . 37

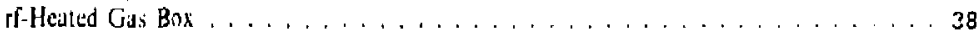

Electrical Engineering Support . . . . . . . . . . . . . . . . . 38

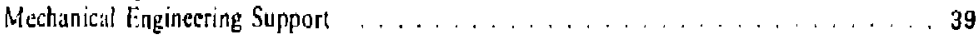

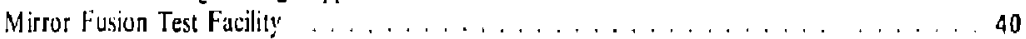

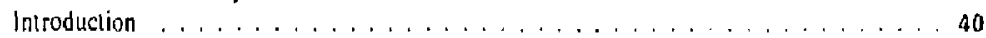

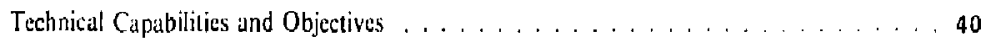

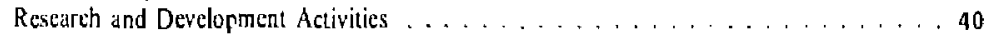

Project Design Update . . . . . . . . . . . . . . . . . . . . . . 43

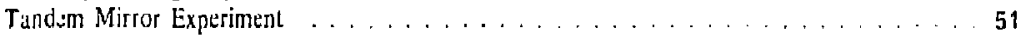

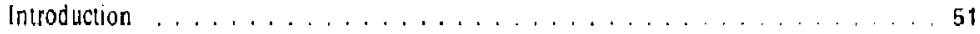

Physics Parameters ................................ 51

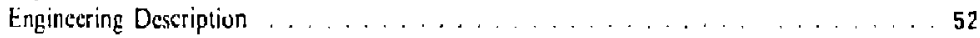

Sution 2. Development and Technolngy .................. 56

Introduction and Summary $\ldots \ldots \ldots \ldots \ldots \ldots$

Superconducting Magnet Development . . . . . . . . . . . . . . 58

Direct Energy Conversion $\ldots \ldots \ldots \ldots \ldots$

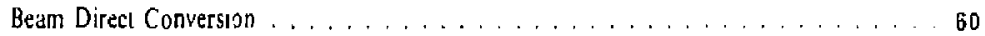

Advanced-Fueled Fasion Reactors Suitable for Direct Energ: Conversion . . . . . . . . 62

Neut ral-Beam Conceptual Studies . . . . . . . . . . . . . . 63

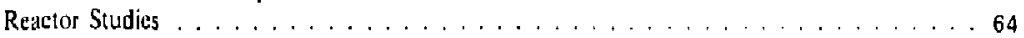

Field-Reversed Mirror Reactor . . . . . . . . . . . . . . . . . . . . 64

Preliminary Design Study of the Tundem Mirror Reactor . . . . . . . . . . . 66

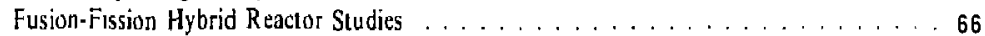

Small Mirror Reactors . . . . . . . . . . . . . . . . . . . . . . . . . . . . 69

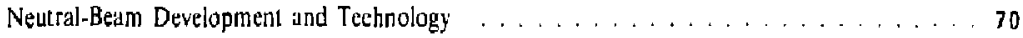

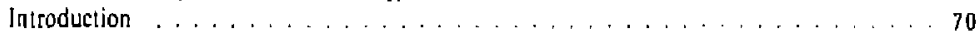

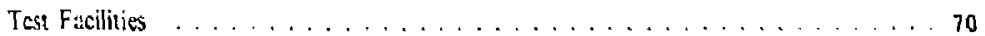

Positive-Ion-Based Program . . . . . . . . . . . . . . . . . . . . 73

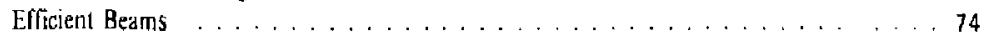

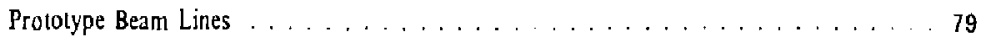

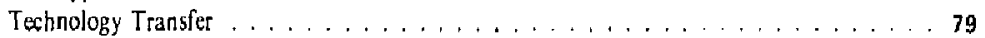




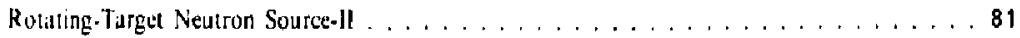

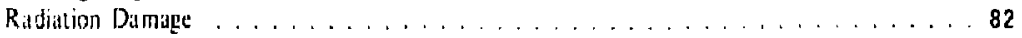

Correlation of Neutron Damage with Neutron Sources $\ldots \ldots \ldots \ldots \ldots$

Helium Elrexts on Mechanical Properties . . . . . . . . . . . . . . . . 89

Radiation Damage in Superconductors . . . . . . . . . . . . . . . . . 90

Rusistivily Measurements of Radiution-Dumage Rates . . . . . . . . . . . . . g1

Computer Wodeling of Radiation Damage . . . . . . . . . . . . . . . . 94

Rotating-Target veutron Source-! Iradiations and Dosimetry . . . . . . . . . . 95

I ritiun Handling and Control $\ldots \ldots \ldots \ldots \ldots$

Tritium Conlainment and Blanket Designs for a Mirro Fusion Central

Power Plant . . . . . . . . . . . . . . . . . . . 96

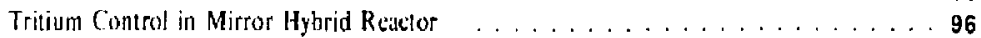

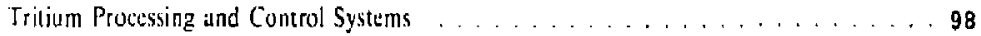

Tritiun Processing and Control Using Acljve Metal Getters . . . . . . . . . . . . . . 99

Improved Equipment and Production Procedures for Rotating-Target

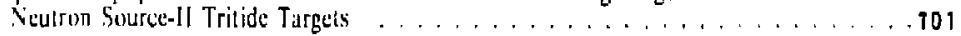

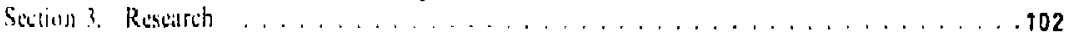

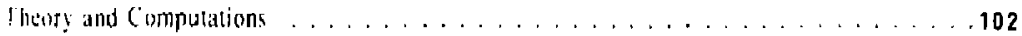

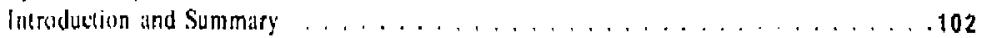

Quasilinear Codes for Ion Transpors in Mirrors ................. 103

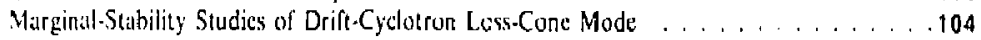

$M=1$ WOBBLE Instablity Driver by Rotation . . . . . . . . . . . . . 108

I.lectron Lflects in Ion-Current Fitd Reversal . . . . . . . . . . . . . . . 108

Reassessiment of Requirements to Obtain ficld Reversat in Mirror Machines . . . . . . . 109

Therory lor Tandem Mirror Experiment Proposal . . . . . . . . . . . . . . . . 109

Monte Carlo Veutrul-Transport Code . . . . . . . . . . . . . . . . 109

Monle Cario Simulation of the Elfects of Drift Cyclotron Loss-Cone

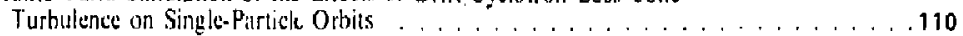

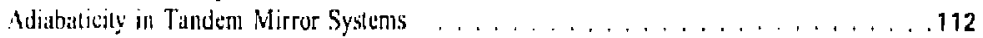

Polential-hided Conlinement in Mirror Machinıs . . . . . . . . . . . 113

Talndem Mirror Rale Code . . . . . . . . . . . . . . . . . . . . . . 114

Hisic Studies of Dynamical Systems . . . . . . . . . . . . . . . . . . . . 114

Axjal How Code for Warm Plasma in a Mirror Mahine . . . . . . . . . . . . . 115

Wonte Carlo Simulation of Neutral Partickes . . . . . . . . . . . . . . 115

diabutic Invariants by Lic Transforms . . . . . . . . . . . . . . . . 116

Tinden Mirror Studies . . . . . . . . . . . . . . . . . . . 117

Conversjon of Bounce-Average Code $10 \mu$.J Spice . . . . . . . . . . . . . . 119

Milenetohydrodynamic Equilibriun and Stibiliay of Minimum-B Mirror Traps . . . . . 120

the Inirio Multicunfiguration Sell-Cansistent Grosid-State-Putential

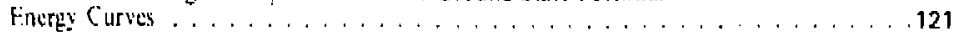

Finmation Processes and Secundary-Emission Coefficients for Negative-Deuterium

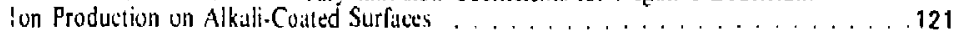

Ridiation Losses an 1 XIIB Using the Prono Source . . . . . . . . . . . . . 121

Cimputer Calculations of 2 XIIB Field-Reversed Mirror Configurations . . . . . . . . 121

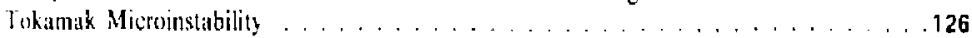

Computer Simulation of High-Beta Mirror Plasmas . . . . . . . . . . . . 126

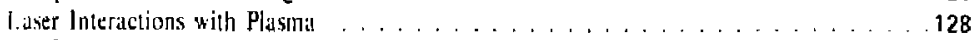

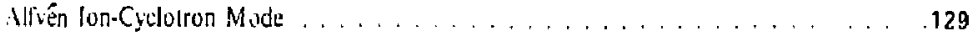

i-D (alculations of Mirror Equilibria with the Finite-Element

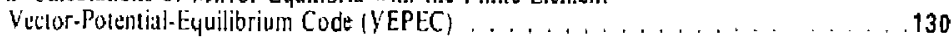

Preliminary Planning for a 3-D Multifluid Magnetohydrodynamic Mirror-Plasma

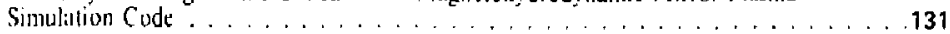

Accurale Single-Purcicle Orbils in Reulistic 3-D Minimum-B Mirror Ficids . . . . . . . 132

Paranter Studies of Axisymmetric Reversed. Field Vlasov Equilibria for the

2XIIB Regime with the CYLEQ Code . . . . . . . . . . . . 132

Cilleulation of 2 XIlB Sello Fields from Experimental Data . . . . . . . . . . . 132

2.D Axisymmetric Fluid Simulation of Plasma Production and Flow in lon Beams . . . 133 
Implementation of Incomplete Cholesky Conjuquate-Gradient Mathod . . . . . . 133

3-D Plasma Equilibrium . . . . . . . . . . . . . . . . . 134

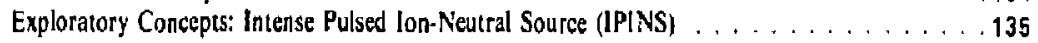

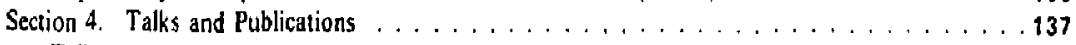

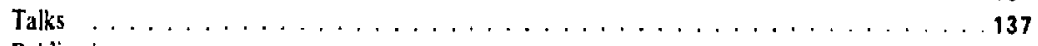

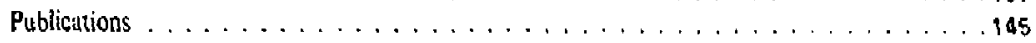

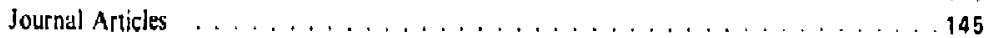

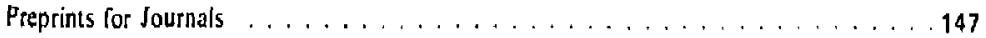

Reports . . . . . . . . . . . . . . . . . 148

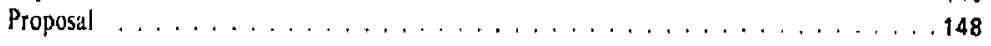




\title{
MAGNETIC FUSION ENERGY ANNUAL REPORT October 1976 through September 1977
}

\begin{abstract}
This year we moved beyond the straightforward magnetic mirror experiments (of 2XIIB and Baseball II-T) to substantially larger ones. These new experiments, the Tandem Mirror Experiment (TMX) and the Mirror Fusion Test Facility (MFTF), will bring us closer to reactor concepts and to issues that must be settled before reactors are built.

Our confinement-systems activities reatured improved operating and plasma parameters in 2XIIB, the start of TMX construction, and extensive engineering design on MFTF. We upgraded the performance of 2XIIB's neutral-beam sousces, doubling injected current and electron temperatures. Also, we achieved even higher values for peak beta (plasma pressure/magnetic pressure). The higher beta implied a close approach to a fieldreversed state. Along with the construction start on TMX, we performed further computations relating to this promising idea. On MFTF, we completed the design of its large coil winder and development of its coil conductor.

To support our mirror-confinement experiments, we furthered the development of state-of-the-art technologies in many areas. Our superconducting magnet program saw successful operation of a production line for adding a "wraparound" stabilizer to the MFTF coil's superconducting core. We successfully developed a cold-weld technique for making superconducting joints. As a result of mechanical strain tests, we concluded that the superconducting material niobium tin could tolerate practical strain and be used in high-field magnets. After meeting our goals at $15 \mathrm{keV}$ in the direct energy conversicn program, we built and installed a $120-\mathrm{keV}$ beam-direct convertor in Lawrence Berkeley Laboratory's IIIA test stand. In the area of reactor studies, several designs were completed: a conceptual design of a 100-MWe vertical-stacked multicell reactor, a preliminary design of a 1000 MWe tandem mirror reactor, and a reference conceptual design of a fusion-fission hybrid retictor based on a classical mirror plasma and a depleted uranium blanket. Our neutralbeam program reported significant improvements in two major test facilities. On the IllA stand, we successfully evaluated "magnetic core snubbers" for spark-damage control; the IIIB stand became operational, powering and controlling our first full-curtent neutral-beam source for the Tokamak Fusion Test Reactor. Construction continued on the RTNS-II (Rotating-Target Neutron Source), a new 14-MeV neutron source to obtain data on reactor materials at higher doses. Using RTNS-II and beryllium $(d, n)$ sources, we explored the nature and magnitude of radiation damage effects produced by their neutrons. The tritium technology group continued its studies to control tritium emissions and clean up tritium in both fusion and hybrid reactors.

The theory program had imprevements in the linear theory of drift cyclotron loss cones and in the concomitant quasilinear theory. We delineated the major theoretical problem areas for tandem mirrors and performed first-cut analyses of many of these. Field-reversal studies led to an understanding of the role electron currents play on the buildup to and mainterance of this configuration. Our computational gro:in focused on understanding field reversal in 2XIIB and on modeling for TMX. A large effort went into applying the
\end{abstract}


SUPERLAYER computer code to modeling rf drift-cyclotron loss-cone diffusion. We underlook a variety of parametric studies to accurately model $2 X I I B$ and to determine mode] sensitivities. Development continued on physics models and new simulation methods that describe important electron physics features in a high-beta plasma. Using a 2-D mullispecies Fokker-Planck code, we began a number of studies on tandem mirror systems. A 3-D fluid-equilibrium code, McGus, was applied to studies of MFTF, the TMX end cells, and several reactor designs. 


\section{SECTION 1. CONFINEMENT SYSTEMS}

\section{Introduction and Summary}

Our main con'inementi-related developments concerned further improvements in 2XllB operating and pla sma pararineters and design anć construction of two new mirror facilities, the Tandem Mirror Experiment (TMX) and the Mirror Fusion Test Faciliy (MFTF).

By upgrading the performance of the neutralbeam sources in $2 X][B$, we doubled the injecled current-from 250 to $500 \mathrm{~A}$. As a result of this increased current und of improvements in the vacuum pumping and other paramelers of 2XIIB, electron temperatures also roughly doubled-up to a maximum value of $180 \mathrm{eV}$ and routinely atlained values of $140 \mathrm{er}$. That such clevaled values could be ab. tained was especialiy significant from a plasma physics standpoint for the following reason: demonstration of such values removed a possible ambiguily in the interpretation of heal-conduction effects between the hot plasma and the outside world. Al 60 to $80 \mathrm{eV}$ it might have been claimed that electron temperature $\left(T_{e}\right)$ was being controlled by classical electron thermal conduction, a process thal would represent a "clamp" on further increases in $\mathrm{T}_{e^{\prime \prime}}$ The achievement of 140-10-180-eV alectron temperatures implied a substantial degree of decoupling present between the interior plasma and the exterior regions. Though we would expect this result from our picture of the physics of mirror confinement, its direct demonstration. refuting the pessimistic interpretations, was gratifying.

Another rcsult of the upgrading of 2 XIIB paramelers was the achievement of even higher values for peak beta (plasma pressure/magnelic F. essure): up to 2.S. This implied a close approach to a field-reversed state. Experimentally, the fieidreversal parameter $(\mathrm{AB} / \mathrm{B})=0.9 \pm 0.1(\mathrm{AB} / \mathrm{B}>1.0$ corresponds to field reversal). While we do not know whether lurther increases in $\triangle B / B$ will be possible with 2 XIIB as it stands, we were encouraged by the achievement of such high bela values with the present facility. We formulated plans for additional upgrading to push further toward field reversal, including the possibility of higher current, pulsed neulral-beam sources.

Consisuction began on TMX, and further compulations relating to this promising idea were per. formed. The planned TMX completion date is October-November 1978.

We completed the design of the large coil winder and development of the coil conductor for the large mirror facility, MFTF. Extensive enginecring design was also performed on MFiF, which is planned for completion in 1981-1982.

Thus, we vigorously pursued implementation of new directions for mirror research. the tundem. mirror, and the field-reversed micror, as ourlined in the last progress report.

\section{Author \\ R. F. Post}

\section{XIIB Experiment}

\section{Introduction}

During FY 1977 we directed ous activities toward the investigation of field-reversial geometries in mirror-configured plasmas. Simultuneously, we developed new diagnoslics, improved existing ones, and started supporling projects in such areas as new plasma-stream sources and higher energy neutral beams.

Using existing high-current neutral-deuleriumbeam injectors ${ }^{1}$ and stabilizing the drift-cyclotron loss-cone (DCLC) instability, ${ }^{2}$ first with streaming. plasma injeclors ${ }^{3}$ and then with a gus-feed system. ${ }^{4}$ we achieved an unprecedented high $\beta$ (plasmil pressure $/$ magnelic pressure $)=8 \pi n \mathrm{E}_{\mathrm{i}} / \mathrm{B}_{\mathrm{vic}}^{2}(\mathrm{n}=$ plasma density, $\vec{E}_{j}=$ mean ion energy, $B_{\text {vac }}$ = vacuum magnetic-field strength) in our 2 XIIB series of magnetic mirror plasma-conlinement experiments. With gas-feed stibilization the peak beta $(\hat{\beta})$ at the plasma center exceeded unity. This development, logether with 1 he recognized necessily of enbancing the $\mathrm{Q}$ (fusion power oulput/neulra) beam injected power inpul) of reactor schemes based on the mirror mackine concept. ${ }^{5}$ led to the field-reversal experiments on $\mid x e$ 2XllB device described hete. Fokker-Planck culculations of classical mirror transport, with all the plasma confined on open field lines, predieted $Q$ values close to unity. ${ }^{6}$

A preliminary study of a field-reversed mirror reactor (FRM), in which the bulk of the plasma is confined on field lines closed by plasma diamagnetic currents, predicts $Q \simeq 5,7$ assuming Iransport dominated by classical collisions. The concept of the FRM differs from the earlier Ástron scheme ${ }^{8}$ in that field reversal is maintained by bulk plasmadiamagnelic currents rather than by a separate layer of energetic electrons or ions, Other approaches to field reversal include the ion-ring compressor, ${ }^{9}$ field-reversed ion rings formed by cusp injection. ${ }^{10}$ field-reversed theta pinch. " and adiabatic compres- 
sion of plasma-gun-injected vortices. ${ }^{12}$ To date ficld reversul, in the sense of internal magnetic field upposilc applied field, has been achieved by trapping relativistic electron rings in gas, ${ }^{13}$ cusp injec. tion of a relativistic electron beam into gas ${ }^{\text {if }}$ or preionized plasma, Is and in field-reversed theta pinches. ${ }^{\prime \prime}$

We directed the 2XIIB experiments described here toward obtaining the largest reversal of the vacuum magnetic-field strength with our existing set of neutral-beam injectors and a streamingplasma/gas-feed-stabilization method. Principal clianges in 2XIIB operation compared with earlier experiments were

- Increased neuirat-beam injection power achicved mainly by installation of improved neulralizers.

- Off-axis aiming of the beams tangential to trapped ion gyro-orbits to enhance the axisencircling component of the ion-diamagnetic current and to intreuse the plasma cnergy density.

Tuble I sumntrarizes the best results outained for three particula! data runs. Shown in Table I for each data run are $B_{\text {vac }}$ at the center of the minimum. B mugnetic well, I $I_{\text {bain }}=$ injected neutral-deuterium $\left(D^{\circ}\right)$ current in equivalent amperes, $R_{p}=$ mean plasma radius, $m=$ total plasma magnetic dipoic moment, $\bar{E}_{j}=$ mean ion energy, $T_{e}=$ dectron lem. perature, and the estimated field-reversal parameter $(\zeta)=\lrcorner B / B_{\mathrm{yje}}$ ( $\zeta$ is the change in field strengt. at the plasma center divided by the vacuum-field sirength.)

For the internal field point opposite the vacuum field and slosed field lines to form, 5 must exceed unity. Measurement of this parameter requires an inlernal nonperturbing measurement of magneticfield strength. Two methods being developed for this measurement on 2XlJB-a Faraday rotation measurement 16 and a resonance fluorescence Zecman probe ${ }^{17}$-are unavailable for the data reported here. The values of $\zeta$ in Table $!$ are estimated from the bulk plasma dipole moment (m), measured by a large diamagnetic loop a round both the plasma volume and $R_{p}$. Internal probe measurements are not possible because of noniocal destruction of plasma confinement and melting of probe material.

Table 1 . Summary of 2 XIIB field-reversal experiments.

\begin{tabular}{|c|c|c|c|c|c|c|c|}
\hline Date & $\begin{array}{l}b_{\text {vac }} \\
\langle\mathrm{kG}\rangle\end{array}$ & $\begin{array}{l}\text { Ibeam } \\
\text { (A) }\end{array}$ & $\underset{(\mathrm{cm})}{\mathrm{R}_{\mathrm{p}}}$ & $\left(M A \cdot \mathrm{cm}^{2}\right)$ & $\begin{array}{c}\bar{E}_{i} \\
(\mathrm{keV})\end{array}$ & $\underset{(\mathrm{e} V)}{T_{\mathrm{r}}}$ & $\frac{\Delta \mathbf{B}}{\mathbf{B}}$ \\
\hline $3 / 30 / 77$ & 6.7 & 400 & 8.7 & 18 & 12.5 & 75 & 0.4 \\
\hline $4 / 14 / 77$ & 4,35 & 400 & 6.5 & 14 & 10.0 & 50 & 0.9 \\
\hline $9 / 12 / 77$ & $i .7$ & 500 & 6.5 & 14 & 12.5 & 30 & 0,6 \\
\hline
\end{tabular}

For the first data run. shown in Table $I$, we injected up to $400 \wedge D^{\circ}$ at a mean energy of $14 \mathrm{keV}$ into a $6.7-\mathrm{kG}$ vicuum field (mirror ratio $=2.0$ ) achicuing an estimated $\zeta=0.4$. Subsequently, we attempted to reverse a lower vacuum.field strength of $\mathrm{B}=4.35 \mathrm{kG}$ (mirror ratio $=1.8$ ); this produced the best result ( $\zeta=0.9$ ).

Reducing the field further is not uffective because it lowars the electron temperature (not unless the mirror ratio is helu constunt) and results in poor ion confinement owing to Spizer drag. This trend can be seen in the first two rows of Tuble 1 , where $T_{c}$ dropped from 75 to $50 \mathrm{eV}$ as $B_{\text {wac }}$ decreased from 6.7 to $4.35 \mathrm{kG}$ and where the increased Spilzer drag craused $\overline{\mathrm{E}}_{\mathrm{j}}$ to drop from 14.5 to $11.8 \mathrm{keV}$.

The next series of experiments sought to improve $\zeta$ by raising $T_{e}$. Our motivation for increasing $T_{e}$ was twofold. First, the ion energy loss rate of the earlier experiments could be accounted for by classical Spitzer drag on the electrons, and this was reduced by raising $T_{c}$. Second, the particlesimulation computer code SUPERLAYER ${ }^{18}$ predicled an increase in $\zeta$ for an increase in $T$, provided the ion loss rate was dominated by Spitzer drag. We raised $T_{c}$ by increasing the neutral-beam injection curfent to $500 \mathrm{~A}$ (primarily by installation of improved neutralizers), by using stubilizing̨, streaming plasma injectors on the radial boundary of the plasma rather than the center, and by retursing to the $6.7-\mathrm{kG}$ vacuum field. As can be seen in the third row of Table I. $T_{\mathfrak{c}}=130 \mathrm{eV}$ was atlained, a nearly two-fold increase compared with the earlier experimen! at $6.7-\mathrm{kG}$; the estimated $\zeta$ increased $50 \%$ 10 0.6. However, the field reversal altained was nol as high as the $\mathrm{B}_{\mathrm{yat}}=4,35-\mathrm{kG}$ experiment and it fell below the expectation of the SUPERLAYER code, $^{18}$ whict pledicted $\zeta>1$ for $T_{t}=130 \mathrm{eV}$ and $I_{\text {beam }}=500 \mathrm{~A}$

Examining the data to more detail reveals that ion-energy confinement, although improved $\mathrm{cm}$. pared with the earlier experiments at lower $T_{c}$, does nol contincie to increase with increasing $T_{e}$ above $T_{e}$ $\simeq 80 \mathrm{eV}$, contrary to what would be expected if classical Spizer drag were dominant. The saturation of ion-energy conlinement correlates with an increasing level of ion-cyclotion fluctuations having the same spectral character as the fluctuations stabilized by streamingeplasina injection. This suggests the presence of ion losses due to the DCLC mode.

The experiments summarized in Table I indicate the way to attain increased field reversal by neutralbeam injection into a mirror machine. $T_{e}$ should be increased, thus reducing ion losses due to classical Spitzer drag. Simultaneously, fluctuations due to 
the DCLC mode should be suppressed, so that 5 pitzer drag is the dominant ion-loss piocess. Recent experiments on $2 X I I B$, at a lower $\zeta$ than reported bere, indicated that $T_{t}$ may be rajsed independently of the magnitude of $\mathrm{B}_{\mathrm{vac}}$ by increasing the mirror ratio.

In addition to exploring combinations of the strean-gun and gas-box stabilization methods, we may consider electron-beam stabilization recently teported by Klinkowstein and Smullin at MIT ${ }^{19}$; of we may consider field reversal in a mirror end cell of the Tandem Mirror Experiment (TMX), ${ }^{20}$ with the end cell stabilized by the Maxwellian solenoidal plasma. Other possibilitis for field reversal in a mirror machine include using one of the fast-pulsed mahods-electron beam. field-reversed theta pinch-to crutute a lield-reversed target for rieutralbedm trapping.

Since the experiments described here were initiated. there sas an intensive theoretical effort ${ }^{21}$ to assess the requirements of reaching field reversul by neutra].beam injection into a mifror machine. We aimed these investigations primarily at the question of electron cancellation of the ion current at the ficld null $\mathrm{B}=0$. Wo demonstated that (I) for a field-reversed st ate to exist. a finite current density must flow at the field nuil: (2) in a fully jonized deuterium plasma, finite current at the null requires an admixture of high-atomic-number (Z) ions: (3) for $y=\Delta B / B<1$ (i.e., a field null does nol exist), electron currents may be ignored as in the present SUPERLAYER simulation work: and (4) for $5=$ $\triangle B / B>:$, electron currenls must be included in a simulation of fully ionized plasmas. The role of the high- $z$ ions is to scitter the electrons, preventing them from being accelerated up to the mean ion velocily of the $Z=1$ component. + rough prescrip. tion. given by Baldwin and Fow er. to achieve field reversal in 2 XIIB-like conditions is - that plasma radius equals iour vacuum-field larenor radii (about twice the radius of present experiments) and that the injection current or ion-energy confiikenent be int. proved a factor of about liser.

\section{Field-Reversal Experimen}

The plasma in the 2XItB Experinent (Fig. I) is driven by 12 Lawrence Berkcley Laborawor, 2(1-k V. 50-A neulral-beam modules. 'arranged siv on each side of the experinent. U.p to $7 \mathrm{MW}$ of neutral. beun power have been injected. For the densest plasmits. 4.5 MW are absorbed by the plasnia. I.5 MW are terpped by ionizulion, and $3 \mathrm{MW}$ are reradiated as energetic charge-Lxch:age ?lux. A

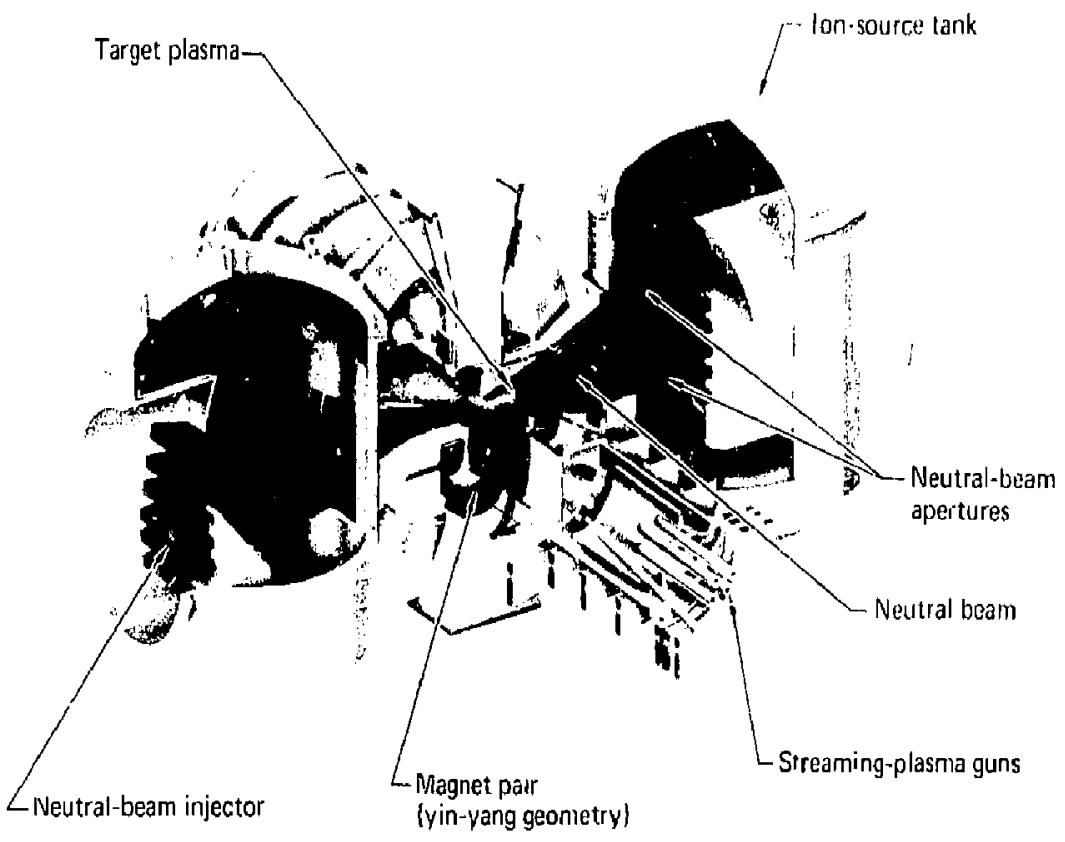

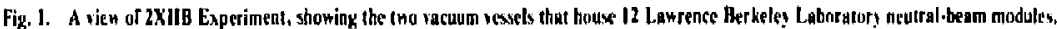
Also seen are the ceramic highi-sacuum chambet, the yin-y ang minimumi-B coil set. and the streami-g-plasma guns used for startup and starilization. 
nonconducting ceramic vacuum chamber surrounds the plasma, which is confined in the minimum-B mignetic well of a yin-yang coil. The plasma is stabilized aguinst jon-cyclotron fluctuations by (1) plasma-stream injection along a solenoidal guide field to the mirror-confined plasma and (2) by gas injection into a box with elliptical apertures just outside the mirror opposite the stream guns.

Figure 2 shows the most important diagnostic equipnient for the data reported here. A $90^{\circ}$ Thomson-scultering system measures elcctron temperature $\left(T_{q}\right)$; a 15-channel charge-exchange analyzer measures ion erergy $\left(E_{j}\right)$. Radial scans of $T_{\mathrm{c}}$ can be made from $\mathrm{r}=-2 \mathrm{~cm}$ on one side of the vertical plasma midplanc to $\mathrm{r}=6 \mathrm{~cm}$ on the other side. The charge-exciange flux can be scanned from $r=-1210+12 \mathrm{~cm}$. We measure plasma line density with a $2-\mathrm{mm}$ microwave inler ferometer and plasma. density shape with a crossed array of collimated detectors that measure neutral-beam attenuation along chords though the plasma. Adjacent channel separation is $2 \mathrm{~cm}$ for the vertical array and $5 \mathrm{~cm}$ for the horizontal arrily. The spatial resolution of all these diagnostics is $1 \mathrm{~cm}$ at the plasma. Plasma

\section{Thompson-scattering}

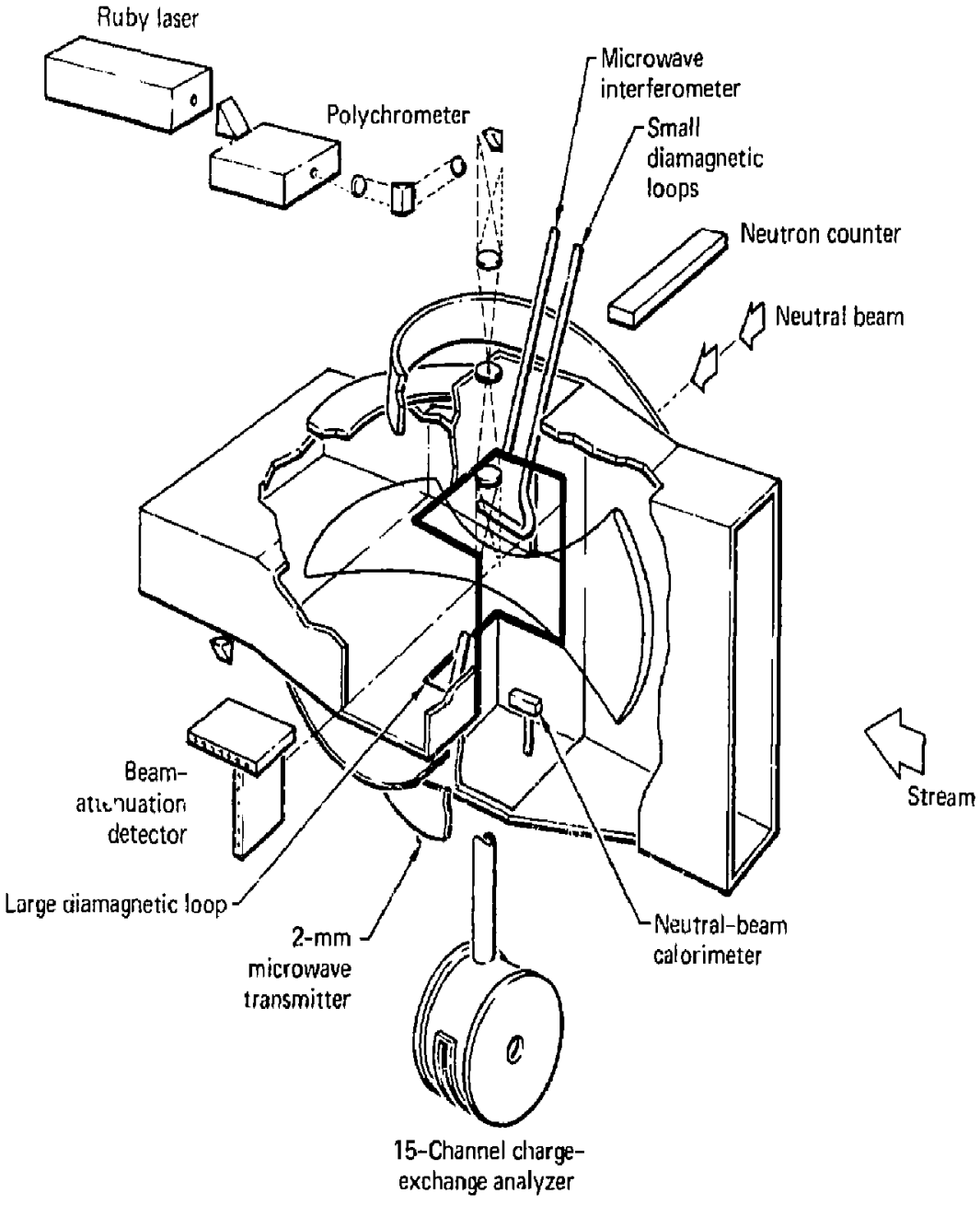

Fig. 2. Principal diagnestic equipment used on 2 XllB. 
diamagnetism is measured by a large loop wound ajound the vacuum-chamber wall and three small loops inside a thin wall tube $25 \mathrm{~cm}$ from the plasma axis. Since the area of the large locp is $-1 \mathrm{~m}^{2} \mathrm{com}-$ pared with a typical plasma cross section $\sim 150 \mathrm{~cm}^{2}$, the large loop measures the total plasmi magnetic dipole moment and is insensitive, for constant dipole momenl, to changes in scale length of the order of plesma dimensions. The small loops at $r=25 \mathrm{cril}$ and $\mathrm{z}=0,8$, and $22 \mathrm{~cm}$ are sensitive to the radial and axial scale lengths of the plasma. current distribution. We aim the neutral-beam injectors and measure the neutral-beam injected rut with a calorimeter that car be extended into the plasmd-confinement region.

For experiments that have obtained the highest fielcireversal parameter, the neutral beams from opposite sides of the experiment are of fset $1=$ $4 \mathrm{~cm}$, as in Fig. 3(a), so that ions tend to be trapped on urbits enciscling the magnetic axis. Head-on injection with $\lrcorner=0$, as in Fis. $3(b)$. improves beamtrapping efficiency but results in increased plasma radius: so the licid reversal attuined is less than in Fig. ?(d). Calorimeter profiles of injected beam power, averaged over the six beams on each side, appear in Fig. 4 . The $7 \times 35-\mathrm{s}$ extraction grids of the bean nodules are uritented with the $7 . \mathrm{cm}$ slots in the verlical direction so the vertical height of the
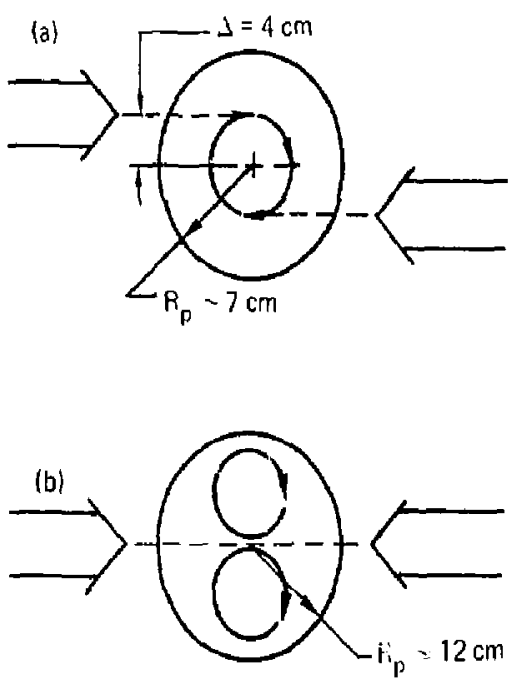

Fig. 3. Bearn-injettion usrungument. (4) For field-terersal experiments, the beams nere aimed tungentially with a vertical offsct of $\pm 4 \mathrm{~cm}$ that trapped ions on abits encircling the magnesic avis. thus producing diamagnttic currents. (b) In comparison. head-on injection improtes the boam trapping but results in loHor diamaguetic currenes. beam loutprint at the plasma is much smaller that the horizontal width. The vertical profiles have a 3 c.n halfwidin measured to the l/s point so that the beams are well focused complated with the $4 . \mathrm{cm}$ vertical offsct.

Experimental Data, In this section we will present the experimental dalta regarding field reversal: the scaling of plasma line density , mean plasma radius $\left(\mathbf{R}_{\mathrm{p}}\right)$. peak plasma beta $(\hat{\beta})$, and estimated field reversal parameter $(\zeta)=\mathrm{B} / \mathrm{B}_{\text {tac }}$ with injected reutral-beam current $\left(\boldsymbol{l}_{\text {heam }}\right)$. To satisfaclurily understand this dala, particularly the degret of field reversal achieved, requires a theoretical model com. patible with all the observations. Such a comple : theoretical simulation does not presendly exist: this poses some difficulty in organizing the remainder of the data to be presented in a useful way.

lon confinement is clearly importunt since. if magnetohydrodynamic stability is issuned. it pus the injecled beam power will delermine the degres of field seversal achicyed. For this reason, we pretsent the scaling of elestron temperature $\left(T_{d}\right)$ with $I_{\text {heam }}$ so the classical Spilzer now of energy from ions to elections can be calculated. We allso compute the mein ion-entrgy confinement parameter $\left\langle\langle n s\rangle_{l_{j} j}\right)$. It :.ill then becone appiarent that

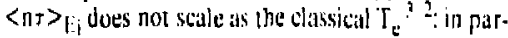
ticular, above $\mathrm{T}_{\mathrm{t}}=80 \mathrm{eV} .\left\langle\mathrm{nt}_{\mathrm{t}_{-}}\right\rangle$is neirly in. dependtun of $T_{. .}$Similarly. a simple rate tiquation for the iun power halinee based on the scaling of line density with $I_{\text {he:alu }}$ implits that jon-energ! wnfinement is not limited by electron drag. This leads lo consideration of ion-loss neshamioms other than electron drag.

One possibility is that the drift-by dolon losscone mode at the high densities reported here wits

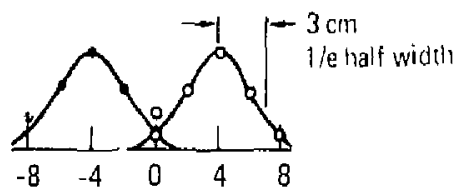

Vertical position, $X-\mathrm{cm}$

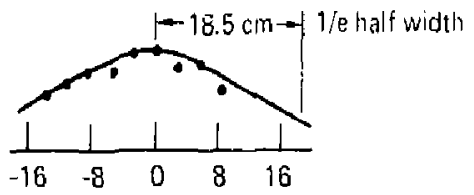

Horizontal position $Z-\mathrm{cm}$

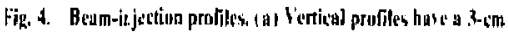
balfwideh measured to the corolding point. (b) Horizonlal profiles bse an $1 \mathrm{k.5}-\mathrm{cm}$ halfuish measured to the e-folding perint. 
not sufficiently stabilized with the present stream gins and gis-feed system; so there were additional ion losses due to ion-cyclotron fuctuations. Evidence of this is the amplitude of ion-cyclotron oscillations delected by a $2-\mathrm{mm}$ microwave beam that increases with increasing $T_{8}$.

Secondly, recent electron-ring experiments at Cornell 22 have identified an anomalous electronloss rate dependent on the strength of the quadrupole field. Since the mininum-B field strenglls of the 2 XIIB Experiment has a large quadrupole component, it has been suggested 22 that this quadrupole loss may appear here as an ion loss. In an experiment reported later (see "Variation of Quadrupole Component of Vacuum Magnetic Field"), we have varied the strength of quadrupol field but have not observed a significant variation of ion confinement.

Plasma lime Density. Plasma Radius, Beta, and Field-Reversal Paramerer. Figure 5 provides scaling of plasma lime denvity and mean plasma ratius with neutrai-beam injection current ( $\left.l_{\text {huam }}\right)$ for two values of central-vacuusi mignetic-field sirength, $B_{v a c}=4.35$ and $6.7 \mathrm{kG}$. For these experiments, the solenoidal-guide field was $2 \mathrm{kG}$ with the remaining field supplied by the yin-yang coil. The mirror ratio at radial position. $z= \pm 7,5 \mathrm{~cm}$ is $R=1.8$ and 2.0 for the central field's 4.35 and $6.7 \mathrm{kG}$, respectively. This data was taken with the tangential beam-aiming arrangement shown in Fig. 3(i). For both sets of data, the line density increases approximately linearly with $I_{\text {beam }}$ as it increases by a factor of two. Mean plasma radius, defined as the 1/o point of the line-density profiles, is nearly independent of $\mathrm{I}_{\mathrm{hcam}}$ for $B_{\text {vac }}=4.35 \mathrm{kG}$ and increasses slowly with $\mathrm{I}_{\mathrm{buam}}$ for $B_{\text {vac }}=6.7 \mathrm{kG}$. Data for head on beam injection, os in Fig. 3(b) and with $B_{\text {vilc }}=6.7 \mathrm{kG}$, showed similar scaling. The mean plasma rudius, however was larger, i.e., $R_{p} \simeq 11.5$ inslead of $6.5 \mathrm{~cm}$. The maxinum line density was the same as for tangential iniection.

Becu. The data in Fig. 5 can be combined with
Low field

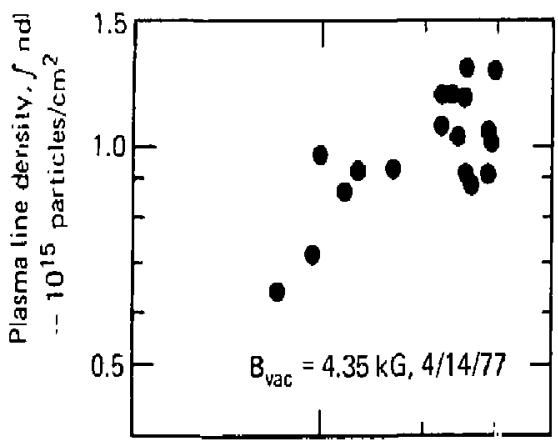

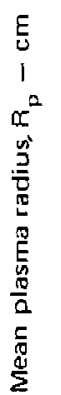

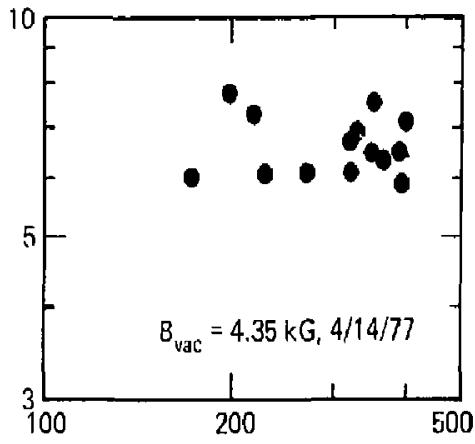

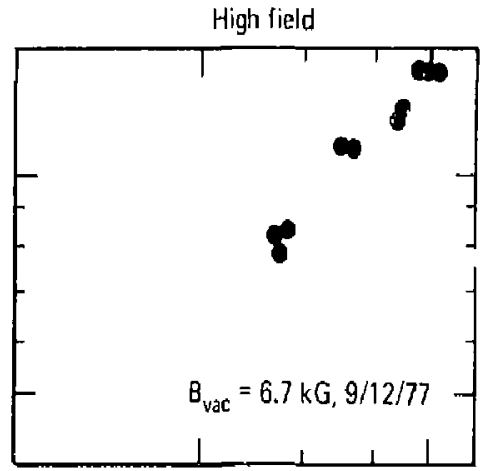

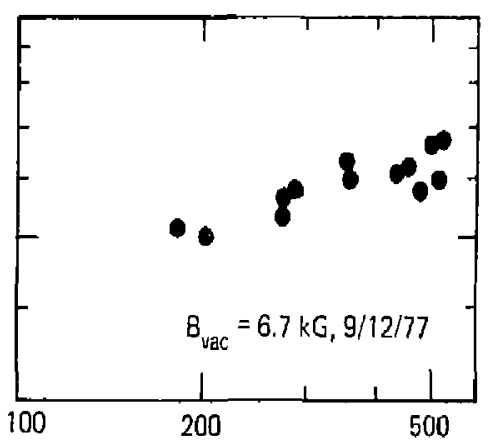

Injected neutral-beam current, $I_{\text {beam }}-A$

Fig. 5. Plasma line densily and radius for Iwo vacuum magnetic-field strengths, with tangential heam aiming as seen in Fig. W(a) - (a) Line density increascs linearly mith neutral-beam curren* ;b) Plasma radius increases slowly ur is independent of beam sur rent. 
charge-exchange measurements ct mean ion energy $\left(\vec{E}_{i}\right)$ to compute the peak plasina beta $(\hat{\beta})$ at $r=0 \mathrm{ac}$ cording to the formula

$$
\dot{\beta}=8 \pi \frac{\hat{n} s_{i}}{B_{v i d}^{2}}=8 \pi \frac{\int n d l}{\sqrt{\pi R_{p}}} \frac{\bar{E}_{i}}{B_{t a c}^{2}}
$$

The scaling of $\hat{p}$ with beam current $\left(l_{\text {beam }}\right)$ is in Fig. 6. Since $\bar{E}_{j}$ and mean plasma radius $\left(R_{p}\right)$ did not change appreciably with increasing $I_{\text {beam, }}$ the variation of of $\mathrm{ks}$ beom comes from the linearly increasing line density (Ind). For both values of vacuum magnetic-ficld strength $\left(\theta_{\text {ugc }}\right), \hat{B}$ increases with $\mathrm{I}_{\text {beam }}$ reaching $\hat{\beta}=2.2$ for $\mathrm{B}_{\text {yac }}=4.35 \mathrm{kG}$ and $\hat{\beta} \simeq 1,2$ for $B_{v y c}=6.7 \mathrm{kO}$. These is no evidence of a saturation of $\beta$ as $\mathrm{I}_{\text {heam }}$ increases. It is noteworthy that reducing $B_{y u t}$ resulted in higher $\hat{\beta}$. This is evidence thit a $\beta$-limil has not been reached in the high-field $B_{\text {valt }}=6.7 . \mathrm{kG}$ expuriment, in which case 3 would have decreased by a factor $(6.7 / 4.35)^{2} \simeq$ 2,4 as the field was lowered.

Models of field-reversal parameter. For a plasma with an axial scile length $\left(L_{p}\right)$ that is large compared with the radial scale length $\left\langle\mathbf{R}_{p}\right\}_{\text {, or }}$ equivalently negligible field-line curvature near the plasma midplane, $\hat{\alpha}>\mid$ would imply $\vec{B} / B_{\mathrm{V} p}>1$ on axis. For the plasmas under consideration, since we have $L_{p} / R_{p}-2.5$, it is essential that the finite length be taken into account when estinating the field-reversal parameter $\left(\triangle B / B_{\text {val }}\right)$. This has been done with two simple models, both yielding essentially the same result.

The first is an equivalent-cylinder model of the plasma-current distribution, supposing that the current flows in a thin cylinder of radius $R_{p}$ and length $2 L_{p}$ with a total magnetic dipole moment (m) $=I \pi R_{p}^{2}$, where $I$ is the total circulating current. For this model

$$
\frac{\Delta H}{B_{\text {vac }}}=\frac{1}{B_{\text {vac }}} \frac{\mu_{0}}{2 \pi} \frac{m}{R_{p}^{2} \sqrt{R_{p}^{2}+L_{T}^{2}}}
$$

Here $R_{p}$ and $L_{p}$ are taken us the $1 / \mathrm{e}$ halfwidths of line-density profiles. The total $\mathrm{m}$ is related to the measured large diamagnetic loop voltuge by

$V_{\text {loop }}=\frac{ \pm}{R C} v_{\pi} \mu_{0} \frac{m}{\left(4 h^{2}+\pi H^{2}\right)^{3 / 2}}$.

where $R C=0.1 \mathrm{~s}$ is the integration constant and $\mathrm{h}$ and $\mathrm{H}$ refer to the large diamagnetic loop dimensions shown in Fig. ?.

The second mod:al is a rigid rotor, supposing that the observed approximately Gaussian plasmi linedensity profiles rotate about the plasma axis al a frequency $0<\omega_{\text {car }}$ leading to a field change on axis:

$\frac{\Delta B}{B_{v a c}}=\frac{1}{B_{v a c}} \frac{\mu_{0}}{2 \pi} \frac{m 1}{R_{p}^{3}} \div\left(\frac{L_{p}}{R_{p}}\right)$, where
Low field

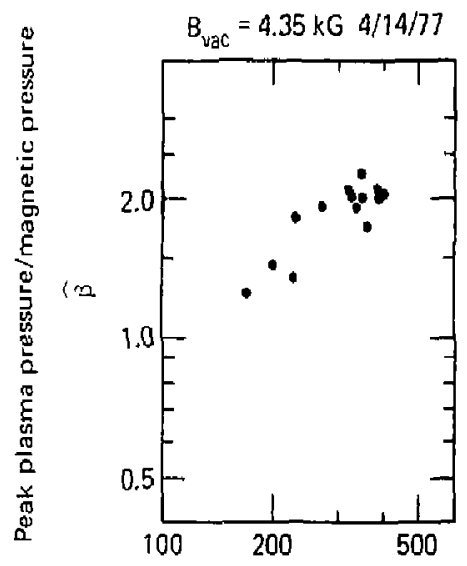

High field

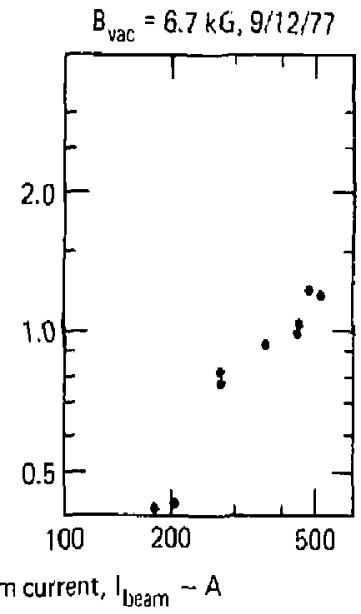

Fig 6. In this comparison of low and high fields, peak plasma bera increases with beam sur rent, $\hat{j}=8 \mathrm{~F}$

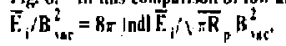




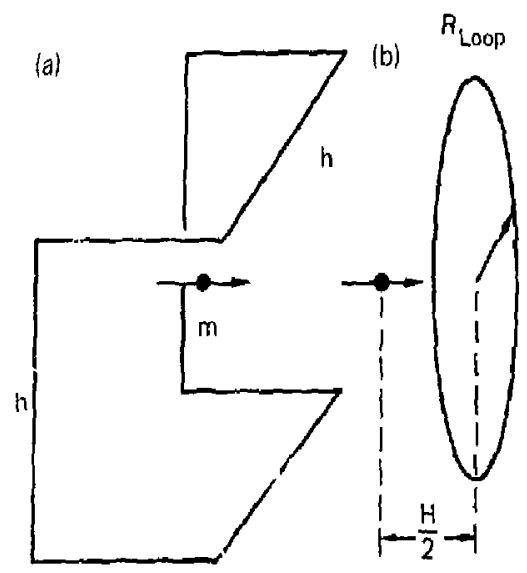

$H$

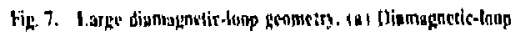
of tig. 2 is shaw with no tqual to the tolal plusma dipole moment. $h=\$ 4.4 \mathrm{sm}$. and $H=38,1 \mathrm{~cm}$, (b) With un equisislent circulur hiop of rudius $H_{4}=h_{1}=$ the titul magnetíc Mux, sit $=$

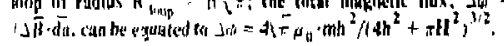

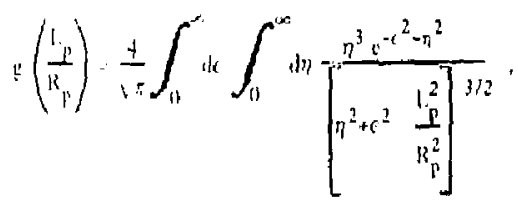

and aherem, $R_{p}$. and $L_{p}$ are as before.

For a lypical aspect-ratio $L_{N} / R_{N}=2,5$, estimates of $\triangle \mathrm{B} / \mathrm{B}$, laccording to the (wo models) differ by only $3^{m} r$, which is insignificant compared to shot-toshot fuctuations of $R_{p}$ and uncertainty of the axial hot-plasma stale length.

lins'densit! srofiles The radius and length of the plasmi-current distribution are nceded to estimate the field+reversil parameter $\left(A B / B_{\text {vac }}\right\rangle$ using Eqs. (2) or (5). In this section wo present typical beam-illenuation measurements of radius and length of the plasma line-density distribution. In the next section we infer the radius and length from the small magnetic-probe measurements.

Figure 8 shows typical line-densily profile daid obtained by beam attenuation. The radial linedensity data are it is . Gaussian profile shape $F_{0} \exp \left[-\left(x-x_{0}\right)^{2} / R_{p}^{2}\right]$ with the prak line density $\left(F_{0}\right)$, plasma center $\left(x_{0}\right)$, and radjal soale length $\left(R_{p}\right)$ as Iree parameters. Density is related to line density by Abel inversion. Since the Abel inversion of a Caussian function is again Gaussian with the sume c. folding widih, the radius $\left(R_{\mathrm{f}}\right)$ that we calculate by a reasonable Gaussian fil to line densily yields the density radius. The axial line-density profile is more difficult 10 interpret becausc it consists of two components-ma hol-ion component centered at axial distance, $t=0$ and $u$ cold-streaming component. We huve also observed axial density protiles similar to Fig. $8(\mathrm{~b})$ in computational work simulating the cold-streaming plasma. ${ }^{33}$ Often the kink at the $z=$ $10-\mathrm{cm}$ probe position in Fig, $8(\mathrm{~b})$ is not observed. and the axial line-density data decrease smoothly from $z=01025 \mathrm{~cm}$. If the sides of the peak centered at $z=0$ art simply exlrapolated to zero, in axial c-folding tength $L_{\Gamma} \simeq 13 \mathrm{~cm}$ is inferred. This length is somewhat shorter than that inferred from magnetic-loop probe data discussed below. Ad.

(a)

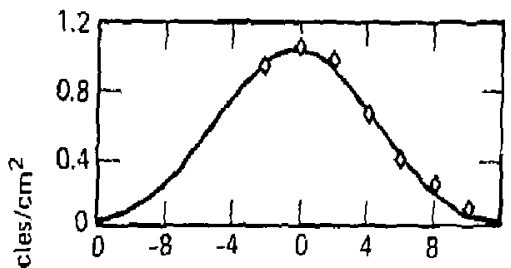

Radial distance, $r \sim \mathrm{cm}$

(b)

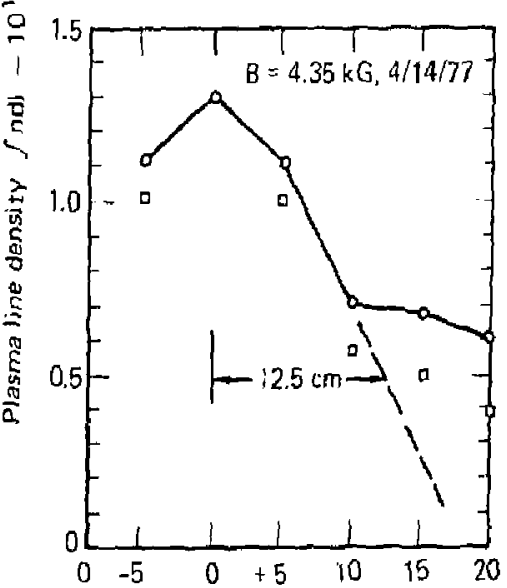

Axial distance, $z-c m$

Hig. S. Tspical line-densily profile data obesined Irom beam at(enuationt. (a) Jhe radial line density daly ore fit to Gauscian

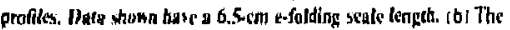
oxial line densily data does not apperur fiaussian dise to is two-

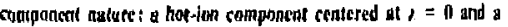
cold-itreuming component flowing in from the ends. Square blocks indicule costections to the data for tacuum-field-line fanning. 
ditional uncertuinty arises from the sffects of fieldline funning due to the minimum-B vacuum field strength. The line-density measurements Irom $\angle>0$ in Fig. 8(b) are in the plane of the fanning field lines and, therefore, indicate larger line densities than appropriate for an equivalent-cylinder model of the plasma The correction to be applied to the data is uncc:-ain because of the finite-is (plasma pressure/nagnetic pressure) distortion of flux lubes. An upper limit, calculated for the vaciunn. field lines, is indicated by the $x$ s on Fig, $8(b)$.

Simall magmeric-hop daua $\mathrm{A}$ second estimate of the scile lengths appropriate for estinating the Field-reversal parameter $\left(\Delta B / B_{\text {, arc }}\right)$ calle from three small magnetic-loop probes at $r=25 \mathrm{~cm}$ and axial distance, $z=0.8 .6$. and $21.8 \mathrm{~cm}$, Dala from these probes were only availatele for sacuum field strungth $\left(B_{\text {inis }}\right)=4.35 k G$ and injected butim current $\left(I_{\text {met }}\right)=410 \mathrm{~A}$ (Fig. 9). We ploted the change in the ax iall component of magnelic-ficld strength at the probe wa axial-prube pusitum. The data were with the rigid-rotor model, with the cerrtral line density and total magnelic moment constrained to the ohserved values. $1.3 \times 10^{15} \mathrm{~cm}=$ and $1.1 \times 10^{6} A \cdot c{ }^{2}$. respectively. The radius and length were free pirameters. The current distribution for this model was given by the formulat

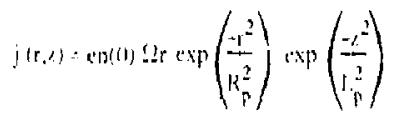

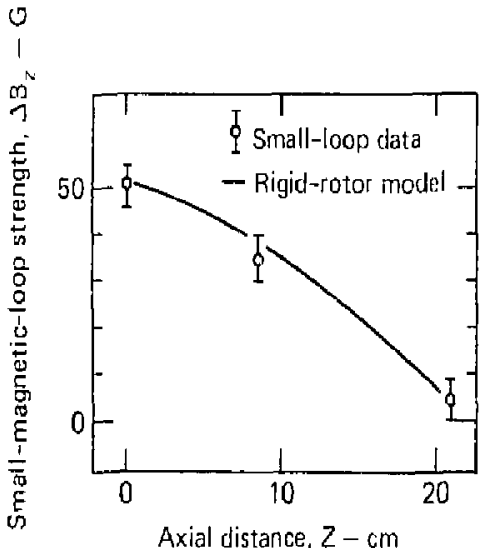

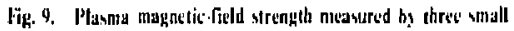
magnetic-lows probes at $\mathbf{r}=25 \mathrm{~cm}$ arte plotted against the us ial persition of the three probes. Plasnas stule lengths of $R_{p}=6.8 \mathrm{~cm}$ and $\mathrm{I}_{\mathrm{p}}=\mathbf{1 8 \mathrm { cm }}$ are derined Iram a hest fit to the dala from a rigitretor model of the diamagnetic torerents.
The solid eurse in Fig. 9 was the hest lin ubstuned for radial scale length $\left(R_{p}\right)=08 \mathrm{~cm}$ and an lial scille length $\left(L_{R}\right)=18 \mathrm{~cm}$, giving a rentation frẹucent?

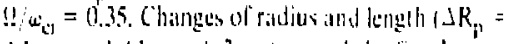

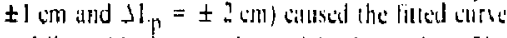
to fall outside the error bats of the ditt puints The radius determened this will agreed weth with th:

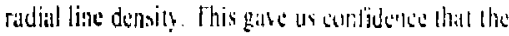
ridial line-dentity proliles prouded an adequate me:tsure of platsmit-current distribution the alvial

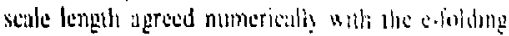

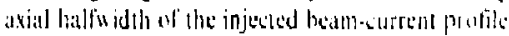

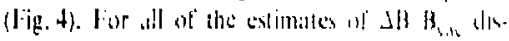

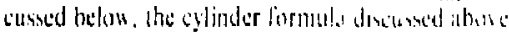

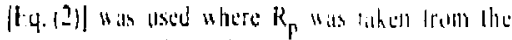

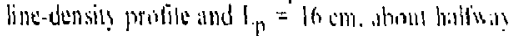
betwe cen the value detcrmined by this til to the lowp. probe dillu and that determined hy llae centrat peiak in the a rial line density provile in 1 ig $8(h)$.

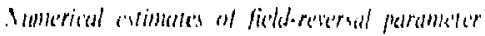

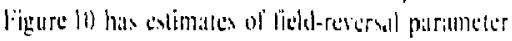

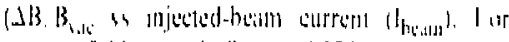

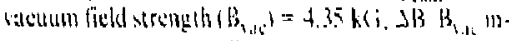

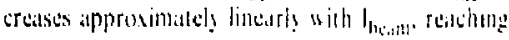

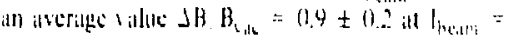

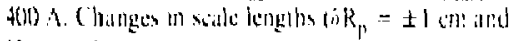

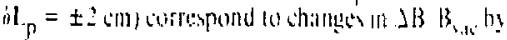

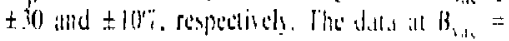

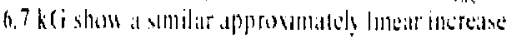

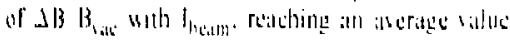

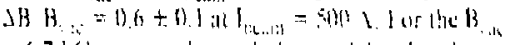

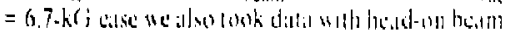

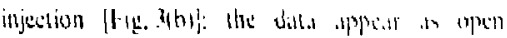
triangles in I is. 10.

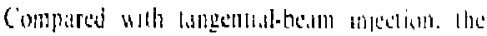

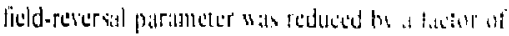

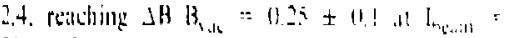

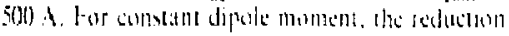

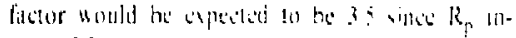

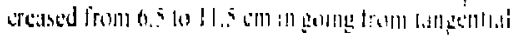

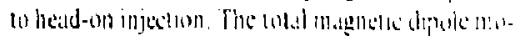

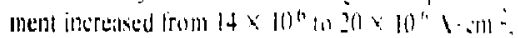
homeser. accounting for the tastur : 4

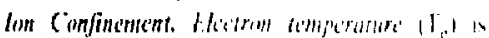

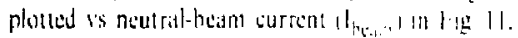

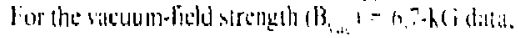

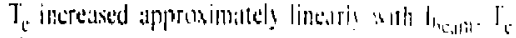

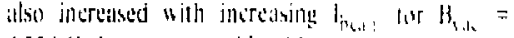

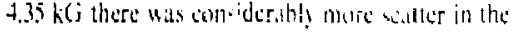

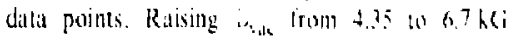

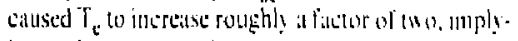
ing a dependence of $T_{\mathrm{s}}$ an totid histd strengeth or iacuum mirror ralio (which increased from $R=1.8$ to 2.0).

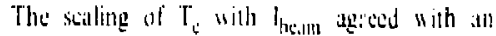




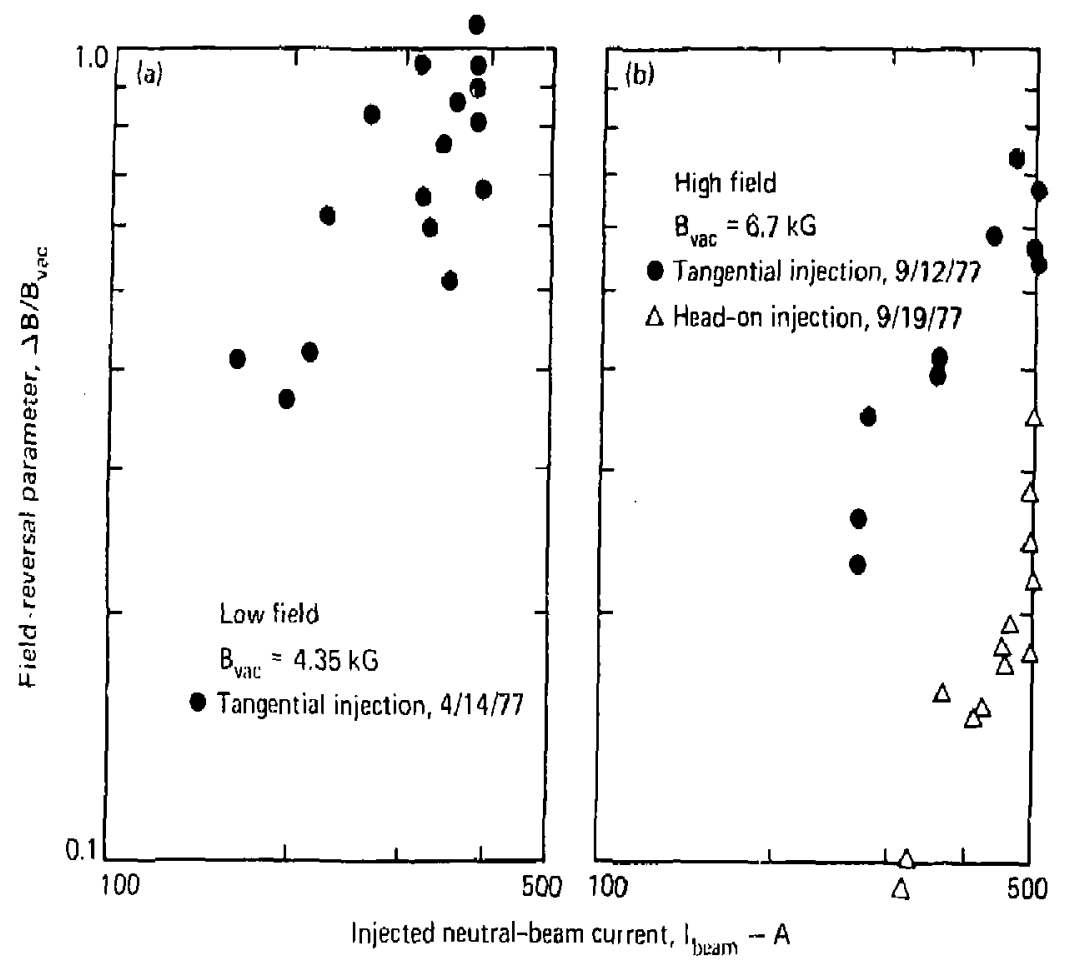

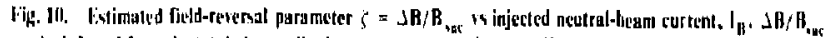

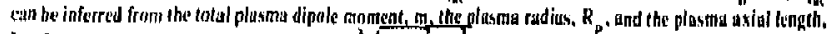

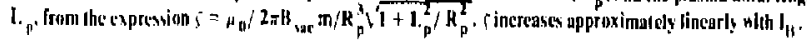

electron-power balance that equated the flow of energy from isons to electrons with the power carried oul by electrons produced by ionization in the gas box:

$\int \frac{n w_{i}^{\prime}}{r_{i r}} \cdot d^{3} x=\eta T_{i} \cdot I_{g a s} \cdot$

where 1$) \tau_{T \mathrm{t}}=4, ; \times 10^{7} \mathrm{~T}_{\mathrm{e}}^{1: 2}$ for deuterium plasmas, $T_{c}$ is in $\mathrm{eV}, \mathrm{I}_{\mathrm{g}: \mathrm{t}}$ is the neulral-atom curren! fed into the gas box, and $\eta$ is a proporticnality constant describing the multiple of $T_{L}$ each electron carricd to the wall. The equation predicts $T_{e} \sim n^{4 / 5} W_{i}^{2 / 5}$ or $T_{\mathrm{e}} \sim \mathrm{I}_{\text {hejum }}^{4}$, for $n \sim \mathrm{I}_{\text {beam }}$ as in Fig. $5: W_{i}$ is independent of $\mathrm{I}_{\text {heam }}$ (Fig. 12). The 4/5 scaling of $\mathrm{T}_{\mathrm{e}}$ wals consistent with the data in Fig. 11. We oblained the $\mathrm{T}_{\mathrm{z}}$ datia displayed an Fig. 11 at $\mathrm{r}=0 \mathrm{~cm}$. Rudial scans of $T_{6}$ in $2-\mathrm{cm}$ intervals from $r=-210+6 \mathrm{~cm}$ at $l_{\text {bram }}=490 \wedge$ for the $B_{\text {rac }}=4,35-k G$ data and $\mathrm{I}_{\mathrm{heam}}=500 \mathrm{~A}$ for the $\mathrm{B}_{\mathrm{yac}}=6.7-\mathrm{kG}$ data, revealed that the $T_{c}$ profile was essentially flat over this spatiul range.

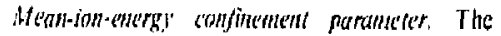
mear-ion-energy confinement time was the total plasma-ion entergy divided by the trupped neutralbeun power:

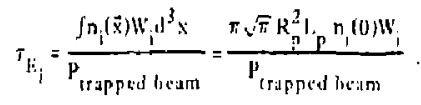

where we assimed Gaussian shapes for the plasmidensity profile $n_{i}\left\langle x^{i}\right)=n_{i}(0\} \exp \left(-r^{2} / R_{n}^{2}\right)$ $\exp i-i_{2} L_{p}^{2}$ and $W_{i}$ independent of $x$. Multiplying ${ }_{{ }^{2}} \mathrm{E}_{\mathrm{i}}$ by the newus ion density $\left(\left\langle\mathrm{n}_{\mathrm{i}}\right\rangle=\right.$ $\ln _{\mathrm{i}} \mathrm{d}^{3} \mathrm{x}_{i} \mathrm{in}_{\mathrm{i}} \mathrm{d}^{3} \mathrm{x}=\mathrm{n}_{\mathrm{i}}(0) / 2 \sqrt{2}$ defined the mean-ionenergy confinement parameler $\left\langle\left\langle n \pi_{b}\right\rangle\right.$ :

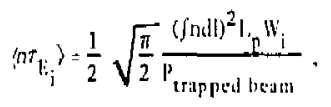

whrre !ndl $=\sqrt{\pi} R_{\beta} n(0)$ is the line density measured through the center of the plusma. The trapped beam power contained contributions from 


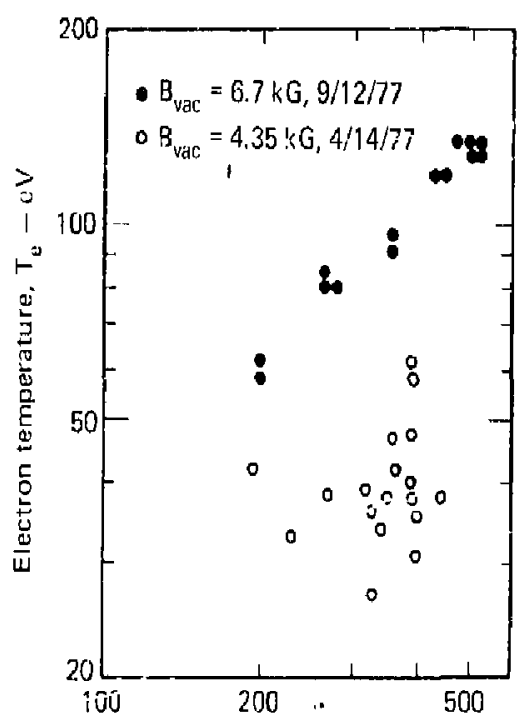

Injected neutral-beam current, $1_{\text {beam }}-A$

Fig. 11. Shasuremenk of dherm temperature, $T_{r}$, winciónt

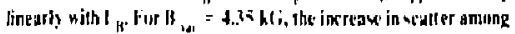
the data povinis mea be due la purerer sacuum sanditions ar sall offecl or hulh.

icnization of ale neulral beam and from chareseuxchange replacentent of a plasma ion by a beaninjectod neulaal parlicle:

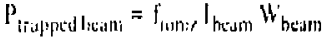

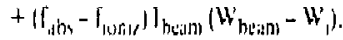

The parameters $f_{\text {ahs }}$ and $f_{\text {manie }}$ are the fractions of incident neutral-beam current ( $I_{\text {hearn }}$ ) absorbed by the plassna and trapped by ionization. respectively. The difference $f_{a b 4}-f_{\text {laniz }}$ is the fraction of the incidentbeam current reradiated lrom the plasma as chargeexchange neutrals with mean energy $W_{1}$. W'e calculated the fractions $f_{\text {abs }}$ and $f_{\text {ioni }}$ by integrating beamlets over the spatial distribution of the injected-current profiles (Fig. 4) for a specified lengths $R_{p}$ ar,d $L_{p}$; ur calculation included ioniza. tion after multiple charge-exchange collisions. $\lambda$ the highest alectron temperature $\left(T_{\partial}\right)=130 \mathrm{cV}$ $\left(I_{\text {hearm }} W_{\text {bean }}=7 \mathrm{MW}\right)$ we estimated that $f_{\text {do }}=$ 0.61 of the beam current was absorbed by the plasma and $\mathrm{I}_{\text {ioniz. }}=0.23$ of the beam was trapped by jonization. The energy content of the plasma ions for these shols was $W_{\text {plasmat iuns }}=\ln _{i} W_{i}{ }^{3} x=$ $1100 \mathrm{~J}$. neutrel-heam currinl, $I_{H}$, thos $J$, increasing approvimatels center-plasma density $n(0)$ and Gaussian scale

In Fig. 13 wo plot $\left\langle\mathrm{nr}_{\mathrm{r}}\right\rangle_{\mathrm{ri}}$ calculated according to Eq. (9) for the $B_{\text {rac }}=4.35-k$ (i) dala (open triangles) and $B_{\text {;ia }}=6.7-\mathrm{k} G$ dita (closed circles). If classical drag of ions on the couler electrors is the dominant ion loss, ther $\left\langle n_{r}\right\rangle_{1, \text { w ould be expected }}$ to follow Spitar's relation $\langle\pi r\rangle_{1}=4.4 \times 10^{7}$

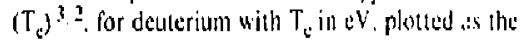
dushed line in Fig. 13. Comparing the $B_{. .1}=4.35$. kG data al low $T_{6}$ with the $B_{\text {lat }}=6.7-k$ (i ditit al higher $T_{c}$ we note a gentral trend of $\langle n r\rangle$, improving at $\mathrm{T}_{c}$ increases Abore $\mathrm{T}_{c} \simeq 80 \mathrm{eV}$.

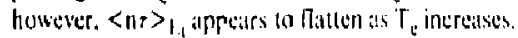
One nay expest. ilatelore. that the field-retersil

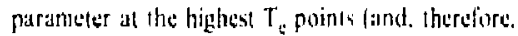
highest $I_{\text {be.tal }}$ ) for $B_{1 x}=6.7-k$ ( $i$ will liall below predictions that assame clectron drite is the dominant ion-loss mectantism (nse the upsoniline diseassion that compares SL!PIRIAYlR calkulations

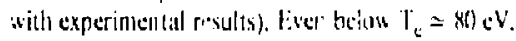
however, the detailsd ateremer: with the siniter essult in bott insolute mignitude and powe litw

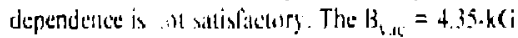
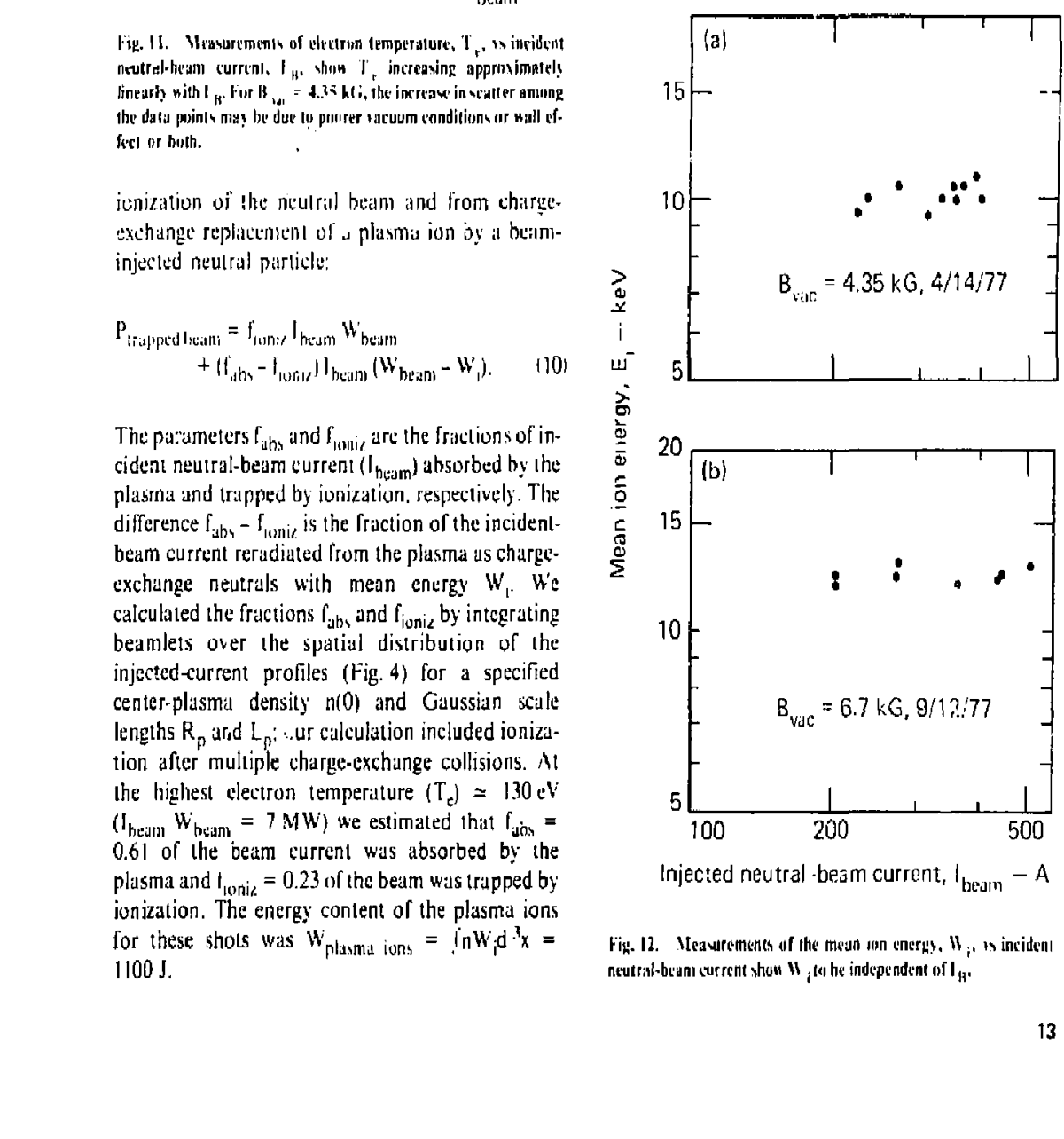

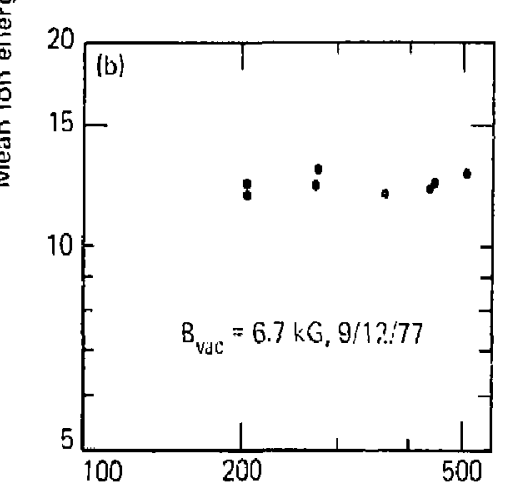

Injected neutral beam current, I bejm $-A$

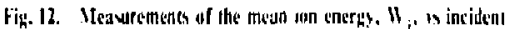
nevtrath beanl current ahou $W_{i}$ la he independent of $I_{B 3}$. 


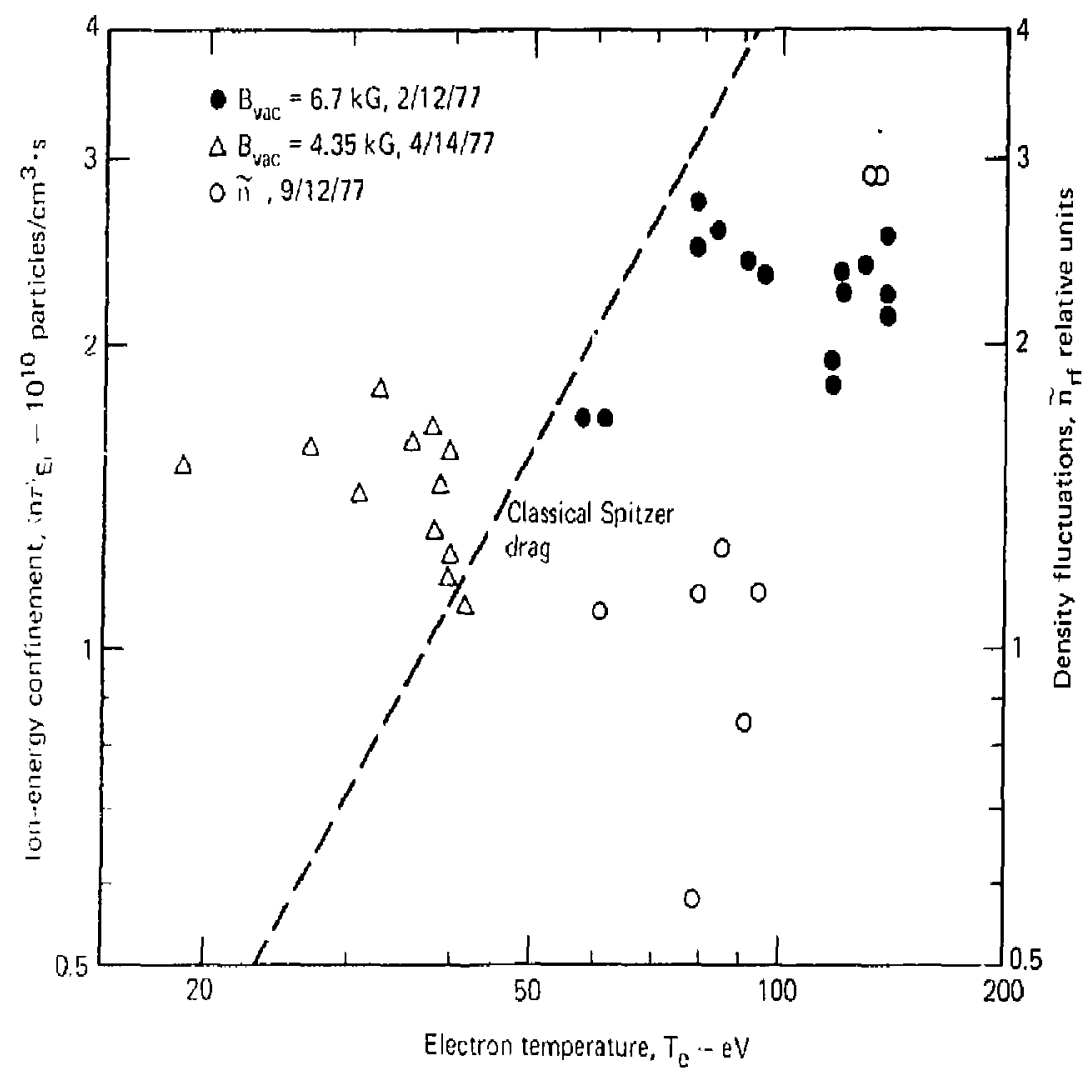

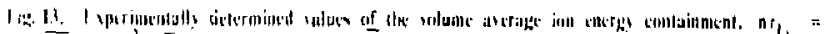

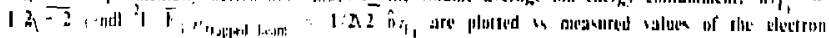

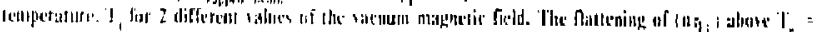

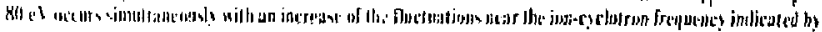
nft'll sirster.

$\langle\pi r\rangle_{1}$, data all fall above the Spitar result, a hich ¿) nol unduraluod.

1 the possibly explaining the fattening of $\langle\text { ir }\rangle_{1}$, ahove $T_{E} \simeq 80$ eV is provided by the amplitude of lon-cyclotron oscillations detected by phase modulation of a 2 -mn microwave beam shown in lig. 13 (indicated by open circles). Speciral analycis of these fluctuations shows that they are centered in a narrow band at the fundamental of the ion-cycloton frequency. They are, therefore, similar to the fluctualions previously measured in detail. Also, they have a delelerious effect on ion confinement and a wave-number consistent with the drift-cyclotron loss-cone mode, 2t

Evidence that there are ion losses in addition to efectron drag nily also be inferred from the scaling of plesima line densily (Fig, 5) and $\mathrm{T}_{\text {a }}$ (Fig. IJ) with $I_{\text {beilsi }}$ A simple rale equation for the ion-power bullantec is

$$
\begin{aligned}
& \frac{d}{d d} \mathrm{~d}^{3} x \sin
\end{aligned}
$$

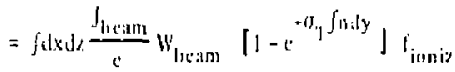

$$
\begin{aligned}
& +\int d x d z \frac{J_{b x a m}}{c}\left|w_{b e+a m}-w_{i}\right|\left[1-c^{-\left(b_{1} \int n_{1} l y\right.}\right]
\end{aligned}
$$

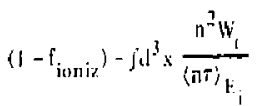

$J_{\text {beint }}$ is the injected neutral-current density, normalized so that $I_{\text {bean }}=/ \mathrm{d} x d z, J_{\text {bumm }}$. fioniz is the fraction of absurbed beam particles trapped by 
ionization. In the thin-plasma limit $\sigma_{T}$ indy $\ll \varsigma$, Eq̨. (10) predicts in steady state,

$$
\mathrm{l}_{\text {leam }} n(0) \sim \frac{n^{2}(0)}{\langle\mathrm{n \tau})_{\mathrm{l}_{i}}} .
$$

and in the thick plasma limit $n+1$ ndy $y>1$,

\}$_{\text {Hea an) }}=\frac{n^{2}(0)}{\langle n \tau\rangle}$,

If $(n t)_{i: j}=4.4 \times 10^{7} \mathrm{~T}_{\mathrm{g}}{ }^{1 / 2}$, appropriate for electron-ci-g-dominaled conlinement, then in the thin plasma, $n(0) \sim I_{\text {beam }} T_{e}{ }^{1 / 2} \sim T_{e}{ }^{3 / 2}$; whereas in the thick plasma limit, $n(0) \sim\left[I_{b e a n j} T_{b}, 3\right\}^{1: 2}=$ $I_{b u a m}$ s:4. We have assuned $T_{c} \sim I_{b}$ (as in Fig. 11), Both limits predicl $n(0)$ : inerciore, indl = $\checkmark \bar{\pi} R_{p} m(0)$, which increases faster thon linearly with $\mathrm{I}_{\text {heam }}$ in conslrast with the neirly linear increase in Fiz. 5 .

Comparison of Experimental Results with SL'PERLAYER-Code Simulation. Ous most delialed ittempt to theoretically describe the 2 XII B axperimental results was simulations by the SLPERLAYER code. ${ }^{14.25}$ This code computed the self-consistent mugnetic feld from ion orbits in their ow'n self field glus an applied axisymmetric mirror lield. The ion orbits were followed in five phase-spacc dimensions-threc velocity coordinates and radial and axial spatial coordinates. The simulated plasma buill up by neutrul-beam trapping on a cold target. We chose the geometry, energy distribution. and ionization and charge-exchange cross sections to accurately model the 2 XIIB neutral. beam injectors. Electrons were tseated as a chargeneutralizing buckground with a specified temperature $\left(T_{v}\right)$. The effect of electrons on the ions wis included as Spizzer velocily drag in the ion equation of motion.

In the present SUPERLAYER version the elecirons do not carry current, so electron cancellation on closed field lines is nol assessed. Line tying is believed to prevent electron return-current cancellation on open field lines. so the code calculalions are thought to be reliable in this respect up to the condition $\lrcorner B / B_{\psi \cdot C}=0$, which includes the range of 2XIIB data.

lon-cyclatron oscillations duc to the drift. cyclotron loss-cone modes are treated by a Muntc Carto method ${ }^{26}$ that includes diffusion due to a specified constant-wave amplitude in the particle motion. This calculation is nol done selfconsistently with the wave amplitude and growth rale dependent on the shape of the velocity djstribu. tion and radial density gradient as with the quasilinear codes, ${ }^{77}$ Inctuding the ist-cyclocron (o... cillations, this way does not have at litige effect in altering the ion-energy confinement, but it dwes. change the ion-energy distribution compared with il purely electron-Jrug-dominated situation. Thi ampitude of wave oscillation is empirically idjusted until the mean ion energy of the simulation is clins! to the experimental result. For the conde calculitions to be practical, it is necessary that all time scales-beam-lrapping rates, electron.drig rate. wave-diffusion time-be accelerated hy a constunt multiplicative factor of the order of 100 compared with the ion-cyclotron motion. With this acceleration factor. the ions execute several axial bunnces in a confinement tine. For the simulations presened here, orbits of approximately $2 \times 10^{4}$ "super" parcicles are followed for 40 ion-cy thelron orbits with 30 times steps per vrbit. This length of time is sul-

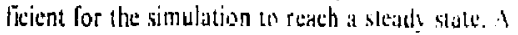
lypical code run lukes 30 min 10 exesuls on a $(\mathrm{DC}$. 7600 consuter.

The code calculations that wi will present include prediclions of the ficid-reversal paratmeter (i) $=$

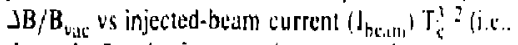
the ratio for the ion-teapping rule 11 lass ralel, as point comparison of simulation atid plasma

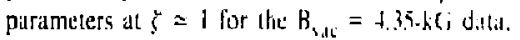

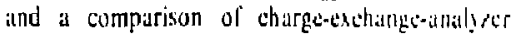
energy spectra and spatial scan of clais: sxchinge flux and mean ion energy. The latter are important beciuse they contain detailed infornaltion on the ion orbits that generate the lield-ret cosing curreni.

The SUPL:RLAYER prediction of $i=J \mid B_{1} B_{1}$ us $\mathrm{I}_{\mathrm{b} \text { ann }} T_{\mathrm{a}}, 3$, is shown in Fig. Is cogether with the experimental data for $B_{1 \mathrm{at}}=4.35$ and $6.7 \mathrm{k} \mathrm{G}$. The experimental data al $B_{3,1:}=4.35 k C$ reasunabls agree with the scaling and absulute mannitude of achieved. The high-field $\mathrm{B}_{\mathrm{vac}}=6.7 \mathrm{k} \mathrm{G}$ dilla disagree. falling about a listor of lwo helou the code prediction. The difference between the ine calses is likely due to dominanee of electron drig for the low-field data (which is properly lrealed in the SUPERLAYER culculations) and the increasing importance of wave diflusion for the higher finld. higher electron comperature data lwhich is not treated self-consistently in the SUPERL IYER c. Jeulations).

Table 2 cumpares simulation anj plisma parameters for the $B_{\text {a: }}=4.35-\mathrm{kG}$ wate with $I_{\text {hoim }}=$

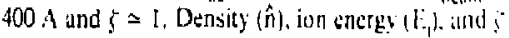
reasonably agree. The plasma shapes af the wode results and experimential data differ. The code cends to predict shapes larger in radius and considerahly shorter in axial length than those for the experiment. 


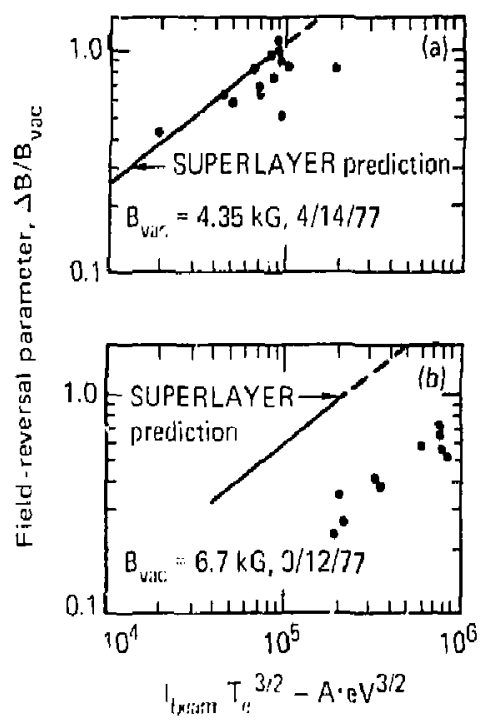

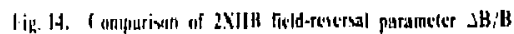

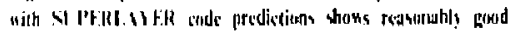

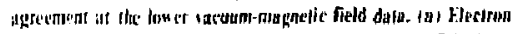

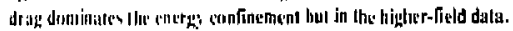
(b) I let agrecentent bretahe derth possibly dut to the inereasing in-

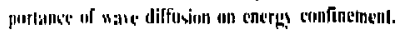

Conclusions. We have presented results of experimonts dirsced loward achieving the largest field reversil possible in the $2 \times 11$ l mirror machine lus. ing our existing set of neutral-beam injetors ant the alread demonstrated streaming-plasma gun giss-feed methods of stabilizing ion-cyclotron fluctuations). The experiments have mainly been done al lwo values of vacuum magnetic-field strength $\left(B_{1, a t}\right): 4.35$ and $6.7 \mathrm{kG}$. For both sets of dita. the plasma line density and peak plasma bela (i) incressed approximately linearly with injectedbeam curren $\left(I_{\text {has am }}\right)$ while the plasma radius $\left(R_{p}\right)$

Table 2. Comparison of 2XIIB and SUPER LAYlik

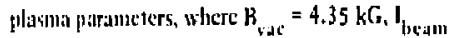
$=4100 \mathrm{~A}$ (tangential injection), and $\mathrm{T}_{\mathrm{e}}=50 \mathrm{cV}$.

\begin{tabular}{|c|c|c|}
\hline Parancter & $\begin{array}{c}\text { 2XIIIs } \\
\text { experiment } \\
(4 / 14 / 77)\end{array}$ & $\begin{array}{c}\text { SLPEKI.AYEK } \\
\text { cilculatious } \\
\text { (KJ 17) }\end{array}$ \\
\hline$E_{i}(k e v)$ & 10,0 & 10.8 \\
\hline$R_{p}(\mathrm{cr})$ & 6.5 & 10.0 \\
\hline$L_{p}^{\prime}(c m)$ & 16.0 & 4.9 \\
\hline$\hat{n}=\frac{\text { fndl }}{\sqrt{\pi k}}\left(\mathrm{~cm}^{-3}\right)$ & $1.0 \times 10^{14}$ & $0,95 \times 10^{14}$ \\
\hline$\zeta=\frac{\Delta B}{B_{\text {Vac }}}$ & 0.4 & 1.1 \\
\hline
\end{tabular}

remained constant, indicating that a $\&$ limit had not been reached up to the highest values of $I_{\text {beam }}$.

The best field-reversil result was obtained at the lower field selting $B_{\text {vicc }}=4.35 \mathrm{kG}$, achieving $\hat{\hat{p}}=8 \pi$

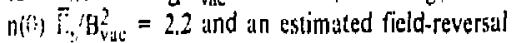
paratineter $(\zeta)=58 / B_{\text {vac }}=0.9$ at $400 \mathrm{~A}$ equivalent injected-beam current. For the $B_{\mathrm{vas}}=6.7-\mathrm{kG}$ experiment, the correspondise parameters were $\hat{\beta}=$ 1.2 and $\zeta=0.6$ al $\mathrm{I}_{\text {bum }}=500 \mathrm{~A}$. Electron temperature $\left(T_{0}\right)$ increased approxirnately linearly with $\mathrm{I}_{\text {beams, }}$, reuching $\mathrm{T}_{\mathrm{b}}=130 \mathrm{eV}$ at $\mathrm{I}_{\text {heam }}=500 \mathrm{~A}$; since $i<1$, it was not possibie to observe the large increase in $T_{\text {e expected if internal closed-field lines }}$ had been formed.

For the $B_{\text {vac }}=6.7-\mathrm{kG}$ data, the ion-energy conlinement parameter $\left.(\langle n \tau\rangle\rangle_{: j}\right)$ reached $2.5 \times 10^{10}$ (n) $^{-3}$ s at $T_{a}=80$ eV: it no longer continued to improve as $T_{t}$ increased. $A n$ increasicg amplitude of ion-cyclutron oscillations suggested that there wite ion losses (in addition to electron drag) due to the drifi-tyclotion loss-cone (DCI.C) mode. This caused the I achieved to be less than that if ion loss wetc dominaled by electron drag alone.

Ciross comparisons of the SUPERLAYER simulation code with the field-reversal purameters athieved experimentally showed that the $B_{\text {vac }}=$ 4,35-kG data agreed with the simulation prediction, while the $B_{\text {wac }}=6.7-\mathrm{kG}$ data fell a fuctor of iwo below the prediction. It was not possible to assuss the losies due to the DCLC mode with the presen! version of the SUPLRLAYliR code. Detailed com. parison of experiment and code results indicated disagreement of plasma shape, the ratio of plasma radius lo plusma length being $R_{p} L_{p} \simeq 2$ in the simulation and $R_{p} / L_{p} \simeq 0.4$ in the experiment.

Additional experiments demonstrated that the plasna radius and degree of field reversal achieved could be controlled by precise aiming of the newtralbeum injectors. The results summarized above were obluined with the beams aimed tangentially so that trapped ions tended to encircle the axis. Aiming the beams directly at the axis approximately doubled the plasmis radius and reduced the estimated $\zeta$ a factor of three.

The experimental data suggest that an increased ? could be achieved by improved stabilization of ioncyclotron oscilations. In addition to modification of the streaming-plasma gun/gas-feed stabilization method reported here, wa miay consider electron. beam stabilization ${ }^{19}$ or field reversal in a mirror end cell of the Tandem Mirror Experiment, 20 with the end cell stabilized by the Maxwellian solenoidal plusma. For future experiments, there is also the possihility of creating a field-reversed larget by one of the ciemonstrated fast-pulsed methods 11.13 .15 
and then using neutral-beam injection to heat the target.

\section{References}

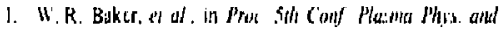

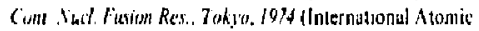
Energy Agency, Vienni, 1975).

2. R. R. Post and M. N. Rosentluth. Phis. Fheds 9, 730 (1966).

3. H. H. Coensgen ai al., Phis Rev. Ietl 35, 1501 (1975): I. H. Coensgen. at al Phis. Rer La't 37. 1+3 (1976).

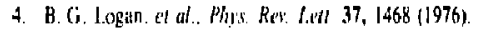

5. W. C. Condst, T. K. Fowler, and R. F. Pasi, Stanas Reparr

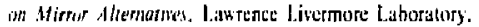
LF'R!.5.5008 (1976).

b I II. Fulch. at al. Plasma Phys. 14211 (1972).

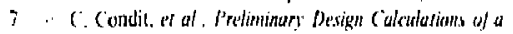

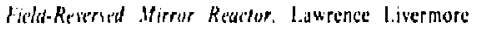
Laboritury. LiCRI.5?17) (1976).

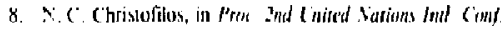

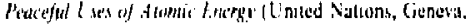
Swileerland, 19.58). vol. 12. p. 279.

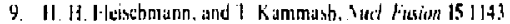
$(1975)$.

10. C, A Kapelunakin, R. K Pasker. aild KR Chu, Appt Phy Lefl 26, 2K4 (1975)

11. A I bethagen and W. (irossman. Z. Phasik 244, 1.30 (1971):

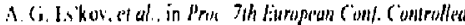

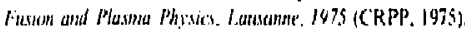

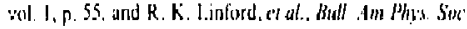
$22+19141979)$

12. D). Heils. at at, Ph! Rev lent 33, 1203 (1974). W. B Junes and R. D. Miller. Mlly. Fiudd II, 1550 (1968). R. Turner, Mhas Hends 1.3, 2398 (1970).

13. H. A. David, D. J. Rej, and H. H. Feischmann, Mlig:s Ret: L.efl 39. 744 (1977) and its references.

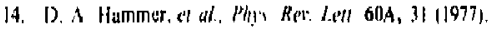

15. C. W. Roberson. Obsernatioms of the Interoctitm of a

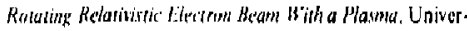
sity of Californitu, I wine. Teech. Repr. a77-6k (1977).

16. B. W. Stallard, A, l rank, and J. Shcurar. Bulli, am. Mhas Siat 22. $1144(1977)$.

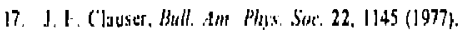

18. J. A. Byers, this Rev. L.ert. 39, 1476 11977).

19. R. Klinkowstein and L. Smullin, Bull. am. Mhys Sor 22. $1065(1977)$.

20. F. H Coensgen, TMII Mojor Projea Propusal. L.awrene Livermore Laboratory. LI.I. Prop-148 (1977).

21. D. E. Haldwin and T. K. Fowler. Lawrence Liysermore J.abol ulory. UCID-17691 (1977); also D. F. Buldwin and M. E. Rensink, rept. in prenuration.

22. S. C. Luckhurdt, H, H. Fleischmann, Phys Rev; Ltth, 39 747 (1977).

23. T. I: Rogrlien. T. A. Brengle, and T. A. Cutler, Bull, am. Phy: Soc. 22, 1066 (1977)

24. H. C. Turner, t.. J. Powers, and T. C. Simonen, Phis Row l.ct1. 39, $1087(1977)$.

25. R, l', Iries, al al. Bull. fm. Phis. Suc , 22, 1192 (1977).

26. T. B. Kaiser. l.awrence livermore l.ahoralory. rept in preparation.

27. H. L. Berk and J. J. Stewar t. Mhrs. Finids 20, $1080(1977)$

\section{Author}

W. C. Turner

\section{Major Contributors}

$$
\begin{aligned}
& \text { I. Clauser } \\
& \text { F. H. Coensgen }
\end{aligned}
$$
D. L. Correll
W. F. Curmins
A. H. Fulch
R. K. Goodman
A. L. Hunt
G. M. Nelin
A. W. Wolvik
R. H. Munger
W. E. Nexsen
J. E. Osher
T. C. Simonen
B. W. Stullard

\section{Thomson-Scattering Measurements}

Using a Thomson-scattering system, we me:tsured the dependence of electron temperature $\left(\mathrm{T}_{\mathrm{c}}\right)$ on various muchine paramelers for two modes of plasma stabilization: giss box and stream gun. We found that $140-\mathrm{eV}$ electron temperatures at plasma center cun be roulinely generaid: on occasional shots, $T_{s}$ reached $180 \mathrm{eV}$. This gentrai increase in electron temperature wis attributed to the following: more beam power, improved stream-gun stabilization, and belter vacuum conditions. The betucr vacuum conditions were achieved by using the newly inslailed liquid-nisogen-cooled liners.

Improved stram-gun stabilization is associaled with the use of stream guns that map into the edges of the plasma. For streane-gun stabilization. $T_{\mathrm{t}}$ can be changed a factor of two by using different stream guns. With gas-box stabilizution, the changes due to different stream guns are not as severe. This stream. gun eflect is not due to changes of the electron densily as measured by Thomson scattering. The

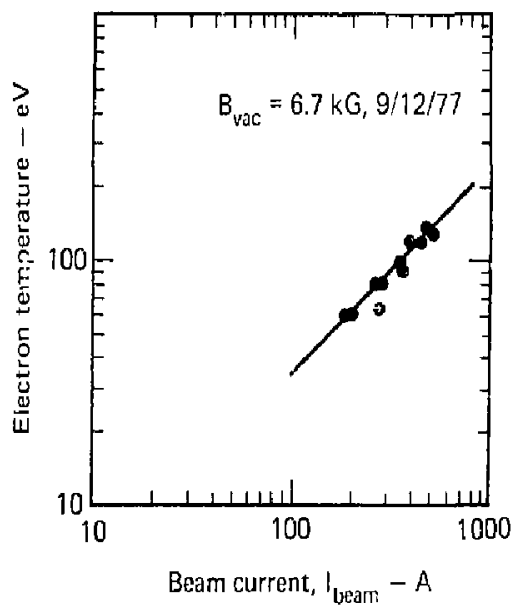

Fig. 1. Measurements of electrot lemperature, $T_{\text {, }}$, by Thomsun scallering show a lintar dependence of $T_{\text {t }}$ on the incident neutralbeam cuifunt. I trant" 


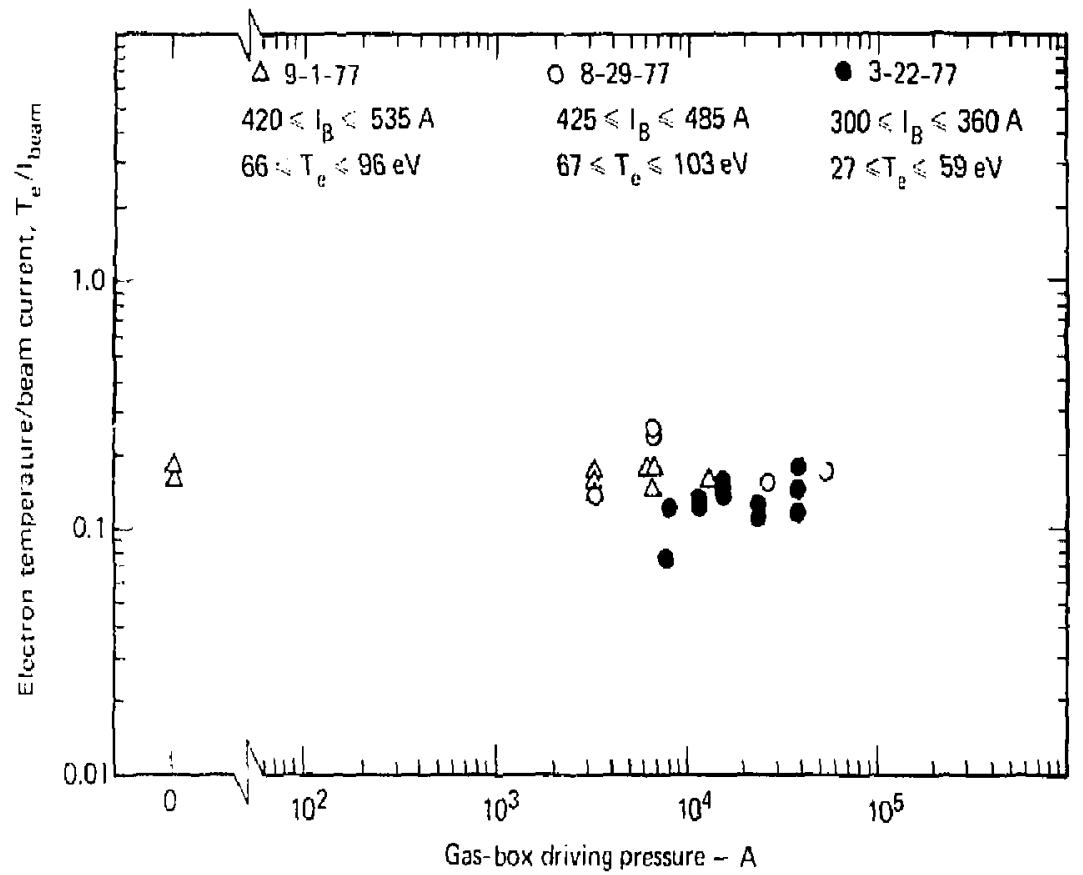

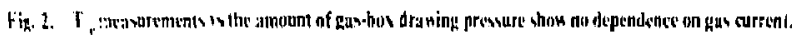

dependenee af $J_{c}$ on beim eurrent $\left(I_{\text {heam }}\right)$ is seen in

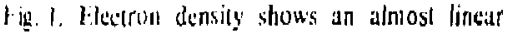
dependence on $l_{\text {berm. }}$. With the neutral beanss aimed iungendially (plitsmal radius $\rightarrow 7 \mathrm{~cm}$ ). muasurtments of $T$, al radial positions $R=0106 \mathrm{~cm}$ show it to be netrly independent of $R$, but slightly lower for $R \geqslant$ $4 \mathrm{~cm}$. Wilh the beams ained head-on iplatmi radius $=12$ en), the dependence of $T_{e}$ on $R$ is vers llat aut to ficm.

For gas-hox stabilization the relation of $T_{C}$ to the gas-flort tate is shown in Fig. 2. Here, $T_{e}$ is normaliaed to $I_{\text {heam }}$ and plotaed against the gas -box Jrikng pressure (proportionsl to the gas-flow ratc). This plot. which ranges from no gas to $\sim 10^{4} A$ equisalent. shows that $T_{\text {c }}$ is independent of this current. Messuruments of electron densily ulso show no dependence on this gas current.

In another series of experiments we changed the gas species whilc holding the gas-driving pressure constunt. for most of the gases used-deuterium, nitrogun, neon, and belium- $T_{c}$ did not change. However, when we used argon, $T_{c}$ was reduced by al factor of three. Electron densily was also lawered by a similar factor.

when the solenoutal and quadrupole-mirror magnetic fields were independently varied, both the central magnetic field $\left(B_{2}\right)$ and the vacuum mirror
Iitio $\left(R_{\text {, de }}\right)$ could be vilried. Unfortunately, in the present experimenls, the quadrupole contribution and mirror ratio sould not be varied independently: thus their individual eflocts could not be Jeter. mined. Figure 3 shows the dependence of $T_{c}$ on

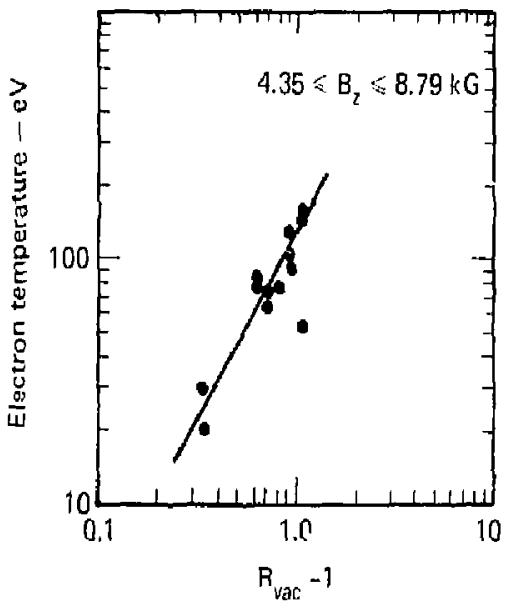

Fig. 3, $T$, measurements sthon a dependente on the varuam mir rot ratio, $R_{\text {,erc }}$, The centul mapelis fietd unied bethen 4.35 and $8.80 \mathrm{kC}$. 
$R_{\text {Yac }}-1$, In this experiment, $B_{2}$ was also changing. However, another experiment in which $B_{z}$ was varied while $R_{\text {vite was held nearly constant indicated }}$ that aver this range of $\mathrm{B}_{t} \mathrm{~T}_{c}$ strongly depended on $R_{\text {vilc }}-$ !

Author

R. K. Goodman

Major Contributor

J. F. Clauser

\section{Plasma-Diamagnetism Measurements}

We have inlegrated data from the diamagnetic loop [a single-turn witc around the py roceram highvacuum cham; er (Fig. Ii) into the computer dataacquisition system of 2XIIB. Where i.s the past it was necessury 10 compare Polarois filin records 10 quanify ine measurement of plasnia diansagnetism. a conpuler printoui is now availibble af ter esch dati shot. The duta is presenteo in its lisal lorm, with all necessary compersistion being done by the comnuter. The formul appears in Fig. 2 .

The magr - cic dipole monsent of the pissma (n)) associated with the measused excluded magnetic flux ( $\Delta$ W) is given by

$$
\left.\mathrm{m}\left(10^{6} \mathrm{~A} \cdot \mathrm{cm}\right)^{2}\right)=40 \mathrm{~V}(\mathrm{mV}) \text {. }
$$

where $V=j \psi_{i} / R C$ (integration time) is the voluge signal displayed as a function of time (Fig. 2), For example, at cime $6 \mathrm{~ms}$ a value of $\mathrm{V}=0.4 \mathrm{mV}$ is equivalent 10 at dipole moment. $m \cong 10 x$ $10^{6} \mathrm{~A} \cdot \mathrm{cm}=$. For typical plasma radii of about $6.5 \mathrm{~cm}$ determined under the field-reversal experimentil conditions. this measurement of m intplies plusma circlilating currents in excess of $10^{5} \mathrm{~A}$ $\left(\mathrm{m}=1 \pi \mathrm{r}^{2}\right)$. The offset from zero ufter $10 \mathrm{~m} \mathrm{~s} \mathrm{dis}$ played in Fig. 2 is due to the variation in shol-10. shat reproducibility of the vacuum nagnetic field.

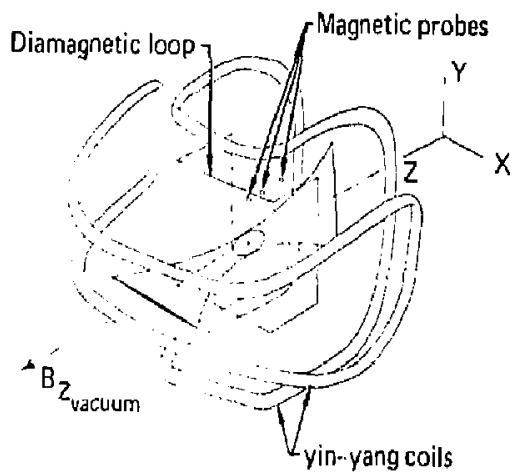

Fig. L. The diamagnetec loop and its geometrical retationship to the yin-yang woil see and plasma.

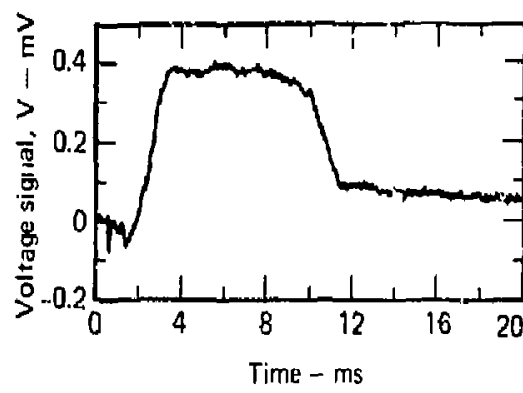

Pig. 2. Megurement of the bulk mapretic dipoils mom:ant, m, of the plusme as a function of tinise nhere nI $\left.110^{A} 4 \cdot \mathrm{cm}^{2}\right)$, = 40. Yolinge Signal, Viniv).

The diamagnet ic loop directly measures the tatal magnetic dipole moment of the plistsma. Beciluse of the lack of a direel measurement of the totil magnetic field at the plassna senter, we used the Collowing moùs.

Assume that the diptile mument (m) determined by the diamagnetic loup san be approximated by circulating currents at a ridius $r=$ al and as exlended over a total length $(2 n)$ in the $z$ disection. The plasma's contribution to the magnesic field at i $\because 0$ is given by

$A B=\frac{\mu_{0} \mathrm{II}}{2 \pi i^{3}} \frac{1}{\sqrt{1+1^{2} / a^{2}}}$

At valcuum magnitic fields $B_{0}=6.7$.nd $i .15 \mathrm{k}(\mathrm{j}$ vulues of $\triangle B$ as high is $3.8 \mathrm{kG}$ have been inferred from Eq. (2). In ihe laller case, the vacuum ficid w so reduced $t 513$ to of its initial value. Although the 2XIIB vacuum magnelic lield was not reversed, the field-reversal parameter $\left(\lambda B / B_{0}\right)$ was inc ? ased for $B_{0}=6.7 \mathrm{kG}$ from a high of 0.3 tast fiscal $y$ war to al high of 0.7 this fiscal year. We oblained the highost field reversal matameter, $\mathbf{A B} / \mathbf{B}_{\mathbf{0}}=0.9$, al $\mathbf{B}_{0}=$ $4.35 \mathrm{kG}$. $A$ value of $\triangle B / B_{0}=1.0$ marks the onsel of field reversol, where the lield at $r=0$ is reduced to zero.

We deduced plasmi-curent distributions, other than the cylindrically shuped ones already discussed, from simulteneous measurements of the magnetic dipole inoment, plasma line density, and three-point measurements of the plusina magnelic field at $\mathrm{s}=25 \mathrm{~cm}$ and at various vislues along the length of the plasma. The magnelic probe used for these thret-point measurements is discussed in delail in the new diagnostics section. Current distributions consistent with these measurements were then modeled and numerically snlved for the magnetic lield at $r=0$ by neans of $a-D$-axis symmetric code. All the various current distributions, 
including the simple cylindrical model, gave the same value of $\triangle B / B_{0}$ within experimental accuracy.
Aut'ior
Major Contributor
D. L. Correll
D. V. Anderson

\section{Parter-Balance Mcasurements}

We incteased neutrul-beam currenl $10500 \mathrm{~A}$ and injecied-beam power to $7 \mathrm{MW}$. Neutral-beam power was measured by a segmented copper calorimeter. The neutral-beam output contaned full-, half-, and third-energy components; consequently, the mean neut ral-particle energy was $\sim 0.7$ of the extraction voltage. From the neutral-beam power and extraction voltage, we determined the neutral-beam current (atom equivalent).

To determine what fraction of the beam power was deposited in the plasma by ionization and charge exchange, we used a small computer code developed by $W$. Turner. This code took into account multiple ionization events; i.e., it allowed for ionization of charge-exchange products.
Using this code we determined the particle and power balance as shown in Fig. 1. This figure is appropriate for line densities of $1.5 \times 10^{15} \mathrm{~cm}^{-2}$ (as measured on September 12, 1977). In these experiments 125. A was trapped in the plasma. In comparison, the gas feed was $650 \mathrm{~A}$ atom equivalent, of which $400 \mathrm{~A}$ was required, by quasilinear theory, for stabilization.

\section{Author}

\section{T. C. Simonen}

\section{Fieutron Measurements}

We measured deuterium-deuterium (D-D) neutron emission $3 \mathrm{~m}$ from the stabilized 2XIIB plasma center, using a lead-shielded plastic scintillation detecto ipolystyrene plus $2.5 \%$ p-lerphenyl and $0.03 \%$ tetraphenylbutadiene), Integrated neutron emission was measured using a calibrated silver-activation postpulse counting lechnique that typically gave $3 \times 10^{9}$ neutrons during the 10 -ms plasma pulse. Both detectors were simultaneousty
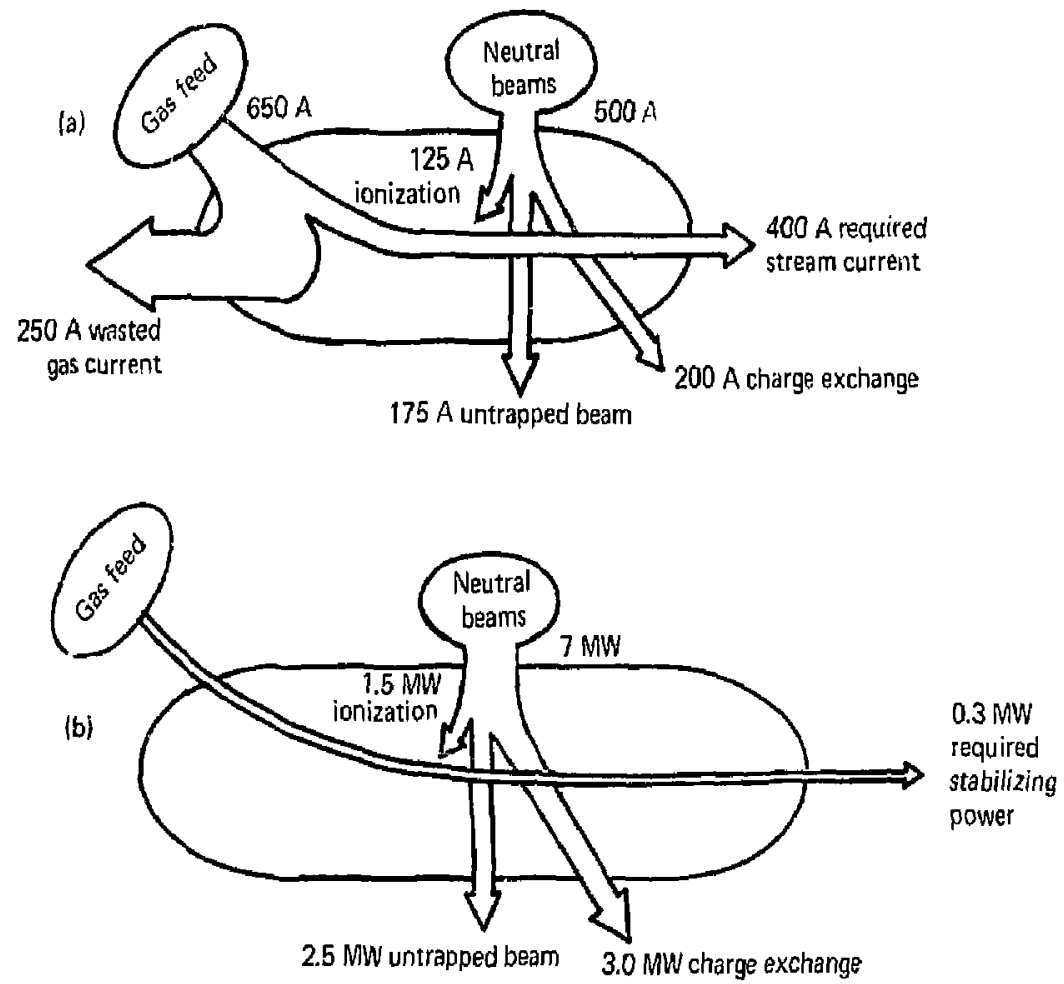

Fig. L. Ion particle balance (a) and ion power balance (b) for a typical field-reversal experimental data shot at a line deasity of 1.5 $x 10^{\text {is }}$ particles $/ \mathrm{cm}^{2}$. 
calibrated with a californium-252 neutron source that had a spontaneous fission neutron spectrum centered on the average energy of $2.35 \mathrm{MeV}$. The californium-252 neutron average energy was close to the average energy of the $2.45 \mathrm{-MeV}$ neutrons from the D-D fusion reactions. We added an unshielded scintillation detector, operaling in a ccunting mode, 8-m from the plasma center and calibrated it by an independent technique. Intercomparison of the results from these three neutron deteclors indicated that no extraneous components existed in the reported data, as illustrated by the linearity (Fig. ') belween the silver-activation detector signals and the 8-m scintillation delector.

Author

A. L. Hunt

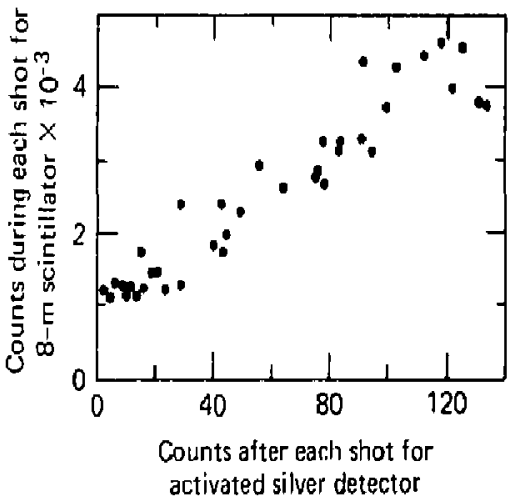

Fig. 1. Comparison of data from \&-m scintillation and activated. silter neutran detectors.

\section{Zeemar-Effect Magnetic-Field Diagnostic}

We pursued development of a new rield-reversed diagnostic that would

- be nonperturbing

- provide a "point" measurement of both the mignetic field strength as well as its direction,

- and have a measurement accuracy expected to be at least $1 \mathrm{kG}$ (although optimistic estimates approached $100 \mathrm{G}$ ).

The system will measure the polarization of the wings of a spectral line induced by the unresolved Zeeman splitting of the line. The measurement will be made by exciting fluorescence in the line by two tunable-dye laser beams. We selected the effective wavelengths of these to simultaneously pump opposite wings of the line.

For the first experiments, we will chnose an excited state line in helium-iodide. The line width will be kept narrow by injecting helium in a neutral beam $(20 \mathrm{keV})$, with the laser beams roughly normal to the helium beam bul parallel to the magnetic field. In practice the two laser beams actually will have the same wavelength, but will impinge on the neutral beam with a small angle between them. The helium forward velocity will then Doppler shift the effective wavelengths relative to each sther. The two laser beams will have opposite senses of circular polarization, senses quickly interchanged halfway through the luser pulse. The resulting change in the fluorescence intensity (monitored through the Thomson-scattering lens system) will then be a direct measure of field slrength and direction. The sampled volume will be defined by the intersection of the fluorescence monitor field-of-view and the laser beams. Initial measurements will use helium in one of the Lawrence Berkeley Laboratory $50-\mathrm{A}$ sources: for more precise results, however, J. Osher has developed a well-collimated SARA source to provide an $\sim 1 \mathrm{ec} V$ linewidth helium beam.

Author

\section{J. F. Clauser}

\section{Faraday Rotation (Interferometer Diagnostic)}

We assembled a system that measures magnetic field and plasma density by using submillimetre radjation al $337 \mu \mathrm{m}$ (hydrogen cyanide, gas. discharge laser). Magnetic fields will be determined by measuring the Faraday rotution of the plane of polarization of a linearly polarized probing beam. Measurements of plasma line density will be deler. mined from the phase shift of the same probing beam,

The rotation of the plane of polarization is given by

$$
J y=2.63 \times 10^{-1+} x^{2} \ln \bar{B} \cdot d \bar{f} .
$$

and the plasmu-1ringe shift is aiven by

$$
N_{f}=4.38 \times 10^{-14} \times i n d \text {. }
$$

where the units are $\mathrm{cm}$ and $\mathrm{kG}$. The densityweighted, line average of the magnetic field is given by

$$
\langle\mathrm{B}\rangle=\ln \overline{\mathrm{B}} \cdot \mathrm{d} / \mathrm{l} / \mathrm{nd} t .
$$

Figure I shows the path of the probing beam. We have chosen the $45^{\circ}$ path to avoid cold, stabilizing plasma, which is exterior to the hol-plasma yolume. 


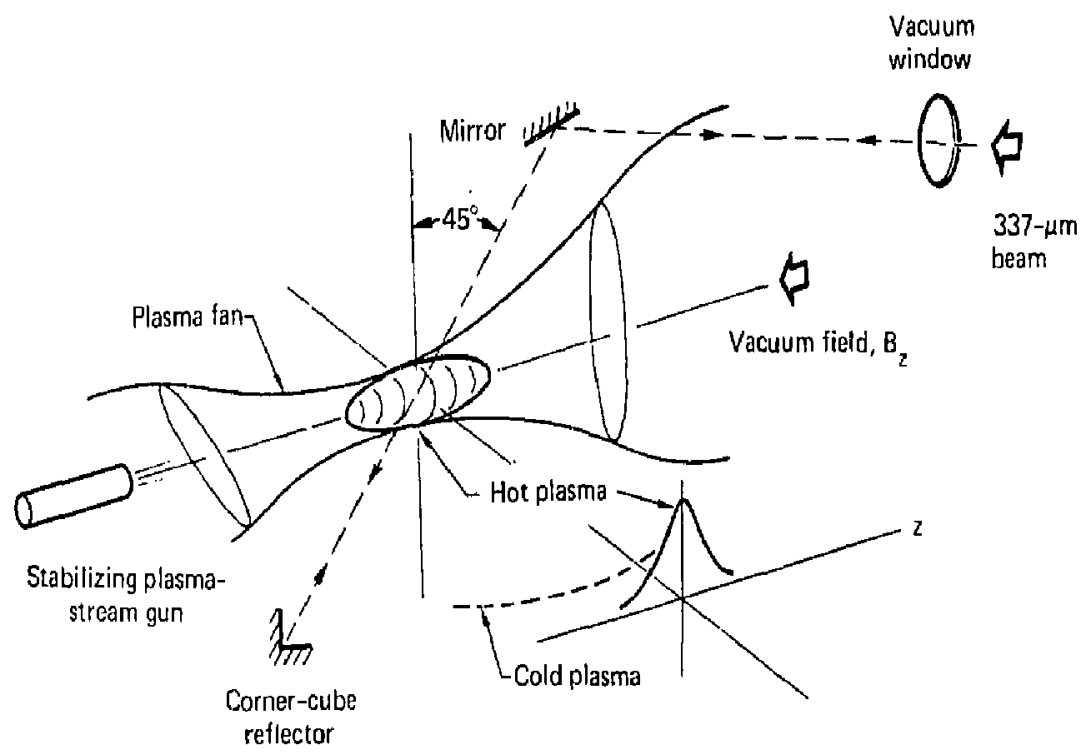

lig. 1. Puth or the $17 \%-\mu m$ heam in the 2 XIIB tixperiment.

A corner-cube rutroreflector is used so the return beam can retrace its original path, thus minimizing the effects of plasma refraction. Since the submillimetre beam passes through the plasma swice, the rotation and phase shift are doubled.

Figure 2 shows a layout of the optics used for the measurement. The laser is remotely located from the 2 XIIB machine and radiation is propagated to the optics table with a pyrex glass waveguide. The beam is split by beam-splitter $\boldsymbol{S}_{1}$; the reflected beam (probing beam) passes into the machine and back out to detectors $\mathrm{D}_{2}$ and $\mathrm{D}_{3}$. Of the portion of the beum transmitted by $S_{1}$ a fraction is focused on detector $D_{1}$ (reference detector). The remainder is reflected from i rotating grating and is Deppler shifted it $125 \mathrm{kH}$. The Doppler-shifted beam is then locused on all three detectors to obtain a beal frequency of $125 \mathrm{kH}$.

Detector $D_{1}$ produces a constant frequency reference that is compared with the time-changing frequency (due to the time-varying plasma density) of deteclor $D_{2}$ to determine the plasma line density

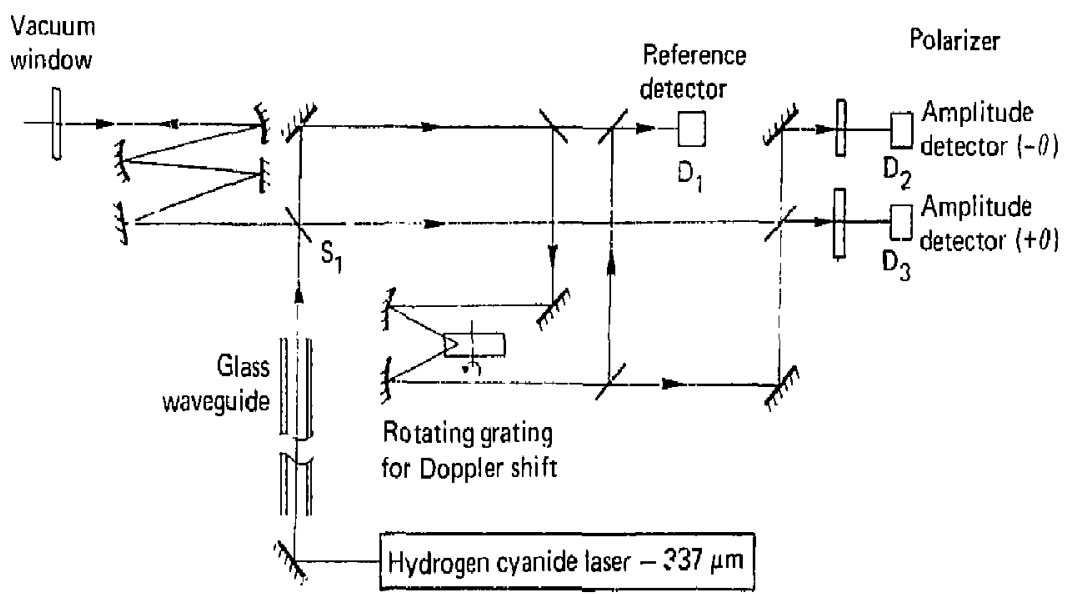

Fig. 2. Layoul of the optics for the Faraday-rotation inlerferometer. 


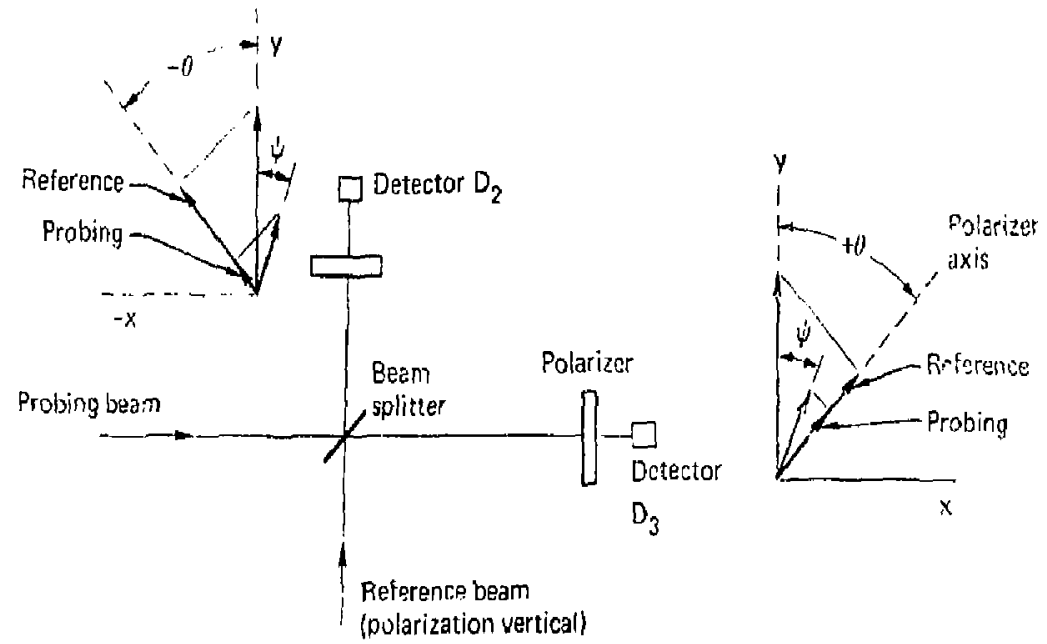

Hïg. 3, Differential deteter arrangement used to measure the direction and magnitude of rotation af the plane of polarization.

as a function of time.

Detectcrs $D_{2}$ and $D_{3}$ ure used in a differential detector arrangement (Fig. 3). The direction of rotution of the plane of poldrization is given by the sign of the differential signil. The differential signal
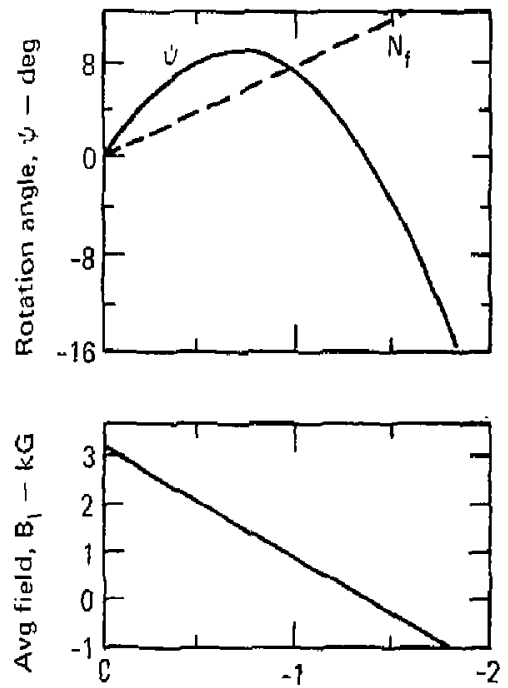

Field-reversal parameter, $A B / B$

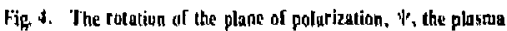
feinge thifls. $V_{r}$ and tte line gutrage of the magnefic field, $B_{\text {, }}$, are plotted against the field-reiersil "arameler, $\triangle B / B$. The data nas generaled from a rigid rolor modal of the diamagnetic plosma currents for a $45^{\circ}$ path angle, $B_{a g}=4,35 \mathrm{kG}, \mathrm{R}_{p}=7 \mathrm{~km}$ and $\mathrm{L}_{\mathrm{p}}$ $=18 \mathrm{~cm}$. is normalized to eliminate amplitude changes (dus to plasma re[raction) in the returning probing beam.

We calculated estimates of the expected rotation and plasma-fringe shift with a computer cadt that solves Amperes Law for the manetic licid for a given spatial-current distribution. The calculated result for a Gaussian-profile rigid rotor wilh radial and axial scalc lenglhs $a=7 \mathrm{~cm}$ and $\mathrm{I} .=18 \mathrm{~cm}$. respectively, is shown in Fig. 4. The rotation is seen to reach a maximum al the field-reversal parameler $(\triangle B / B) \approx-0.75$; negative rotation sciurs for $\lrcorner B: B$ $=-1.35$ (35\% field reversil).

Measurements wilh this diagnostic will he made during our continuing experiments lo reath the field-reversed state in $2 X I / B$.
Author
Wajor Contributor
B. W. Stallard
D. V. Aadersion

Sew Miagnostics: Magnetic probe

The magnutic probe is an axial array ol 100-iurn. $1-\mathrm{cm}$ diam by $1-\mathrm{cm}$ lengh wire loups tased to measure the plasmats self-magnelic field at a thed radial position (r) but al several axial positions in $L$. Figure 1 in the plasma-diamagnetism measurements section shows the position of the 100-iurn loops in relation to the single-turn diamagnetic loop. The small loops are at $r=25 \mathrm{~cm}$ and $z=0,8.6$, ind $21.8 \mathrm{~cm}$. Figure ! of this section provides at photograph of the loops. 


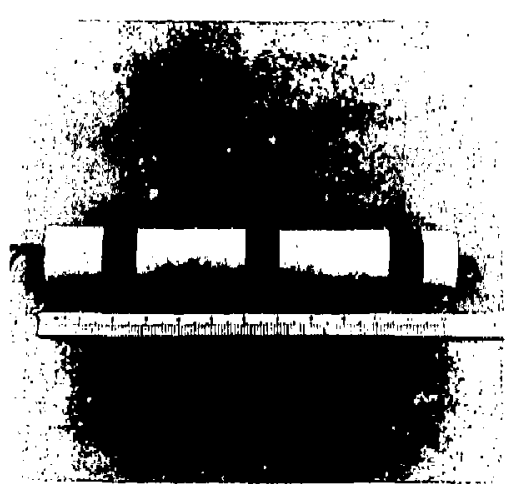

Fig. I. Magnetic proth loops

Figure 2 displays mugnetic-probe data for the $z=$ 0 position. In Fig. 2(a) the integrated electromotive force signul $\left(V_{0}\right)$ due to the yacuum magnetic field $\left(B_{0}\right)$ is displayed as a function of time with $V_{0}=$ $B_{i}, A n / R C$. where $A \cong 71 \mathrm{~cm}^{2} / 4, n=100$, and $R C$ is the inlegration time. Because the plasma signal is
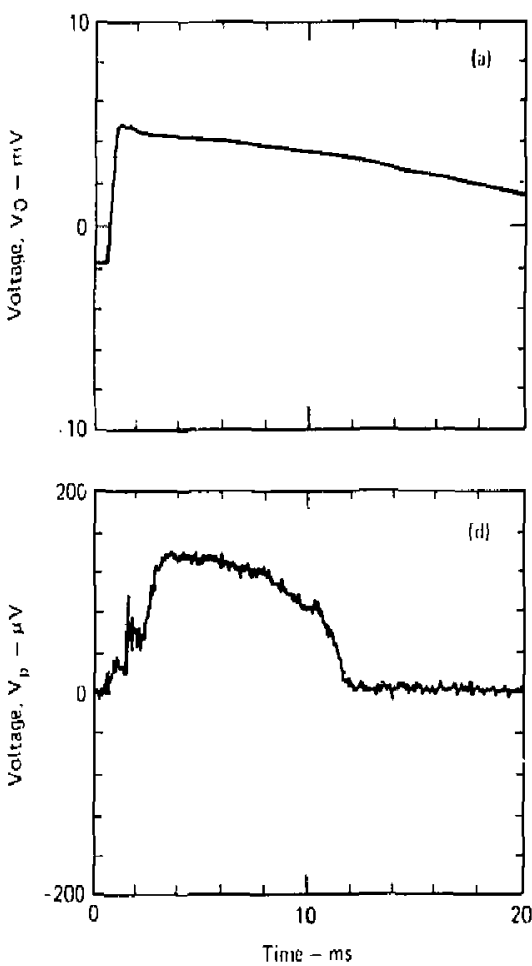

expected to be only a few parts out of a hundred of the background vacuum-field signal, the vacuom magnetic ficld is compensaled against by monitoring the external currents supplied to the yin-yang coils. Figures 2(b) and 2(c) are the result of a commensated data shot without and with plasma being present, respectively. The difference is slown in Fig. $2(d)$, where $V_{p}=B_{p} A \pi_{i} / R C$, with the plasma's self-megnetic field $\left(\mathrm{B}_{p}\right)$ being delermined by $\left.\mathrm{B}_{\mathrm{p}} / \mathrm{B}_{i}\right)$ $=V_{p} / v_{0}$. For a pulsed magnetic-ficld level of $2.35 \mathrm{kG}$ (tolal vacuum lield is $4.35 \mathrm{k}=2.35 \mathrm{kG}+$ $2 \mathrm{kCi} d \mathrm{de}$ guide field), the mejsurement shown in Fig. 2 indicates a plasmal self-magnetic field of $B_{p} \cong$ $70 \mathrm{C}$.

The magnetic probe, by defining the spatial gradient of the plusma"s axial magnetic field. allows current distributions within the plasma to be modeled. These distributions are consistent with the measured magnetic dipole moment.

\section{Author}

\section{1.. Correll}
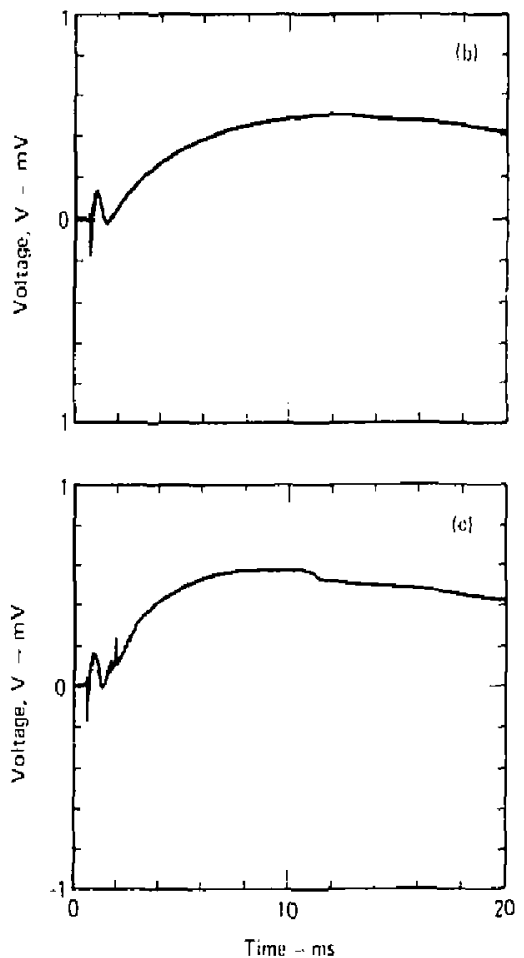

Fig. 2. Vollage, $v_{a}$ due to the raraum mapactic fietd, $B_{0}$, as setn by the uncompersaled magnetic probe, $B_{0}=V_{0} R C / A n,(b)$ and (c) Data shots wittout plasan (b) and with plasilas ( $c$ ), where the innuence of $B_{n}$ on the total magnelic probe signal has been compensated by

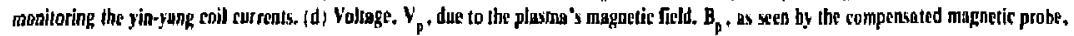
$B_{p}=V_{p} R C / A n_{1}$ 


\section{Reaction-lon Analyzz! Diagnostic}

We emphasized solid-state detectors and particle. counting techniques to investigate ions produced from fusion reactions in mirror configurations. These ions leuve the plasma region with energies in the $\mathrm{VieV}$ range. Preliminary testing of this diagnostic was carried out on 2 XIIB, with applica. lions to the Tandem Mirror Experiment and the Mirror Fusion Test Facilily considered. The ions produced in deulerium-deuterium (D-D) fusion reactions are $3.02-\mathrm{MeV}$ protons. 1.01-MeV tritor. and $0.82-\mathrm{MeV}$ heljum-3. To date, we have detecle. the protons.

We usted silicon surface-barrier, semiconductor detectors (o) readily record encrgetic-reaclion ions. These compace delectors can furr inn in an en. vifunnent that includes high mugntic field, good vacuum. and low temperiture. They produce an output yohtape proportional to the energy denosited in the detector by the incident particls. They also provide the possibility of good energy resolution.

Several plasma characteristics might be examined when delecting ions from fusion reactions. First. this diagnosic may provide a measure of the reaction rute-an independent sheck of neutron results withoul such disudvantuges of retutton measurements as poor spatial and energy resolution. Good spatial resolution of the reaction rate may be practical because ion paths in mugnetic fields are calculable. Radial resolution may be possible from reuction ions leaving the plasmid along magneticfield lines. Axial resolution may be possible from these large gyroradius ions being displuced outward neat the midplanc to regions where deteylors can be placed.

Because reation rate depends on both density and plasma-ion temperature, either of these parameters can in principle be estimaled by assum. ing or meusuring the other. Possibly both density and ion temperature can be simultaneously measured because the energy spread of the final $\mathrm{MeV}$ inn is related to the temperature of the initially reacting plasmi ions. (This energy spread arises from the range of angles possib' between the velocily of the firial $\mathrm{MeV}$ ion and the center-of-mass velocily of the interaction.)

Another conceivable use of reaction ions is for well-collimuted delectors $t o$ detect in coincidence near the midplane the proton and ariton from the same D-D reaction. The ian paths and region of origin may then be well enough defined to give information on the average magnetic field encountered by the detected particles. By comparing the trajectories with those in a low-buta (plasma pressure/mugnetic pressure) situation, information might be obkined on the depressed nagnetic lield in the high-beta plasma region. We may also get information on fietd reversal.

In the initial experimentation with this diagnostic on 2XIIB, we positioned a surface-barrier detector $3.2 \mathrm{~m}$ from the plasma center along magnetic-field lines, outside the mirfor region." Thin $(1.0$. to 8.5 $\mu \mathrm{m})$ aluminum foils werc placed before the detector to shield against unwanted radiations irom the plasma region. When ue decreased the aluminum-

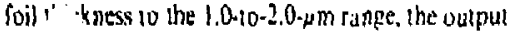
signal of the preamplifier that inn ediatcly follows the detector suturaled during the tir $~ \cdot$ the plasma existed. Our tentutive conclusion was that this large sig tal was caused by photons incident on the deleclor, with frequencies in the uiltusviolel or $x$-ray fegion or both. This fiux was eliminuted with an 8.5 . $\mu \mathrm{m}$ aluminum foit: there was : ncomitant obiervation of 3-MeV protons. Experimentation conlinued with various foil ntaterials and thicknesses, and with appropriate collimation, wo optimiz: the reaction-ion signals.

This diagnostic has already been altuened to the 2 XIlB machine for hundreds of plasma pulses. No apparent damage has been noted to the detector. thin foil, or preamplifier during this period, even though the diagnostic appuratus receives a sharp mechanical shock during each pulse und the envifonment (e.g.. clettrical, thermal, ind radiation) with or without the plasma present can be harsh.

\section{Author}

\section{J. H. Foote}

\section{Improvements to Thomson-Scattering Sỵstem}

We made several modifications in the Thomsonstattering system (previously described in UCRL50002-76). ' Aimed at reducing systematic errors und making the whole system more reliable, these modifications included the following:

Ruby Laser. We installed a beam expander that followed the oscillator and provided more unifurm illumination of the amplifier rod. The lamp and Qswitch timing were also revised: several minor modifications were made in the power supplies and capacitor banks. As a tesulc, the ruby laser became a highly reliable unit. We built and installed a new support structure for the luser and the machine input-optics arm. This provided increased stubility and ease of optical alignment.

\footnotetext{
"For a discussion of preluminary testing of hlis diughusisc on it

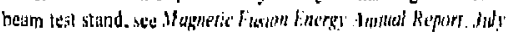

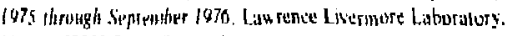
UCRL-50002.76 (1976). p. 36.
} 
Viewing System. The viewing optical system was aligned to maake measurements at plasma radial positions of $R=-2,0,+2,+4$, and $+6 \mathrm{~cm}$. $A$ moveable mirror system allowed the polychromator 10 look at any of the above positions. Interference filter sets louked at the $R=+2$ and +6 positions To improve measurement uecuracy. we increased these filter sets from four to six filters each. A quartz heam splitter, for the calibration light source, replaced a previous one that had poor ${ }^{i}$, ansmission and reflection characleristics over the Hilyelengths used.

Data Analysis, In generial, the computer dilta analysis proved useful. The original integrators, however, were not reliable and gave random trrors. We replated these and added a microprocesser for emporary data storuge. This system also allowed for more ellicient use of the malin computer. Comparisurs midde hetween compuler and hand.reduced dilti then showed comparable results, indications that the sistem was retiatle and accurate. Mainly, the laborneus process of manual data reduction was clinithated. Thus the volume of data that could be ansllyed in a restontable time was greatly increatsed.

\section{Referente}

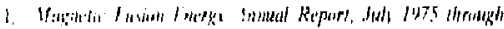

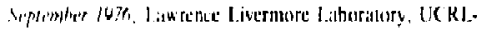

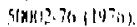

\section{Authors}

\section{R. K. Goodmin \\ J. F. Clauber}

\section{Langmuir-Prube Measurements}

Elettron Temperature. We used Langnuir probes in the end lanks, both east and west, 10 evuluate the purameters of the external plasmil, the electrinn temperature ( $T_{e p}$, and the ion flux across the fan. idded information sbout the ion tenperature and the local ambipolar potential could be obtuinted at least qualitatively. These metsistements were performed in a tine scale of about $20 \mu$ s. One set of three probes spaetd verticully across the west horizontal iun was usually localted al $(Z)=-220 \mathrm{~cm}$ from the $2 X 11 \mathrm{~B}$ center, but could be positioned be wwen $Z=-185$ and $-275 \mathrm{~cm}$. $A$ single probe was used in the east tank at $\angle=+160 \mathrm{~cm}$ lrom the center.

There are two different series of measurements that depend on the plasmu-stabilization method:

- Gas-Feed Stabilization. The gas box was lirst located outside the west mirtor at $90 \mathrm{~cm}$ (slit aperture, $1.4 \mathrm{~cm})$. We subsequently moved it to the mirror throal ( 5 lit aperture, $2.4 \mathrm{~cm}$ ). For gas-box (iperation at it con itint gas pressure (25 Torr), the clectron temperature in the external region $\{Z=$ $-220 \mathrm{~cm}$ west) was slamped at a low valuc: $T_{\text {p }}$ $-30 \mathrm{cV}$. This valuc only weukly depended on $T_{\mathrm{c}}(0)$. lice electron emperature at the 2XIIB center. The latter scaled approximalely with neulral-beam current.

- lidge Streani-Ciun Stabilization. We obtained similiur, but less consistent. results with edge stream-gun stabilization. For most shots we found $T_{e p} \approx 30 \mathrm{eV}$ in the ctatsifan region while $\mathrm{T}_{\mathrm{e}}(0)$ taried up to $\approx 90 \mathrm{eV}$ with beam current. On the olher hand. depending on sireume-gun connliguration, we fround occasional shots for thich $T_{\text {ep }} \approx T_{0}(0)$. These resulls appeut in rigss. 1 and 2.

Alihough in most calses $T_{\text {up }}$ is independent of $T_{c}(0)$, we find. for gas-box operation, that it strongly depends on gas pressure $\left(P_{\text {gisl }}\right)$. Figure 3 shows this variation ats a function of $P_{\text {sid }}$ and beam current. In contritst, $T_{e}(0)$ is vir"silly independent of $P_{\text {pats }}$ over an secen wider range 10 to 1000 Torrl.

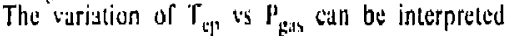
qualitalis cly in lerms equipartition between mirrorconlined hut electron losses $(140 \mathrm{eV})$ and both cold electrons cuming from the walls and gas ionization. (jas feed, for reasions not yet understeod, evidenely coous only the electrons in the exlernal plasmia regions.

(i) quantilutive energy balance has yet heen meide; nontethultss the lollowing phenomenta seem gauite clatar. The behavior of the exlernal electron emincrature is markedly different from that of $T_{e}(0)$. It is nol possibie to fit these values of electron lemperature with a collisional electron-energy Iranspiorl nodel along the lield lines, even when the he:it-conduction equation includes the thermocles-

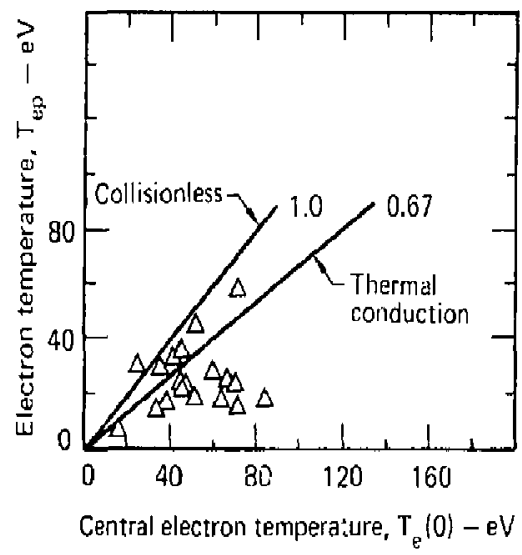

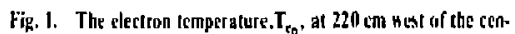
ter, is reakls dependenl of the crntral clectron temperature. $T_{f}$ ( $(1)$. 


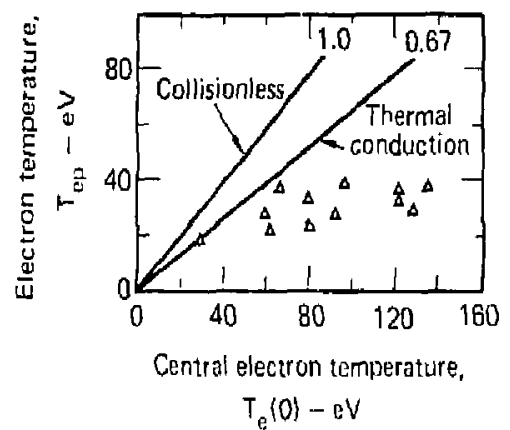

Fig. 2. Same plot as Fig. I. The electrun teinperature $T_{t_{0}}$ is measured at 1 thl em cast of the cencer.

tric term caused by the ambipolir potential $(-50 \mathrm{~V}$ at the probe locution. and probably a few hundred volts at the exnter). This model makes two quan(tituively precise predictions in sharp distgrement with our obscrations: (a) $\mathrm{T}_{\text {up }}, \mathrm{T}_{\mathrm{c}}(0) \cong 0.67$ and $(\mathrm{b})$ for hot plesma lenghth. density, and average energy. $\mathrm{T}_{\mathrm{e}}(0) \leqslant 65 \mathrm{eV}$. The electron heal-conduction model may still hold in the external region where the

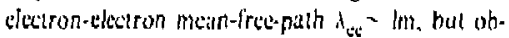
viously it is not valid ill the way wo the center where $T_{s}(0)-140 \mathrm{eV}$. One is thus led lo ask what is the insulation mechanism betwet the 10-eV central electrons and the 30-cy slectrons in the external regions" With the gas hox located at 90-cm west.

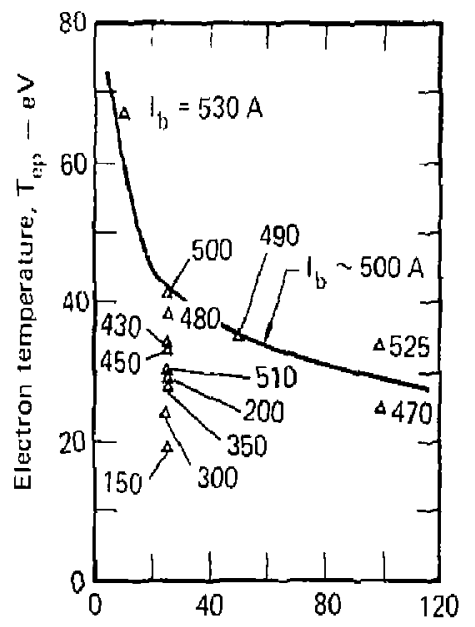

Gas pressure, $P_{g a s}-$ tor

tig. 3. The election emtperature. $T_{\mathrm{rp}}$, at $220 \mathrm{~cm}$ best of the ceth-

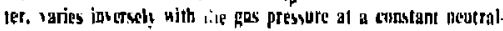
beats current, $I_{b}$, of about șan $A$. The rariution of $T_{e_{0}}$ nilth the neutral-heasn current is shown al a giv en gats pressure of 25 Torr. meissurements made as far in als 10 cm outside the

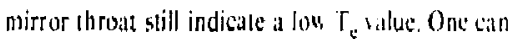
expest a sharp variation of $T_{\text {a }}$ near the mircor (hatal. We plan further measuroments with an artaly of probes along the avis.

Stream transmission. from the intr-xilturation current $\left(I_{\text {and }}\right)$ collecled by 1 angmuir probes Idescribed in lie sectron temparalure ectiont. bite

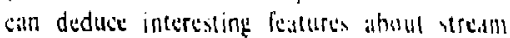
transmission through the hol plistriba In gils-bus

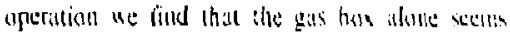
dominamly responsible for the llus ol inm measured at the probe position: i.s. no wher soldplasma wources are rekevarl.

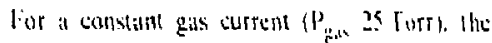

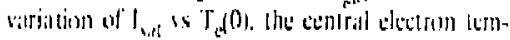
perature, shows a that portion below s() \& 5 and (bed a roughy linear increalse hets tón 80 and $140 \mathrm{er}$. This kink at 80 eV is apparent! sorretiled will a corresponding kirk observed for the sumb sonds-

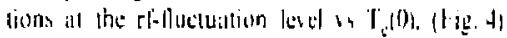
flete following sxplanstion stems tomsistent whth these ohsers atioms.

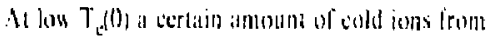

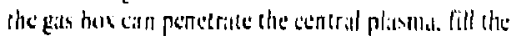
ambipolar bole sh the ion-distribution function. and

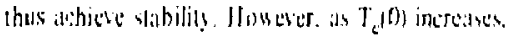
so does the amipolat burrier. More cold ions then get rellecled. The slabilization deleriorates and the

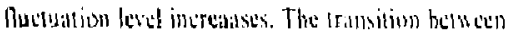

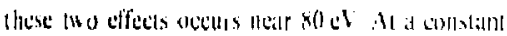

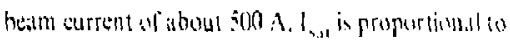

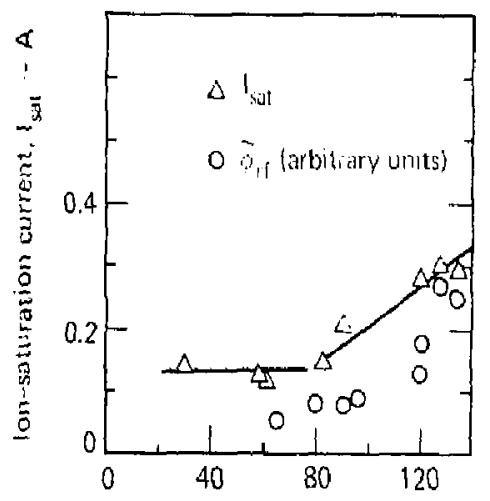

Central electron temperature, $T(0)-\mathrm{eV}$

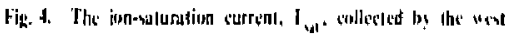

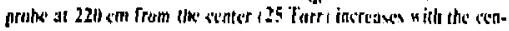

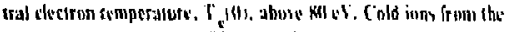

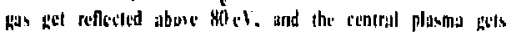
destabilined us shoun by lhe insrease of the of Ructualian lesel above BII et. 
$\mathrm{P}_{\text {gas: }}$ but near $\mathrm{P}_{\text {gis }} \approx 25$ Torr a net decrease of slope occurs, witnessing an increase of transmitted cold ions across the hot plasma with increased gas pressurc. Operation at higher gas pressure evidently will not txclude gas for $T_{c} \subseteq 80 \mathrm{eV}$. By using the probe array perpendicular to the west fan at $Z=$ $-220 \mathrm{~cm}$ we have crudely evaluated the $I_{\text {sat }}$ profile (Fig. 5) and thus eslimated the total current of cold ions fluwing through the fan. One can then plot $I_{\text {sat }}$ is $P_{\text {pal }}$ ats this total current vs the total coid-gas currenl injected. This is shown in Fig. 6. Below 25 Torr $(650 \Lambda)$ the slope is about unity. Nearly all the cold jons are reflected; thus they do not participate in the stabilization mechanism. Further confirmation of this hypothesis is that we observed pone stabilization at low gas pressure (10 Torr). A hove 25 Torf the slope is aboul 0.2 , indicating that 807 of the incresse of cold-ion current above $650 \mathrm{~A}$ is transmitted. With the gas box positioned outside the mirror throal. measurements have also been made simultancously using both the east and west probes. These duta show the sume behavior: negligihle transmission for lowngas pressure but increasing transmission at it etertain threshold pressure, with the transition denending on $T_{x}(0)$.

A possible explanation of these observalions lies in the liat thit a I teservoir of cold-ion density has to

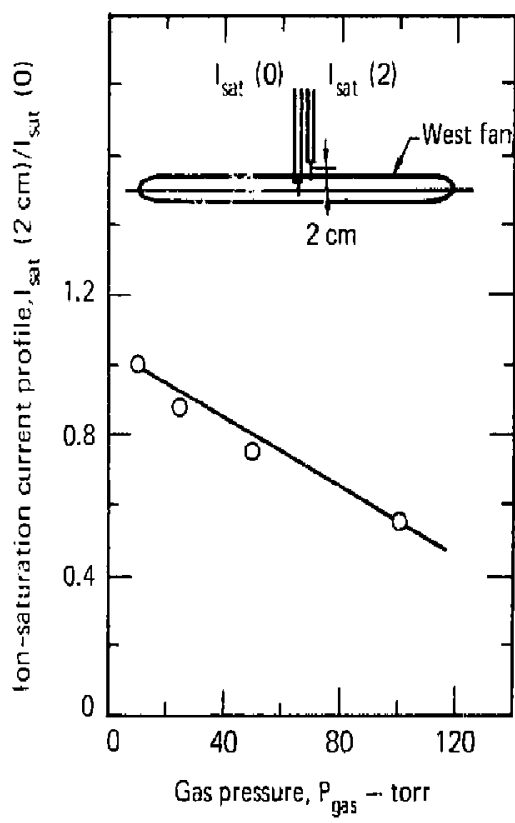

Fin. 5. The iun-saluratiun current profile, heing characterized by the ratio "I the inrewluration currents collecled by tho probes locisled al 2 cm from tach other across the uat fan, in gutting more and mure peaked as the fous prosute increases. be filled between the gas box and the central hot plasma to raise the ambipolar potential locally. Once the reservoir density is sufficiently high, the cold ions can penelrate the central barrier. However, a more precise quantitative evaluation of the transmitted and reflectad cold-ion fluxes will require many different measurements (profiles across and through the fan) or various assumptions concerning the density profile or both. Nonetheless, we do have solne good experimental evidence of cold. ion exclusion.

In the edge-siream stabilization operation, the variation of $I_{\text {sal }}$ given by the east probe is nearly linear ws $T_{k}(0)$. The absolute magnitude of $I_{\text {sul }}$ is higher, by almost an order of magnitude, than that for the gas-box uperation. The interpretution is more difficult because of the numerous streaming guns used on both the east and west sides. Also the data strongly depend on the stream-gun configuration.

A.uthors

J. F. Clauser

G. M. Mclin

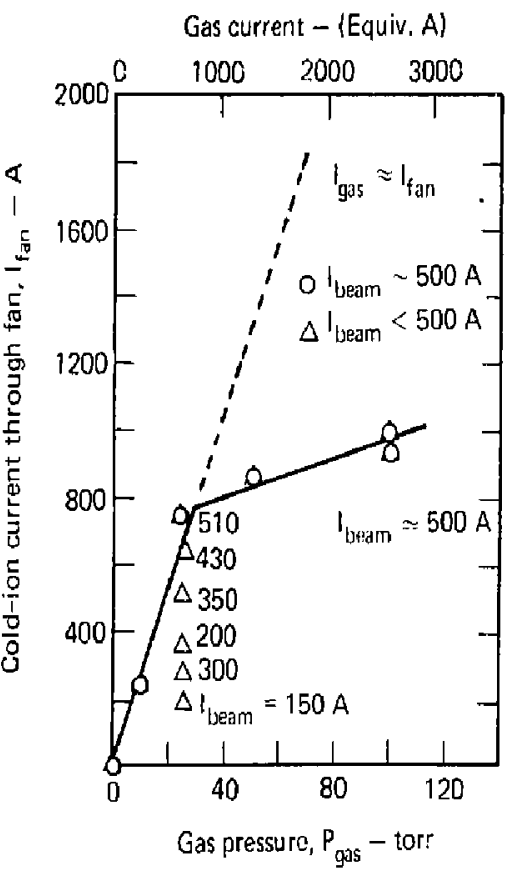

Fing. 0. The cildaion current through the use fan (mugnilude and profile being eraluatiod by isagmuir probes) is found to increase linensly with the gan presure up lo aboul 25 Torr. All the cold ions rrom the geas are fellected by the central plesma. Auove 25 Torr, the cold iuns slatt penctraling the central barrier, as shouto by the change in slope at a given neutraltienm curreat $\mathrm{I}_{b}=500 \mathrm{~A}$. Similar curues cuuld be brann at lower beam cuncents. 


\section{Neutral Beams}

The amount of neutral-heam current delivered to the center of the machilit wals doubled from 250 to $500 \mathrm{~A}$. This increase is seen in Fig. I, where neutrailbeam current $\left(I_{B}\right)$ is ploted chronologically. The spaces in the plot represent shutdown periods of the experiment. Beam currents greater than $150 \mathrm{~A}$ were achicved before October 1977 but only fo: a limited number of data shots. The value of $I_{B}$ ploted in Fig. I is not a "best shot" value but is an dverage value that could be oblained with greater than $50^{5}$. reliability.

The 100-A in provement during the first quarter of FY 1977 catn be mainly auributed 10 iwo lactors:

- Improved operating besm oplics through the aid of a computer program that reduced the calorimetric dalu.

- Staggering of the firing times for the 12 beams. This reduced the antount of interference due to current from opposing beams on the machine striking euch other's grids.

During a 6-weck shid lown from January is wo March I, we optimized cal h beam-ik veliated power supply and in sume ca.s.s. replaced the beam module. This improved the average deliserable current per souree from 25 to $30 \mathrm{~A}$.

We installed longer neutralizer sections on the beams during the shutdown from April through July. This allowed the are chambers of the beam modules to be run at a more optinum vilue of gus density for better beam optics wishout sacrificing the versall neutral particle to the ion-atom ralio of the extracted current. Al the same lime, each beum received its uwn gas-pressure control to the arc

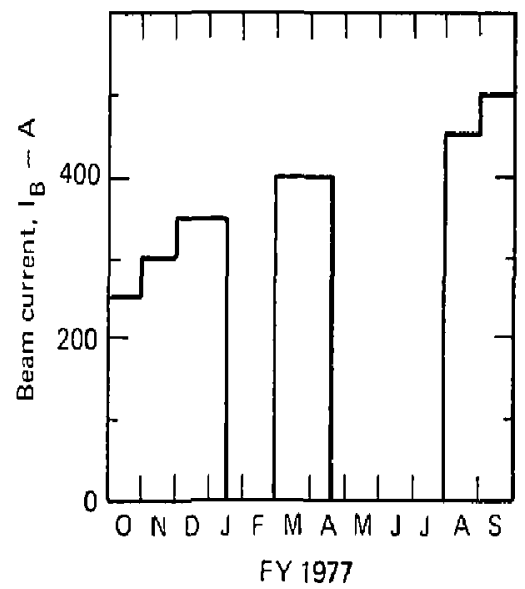

Fig. 1. The inprosoment in the incident neutral-besm current on the plasma, I , is plotted chra nalapicylly for FV $197 \%$. chamber. All beants were then pretested during a burn-in cycle of about 800 shots tach on the 2XIIB test stand before instillation. The linal result wists an average current injected into the senter of the muchine of $45 \AA$ per be:Im, giving al lotal of $500 \mathrm{~A}$ for all I? sources.
Author
Majjor Contributur
D. L, Currel!
W. E. viewen

\section{0-kel Yeulsal-Bum Fiviractors}

During F' 1977. des clopment of t(1-ket exurat'tors made sufficienl progeses to meel the neulrillhealm requirements ol $2 X \mid[B$ and the Fandem

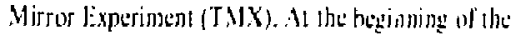
year, we remoled the th-kel extracturs that had betn tried on 2xills. They were replated by 20-ket units beraust beallt current wils intudequatc all the reduced entergy required for whoration. The 2XIlH

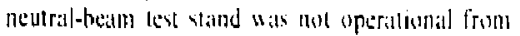
October 1976 lo Iantary 1977 during remodeling of that fitcility. Me then tested seteral estracturs on the 2XIIB test stind. but t0-ket uperation wis nut pussible due to powere suppls problems.

One cxtractor. modified h! the Lawrente Berkeley L:atherillury (I.BI.) ncutril-heam trown.

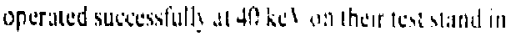
December 1976. Several af aur entrikisur modifici-

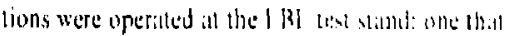

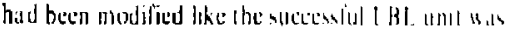

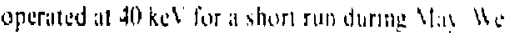
tried thany more modificalioms bul finled allic lex) or lewer shols al $10 \mathrm{kct}$

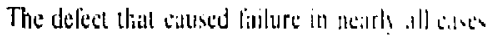

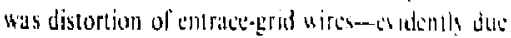
10 averheating. The damaged wises nere alwan locited near the end of the arroly. We used littrial

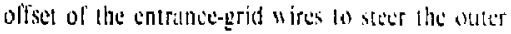
beamlets toward the cemer of atic kirget plitrm.t.

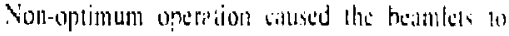
graze the aterly suppressor and exil grids. Stoondary electrons then struch the entranse wires. causing abnormal healing. To il wid thir probletol. we assembled an extralefor withoul allset the wires were bowed. as usual, for vertical fecus. This unit was uptraled al $40 \mathrm{keV}$ for orer lewh whols withsut

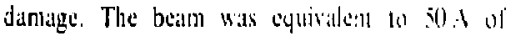
neutral-atom current in a $10 \times 3.3 \mathrm{stm})^{\circ}$ arcal tociled $3,2 \mathrm{~m}$ from the first grid. As T.MT perturmance wits

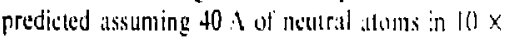
$33 \mathrm{~cm}^{2}$ it $3.2 \mathrm{~m}$, the ecro-ellsel mudule was adequate for TMX.

Steering of the suter hearnlets tomard the cenler is necessary to concentrite dle bealten on the larget 
plasma. To obtain horizontal focus without offset. we began consiructing a newly designed extractor. There wete many changes, including horizontal curvalure of the grids to poinl each beamlet at a common puint at the plasma center. The wires were still boved lor vertical focus. Our isst of the straight. cero-oflisel grid also lested feasilibily of the curvedgrid design. The new extractor design has grid wires that are 4i? the sige of the old ones. This increase lowers the spatial tulerance of wire placement and makes a mure rugged. more casily fabricated ilsitulub]y.

\section{Author}

\section{Vajor Contrihutor}

R. H. Vunger

$$
\text { K. Gillespice }
$$

\section{Bll-kel Source Design for Mirror Fusion Test Facilit!}

The Mirror Fusion Test Facilily requires 48 netural heartss ?t sustaining beams $(80-\mathrm{kev}, 80-\Lambda$, $0,5-3)$ and it statup heiln!s (20)-kev, 80-A, 10-ms). Consrains must be plated on the cross-sectional areil al sach module to locale every 80-kev sustaining beani withu whe solid angle that hils the plasma hat missus the mignet al eniance and exit.
Integration of the are chamber/extractor with the isolation valve and magnetic shield produces the more compaci design shown in Fig. 1. Compaciness is achirved by immersing the arc chamber/extractor in a high vacuum, where high voltage can be held over smaller distances by sedesigning grid-support structures and by bringing services (water. deuterium, power) in only at the backplate to allow close packing of sources.

Ruliability is increased by reducing the electric fields everywhere else below those present between grids. Design innovations also increase reliability. The Jatter includes icchntques to reduce strily magnetic fields and unifcrmly disperse gas, all metal-ceramic construction and a $60-\mathrm{k} V$ shield enclosing all 80-kV electrode: Eary maintenance is obtained by a compacl isolation valve and by modulur construction. Curving hoth the grid wires and their holders provides focusing in two planes.

The source module and the details of the arc chumber and extractor appeu: in Figs. 1 and 2. respectively. The design is being completed, and the arc chambir and extractor will bo constructed during FY 1978. Initial testing will be at Liwrence Berkeley Liboratory, to be followed by testing with the ro-kev model power supply on the High-

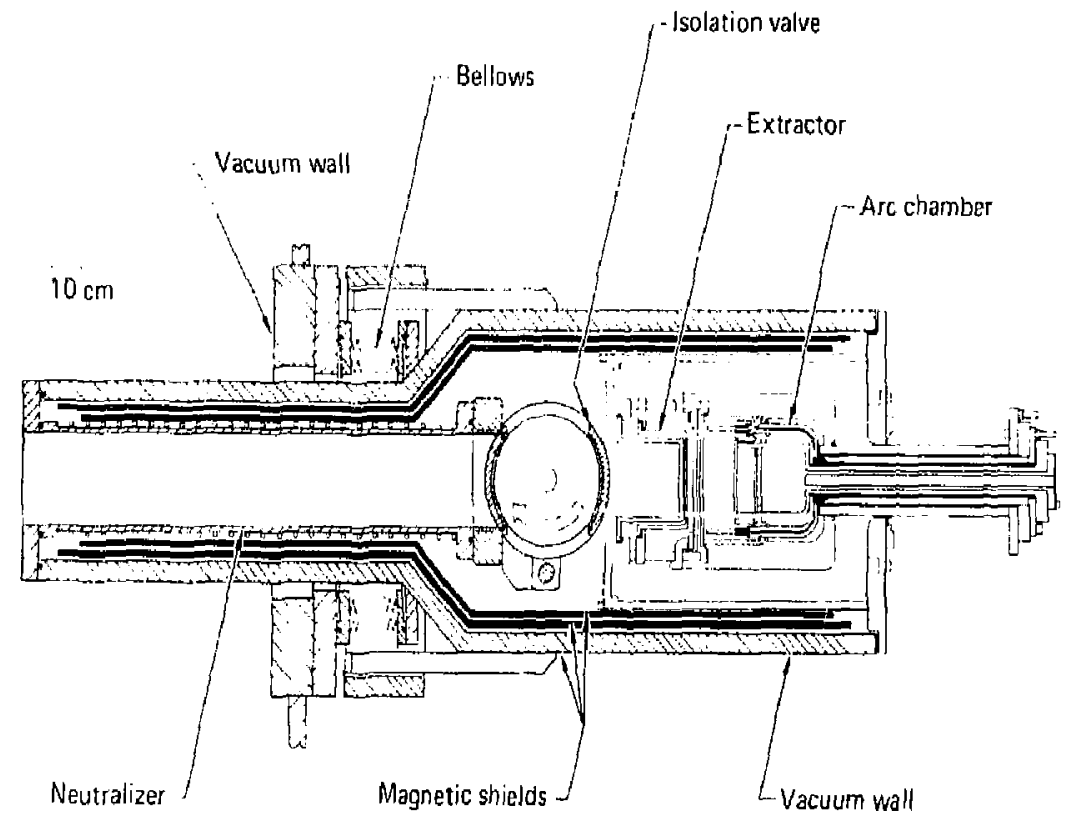

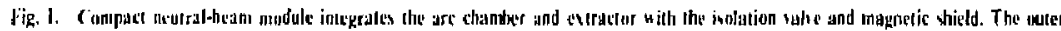

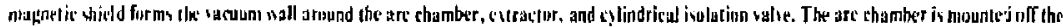

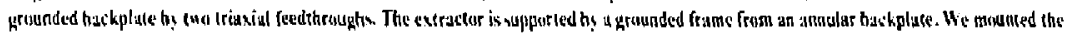

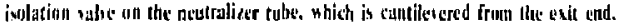




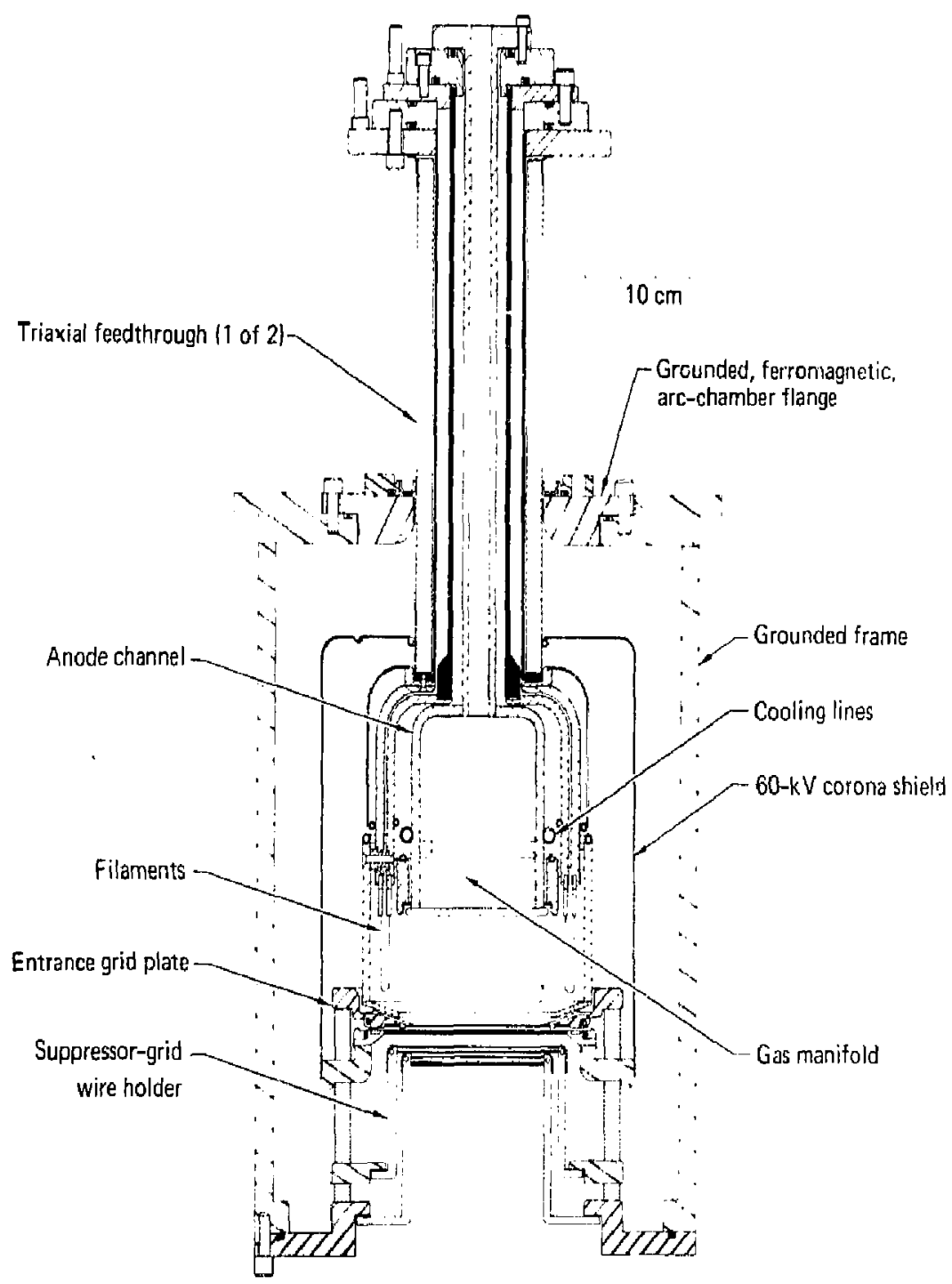

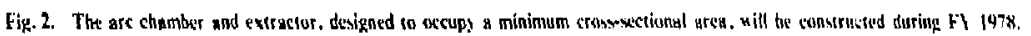

Voltage Test Stand at Lawience Livermore I.aburatory.

\section{Author}

\section{A, W. Molvik}

\section{Computer Control}

The omputer-control system for the 12 neutral beams became fully operational on a regular basis. During normal operation, this system monitors the operation of each beam on eath shol, automatically adjusting the beam controls to maintain a predeter. mined operating level. The system continuously adapts to the changing individual charascleristics of the sources by adjusting the control equations to maintain constant output current and locus.

The computer system provides automatic sonditioning for all 12 sources simultuneousily. In this "hreak in" process, the sources are carefulty advanced from $51020 \mathrm{kV}$. Each source is reated individually and allowed to progress at its own rale. 
Dilla collected from a retractable calorimeter is also processed. providing numerical and graphical output to the operator for energy calibration, focus adjustntent. and aliming adjusiment.

\section{Author}

G. G. Pollock

\section{Data Acquisition and Prosessing}

We had three main develupments in the data asupisilion and processing syblem:

- |-ul| implementation of the Real-Time laceutis Balcli-Spool Wonsor (RTE:BSM) sysictil.

- Derelepment of efficient processing codes.

- Installation of digital alequisition and control

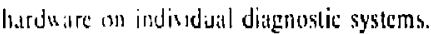

This compuler system is presently operdting at bipacius and ine demands on it are constantly grow-

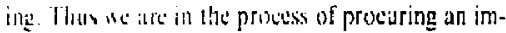
nroces shesem that should salisfy experimental reguirements lirough the TYX operating period.

The RTI: BSSM aperating system, which was coming an lins at the end if the last repoiting perad. us aneraded and developed to its practical Imini The cypermental datal buse grew to $\sim 185 \mathrm{~K}$ dall words per shot from 22 to 26 diagnostics. There als' -70 channels of dalla. About look of this is prosenced between shots and retrieved to the physics atili ats hardcopy. An interruptable batchprocessine job rums in background with a couple of ihe dilghositis sodes that cannot linish between shuss. Olline, the system will support about four whers doing prograr:ming. Jata retrieval, processing. or miscellaneous calculations.

Hi enhanced our ability to quickly process a larece yt:antily of dita belween shols by devcloping codes llitt use table-look up and integer-calculation iechniyles. This replaced a large amount of thontine-puint calculations for what is primarily data conversion to physical quantities. Once the neceswary tuhles are inilially generated, the raw inpul dala can-witl a few integer manipulationshe mapped directly onto a graphic screen. These lechnigues were perticularly effective on our largedala-basc diagnostics. For example, we reduced processing time for the 15-2hannel neutral analyzer from 90 to $8 \mathrm{~s}$. The other class of problems that required data analysis tended to have a small amount of dala (as in the ste of the Thomson-scattering necasurement) or liad to run in background.

Multichannel transient recorder systems were installed on these diagnosuc systems: neulral analyzer, beam-attenuation probes, and magnetic- loop probes. They handlc 48 channels of data and are a distince improvement over the analog-disc system. In addition we developed dedicated miniprocessur (LSI-I I) systems for control and data ucquisition and for the Thomson-scattering and hydrogen cyanide (HCN)-laser diagnostics. These devices communicate with the Hewlett-Packard cquipment. using a standard CAMAC (computerau tomated measurement and control) protocol. An eflort is under way to establish a CAMAC inpul;oulput standard on the whole diagnostic system. Wu continued replacement of analog-disc recording with modular transient-recorder systems.

Delivery began on an improved central processor (2IMX-E) and storage sysiem. This machine will be the main executive for : distributed system consisting of the present diagnoslics computer, the neutral-heam system, and the getter/vactum controller. Most of the presen data processing load will also be shifted to this machine. A 50M by'te disc pack will allow $>2$ dilys of dita to be stored for quick utecess. An improved data management system is being developed to enhance our ability to retrieve, process, and compare experimental results.

\section{Authors \\ W. L. Cunmmins \\ C. P. Parrist}

\section{Streaming-Plasma 1-kV Ion-Source Development}

Recent theory and experiment indicale that a watm plasma is required to stibilize the hol plasma in 2XIIB against the drili-cyciotron loss-cone instability. The streaming current needed to furnish the predicted minimum warm-ion densily for stabilization is

$\mathrm{I}_{\mathrm{s}} \geq 7.4 \times 10^{-10} \frac{\mathrm{T}_{\mathrm{c}}^{3 / 2}(\mathrm{kev}) \mathrm{n}\left(\mathrm{cm}^{-3}\right)}{\mathrm{l}_{i}(\mathrm{keV})}$ mperes,$(1)$

where $I_{s}$ is streaming current, $T_{t}$ is electron temperature, $n$ is plasma density, and $E_{i}$ is ion energy.

Present $2 X$ IIH expcriments with eilher tilanjumwasher stack guns or an end-Fan box show stabilizartion as expected for $I_{s}$ up to $\sim 200 \mathrm{~A}$. There are, however, some undesirable feitures. We thus will describe our work on a low-roltage ion source as a more optimum source of streaming plasma, with the advantages and disadvantages of the several approuches listed in Table 1.

In each case we assume that the resultant warmion stream would be quided along end magneticfield lines into the central hol-ion confinument volume. Thus a new lype of ion source is indicated 
Table 1. Comparison of appro-rhes tol a streaming-plasma source.

\begin{tabular}{|c|c|c|c|}
\hline & Titarijumwashier stack. & Gas $\operatorname{lnax}$ & Low rultage ion sourse \\
\hline $\begin{array}{l}\text { Ion-injection } \\
\text { tfficiency }\end{array}$ & $v_{0}: \mathrm{E}_{i}<\mathrm{co}$ ok ahove & $\begin{array}{l}20, F_{i}<c \phi_{i} \text { severc } \\
\text { limituniun, requires }\end{array}$ & 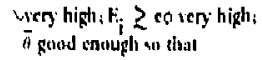 \\
\hline $\begin{array}{l}\text { Gas efficiency } \\
\text { neglecting iun- } \\
\text { ination from } \\
\text { end lossc's }\end{array}$ & $40 \%(h)$ & I.nw: & Maderate:" $401070^{2}$ \\
\hline Impurity & Paor titanium a problam & Good-ren low & (imold-ion low \\
\hline Simplicity & Muderats & Good & Powr-fairly cumpies \\
\hline $\begin{array}{l}\text { Streuning tur- } \\
\text { rent (l) }\end{array}$ & $\because 5$ A w sourst & Unlimiter & 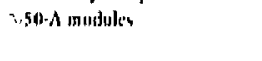 \\
\hline $\begin{array}{l}\text { Long.pulst: } \\
\text { cepsability }\end{array}$ & $\begin{array}{l}\text { Diffteult, requires research } \\
\text { and development }\end{array}$ & (ivit) & $\begin{array}{l}\text { Molerate lungth ak; long pulst } \\
\text { pour without receareh and } \\
\text { development }\end{array}$ \\
\hline Cost $(\$)$ & Modersate & Rolatively blusp & Relatively expensisc \\
\hline Heat flux a problem & Yes & Minort & $\mathrm{Yax}$ \\
\hline
\end{tabular}

with plasma formation and ion extsaction ocrurring in the fringe magnetic field $\left(B_{s}\right)$ to avoid the necessity of a non-adjabalic transition for the ions on to the field lines. The initial, fringe field $\left(B_{s}\right)$ also allows compression of the plasma stream by $\mathrm{B}_{0} / \mathrm{B}_{\mathrm{s}}$ : thus its allow's use of a large-urea ion source al only $-150 \mathrm{~mA} / \mathrm{cm}^{2}$ to achieve the needed midplane density of $>1 \mathrm{~A} / \mathrm{cm}^{2}$ at a cestral field $\left(B_{0}\right)$ (i.e... field ratios $; 6 ; 1)$.

Low-Yoltage-Source Construetion. The presence of a substantial axial magnetic field and the desire for high gas efficiency suggested the use of a penring discharge as a plasma source. To insure plasma uniformity over the lype of large area needed, we chose a large-d-ad oxide-coated cathode. We borrowed a suitable $18 \mathrm{-cm}$ dian unit from the old Astron electron linęar ascuerator. To achieve discharge uniformity with shor Debye lengths, we chose a coarse tungsten-mesh unode. The resultant perning geometry was tested on the BicentennialTank Test Stand and found to yield a relatively low If noise and fairly uniform plasma, providing the cathode temperature was maintained over $\sim 1000^{\circ} \mathrm{C}$. The observed density gradien I (measured by Langmuir probes) was consistent with that expected for gas injection from a single gas feed. We then incorporaled this type of arc in a small (10 X $15 \mathrm{~cm}$ extraction area) "prototype" low-voltage ion-source test unil (Fig. I). The extraction-grit details are shown in Figs. 2 and 3.

Iritial iests resulted in the datu shown in Fig. 4 , with drain currents of positive-hydrogen ions extracted to $20 \mathrm{~A}$ total a: $1.2 \mathrm{kV}$, but with a distinet gas-pressure-(and delay-ssensitive drop $10 \sim 12 \mathrm{~A}$ before leveling off. We conlinued work 10 even out and optimine the gas-feed distribution. Also, after $\sim 500$ pulses, the tantalum wire worked loose and sagged. So we began a sludy of a molybdenum wirtwound exlractor system.

Table 2 summarizes typical dala oblained on the Bicentennial-Tank Test Stand. Diagnostics in iluded a large-urea calurimetric and eleutrical signil larget. a 45-element Faraday Cup array for spacial resolu. tion, and a gridded detector to evaluatet ion composition.

Results are very encouraging (though more research and development is indicaled). Plans are under way to install the smiall prototype test unit on 2XIIB to evaluate its cifectiveness for a streaming source $(\sim 10 \mathrm{~A}$ level) and to delerminc il plisisma end losses will reveal any adverse walkags holding probiems. If these tests meet expectations, larger 50-A nodules will be fabricated for use with either the Tanderm Mirror Experinemt or the Mirror Fusion Test Fucility.

\section{Authors}

J. E. Osher

G. M. Melin 


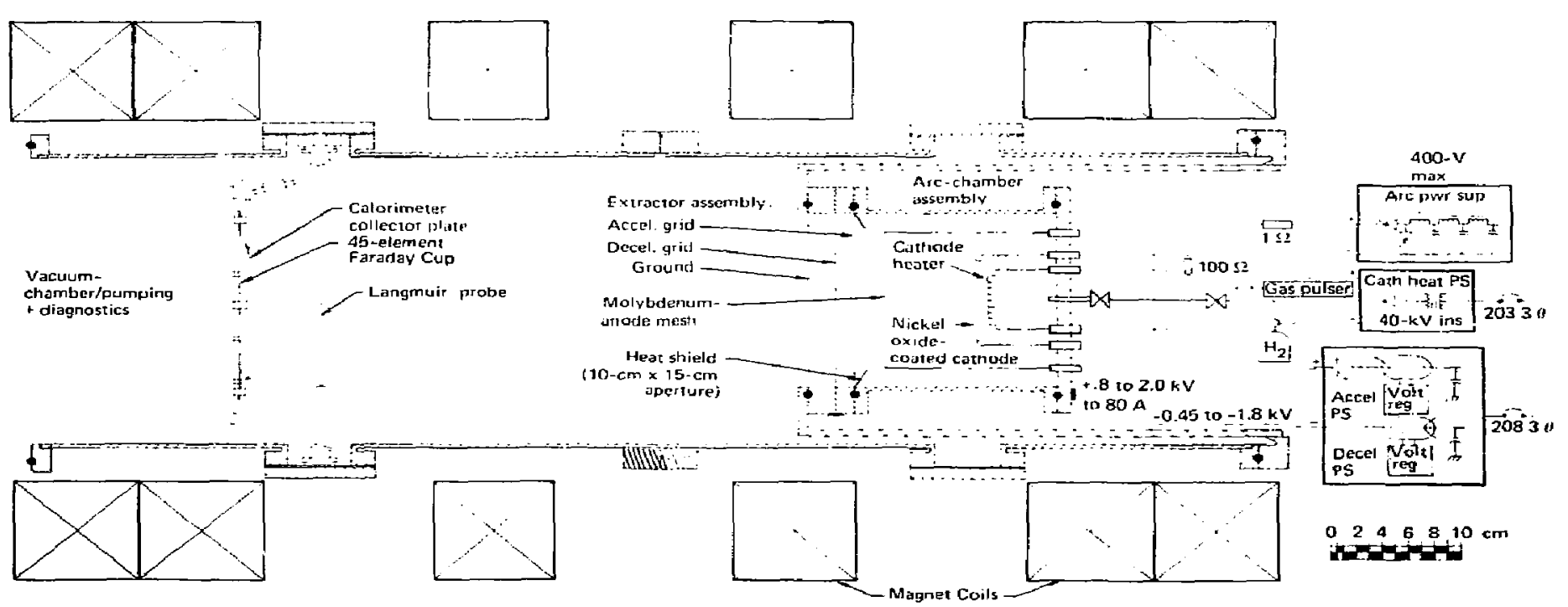

Fig. 1. The 1-kV source within a vacuum test stand. 


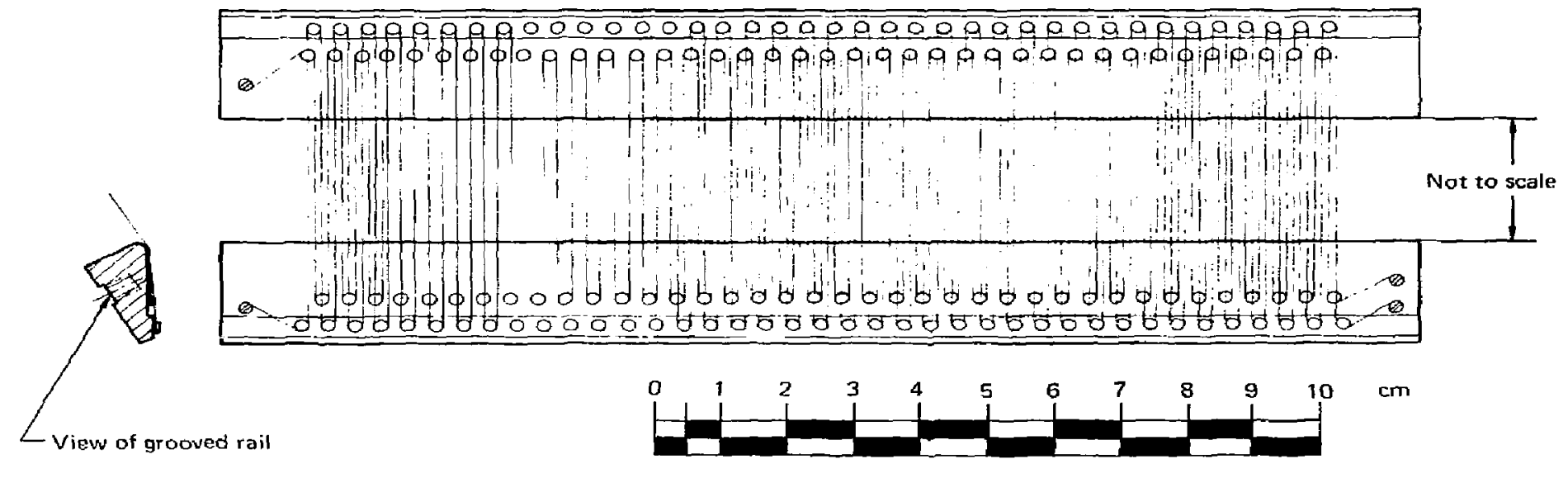



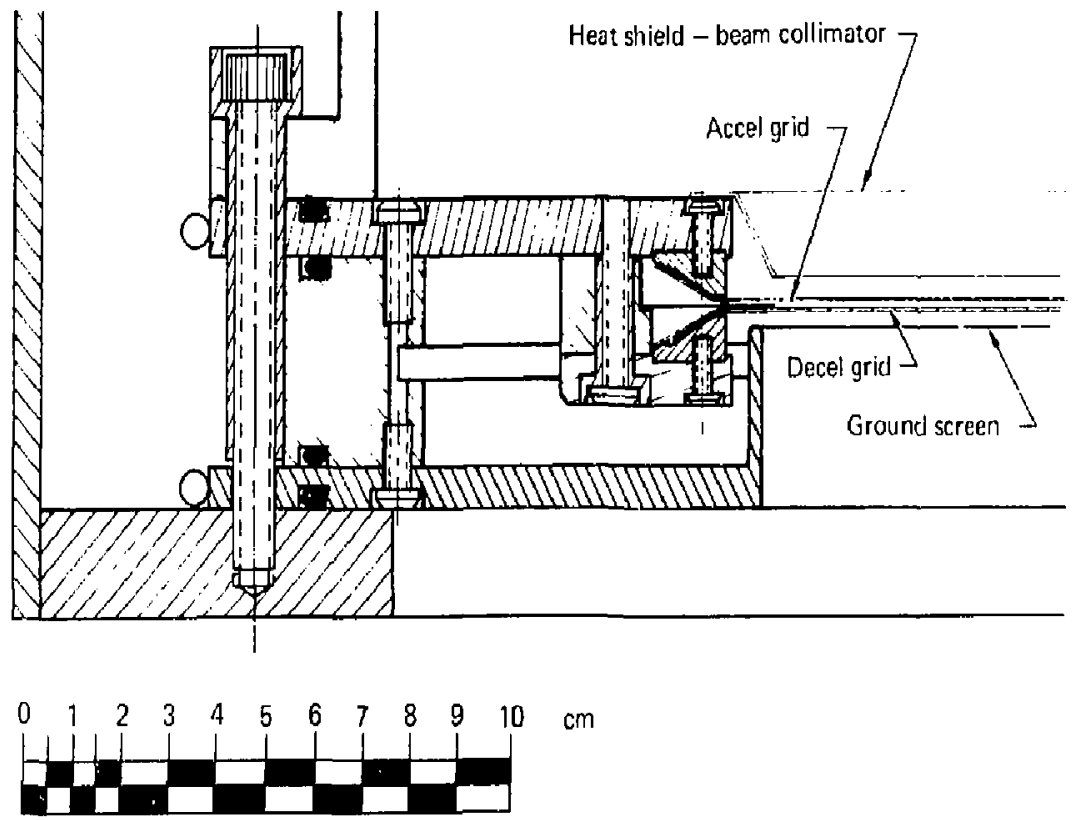

Hig. 1. Detail af ex/ractor astembly: insulaters made of symbane (toltage feedthrough fos decel not shoun।.

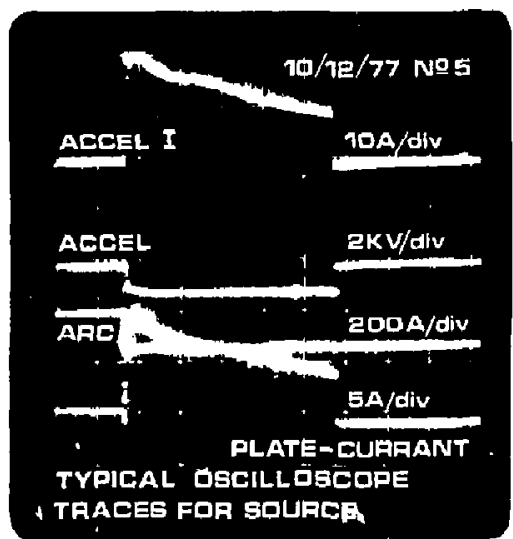

Fig. 4. Curreat and voltage characteristics of the $1-\mathrm{k} Y$ source as a function of time $(2 \mathrm{~ms} / \mathrm{div})$.
'Table 2. Performance of streaming-ion suurce $(10-m s$ pulses; magnetic ficld, $\mathbf{B} \sim 1 \mathrm{kC}$; hydeogen gas).

\begin{tabular}{|c|c|}
\hline Hopters & Valus \\
\hline Drails cursent, Idrain (A) & $\begin{array}{l}\sim 20(p e n k) ;-12(f l a t) f(w r \\
v=1.5 \mathrm{kv}\end{array}$ \\
\hline Arc current, I arc (A) & 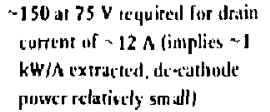 \\
\hline $\begin{array}{l}\text { Colurimetric curtení, } \\
\mathrm{J}_{\mathrm{Cal}}(\mathrm{A})\end{array}$ & 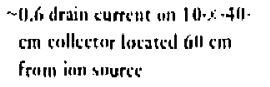 \\
\hline $\begin{array}{l}\text { Filectrical cinrent density; } \\
\left(\mathrm{m} A / \mathrm{cm}^{2} \text { ) }\right.\end{array}$ & 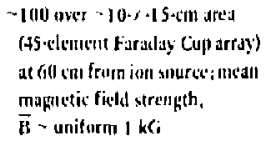 \\
\hline $\begin{array}{l}\text { Int energy, } \mathrm{E}_{\mathrm{i}} \\
\text { Plasma gas density, } n_{\text {gas }}\end{array}$ & 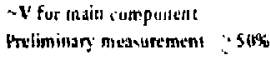 \\
\hline
\end{tabular}




\section{Radially Dependent Fokker-Planck Code}

We developed a radjally dependent buildup code that describes the trapping and loss precesses of mirror-contained plasms sustained by neutral-atom injection. During the past year, we modified the numerical procedure for solving the buildup equaltions. The rew formulation eliminaled the matrix invasion procedure for obtaining the quiding-center distribution function from the real-distribution function. It increased the computational accuracy and effrciency of the coue. In addition, we udded an optional feature that allows election distribution to he calcellated by the Fokker-Plunek equation or hy assumed Maxwellian, with loss terms calculated by Pisiukhov formulus.

The Fokker-Planck equition for the guidingcents: distribution function of each speciss is solved as a iunction of radius and time. The code also solves for the self-consistent radial dependence of vurious neutral species. It lakes into account gas sources such is difluse and direct streaming of gas from bean sources, outgassing from the walls of the vilcuum chumber, and woull rellux of ne ...als following bombardment by various ion and neutral species.

The fokker-Planck equation for the guidingcenter denvily is

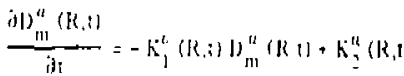

$$
\begin{aligned}
& \left.+\frac{1}{x^{2}} \frac{\partial}{\partial x}[A 1)_{m}^{a}(R, 1)+B \frac{\partial b_{m}^{a}(k, 1)}{i x}\right] \\
& -\frac{c}{x^{2}} D_{n i 1}^{a}(R, t)
\end{aligned}
$$

where the first term on the right side of the equation corresponds to charge-exchange loss of the guidingcenter density $\left(D_{m}^{\prime \prime}\right)$ as a result of collisions with neutial beams and background gas: $K_{2}^{\alpha}$ is the collisionul trapping term. The remaining terms are the usual one for Fokker-Planck, where the coefficients A, B, and C are oblained by averaging the local coefficients over the guiding-center orbils.

The real-distribution finction is then obtained from the guiding-senter density by the Iransformation

$$
i_{m}^{a}(r, t)=\frac{2}{\pi} \int_{r-\rho)}^{r+\mu} \frac{D_{m}^{a} R d R}{\sqrt{4 R^{2} r^{2}-\left(R^{2}+r^{2}-\mu^{2}\right)^{2}}} .
$$

and the density of specie or is calculated by

$$
n^{n}(R, l)=K_{\alpha} \int r(R, t) x^{2} d x .
$$

The plasma potential, $\phi(r, t)$, is compuled at each time step of the calculation by requiring charge neutrality. For a velocity grid of 100 points and a radial grid of 20 points, the rudial fokker-Planck code requires $\sim 2$ min per 100 time steps on a CDC: 7600 computer for a run containing electrons and one ion species.

The Radjal Fokker-Planck (RFP) code was cumpared with a similar buildup code (BUC) by using rate equations. Common input parameters of both codes were identicul. This is not nossihic lor ill parameters since some parantelers such as energies. cross sections, and end-loss parameters ( $\eta$ r), which are inputs for the BUC of Muir and Stallard, are calculated sel-consistently from the distribution function for the RFP code.

For a 3!-keV neulral beam, the BUC code required a current of $3.4 \mathrm{~A}$ to maintain a plusma of $\sim 9 \mathrm{~cm}$ radius at an equilibriun density of $3 \times 10^{13}$ ions $/ \mathrm{e} \mathrm{T}^{3}{ }^{3}$ at the center. $A$ corresponding current of $1.4 \mathrm{~A}$ was required for the RFP code. In both cases the molecular gas density external to the plasnia was $1 \times 10^{10}$ particle $/ \mathrm{cm}^{3}$, buth the thermal-atom density and the Franck-Condon density were set equal to zero for this comparison.

An important feature of the RFP code is its ibility to calculati kinetic parameters such as elec. Iron lenperature. Figure I shows the effect of Franck-Condon neutral purticles on electron tem.

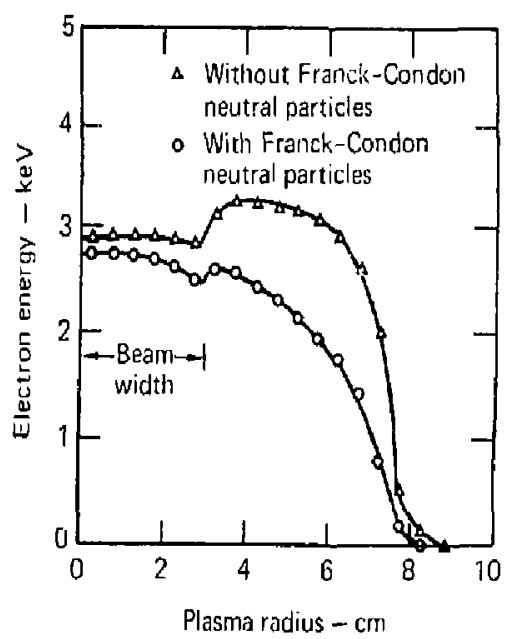

Fip. 1. Comparisun of etesiron tempetaturc bs y function of radius with and without the presence of Franch-Condon neutryl purticles. 
perallure as a function of radius. It gives curves for two limiting cases correrponding to zuro FranckCondon density and a Franck-Condon densily at the surface equal to the molecular gas density times the ratio. $V_{0} v_{f^{*}}$ which is the therinal velocily divided by the Franck-Condon velocity. We expect 10 make a detailed comparison of code parameters with the 2 XIIB paramelers during the next few months.

Author

Major Contributors

A. H. Fuich

D. W. Freeman

A. A. Mirin

\section{rf-Heated Gas Box}

The idea of using of for improving gas-box efficiency has been suggested by D. E. Baldwin and T. $K$. Fowler. The scheme is lo give if perpendicular energy at the mirror throal to the ions coming from the gas box. As this perpendicular energy is then converled into parallel cnergy al the midplane magnetic field, these ions can then more easily climb the ambipolar barrier. We hive analyzed the associated problems of if-wave launching and field ponetration for $2 X I I B$ plasma conditions. In the gas box the following plasma parameters can be considered: plasma density, $10^{13}<n<10^{14} \mathrm{~cm}^{-3}$; electron lemperalure, $\mathrm{T}_{\mathrm{c}} \sim 10(\mathrm{eV}$; ion temperature, $T_{1} \sim 0 .:$ ion-cyclotson frequency, $\mathrm{f}_{\mathrm{ci}}=10 \mathrm{MHz}$; and a plasma thickness (west horizontal fan) of $\sim 2 \mathrm{~cm}$.

The Japanese experiments in cusps in Nagoya show that if coupling is nearly independent of plasma density when one uses antennas carrying if currents parallel to the magnetic field. This is interpreted as tbe excitation of electrostatic waves, in 2XIIB the conditions lor such an excitation, $\omega / k_{c} v_{l s}$ $<<$ I. $k C_{i} ; \omega_{c i} \geqslant 1$ will be perhaps only marginally fulfilled, and the coupling to an $\mathrm{E}_{2}$ electrostatic fieid will be poor. Thus we must use in an $\mathrm{r} \int \mathrm{gas}$ box experiment either the electromagnetic ion-cyclotron wave (slow mode, $\omega<\omega_{\mathrm{c}}$ ) or the magnelo-acoustic Wave (fast niode, $\omega>\omega_{c j}$ ).

We have calcula ted the fields inside the plasma by using the following approximations. A cojd-plasma slab is used to simulate the inizontal lan. The plasma density is assumed to be uniform. One excites $t$ ff fields by rf sheets currents ( $\left.l_{y}\right)$ perpendiculir to the magnetic field in the horizontal plane. The displacement current is neglected ( $\omega<<\mathrm{kc}$ ). The electric field ( $E$ ) can also be negiected. (In vacuum, the excitation does not facilitate the $E_{2}$ field, and in the plasma the dielectric tensor element $\mathrm{K}_{z}$ is high).

From these calculations we find that the excilition by antisymmetrical currents (currents on top and bottum of the gas box flowing in opposite direction) is poor and that symmetrical excitation has to be used. The distilice between the shet currents and the plasms trust be as short as possible. Better penetration is obtained while minimizing the wave number $\left(k_{y}\right)$ along the excitation currenl and $m a x$ imizing the wave number $(k$ ) along the magnetic field. Fâst-wave excitation $\left(\omega \sim 2 \omega_{\mathrm{ci}}\right)$ warks well, but heiting will aflect only the tail of the iondistribution function-not what is desired. Finally, ion-cyclotron wave excitation $\left(\omega<\omega_{\text {ci }}\right)$ appears to be the best solution. The of penetration ean be made very good at high density $\left(\sim 10^{14} \mathrm{~cm}^{-3}\right)$. A maximum absorplion volume will be obtilined at large $k_{,}$since the resonant-heating condition, $\omega-\omega_{\mathrm{ci}}-k_{z}$ $v_{t i}=0$, will be broadened. Experimentally, it secms possible to design the requisite coil. The if power will be transmilted to the cold ions with a maximum coupling efficiency of $50 \%$ while the remainder of the power may, at least partially, be absorbed by the electrons through Landau damping.

\section{Author}

\section{G. M. Melin}

\section{Electrical Engineering Support}

Following successful i:stallation and operation of the "liat top" power supply at the end of last yeur, we worked on maintainence and improvement of existing systems, A major muintenance item was repair of the flat-top system. This happened when a planned nonslandard flat-lop operating sequence resulted in fialure of a large number of semiconductor diodes.

We riade improvements and additions to the stream-guis supplies and continued our improvements in neutral-beam pou'er-supply operation. Stream-gun capabilities were increased by the construction and installation of added pulse-forming networks. We increased operaling pulse length from $51010 \mathrm{~ms}$ and also increased the number and versutility of the supplies so that up to four of the 2 in guns and four of the 1/2-in guns could be pulsed for $10 \mathrm{~ms}$ or less.

Neutral-beam power supplies progressed through a sequ shce of gradual improvements that permitted even higher levels of reliable source operation. We developed a new accel voltage regulator that will provide improved regulation and switching performance along with a high degree of noise immunity. The new regulator assembly will replace the existing hot-deck assembly and control amplifier.

\section{Author}

G. G. North 


\section{Mechanical Enginezing Support}

Our con $\ldots+$ improvemerts to the 2XIIB vacuum systema included the following;

- Liquid-nitrogen (LN)-cooled liners were added.

- Smooth vacuum-chamber walls were incorporaled in the $2 X I I B$ machine.

We rabricated L.N-cooled liners and installed them in the two source tanks. Each assembly comprised five liners: bottoms, aperture, re-entrant tank, cylinder. and cuver (Fig. IJ. The liners were made of corrosion-resisting stecl, 316 or $316 \mathrm{~L}$. The total cost of the LN.liner system (including engineering, procurement, and instullation) was $\$ 520000$.

Smooth vacuum-chamber walls de cribe a lype of surface treatment upplied to no metallic walls (Pyroceram) exposed to the plassma The treatment iniended to minimize the wall background-gus fluxes, which allece plasma parameters, by reducing wall-surface crevices containing gases not released during gettering. We obtained a smoath wall sur. tace on the Pyrocerum wails by (a) vacuum depositing a thin layer a chromium is a substrate and then (b) placing a layer of gettered titanium on the chromium before installation is the 2XIIB imachine.

Calculated results of the effects of the LN-liner installation indicuted that thermal gas load on the 2XIlB plasma wouid be reduced by up to two orders of magnitude. Observations under actual operating conditions showed the pressure rise in the machine to be small. This indicaled that background gases slayed on the pumping surfiuces as predicted. Also, the installiation reduced recovery time to reach basc-michine pressure following ant experimental shot.

\section{Author}

n. F. Hillyer, Jt.

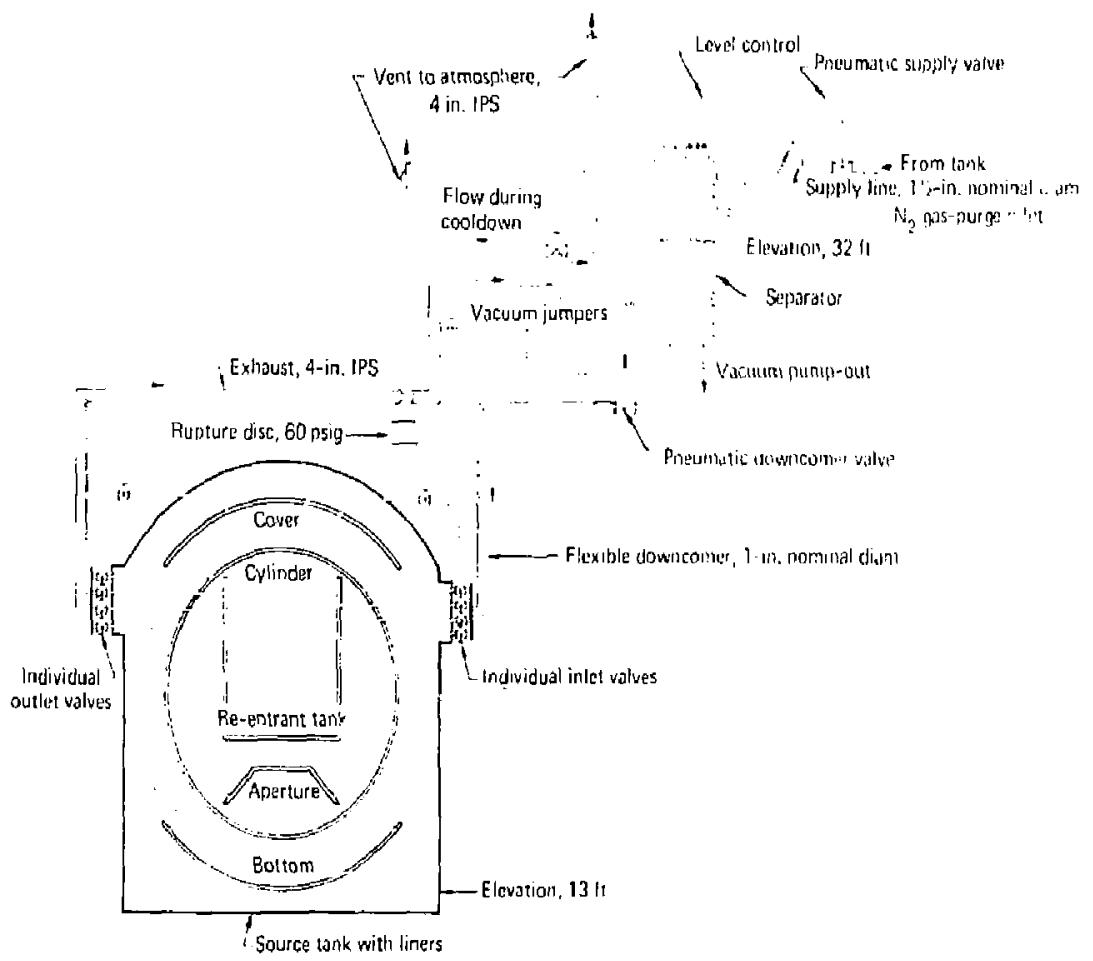

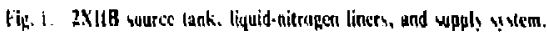




\section{Mirror Fusion Test Facility}

\section{Jntroduction}

Lawrence Livermore Laboratory (I LL) proposed the Mirtor Fusion Test Facility (MFTF) to the Department of Energy (DOE) in March i $976^{\prime}$ as the MX (Mirror Experiment). A review of the proposal was conducted by the Energy Research and Development Administration's Division of Controilcd Thermonuclear Research, now the Division of Magnelic Fusion Energy. The review, held at LLL in May 1976. confirmed the scientific and technological value of larger experiments on the scale of MFTF. The review committee recommended proceeding with the propased project. ${ }^{2}$

DOE included METF in its FY 1978 budget, and LLL published a report in June $1976^{3}$ that summarized the conceptual design. Based on the original concepts, LLI completed further developmenis and design improvements in the past year. The MFTF Project is orgarized to move ahead with design and construction when funds become available in October 1977.

\section{Technical Capabilities and Objectives}

The facilities provided by the project will build on the succession of experimental and theorelical breakthroughs during the past two years at I.LL. Both scientific and teclinological advances ate an essential part of the capubilities now in MFTF conceptual designs and experimental plans for facility operations.

Table I presents the main machine paramelers.

With these parameters we expect to achieve the initiai experimental objectives, or plasma parameters (Table 2).

To estimate ion energy ut $T_{i}=50 \mathrm{keV}$. we estimated that the extracted deuterium-ion currents available at $80 \mathrm{keV}$ contain the sime ratios of deuterium components $\left(\mathrm{D}^{+}, \mathrm{D}_{2}^{+}\right.$, and $\left.\mathrm{D}_{3}^{+}\right)$as in

Table 1. Machine parameters.

\begin{tabular}{|c|c|}
\hline Parameter & Viluc \\
\hline \multicolumn{2}{|l|}{ Magner: } \\
\hline 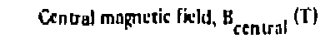 & 2.0 \\
\hline Field length, $L_{\text {mirnortomiror }}$ (m) & 3.4 \\
\hline Mirtor ratio. $H_{m}$ & 2.0 \\
\hline \multicolumn{2}{|l|}{ Sustain ing licam: " } \\
\hline Energy, E (kcV) & 80 \\
\hline Current, I (N) & 750 \\
\hline \multicolumn{2}{|l|}{ Starrup beam; } \\
\hline E (keV) & 20 \\
\hline$I(A)$ & 1000 \\
\hline
\end{tabular}

Table 2. Ylasma paraneters.

\begin{tabular}{ll}
\hline Pl lsma parameter & Value \\
\hline Density, $\mathrm{n}\left(\mathrm{cm}^{-3}\right)$ & $10^{14}$ \\
Imn energy, $\mathrm{T}_{\mathrm{i}}(\mathrm{keV})$ & 50 \\
Cnnfinement, ar $\left\{\mathrm{cm}^{-3} \cdot \mathrm{s}\right)$ & ${ }^{12}$ \\
\hline
\end{tabular}

present 20-keV sources on the 2XIIB Experiment. A1 $T_{i}=50 \mathrm{keV}$ and mirror ratio $R_{m}=2$, the "classical" value of $\mathrm{nt}$ for deuterons would be $2 \times$ $10^{12} \mathrm{~cm}^{-3} \cdot \mathrm{s}$.

Our goal of $\mathrm{nr}_{\mathrm{r}}=10^{12} \mathrm{~cm}^{-3} \mathrm{~s}$ reflects the expected supply of cold plasma to maintain stability in face of the drift-cyclotron loss-cone (DCLC) mode microinstabilities that previously limited continement limes to a few hundred microseconds, as overcome in earlier 2 XIIB experiments. The density of cold plasma to be supplied. $n_{w_{\text {atm }}}$ depends on the size of the plasma, radius $R_{n}$, relative to the ion gyrorudius, $p_{\mathrm{j}}$, in the magnetic field. or $\mathrm{R}_{\mathrm{N}} / m_{\mathrm{i}}$. For MFTF the ratio is 13, which corresponds to an elecIron temperature, or energy $T_{c}$ of $\sim 1 \mathrm{keV}$ consistent with $n_{\text {warm }} / n$ of $2 \times 10^{-3}$ to mainlain a plasma at $R_{p}=30 \mathrm{~cm} \quad$ h $750 \mathrm{~A}$ of injected sustaining bearns.

With the increased size and strength of the magnetic field and increased neutral-beam/ streaming-particle energy and current for startup and sustainment of plastma inleractions, a range of new experimental opportunities becomes availuble. Three types of plasma instabilities will be subject to enhanced investigation:

- The DCLC mode, which occurs for smilli $\mathrm{R}_{\mathrm{p}} / \mathrm{p}_{\mathrm{i}}$,

- The convective loss-cone mode, which ocsurs for large $L / \rho_{i}$,

- The Alfvén ion-cyclotron mode.

\section{Research and Development Activities}

MFTF research and development (R\&D) aclivities seek the technological base necessary for successful and timely accomplishment of project ob. jectives. These activities generally fall into two categories: development of critical items for MFTF construction and development of techriques and subsystems required to conduct the experimental program. Our scientific and engineering team addressed the following R\&D items during FY 1977.

Management Activities. The Project Management Plan was prepared. ${ }^{4}$ In addition, we updated cost and schedule analyses, using a modified I.LL computer code, and made manpower loading projections, using project office-generated computer codes. 
Stress-Analysis Codes. We developed analytical techniques and computer codes for reliable stress analysis of the magnet structure. Magnetic loading on the coils was calculated with a new computer code that yields the actual pressure distribution. Previous mathods were less accurate. We also analyzed the magnet structure (stress and displacement calculations) using an existing 3-D finite element code (SAP-IV). Independent analysis verified the results.

The conclusions of this effort verified the original design concept, and the detailed knowledge gained was incorporated into the magnet design. The net result is high confidence in the structural integrity of the magnet.

Vacuum-Requirements Analyses. We developed analytical techniques and modeling to determine the recessary vacuum requirements for neutral-beamsustained plasmas. A computer code that solved the self-consistent gas balance for beam-driven plasma wils generalized for alter nate geometries. It now handles the transient analysis for startup simulation of MFTF. Time-varying pumping capacity was also modeled to simulate sturtup operations with, for $\mathrm{e}^{\mathrm{v}}$ ample, titanium-getter pumping. Using the above toals, we optimized the placement of the primary pumps (cryopanels) for the most cost-effective operations.

Fokker-Planck Code Development. A radially dependent Fokker-Planck code was developed. This code allows us to include energy effects during plasma buildup.

The radial-buildup code was refined to improve its computing time. This allows us to increase the number of radial zones. We can also add energy ef. fects to crosscheck the results of the radially depencient Fokker-Planck code. We used this code to investigate the suggestion that ionized gas on the boundary produces a plasma shield that reduces the loss of hot ions due to charge exchange on background gas.

Because of extended beath time, we evaluated energy partixion and its effect on system design, using beam times up to $30 \mathrm{~s}$.

Superconductor Development. Derelopment efforts were applied to optimizing the supercon:ductor, the attached stabilizing copper, and the inlegrated magnet conductor. ${ }^{5-7}$ These efforts led to the present conductor design of a wraparound copper stabilizer soldered to a njobium-titanium/copper matrix core [See Fig. I in Superconducting Magnet Development (Section 2)].

Our ultrasonic testing effort detected poor bonding of the wraparound solder. We then improved our soldering techniques and produced im- proved test samples of finished magnet conductor.

We performed thermal tests on short icilgths of handmade dummy conductor to verify the stabilizer design for effective cooling, independent of the spatial orientation (from horizontal to vertical) of the tonductor. Both single-conductor and ninecunductor bundles were tested in liquid helium at about $4 \mathrm{~K}$. The results of the heat-15an sfer tests sup. por ted the design level of heat flux $\left\{0.25 \mathrm{~W} \cdot \mathrm{cm}^{-2}\right)$.

Superconducting-Magnet Coil Design. The precise winding pattern of the coils has been detcrmined ${ }^{8}$ Wc designed and lested the inter-1:irn insulation that separates individual conductors to maintain liquid.helium passage. Conductor splice design, using a cold-weld process, has been proven for the coil. ${ }^{9}$ We are studying acoustic emissiondetection tehniques for identifying weak splices and have completed analysis of the liquid-helium routing and gas flow during boiloff.

Access for neutral-beam injection has been optimized using a 3-D computer-graphics code. saving months of layout time (Fig. 1).
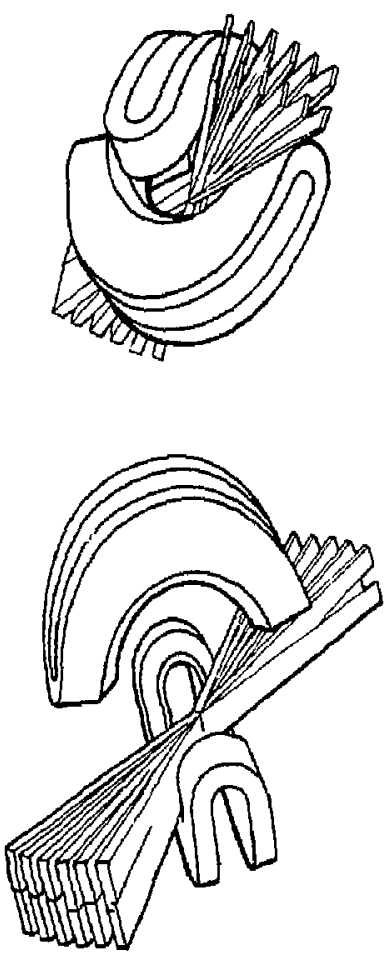

Fig. 1. Computer-generased viess of yin-sang grometry for superconducting magnet. This technique, which enabled us to optimize access for neutral-ban injection, sayed months of layout time. 


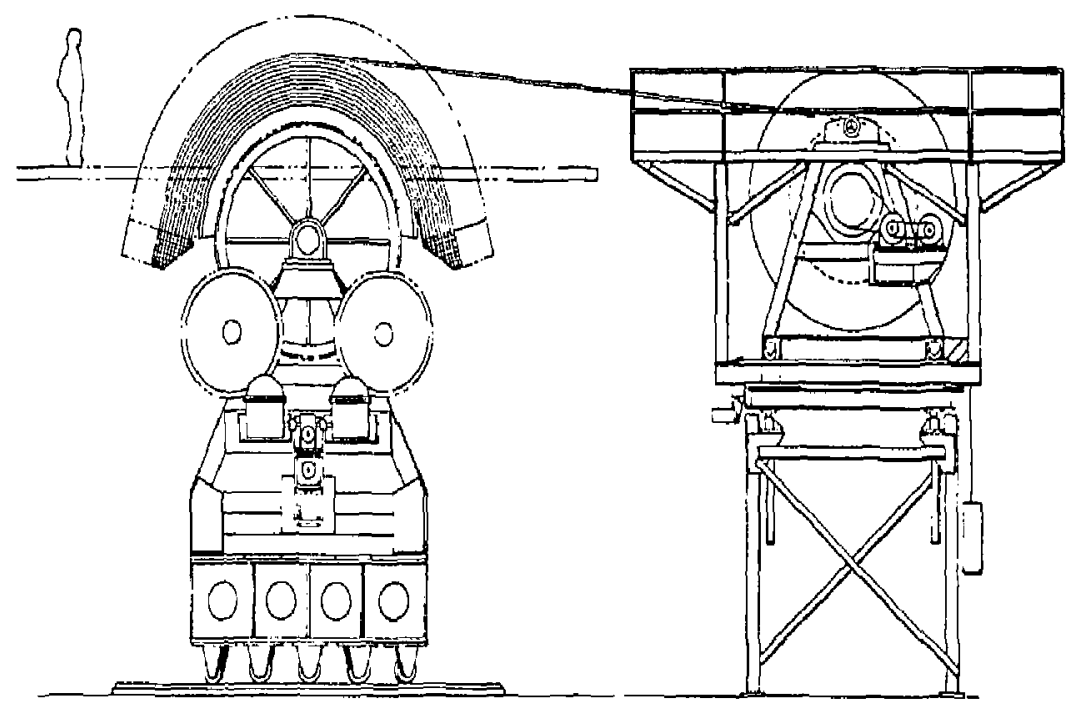

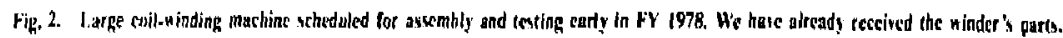

Coil Winder. We completed the conceplual design and specifications for the large cojj-winding machine early in $\mathrm{HY} 1977^{11-13}$ (Fig. 2), The task of perlorming the detailed design and fubrication of this muchine was awarded to Teledyne/Readco Division. The coil-winder parts were delivered to LLL; its assembly and testing will be done early in FY 1978. We identified the tooling necessary to wind the coils and itemized the requisements. The critical items are being designed for fabrication.

Magnet Jacket Design. It was desirible to separale the requirements of vacuum integrity and dimensional stability of the magnet winding from the structural requirements (Fig. 3). We accomplished this with a relatively lightweight stainless. steel jackel used both as a winding form and vacuum-light enclosure for the conductor bundle. The completed winding was then inserted into the more massive structural easing (Fig. 4). The jacket allowed the structural-case procurement schedule to be decoupled from initiation of the coil winding and provided an added vacuum barrier.

We completed a weld development program to provide a step-by-step procedure for welding the segmented jacket around the winding without damaging the composite bundle w'th excessive temperalure.

Neutral-Beam System Design. The physical layout of the neutral-beam injectors within the vacuum vessel was refined for improved beam use and operational flexibility. ${ }^{14-20}$ The computer-graphics code used to optimize beam access in the magnet coil was also used to help relocale the injectors. We completed the conceptual design of the isolation valves.

Vacuum.Vessel Design. We reviewed alternate vacuum-vessel configurations to accommodate the new neutral-beam injector layout and to reduce end-loss intensity at the top and bottom domes.

Cryoplant Specifications. After reviewing system consumplion. we wrote tentative specificilions for the liquid-helium cryoplant.

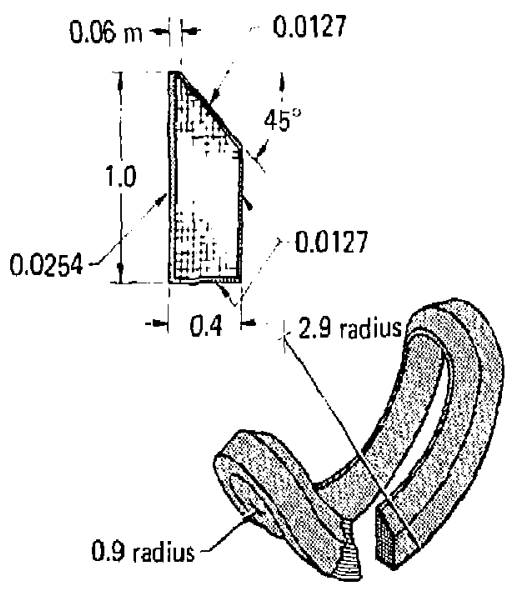

Fig. 3. Stainless-steel jacket used as winding form far superconducting coll. This lightweight enclosure provides an added vecuum batrier. 


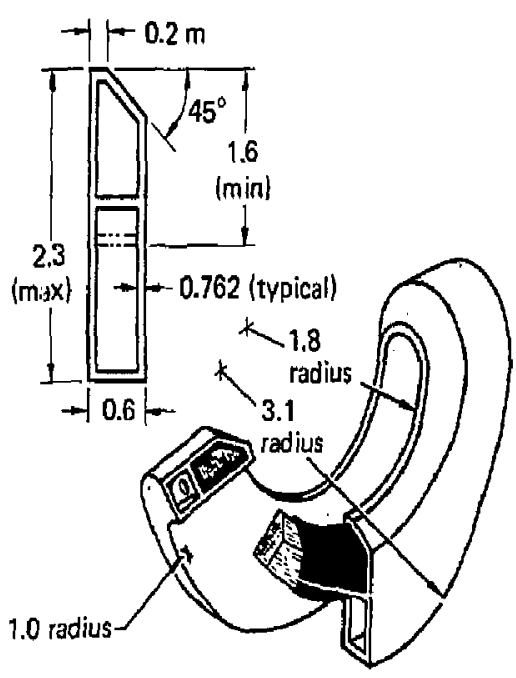

Fig. 4. Completed frindilng inserted in massive structural casing. The inserted facket allowed us to decouple the structural-case procurement schedule from initiation of the coil winding.

Control and Diggnostic Design. We functionally designed the control and diagnoslic system. Control of the overall machine and each system was examined, and funclional requirements were lisled for each areu. The functional requirements serve as in. put to the detailed design phase. We developed stanuiards for interfacing equipment to computer gear. Also, a standard microcomputer system wäs specilied. 21

80-kV Power Supply. We formulated a detail plan and a facililies design to supporl $80-\mathrm{kV}$ powersupply development and testing. "2 A working model of an 80-kV power supply was nearly completed.

\section{Project Design L'pdate}

Based on our FY 1917 R\&D activities, we reviewed and updated the MFTF system requirements and designs. The following system descriptions are based on these updated designs.

Superconducting Magnet. MFTF's yin-yüng magnet consists of ouer $42 \mathrm{~km}$ of copper-stabilized superconducting niobium-titanium ( $\mathrm{Nb}$ - $\mathrm{Ti}$ ) conductor (Fig. 5). Each of two coils forming the yin-yang configuration produces a separating force of $98 \mathrm{MN}$ at maximum field. The design uses the two $150^{\circ}$ coils offset $0.78 \mathrm{~m}$ loward each other 10 give the desired performance with the structural jacket and case to resist forces transmitted through the inter. coil members, which will tie the coils together. The magnet will weight $200000 \mathrm{~kg}$.

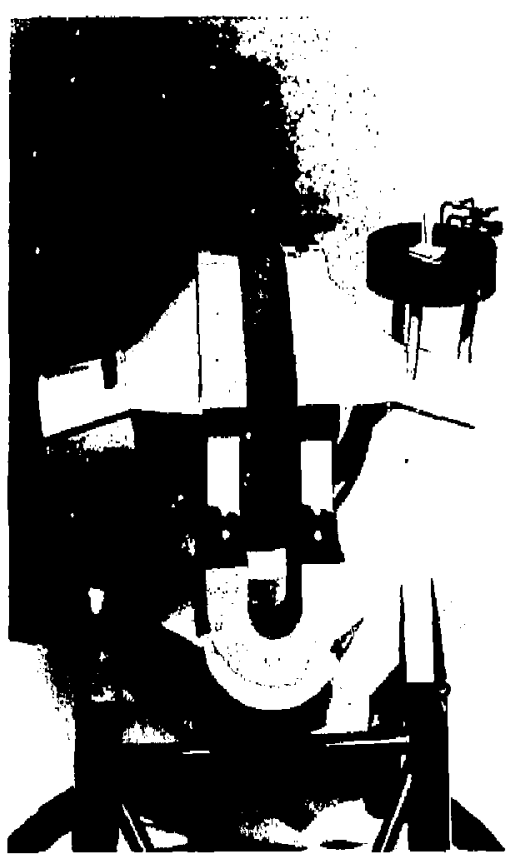

Fiz. 5. Superconducting magnes's darge cuil pair in prot en ! in sanf configuration. Pool-boiling liquid heliun al $4.5 \mathrm{~K}$ will $5 \mathrm{smb}$ this 200 0hro.kg mognet !n the superecinducling stute.

The supersonductor eore is $\mathrm{Nh}$. Ti in a copper matrix $6.5 \times 6.5 \mathrm{~mm}$. $\mathrm{x}$ rapeded in at sheath of wopper to acl dis stabilizer for the superconducting mods. The conductor is $13 \mathrm{by} 13 \mathrm{~mm}$ after insembly. The wraparound stabilizing copper designed to uptimice conling by liquid helium is soldered to the superion. ductor core 10 meet the heat-transfer ind electricalperlarmance requirements for the assembled wyllductor. The conductor winding will be acoumplisted on the inner jacket: the entire jacket will he assembled to fil in the magnel salse. There will he it guard vacuum to prevent helium leakinge into the vaceum chamber atound the magnel suse. Thus, the guard vacuum and double stuinless-steel walls of the jicket and tuse provide high comliudence to protest the racuum environment for effectise plasmal performance.

The assembled magnet is uperated by two sepurale bul coordinale power supply dements. The coils will operate at up to $4.5 \mathrm{~K}$ in post-bwiling liquid helium. The design current is $6300 \mathrm{~A}$, wilh continuous current-segulated combel ower the linll operiting range.

A major requirement for the magnet is 10 maintain access for beam injection through the side openings of the yin-yung configuration. We used aulomaled computer graphiss 10 optimize the 
design and provide beam access consistent with the overall minimum-B field and magnetic mirror parameter during operation.

The magnet parameters appear in Table 3.

Vacuum-Yessel System. The vacuum-yessel system (Fig.6) will integrate the various MFTF mechanical systerts and be the focal point of the experimental facility. This system will maintain the vacuum environment for the plasma, house the superconducting magnet, and provide access and mounting structures for the majority of elements that miake up the experimental configuration. The subsystems associated with the vacuum-vessel system are the vacuum tank and its support, cryopumps, thermal absorbers, beamline assembly, titunium-getter system, and personnel platforms.

The vacuum-vessel system will be housed in a pit and be $\sim 18-\mathrm{m}$ high. The vacuum-lank internal diameler is $10.8 \mathrm{~m}$. The vacuum lank weighs $273000 \mathrm{~kg}$ and will support the added weight of attacined hardware for plasma operations up to $380000 \mathrm{~kg}$.

The vacuum-vessel system will:

- House the superconducting magnet within a suitable vacuum tenvironment.

- Fstiblish and maintain a system base pressurt of $\sim 1.3 \mu \mathrm{Pa}$ during experimental shots.

- Maintain a pressure in the plasma chamber of $\sim 400 \mu$ Pu during experimental shots.

- Provide mounting and remote uiming of the 48 neulral beams over a suitable range.

- Provide thermal absorbers, with the necessary cooling water, and other accessories to remove $\sim 160$ peuk $M W$ of energy for 0.55 every $5 \mathrm{~min}$,

Table 3. Magnet paramcters.

\begin{tabular}{|c|c|}
\hline Parancter & Value \\
\hline Type of field & Minimum-H mirrar \\
\hline Magket rype & $\begin{array}{l}\text { Displased yin-yang } \\
\text { pair }\end{array}$ \\
\hline Major radius, mean (n) & 2.5 \\
\hline Mlinar madiut, masu (m) & 0.78 \\
\hline Ax ial hلdf-displarement (m) & 0.78 \\
\hline Cuil scrion (m) & $0.28 \times 0.44$ \\
\hline Mirrar-\{1)-mirror length (m) & 3.4 \\
\hline Vacuumecenter field (T) & 2.0 \\
\hline Mirror ratio & 2.09 \\
\hline Overall surrent density (A/mm & 3100 \\
\hline Turns (ench coil) & 1180 \\
\hline Ampere turns, each ctil (MA) & 8.03 \\
\hline Tord mass of coils with structure $(\mathrm{kg}$ ) & $195 \times 10^{3}$ \\
\hline Tutal sturcu enctgy $(M J)$ & -500 \\
\hline Maximum allowalile plasma radius (can) & 120 \\
\hline
\end{tabular}

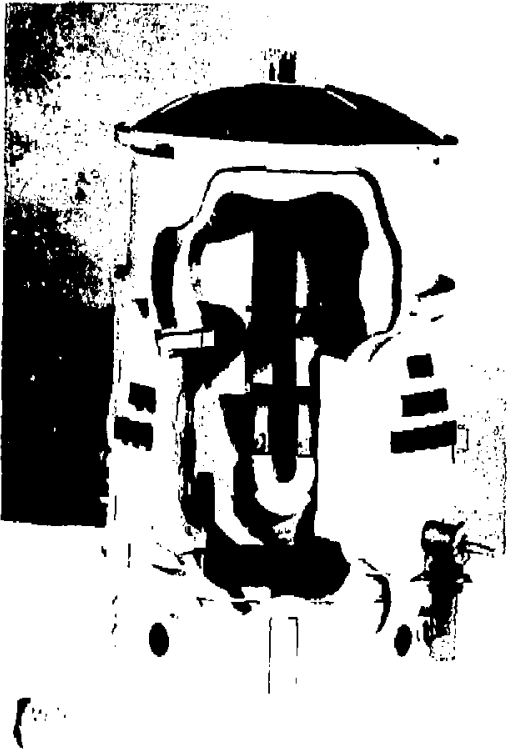

Fig b. Vacuum-vcssel s)stent to house supercanducting magnat, A hout 18-m high, this system maintgins a vacuum environment for the plasma. Modules for neutral-beam injection rest along its sides; streaming-plasma guns sit on top.

- Povide cryopumps designed to handle $96 \mathrm{~Pa} \cdot \mathrm{ml}^{3} \cdot \mathrm{s}^{-1}$ of molecular deuterium gas by condensation pumping on a bare metal surface maintained at $\sim 4 \mathrm{~K}$.

- Provide for periodic degassing of the cryopanels.

- Deposir 4 nm of fresh tieunium atoms on the magnet-liner surface facing the plasma region sinortly before each shot.

External Vacuum System. The vacuum in the plasma chamber must be maintained at $\sim 400 \mu \mathrm{Pa}$ during experimental shots. This wjll be accomplished by using an external vacuum system to pump down to $133 \mu \mathrm{Pa}$. Then, the liquid-hetlium cryopumping panels (with radiation shielding by means of liquid-nitrogen-cooled baffes und liquid nitrogen shields in the vacuum vessel) will provide pumping to reach the system base operating pressure of $1.3 \mu \mathrm{Pa}$ (Fig. 7).

The external vacuum system also must pump deuterium and other gases evolving from the cryopanels during regeneration. For regeneration the cryopaneis are raised above the $\sim 4.5-\mathrm{K}$ operating point. As the panels warm up, gas evolves and is puniped out by the high-vitcuum pumping system. 


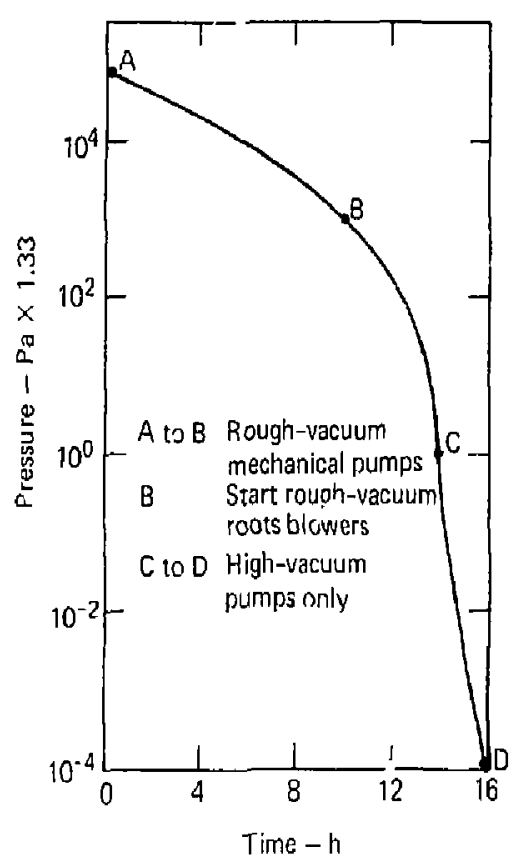

Fig. 7. Typicat pumpdonn profile for exlernal bucuum statem. The cursts shost the sequtuntial stops far bringing the plusma chamher's air dosn fo y decired opserating proswers.

During experimental runs the external vatuum system is valved off from the main vestel. Between shots. eryusorbent pumps will be valved into the system to pump deuterium. hydrogen. and helium.

In addition to the external vacuum system and cryopumps, the titanium sublimator system (getlers) is activated before each shot to provide a thin layer of atoms on the inner walls, or warm liners. nearest the plasmi. The deposited layer thickness $(\sim \mathrm{nm})$ wiil be at least three to five monolayers of tilanium atoms.

The sublimatoss will provide a minimum of 5 monolayers during a !-min sublimation period witl an average of 13 monolayers and a muximum of - 18 monolayers. Each unit will consist of six titanium-tantalum alloy wires $\sim 3-\mathrm{mm}$ dian and 2.5-m long. One wire will be activined, with the others used sequentially as each is exhausted. Six wires provide adequate titanium coverage for 600 to 10 ù shots for a minimum of 2 to 4 weeks of operition. Retructuble wire-support assemblies may be removed through airlocks for routine replucemen without laking the vacuum vessel up to air.

The titanium subiimators will be powered by a high-frequency current ( 10 to $20 \times \mathrm{Hz}$ ). During sublimution. 12 of the $2.5-\mathrm{m}$ wires will he heated. The power supplies will be cortrolled to provide a known quantity of evaporated titanium. One local control miciocomputer controls the getler sytem.

Cryogenic System. The cryogenic systen will supply the helium refrigeration and liquufiction capacity for cooling the superconducting magnet and cryopanels in the vacuum-vessel system. The cryogenic system will also supply the liquidnilrogen requirements for cooling thermal shieds in the vacuum-vesset system, system cooldown, and heat-exchanger loads in the helium liquifier. The system will function in five distinct modes: cooldown, steady-state operation. warmup. standby, and emergency shutdown (Fig. 8).

During steady-state operation of the magnet and cryopanels, and cryogenic system will supply the required quantities of liquid helium and nilrogen to the local use points or local slorige dewars, Estimated heall loads for the magnel. eryopanels, and transfer lines appear in Table 4.

To meet the heal-lodd requirements the heliumlrefrigeration capacily wiil be $3 k \mathrm{k}$ al $4.5 \mathrm{k}$. In a liquelier mode it will produce 700 ltires' $h$. The helium systent, in the normal mode of operation. will be closed-loop with a purificalion siage lior helium recovery.

The mitrogen subsystem will he open-loop. A li. quid use rale of 5800 litres ill will be farnished b? al commerical supplier: nitsogen boil oll will be gis vented. An onsite sturige dewar, biavige al leisls one-day capacity, will be provided.

Sustaining Ncutral-Btan Injectors. Fath injusLor is driven by an $80 . \mathrm{kV}$ pa $\cdots$ er supply comsistimg ol five sepurate elements to drive the experiment neutral-bein source module. Eilch power-supply unit includes an acesteration de power supply, asceleration modulator and gradiem-estid network. filament power supply. are power supply and sup. pressor power supply. To allow for evensions in duration the ligh-voltage sustaining system has a maximum pulse duration of 30 s. MFTl inilial operation will provide a duration of 0.5 , hut the power supplies could hal ndle longer durations. Fiati supply will be capahle of a maximum opcraing

Tahle 4. Fstimated heat loads (in watts).

\begin{tabular}{|c|c|c|c|}
\hline Al $4.5 \mathrm{~K}$ & & Al $77 \mathrm{~K}$ & \\
\hline Magnet & 565 & 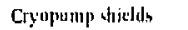 & 115 (n) \\
\hline Cryopane!s & 1400 & Gother shields \& liatrs & $50 \mathrm{lno}$ \\
\hline Transfer lines & 300 & 7 ransfer lasa & +0000 \\
\hline Cryopumps & 30 & & 2050000 \\
\hline \multirow{3}{*}{$\begin{array}{l}\text { Liquid-helium Isewdr } \\
\text { losses }\end{array}$} & 20 & & \\
\hline & & & \\
\hline & 2315 & & \\
\hline
\end{tabular}




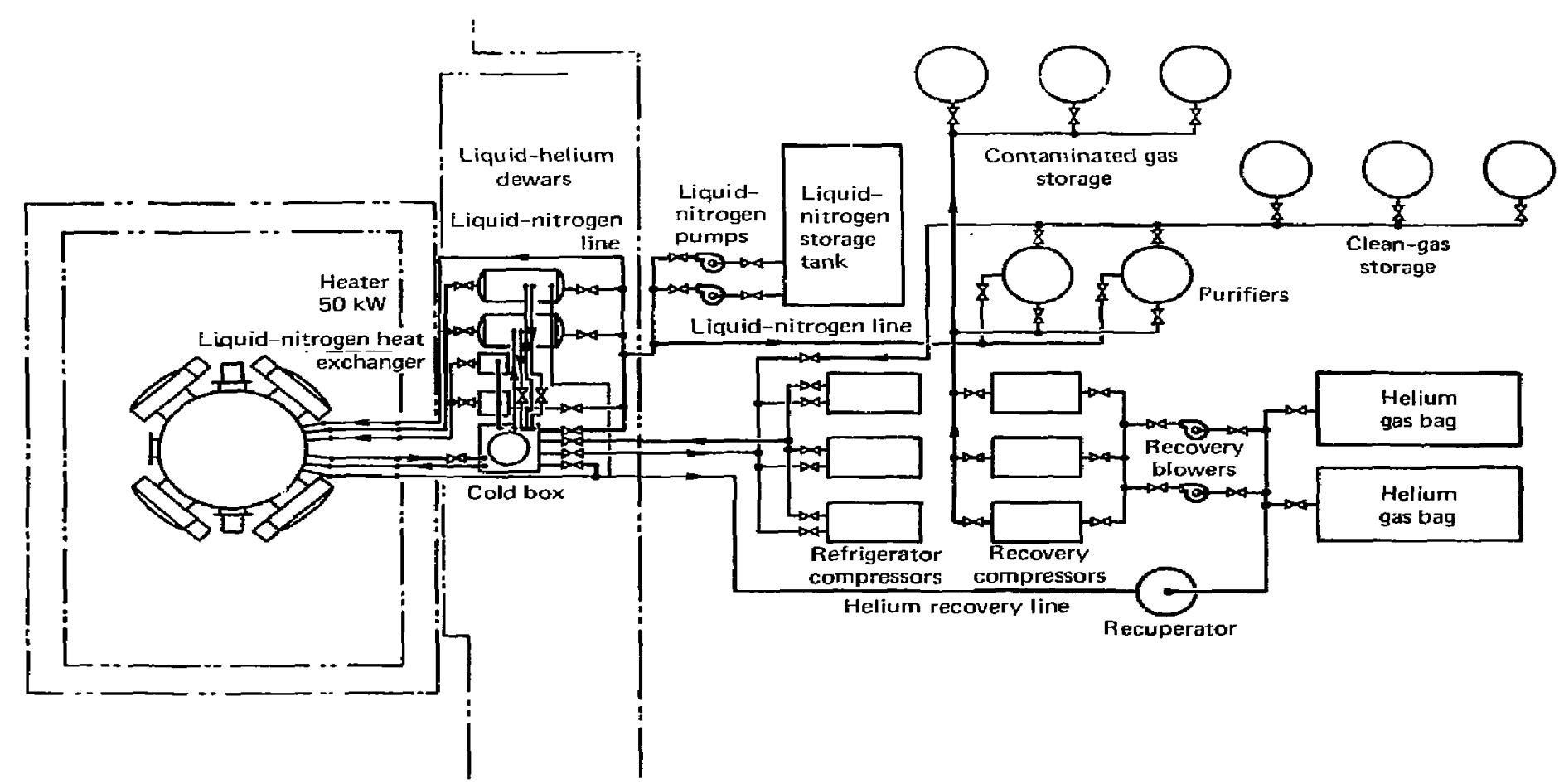

Fig. 8. Floor plan of cryogenic system intended for Blug. 431. This vlew sbows the flow paths of liquid heliutn and liquid nitrogen into the vacuum vessel. 1iyuid helium cools the magnet and cryopanels; liquid nitregen cools the "ithermal shields. 
duty cycle of 10\%. A new 230-kV, 250-MW power line will serve the primary pulsed power needs of MFTF.

A dedicaled substaticn will be the lerminal point of the $230-\mathrm{kV}$ power line. The $230-113.8-\mathrm{kV}$ transformer secondaries provide power to the 80-kV high-voltage rectifiers for acceleration power. Each of thezt power supplies is independently operable. with its local control interfacing to the control and djagnostic system for integrated operutions.

The substition and acceleration de power supplies will be located $150 \mathrm{~m}$ to the east of B]dg. 431 . The acceleration modulator and gradient-grid networks plus the filament, arc, and suppressor power supplies will be in the building.

Startup Injectors. The $20-k \mathrm{~V}$ neutral-beam injectors (similar to those used on 2XIlB) are adeguate to provide the $1000 \mathrm{~A}$ beam current for MFTF. This application requires 24 startup neutral-beam injectors operating for $10 \mathrm{~ms}$ (the 2XIIB duration). The power supply is a capacitiveslorage "pullman" providing a design capability of $50 \mathrm{~A}$ at $20 \mathrm{kV}$. Since the source modules tend to degrade after initial conditioning for beam injection, the 24 startup injectors are included to provide the essential perlormance for adequate plasmis performance.

Plasma Streams. The litanium-washer guns used or. 2 XIIB could provide sufficient target particles for the startup. Development efforts are underway 10 provide improved plasma guns and $10 \mathrm{im}$ prove performance of the current designs. IT we use the $2 X I I B$ washer guns, up to 100 units could be required to stream along the far-shaped field lines in to the plasma largel region inside the coils. The plasmia generators are mounted on the top dome of the vacuum resset.

The current MFTF design provides a magnel collar around each washer gun near the plasma in. jection plane to concentrate magnetic field lines and improve injection effectiveness.

It may be necessary to put a gas box at the mirror throat, as with 2 XIIB experiments, to minimize loss-cone plasma ions escaping from the mirror and to enhance plasma stability.

This expermental addition will interface with MFTF's magnel case. Also, the increased gas load will require more pumping colpability in the vacuum-vessel cryopumps. Continued assessment of this option is planned during the preliminary design phase of the facility.

Table 5 shows the neursal-beam injector module specifications.

Control and Diagnostic System. MFTF will be controlled and monitored by an integrated system
Table 5. Ncutral-beam injector module specifications.

\begin{tabular}{|c|c|c|}
\hline Parameter & Startup merdule & Sustaining muduls \\
\hline Operating number & 23 & 24 \\
\hline $\begin{array}{l}\text { Meximum necultral-brom } \\
\text { energy (heV) }\end{array}$ & 20 & 80 \\
\hline $\begin{array}{l}\text { Aug neutral-beum energy } \\
\text { (heV) }\end{array}$ & -16 & $5 n$ \\
\hline Extracted-ion current $(A)$ & 80 & 80 \\
\hline Pulse 〈enguh (ms) & 10 & up 1110.5 \\
\hline $\begin{array}{l}\text { Deuterium-pas indet } \\
\left(P_{a} \cdot \mathrm{m}^{3} / \mathrm{s}\right)\end{array}$ & 4 & + \\
\hline $\begin{array}{l}\text { Acam divurgenes } \\
\text { (width hy heiglut) }\end{array}$ & $12^{11} \times 0.5^{11}$ & $2 r \cdot 0.5^{\prime}$ \\
\hline $\begin{array}{l}\text { Neutral-jeam current } \\
\text { at plasma (cyuri, A) }\end{array}$ & 50 & 32 \\
\hline
\end{tabular}

capable of automatic and munual opcration. This control and diagrostic system includes dala acquisition, reduction. and unalysis to support operation of the facility and to guide experimental activities.

The nine minicomputers in our distributed hierarchical system allow independen: operation of various subsystems and coordinuted action of the subsysterns, when appropriate. These supervisory compulers are the vessel supervisor (n)ignel. vacuum, getter control system): three beam supervisors (streaming. startup. sustaining): injector supervisor (coordinates operalor interfices with the three beam supervisors): facilities supervisur (control room interfice to the cryoplant. primary power. safety interlocks): systen supervisor (coordinating j: llerface for injeciors, facilities, machine, physicss diagnostics); experimental physics (diagnostics) data processing system: and the duta-hase mansagement system.

A block diagram of the CDS corfigurition (Fig. 9) shows a set of small computer systents interfacing with local control and instrumentation subsystems for each functional element. Control. diagnoslics, datu processing, and monitoring tasks are performed by interconnecling with is bus struciure. This urrangement allows both verical and horizontal communication in the hierarchy. Graphics displays at the central and local consoles minimize display-arei requirements and optin,izc operalor-muchine interfaces.

The distributed control system benelits in operaling flexibility and reliability by using microcompulers in the local control and instrumentation subsystems. The diverse subsystem control and monitoting requirements, along with data processing and storage needs, lead naturialy to the combination of distributed and supervisory functions. The system, which will accommudite dati 
10 units

Streaming-olasma gu n locial contro

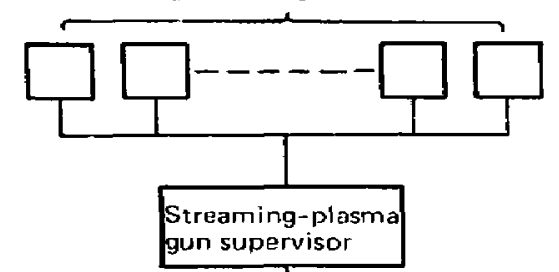

24 units

Startup neutral-beam lucal controf

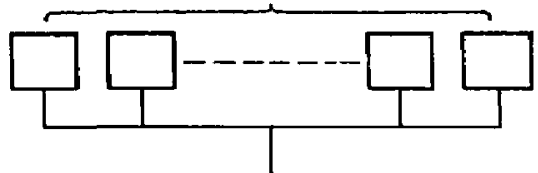

Startup neutral-

beam supervisor
24 units

Sustaining neutral-beam local control

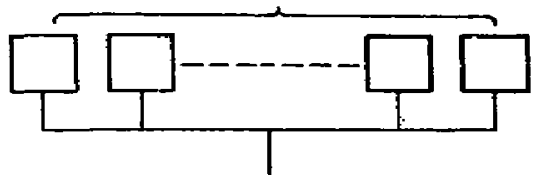

Sustairing neutral-

beam supervisor

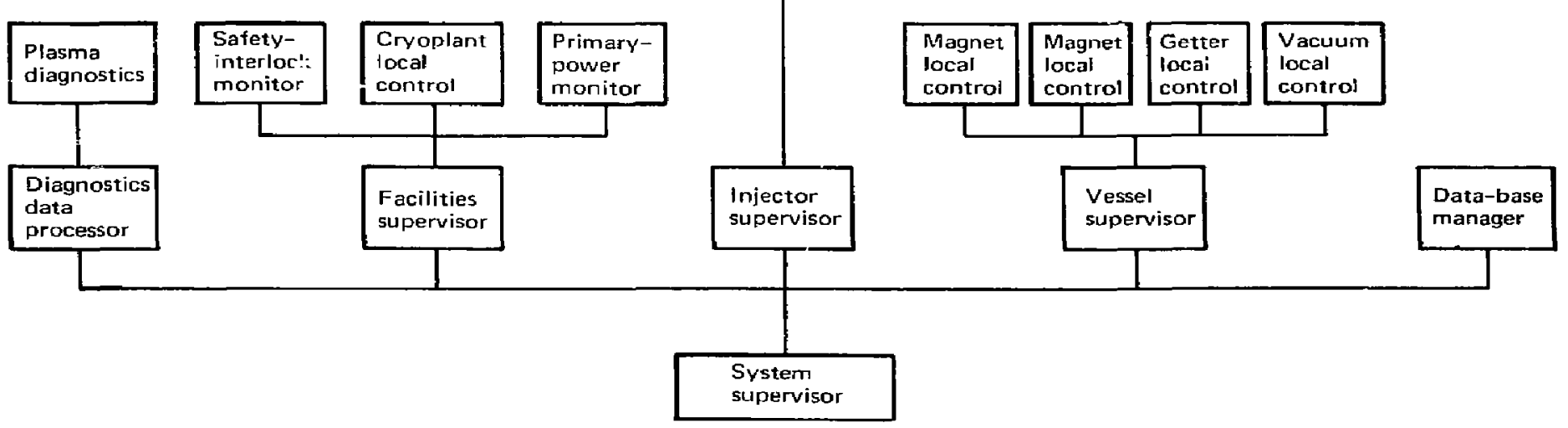

Fig. 9. Hierarchy of nine minicumputers for control and diagnostir system. Such supervisory computers will controt and mennitur physics evperiments run on the Mirror Fusion Test Facility (MFTF) device. 
from each shot, will have a 5 min turnaround to the next run.

Safety System. Our safety system, which meets operating requirements, is an inherent part of each MFTF system and building. Subsystems for personnel-access control, fire detection and control, and radiation protection reach across the systemts and buildings. Safety interlocks, lashing warning lights, and warning horns control access to hazardous areas or conditions. Hazardous areas provide safe/run switches for shutdown by anyone nearby

Fire detection and control is provided by smoke detectors, sprinklers, firewalls, Halon fire retardant, and high-expansion foam in the vaul irea. MFTF's radiation protection system uses monitoring and alarms to prevent inadvertent exposures to hazard. ous levels of radioactivity. Operational and safety interlocks provide hardwire controls. Such a control system maintains interlock status knowledge by monitoring several hundred salety interlock switches hardwired into protective chains. Local control systems gather and transmit the status information on the salety systems to the supervisor and control-console displays. Thus, facility operators and system controllers get the information needed to operate safely. Because of the fail-soft design of the control system and the independence of the safety interlock chains from the monitoring supervisors, we can confirm a high degree of MFTF operating safet; at all times.

Building 431. Our existing B/dg. 431 will be modif ied to hous the MFTF experiment. Most of the supporting research activities now in the building will be relocated to Bldg. 441 .

Building 431 is $50 \times 70 \times 30 \mathrm{~m}$ and conlains a vault-like enclosure of 2 -m-thick concrele blocks surrounding an area $20 \times 32 \times 22 \mathrm{~m}$. The floor of this enclosure is $6.4 \mathrm{~m}$ belowground. A high bay that contains the vault and runs the length of the building is served by an existing $55000-\mathrm{kg}$ bridge crane. Two mezzanine floors (aboveground) run the full length of the building and along both sides of the bay. Total floor space presentiy usable for equipment placement is about $4100 \mathrm{n}^{2}$. Building modification will take place in three phases: demolition. preparation, and integration.

Figure 10 shows the completed MFTF device inside the shielded vault in Bidg. 431. This conceptual design has been updated during the past year. The vacuum-vessel housing the magnet sits in the central area (the vault cutaway shows the $27000-\mathrm{kg}$ bridge crane serving the pit region). The roof has thick concrete beams to reduce "skyshine" effects. The reinforced concrete foundation supports $850000 \mathrm{~kg}$, the combined weight of the vacuum vessel, magnet, and other altached hardware.

Building 441. The new laboratory/office structure, Bldg. 441, will have a gross aren of $29000 \mathrm{~m}^{2}$. Located on the south side of LLL's Inner Loop Road, this building will be constructed of fireresistive and low-maintenance-cost malerials. Corridor partitions will be permanent, with partitions between offices easy to remove for flexible office modifications.

Building 44 will be designed to provide office space for $\sim 300$ scientists, engineers, administrutive people, and visitors. A breakdown of building space appears in Table. 6.

The floor plan will provide a central location for Magnetic Fusion Energy (MFE) scientific research effort, with engineering and support functions localed to optimize interaction among divisions and assure close proximity of supporting groups. Planning and layout of the building will integrate it with other MFE facilities, This new fucility will have a functicaal and attractive working environment for the research staff.

Landscaping of Bldg. 441 uill offer relief from the generally industrialized environment of the adjacent area and present use of $\mathrm{t}^{\prime}+$ site.

Primary Electric Power. Pulse-power requirements will be supplied by a new $230-\mathrm{k} V$ power line from the Pacific Gas and Electric Co, (PG\&E) Tesia switching station. The line will run to a terminal structure at the new LLL substation and terminate in a $230-\mathrm{kV}$ circut swilther. An envronmental im. pact statement for the line will be prepared and submitted hy PG\&E to the California public Utilities Commission (PUC). PG\&E will ohtitin approval for line construction from PUC. Required easements for line construction will be ubtained by PG\&E. The line will start at an existing $230 \mathrm{k} v$ bus position at Tesla. it will require construction of a short 230-kV aluminum conductor section of transmission line to tower $80 / 555$ of the exising Tesli-Newark section of the Tiger Creek-Newark

Table 6. Blug. +41 floor space.

\begin{tabular}{|c|c|c|}
\hline & $\begin{array}{c}\text { Net wed } \\
\left(\mathrm{n}^{2}\right)\end{array}$ & $\begin{array}{c}\text { (irobs ared } \\
\left(\mathrm{III}^{2}\right)\end{array}$ \\
\hline Office \& draftiry & $3+010$ & \\
\hline Lohuratory \& computer & 2400 & \\
\hline \multicolumn{3}{|l|}{ Nisccullanewus } \\
\hline Lecture \& cunferente & 400 & \\
\hline Librory & 2i) 0 & \\
\hline Sturagt & $1+0$ & \\
\hline Other & 330 & \\
\hline Tiot:d & 6870 & 9300 \\
\hline
\end{tabular}




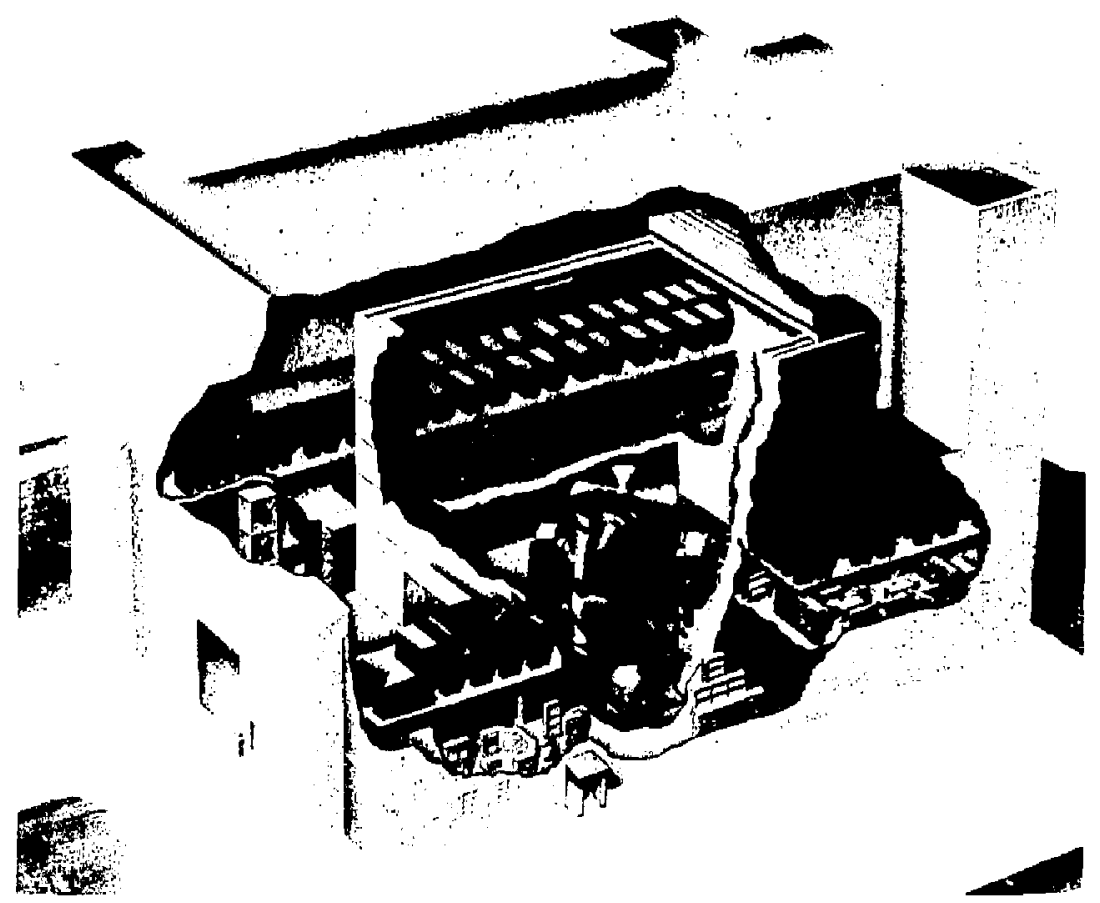

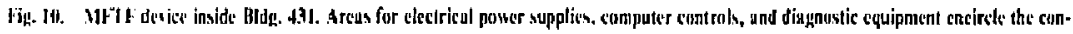

line: il single circuil (three-phuse) on a vacanl position of the Tiger Cleek-Newark line from tower $\mathrm{k} 0$ : 555 ro conse $87 / 596$; artd al $230-\mathrm{k} V$ tap line consisting of a single-circuil line from tower $80 / 555$ to the I.L. substation site (where it will terminate on a 230. $\mathrm{kV}$ circuit switcher). Metering equipment will be instillled in the subsintion. Also included will be Iwo communications channels required by PG\&E between 1.1.L and the PG\&E loud dispatcher.

$A$ temporary 13.8-kV overheid pole line will be installed for testing of rectification power supplies before the new 230-k $\mathrm{V}$ line is on stream. The line will run frobl the main LL.L 115-/13.8-kV switchyard (south of Bldg. 431) to a central location at the $80-k \mathrm{~V}$ dc rectification yard (adjacent to the new $230 . \mathrm{kV}$ substution). Line length is $\sim 550 \mathrm{~m}$.

Three 13.8-k $\mathrm{V}$ underground feeders will serve as primary distribution to Bldg. 431. New loads in Bldg. 431 will require modification of the existing primary distribution system. This will include highvoltuge splicing, swilching feeder positions, reconrecting to match loads, and adding some high. voltage cables in the distribution tunnels.

\section{Referenees}

1. F. 11. Coensgen, Mix Major Mroject Propusal. Lawrencu l. ivermure Laboralory, LLL-Prop-142 (1976).

2. W. R. Hill,s, Regurt of the Open Systemis Techmical Resiew Pand, U.S. Energy Reseurch and Development $\mathrm{Ad}$. ministration, Washington, D.C., ERGi-76/140 (1976).

3. Coureptual Design Repurt-U/t'R Mfirror Expeniment facilin. Laurence Ljvermort Luboratory (1976).

4. HFTF Projert Management Plan. Lawrence Livermore Laburalory, UCRL-52213 Draft 4 (1977).

5. D. W. Deis, D. N. Cornish, A. R. Rosdahi, and D. G. Hir-

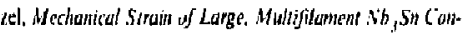
diclors for Fusion Magnets. Lawrence Livermore: Laberatory, UCRL-78890 (1977).

6. H. S. Freynik, Jr., D. R. Roach, D. W. Deis, and D. G. Hirzes], fivaluation of Metal-Fuil Sirrain Gages fur Cryugesic Application. in Magnetic fields. Lalwrence Lirusmore Laboratory. UCRL-79202 (1977).

7. D. W. Deis, D. G. Hircel, and A. R. Roseduhi, Srrain('ritical Curremt bata for Large Wuthililament ith, Sin Cunductors, Lawrence Livermore Laboralury. UCRL. $79724(1977)$.

B. D. A. Cornish, D. W. Deis, A. R. Hartey, D. G. Hirzel, J. E. Johnston, R. L. Leber, R. L. Nelson, and J. P. Lbisnik. Development Work on Superconducting Coils for a Lorge Hirror Fusion Test Facility (MFTF. Lawrence Livermore Laboratory, UCRL-78891 (1977). 
9. 1) X. Cornish, 1). W. Deis, and J. P. Thasnik, cold.

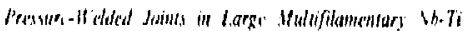

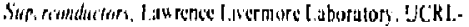
$7,172\}, 1977)$.

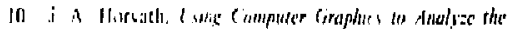

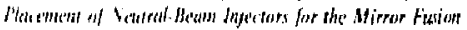

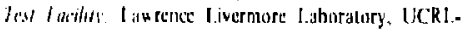
801116 (1977).

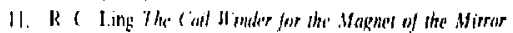

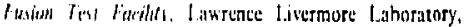
IC RI . 79744 \!977!

12. R. C. I.ing. Y. Chang, and I. D. Huni, Ked Stuphort for

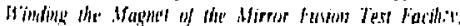
I.aw rence I.iscrmore I.aboralory. IiCRL-7974? (1977)

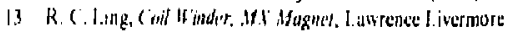
I aboritury. N1:1.7(3.(x) $523(1976)$

14. A. W' Molvik. I. D. Haiud, K H Herknee, W, S. Cuoper

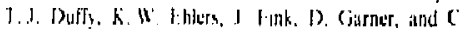

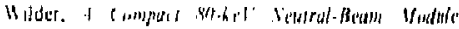

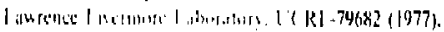

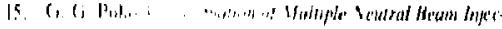

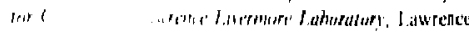

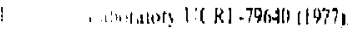

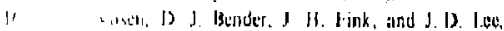

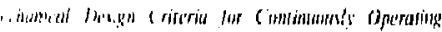

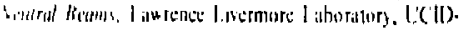
1757,111597

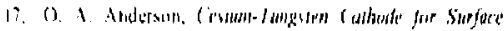

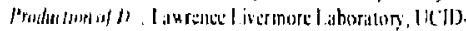
$175 k 111977$

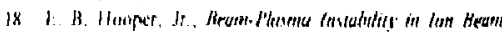

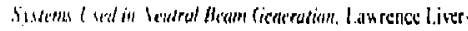
more latherditss. (C(II)-17401 1977).

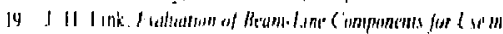

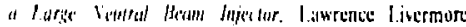
1.dourators, LCKI - 79570 (1977)

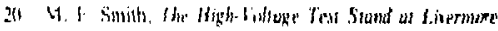

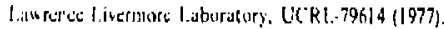

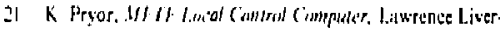

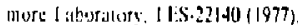

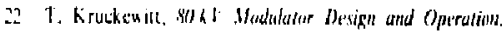

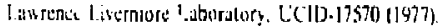

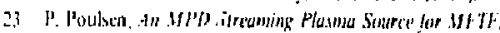

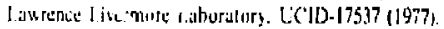

\section{Authors}

\section{R. R. Bunting-Hill}

F. P. Dixon

\section{Tandem Mirror Experiment}

\section{Introduction}

We designed the Tandem Mirror Experiment (TMX) lo test a new principle for improved plasma confinement in open-ended, or mirror, systems. The basie tandem mirfor idea is to reduce plusma-loss rate by electrostatically plugging the ends of a solenoidal central confinement region. We use the high positive ambipolar potential of minimum- $\mathrm{B}$. type mirror end cells to creale our plugs. Each enc plug is driven by neutral-beam injection from 12 source modules in a manner similar to that done on the 2XIIB Experiment.
Extrapolition of the tandem principle to a ceactor configuration yiclds a power balance (nuclearpower outpul to beum-power input) substantially improved over a conventional mirror-type reactor. (Studies of tandem mirror reactors appear in Section 2 of this report.)

The tandem mirror concept originated it: Lawrence Livermore Laboratory (LLL) in 1976. ${ }^{1}$ Following a series of studies of the concept, we selected an experimental configuration that would provide a test of the basic ideas involved. The TMX Major Project Proposul. ${ }^{2}$ based on this configuration, was submitted to the U.S. Energy Research and Development Administration (ERDA) in January 1977. (That proposul conlains a full deseription of the tandem mirror principles and the TMX experiment.) Preliminary TMX design began immediately, and ERDA revicwed and approved the project proposal early in 1977. An administrative plan ${ }^{3}$ for the project was prepared and adopled in August 1977 to provide a basss for planning and reviewing consirus: on progeress. The rroject entered a design and fabrication phase, with complation of consiruction planned by Octoher 1978.

What follows is a brief description of TMX: refer to the project proposal ${ }^{2}$ for morc complete infor. mation. $A$ set of recent teports. ${ }^{4-11}$ presented at the K noxville Symposium on Engineering Problems of Fusion Research, October 1977. gives a detailed jescription of the machine design. $A$ recent issuc of LLL's monthiy journal contains a simplified descriplion of TMX. ${ }^{12}$

\section{Physics Parameters}

The purpose of TMX is 10 provide al proof-ofprinciple evaluation of the tandem mirror concept as rapidly us possible. To accomplish this, we have set three muin physics objectives for the experiment:

- Demonstrate the establishment and maintenance of al potential well between two mirior plasmus.

- Develop a scalabie magnelic geomelry while keeping macroscopic stability at high $\beta^{2}$.

- Investigate the microstability of the plug. solenoid combination to maximize the plugdensity/injection-power ratio.

These objectives, further discussed in ReГ. 2, lead 10 a set of key physics parameters for the experimen! (Table 1). The TMX major-device-fabrication project is designed to provide an apparatus (Fig. I) and facility that meet the parameter requirements of Table I and have sufficient flexibility to meet the physics objectives above. 


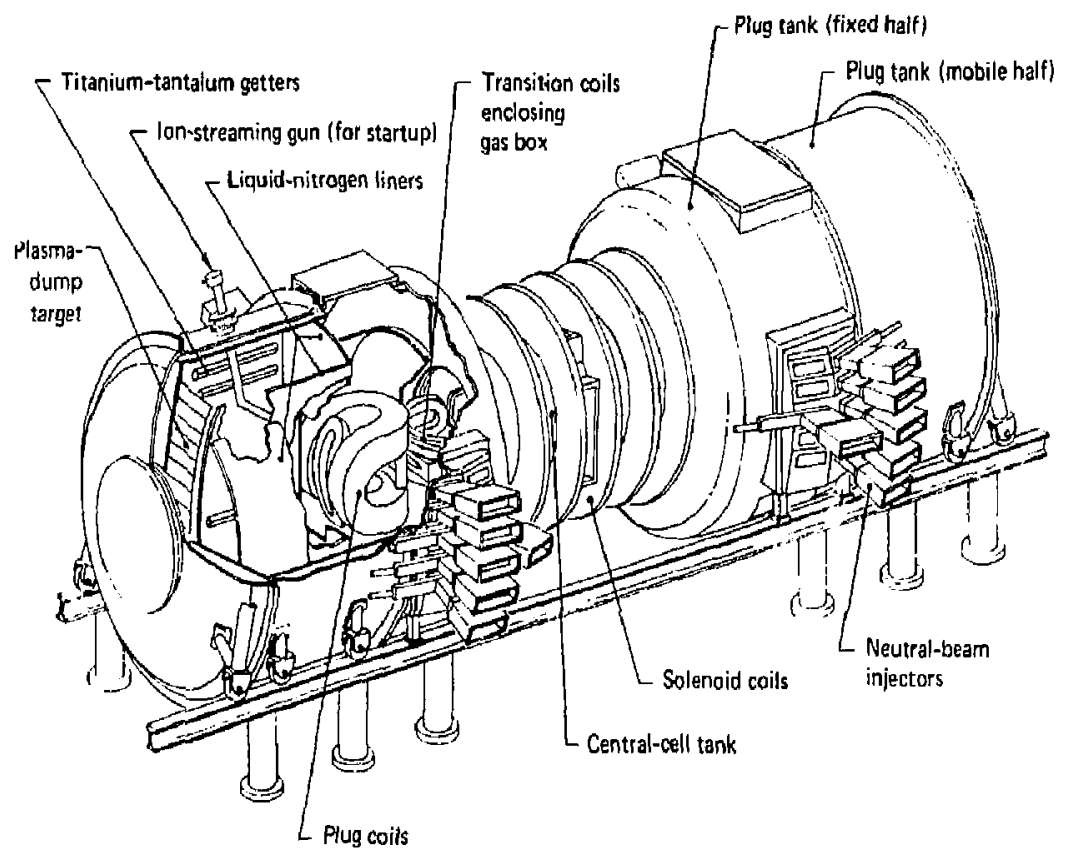

Fig. 1. Anvemblet view of apparalus for Tandem Mirror Experiment (TMX). The plug magnets and transition coils residr in siainless-steel racuun charnhers that bave mounted neutral-beam modules. These large plug tanks provide high-speed vacuum pumping of source gass and tream and olasma purticlest.

\section{Engineering Description}

Magnet System. The magnet system (Fig. 2) wiil consist of two quadrupole-well plug sections, a solenvidal central section, and transition coils. Its

Table 1. Key physics parameters.

\begin{tabular}{|c|c|}
\hline Purameter & Value \\
\hline \multicolumn{2}{|l|}{ Hilectern } \\
\hline Temperanurc, $T_{b}$ & $0.20 \mathrm{keV}$ \\
\hline Confining potential, $\phi_{\mathrm{r}}$ & $1,1 \mathrm{kev}$ \\
\hline \multicolumn{2}{|l|}{ Plug } \\
\hline Density (assumed uniform over $v_{p}$ ) $n_{p}$ & $5 \times 10^{13} \mathrm{~cm}^{-3}$ \\
\hline Average cnergy, $E_{p}$ & $26 \mathrm{keV}$ \\
\hline Radies of plasma half-maximum, $\mathbf{r}_{\mathrm{p}}$ & $7 \mathrm{~cm}$ \\
\hline Central magnetic ficld, $B$ & $10 \mathrm{kG}$ \\
\hline Confinement product, ${ }_{(n T)}$ & $3 \times 10^{11} \mathrm{~cm}^{-3} \cdot \mathrm{s}$ \\
\hline \multicolumn{2}{|l|}{ Central cell } \\
\hline Densing (assumed uniform uver $\left.V_{c}\right), n_{c}$ & $1.2 \times 10^{13} \mathrm{~cm}^{-3}$ \\
\hline InD temperature, $T_{c}$ & $0.080 \mathrm{keV}$ \\
\hline Contining ion potenrial, $\phi c$ & $0.29 \mathrm{kcV}$ \\
\hline LengLh. L, & $5.5 \mathrm{~m}$ \\
\hline Kadius, $r_{c}$ & $31 \mathrm{~cm}$ \\
\hline Magnetic ficld, $B_{k}$ & $0.5 \mathrm{kG}$ \\
\hline Confinement product, (ns) & $3.1 \times 10^{11} \mathrm{~cm}^{-3} \cdot \mathrm{s}$ \\
\hline
\end{tabular}

construction material will be cooled copper conductor, energized by line-powered rectifiers. The magnel system will be capable of being energized at rated current for a time $\geqslant 1 \mathrm{~s}$ with a duly cycle of $3 \mathrm{~min}$. The field is being disigned for magnelohydrodynamic stability by having the high-pressure. minimum-B plugs stabilize the central cell in a pressure-weighted average, as discussed in Appendix A2 of Ref. 2. We began field calculations to op. timize the transition between plug and solenoidal sections.

Each of the two plug magnets will consist of a baseball-type coil with a $\mathrm{C}$-shaped coil inserted in each lobe. The central field, $B_{04}$ will be $1.0 \mathrm{~T}$ with axial mirror ratio $R_{\|}=2,0$ and perpendicular mirror ratio $R_{\perp}=1.04$ at a radius $r=10 \mathrm{~cm}$. Length between plug mirfors will be $\sim 120 \mathrm{~cm}$. The plug magnet will be sized for clear access of neutral beams based on a neutral-beam "footprin" of $10 x$ $33 \mathrm{~cm}$ at the larget. The basebail coils and C-coils are being fabricated.

The ceniral cell will consist of a set of six existing solenoidal units, $185-\mathrm{cm}$ i.d. The length of the central region will be $\sim 530 \mathrm{~cm}$ between inner plug mirrors.

The magnetic-field transition between each plug 


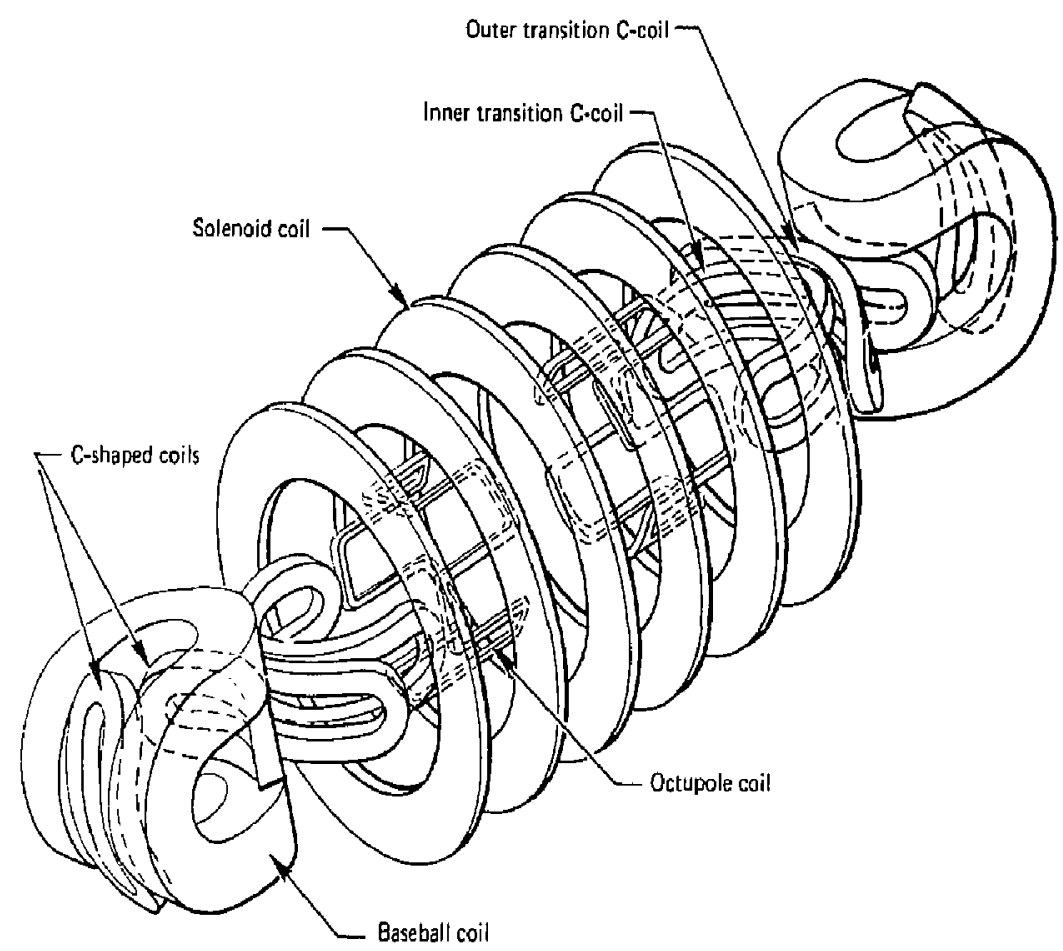

Fig. 2. TMIX coil sel, Massive basebalt-shaped coils in the ends create mirror fields lor the plugh, Large ring-shaped cails finer the central solenvid. C:shaped and octupole crils smooth the transition of firfd lines between plups and solenoid.

magnet and the cenlral solenoidal section will be accomplished by a set of transition coils. Each transition sel will consist of two C-coils and an octupole coil. These are being designed to transform a plug flux bundle out $10 \mathrm{r} \times 10 \mathrm{~cm}$ (in the midplane of the plug) into the solenoidal region.

Each component of the magnet system will be powered individually for maximum flexibility in field shaping. Power supplies will be modular reetifier units.

Vacuum System. The plug magnets and transition coils will be housed in large stainless-steel vacuum chambers that also provide mounting for the neutral-beam modules (Fig. 1). These tanks will be lined with a sut of liquid-nitrogen-cooled baffles, on which we will sublimate titanitum to provide high-speed vacuum pumping of source gas and beam and plasma particles, Surlaces subject to bombardment by energetic particles will be separately cooled to hold a selected temperature between 20 and $100^{\circ} \mathrm{C}$. We will mount the large solenoidal coils outside the central vacuunn chamber (Fig. I).
The vacuum system external to the vacuum vessel will consist of mechanical vacuum pumps, Roots blowers, and diffusion pumps llogether with associated plumbing, va].ing, and gaging).

Injection System. A set of 12 neutral-beam modules of the type in use on 2XIIB will be mounted on each plug lank. To facilitate maintenance, we will individually valve each beam module from the plug tank by means of a rectangular gate value, Each module and neutralizer cell will be mugnetically shielded to maintain a field of $\leqslant 0.5 \mathrm{mT}$ perpendicular to the beam axis, at fullrated plug field. Modules will be mounled on bellows for individual aiming at the plug-axis centerline or aiming as much as $10 \mathrm{~cm}$ off (radially). $0 \mathrm{n}$ each plug tank, eight modules will be rated at $20-\mathrm{kV}$ maximum extractor voltage. These modules will be designed to deliver rated neutral-beam current of $50 \mathrm{~A}$ per source of deuterium ( $\mathrm{D}^{9}$ ) atoms within : target area of $10 \times 33 \mathrm{~cm}$ at the plasna. The other four modules on each plug tank will be taled at $40 \mathrm{kV}$ and will be designed to deliver $40 \mathrm{~A}$ per source of $D^{0}$ to the same area. All modules will be 
capable of operating for a pulse duration of $25 \mathrm{~ms}$, and their astociated power supplies will be matched to this pulse duration.

A pulsed streaming-plasma gun of the loaded tilanium-washer lype will be mounled on the magnetic axis at each end of the vacuum chamber to provide a target plasma for startup, $A$ gus hox, similar in design to that in use on $2 X I I B$, will be lowated in the inner misror region of one plug coil with suitable valving to introduce a controlled amount of gas into the system. This gas box will provide plasma to fill the central region. This pla sma ultimately st reams out of each end and helps stabilize the plug plasma.

Facility. The TMX apparalus will be in an existing building within a $9.8-\times-17.1-\mathrm{m}$ pit (Fig. 3). The pil will be surrounded by concrete walls $0.6-\mathrm{m}$ thick ahoveground to provide personnel shiclding from deulerium-deuterium neutrons. Tiers on three sides of the pit place the neutral-beam power sup. plies slose to the neulral-beam modules, Magnea power supplies in an adjacent building connect by sible though at tunncl. Machine control racks witl be adjacont to the pit.

Diagnostic Systtm. This system will be based on that used for $2 \times 1 / B$. It will be augmented by additional equipment as needed. Raw-data storage and archiving. as well as online dati processing. will be accomplished by a minicomputer. Data process. ing and rudoul between each injection period wilt enable the experimenter to evaluale the dala and direct the course ol the experiment.

Additional instrumentation beyond the existing system will be needed beciuse there are threc plasina regions (two end cells, one central cell) on T.MX. Also, some new neasurements will be required (sec Appendix A8 of Ref. 2 for a discussion of diagnostics), including those of space potential and low-energy jon spectra.

Diagnostic Development. A major effort will be required to have diagnostics sysiems that measure the TMX electrostatic potential. Heavy-ion-beam probing systems appear to offer the best means of making these measurements.

We began two joint efforts with Rensselaer Polytechnic Institute, experts in beam probing. The potential in the central cell will be meusured with a heavy-ion beam injected transversely (as in the usual $a_{i} r$ lication of the technique). The complex magnetic field of the end plug will require careful computer study to identify suitable component locations and to define the plasma volume that can be probed.

Potential will also be measured by probing along the symmetry axis. We ordered some equipment for

this measurement (some is availatilc from the Bascball II-T surplus).

\section{References}

1. I. R. Powler und H. C. L.ugan, "The Tandem M Irror Reas.

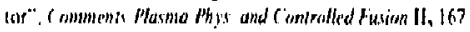
(1977).

2. F. II Coensgen, I Wh Major I'roject Propusal. Liwrence l.ivermope Laboralory, 1.1.L.Prop-148 (1977).

3. IVI diminitrative Miat Lawence Livermors l.ahoratury. L.L.L.Prop-148 Addendum : (1977).

4. A. K. Chaftin, M. O. Caldefon, L. J, Mooncy, and G. I:. Hagtlin. "System Design for the New TMX Machine," in

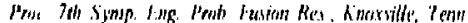
$197 ?$ (Institute of lilectrical and Electronics Fingunets, Ses: York, 1977).

S. F. K. Chen, A. K. Chargin, B. S. Denhoy, A. J. Waugh, "J)esign for the Magnedic Field Requiremenls of the Tinnden Mirfur Fixperiment". in Prus th Symp ling. Prohs

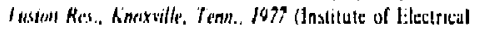

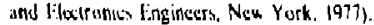

G. R. F. Hinkle, M. O. Calderon. A, K. Chargin, F. F. K (hen, H S. Denhoy. A. R. Hurvs) J A. Horwalh. and J. R Read. "TMX Magnets-Mechanieul Design," in I'rme ?/h

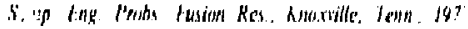
Institult of Electrical and Elecirunics Enginoers, New Yotk. 1973)

7. D. P. Alikinson, M1. O. Caldefon. and R. J. Yagel, "Vatuum System for the Tardem Mirror texperiment." in

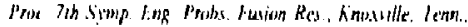

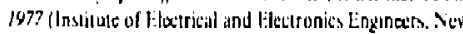
York, 1977)

B. M. O Calderon, F, F, K. Chen, and B S, Denhor. "Mechanical Design for the TMX Injector System." in

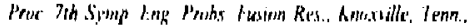

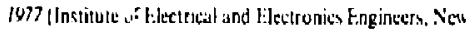
York. 1977 .

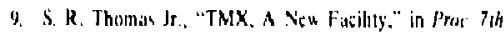

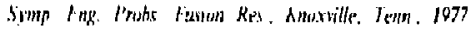
(Instilute of telectrical and filectrunics Enginecrs, $\mathrm{NeF}_{\mathrm{H}}$ Yotk, 1977)

I0. (j. A. l.tuvitI, "A 40-kV, 25 ms Neutral-Buan Pohter Sup.

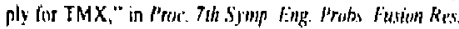

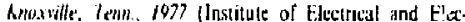
Ironics E.ngıneers, New York, 1977 ).

11. G, T, Santamaria, "A New Generation of ArC and ATE' Flament Power Suppliess for Pulsed Neutral Beams," in Proc. 7h Simp ling l'robs fusium Res, hroxtille. Tenn.

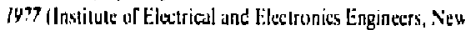
rork, 1977).

12. "TMX: A New Fusion Plasma Expenment," Finergl and Terhul Rel. I (July 1977).

Author

C. C. Damm
Major Contributors

B. G. Logan

A. K. Chargin

R. S. Hornady 


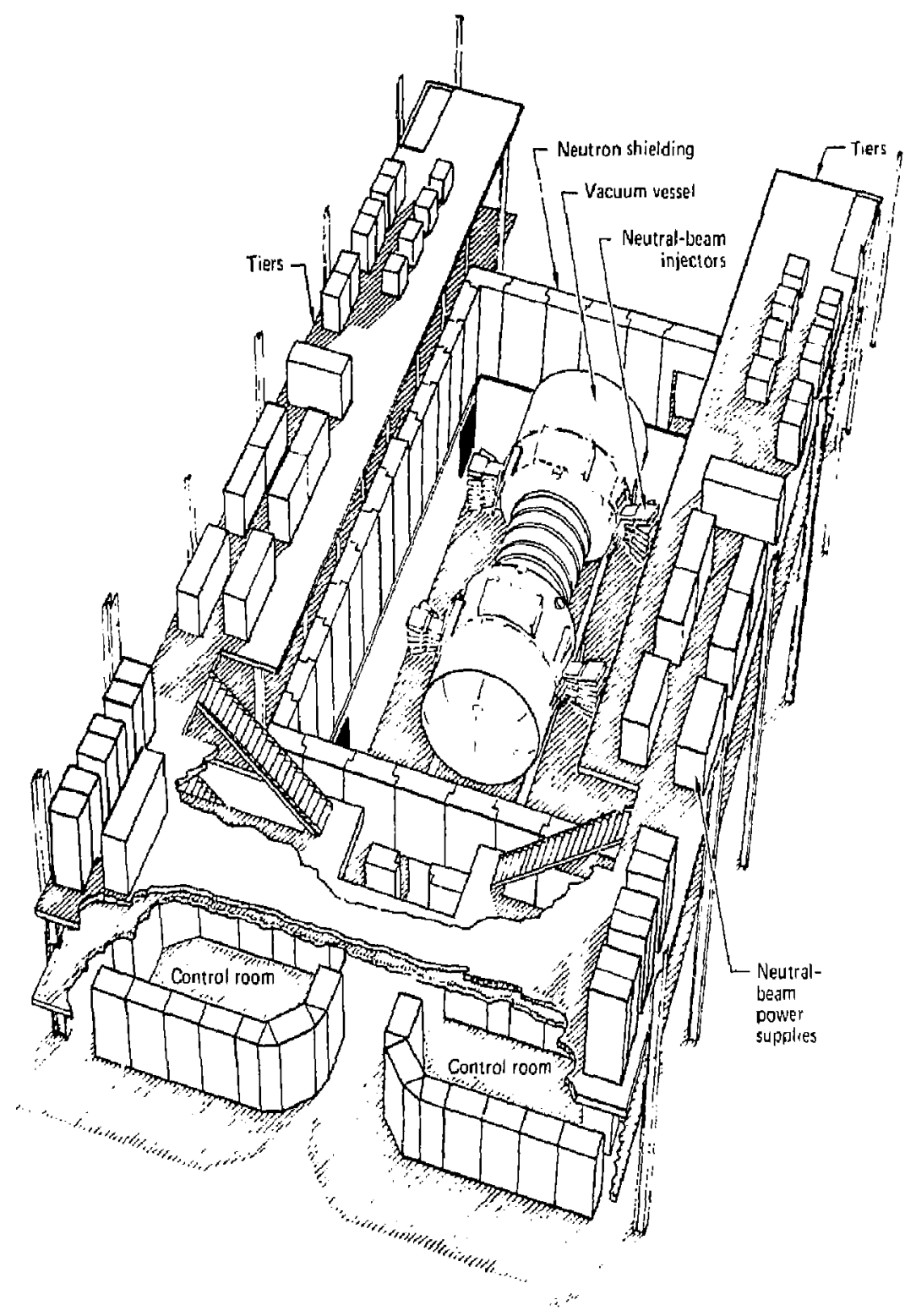

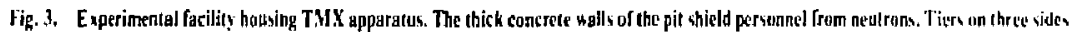
of the pit place the purer supplies close to the niutral-beam modales. 


\section{SECTION 2. DEVELOPMENT AND TECHNOLOGY}

\section{Introduction and Summary}

Mirror-confinement experimenls have always re quired state-of-art tahnology in many arcas. Thus, we are developing in our laboratories intense neutral beams, superconducting magnets, highvacuum techniques, and methods for direct recovery of plasma crergy escaping through "nirrors." Also, several developments are required for eventual application to all fusion concepts. These developments, which use the unique facilities of Lawrence Livermore Laboratory (LLL), include research on tritium technalogy and on the effects of a 14-MeV neulror, sourcc un reactor malerials, The RTNS-II (Rolating-Target Neutros Source), a new $14-\mathrm{MeV}$ neutron source, is under construction to obtain dita on retector materials at higher doses.

Conceptual design studics of fusion reactors and components form a hasis for guiding the program and for establishing technology goals.

\section{Superconducting Magnels}

Production amounts of superconducting corc for the Mirror Fu' n Test Fachia, (MFTF) coil were obtained lrol. our manufacturers and cvaluated. We buil a production line and operated it successfully for addin": "wraparound"stabilizer to the core. $\Lambda$ cold-weld lechnique was suceesslully developed lor making joints.

We investigated mechinical strain effects on multifilamentary niobium lis ( $\mathrm{Nb}_{3} \mathrm{Sn}$ ): tests using fields up to $12 \mathrm{~T}$ indicated no degradation for strain less then $0.8 \%$, We concluded that $\mathrm{N}_{3} \mathrm{Sn}$ could tolerate practical strain and that it could be used in highlield maignets.

Construction proceeded on the High-Field Test Facility (HFTF): the cryostat was fabricated and installed: two of the l-m-bore niobium-tilanium (NbTi) "backing" coils were wound; and the refrigerator liquifier from the discontinued Baseball-1I experiment waj relocated next to the HFTF.

\section{Direct Energy Conyersion}

Following success at $15 \mathrm{keV}$, a $120-\mathrm{keV}$ beam. direct convertor was built and installed in the Law rence Berkeley Laboratory (LBL) IJIA facility. Initial tests indicaled that high gas pressures prevented proper uperation; thus fabrication began on a 150000 litres/s cryopump to pump gas produced in both the direct convertor and the beam dump of the test racility.

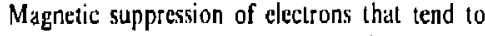
en ter the di rect convertor is being investigated in the $15-\mathrm{kev}$ facility, using iron pole pieces; a field of about $0.3 \mathrm{~T}$ is required. If successful, magnclic suppression will allow the application of direct conversion to much thicker beams than is possitble using electrostatic suppression.

\section{Reactor Stuvies}

We completed a conceptual design of a 100$M W e$ sertical-stacked reactor that has 12 cells. An alternative horizontal-axis design, which was started, might have structural and serviceability advantinges. Alpha-particle heating studies showed an optimum alpha retention of ahout $30 \%$ In-place startup, using neutral beams, requires a large pulse of heam current; thus startup of the field-reversed plasma in an extcrnal chamber secms preferred.

A preliminary 1000-MWe Tandem Mirtor ReasIor (TMR) design was completed. The cenlral cell is $100 \mathrm{~m}$ long and is geometrically simple: the end cells require high magnctic fields (I 7 T) and high energy boums ( 1 MeV) hut are small relative to the central cell and have low neutrun production. $A$ plasma $Q$ (fusion power; injection power) of about $S$ is possible. and it appears that ash buildup will reach an equilitrium that allows steady-state burn.

We completed a reference conceptual design for a fusion-rission hybrid reaclor bused on a classical nirror plasma and a depleted uranium blanket. The neutfons from a $400-\mathrm{MW}$ fusion plasmal can produce $1900 \mathrm{~kg} / \mathrm{yr}$ of plutonium, which would provide makeup fuel for about six j000-M W' lightwater reacturs. Preliminary parametric studies of a hybrid based on a "lo' technolagy" tandem mirror indicate improved economics and geometrically simpler design. A preliminary evaluation was made of a no-reprocessing fuel cycle based on uranium233 produced in a mirror hybrid and burned in high-tem!erature, gus-cooled reactors.

We initiuted a "small mirror reactor" project under Electric Power Research Institute (EPRI) sponsorship to design a reactor that could be operuted in !he late 1980's. Parametric studies started on the standard mirror hybrid (with cylindrical shape and loffe bar magnets), the tandem mirror, and ficldreversed mirror. In all cases, emphasis was on neartcrin tectnology, small size, and significant power production.

Major studies were done of reuctor-scu!. 'tense neutral-baam injectors based on negative ions. These included injectors for the Reference Mirrar 
Reactor delivcring $1800 \mathrm{~A}$ at $150 \mathrm{keV}$ and $81 \%$ efficiency and for the TMR injector delivering $123 \mathrm{~A}$ at $1.2 \mathrm{Mev}$ and $73 \%$ efficiency. The injector design ior the Hybrid Mirror Reactor is based on positive ions and delivers $2600 \mathrm{~A}$ at $125 \mathrm{keV}$ and $60 \%$ efficiency. The main considerations in these designs were efficiency: reljability; long life; and evaluation of high-vollage arc suppression, gas pumping, and neutron bombardment. A $120-\mathrm{keV}$ helium-3 neutral-beam injeclor for heating and fueling a deuterium/helium-3 reactor was designed as part of an ERPJ-sponsored advanced fuels reactor study. We exphasized a minimum 6-month operating life of direct converters and use of cryotrapping for pumping of helium-3 gas.

\section{Tieutral Beams}

Our major test facilities were significantly im. proved. Facility IIIA at LBL, which is rated at $120 \mathrm{keV}, 20 \mathrm{~A}, 0.5 \mathrm{~s}$, and for long pulses, was improved as follows: We successfully evaluated "magnetic core snubbers" for control of spark damage, with shunt-control using silicon-controlled rectifiers, and we greatly expanded our computer diagnostic and control systems. Facility IIIB, the first all-solid-stute, high-power neutral-beam system built, became operational, powering and controlling our First full-c cuirent Tokamak Fusion Test Reactor (TFTR) source. The High-Vollage Test Stand, rated at $200 \mathrm{keV}$ and $20 \mathrm{~A}$. de neared completion at LLL.

Highlights of the development program included the suciessful test of a fractional-area TFTR source ut the III $/$ facility. Sirsilar tests began on sources for MFIF ( $80 \mathrm{kV}$, deuterium) and the Doublat-III lokamak ( $80 \mathrm{kV}$, hydrogern). A full-scale TFTR source was tested to $60 \mathrm{kV}$ at Facility IIIB. To im. prove our hasic source designs. a "Mackenzie bucket" plasma source was bujt and is being evalualed and long-life electron sources, such as hollow cathodes, are being developed.

The negative-ion program, aimed at developing efficient beams for future applications, is based on the high efficiency with which negative-ions can be neutralized. A 100-mA negative deuterium ion ( $\mathrm{D}^{-}$) beam, produced by double charge exchange in cesium, was accelerated to $60 \mathrm{keV}$. Technical problems being actively worked on include the produc ion of an intense high-quality beam of neutral deuterium al $1 \mathrm{keV}$, for subsequent conversion to D - in cesium vapor. At these low energies contre of space-charge neutralization to prevent excessive beam divergence has not yet been achiered. Calculations are also being done on background plasma space-charge effects in the transporl distance required for electrons to leave the
$1 \mathrm{keV} \mathrm{D-beam} \mathrm{before} \mathrm{reaching} \mathrm{the} \mathrm{high-voltage}$ D- accelerator; theoretically, this technique appears to be feasible. We began an experimental investigation on an alternate method for making a high intensily $\mathrm{D}$ - beam using a magnetoplasmadynamic arc jet.

\section{RTNS-II}

Construction of this facility, which sontains two $14-\mathrm{keV}$ neutron sources for fusion matcrials studies. continued on schedule. The building is $80 \%$ complete, $400-k \mathrm{~V}$ power supplies were delivered, and one complete accilerator was assembled. We tested the terminal to $400 \mathrm{KV}$ and lested the siurce at 150 to $200 \mathrm{~mA}$ of molecular hydrogen ions. A full-scale Iritum scrubber was tested, and testing begun on a 50r-rpm, 50.cm-diam target.

\section{Neutron Irradiation Studies}

We made exploratory studies on the nature and magnitude of radiation damage effects produced by neutrons from the RTNS and beryllium $(d, n)$ sources. On the basis of calculated damage energy, the two sources show the sume strengthening effecl on copper, vaniddum, and niobium: whers ..., for fission-reaclor neutrons (Livermore Pool-Type Reactor at LLL), about 2.3 times more damage energy is needed to produce the sume strengthening.

Tests on cold-worked 316 stainlesss steel showed medsurable effects at a $44-m e V$ iluente of $3 \times 10^{21}$ $\mathrm{n} / \mathrm{m}^{2}$; strength increased by :lbout $5 \%$. For atrnealed material the effects wete much grealter. with a $60 \%$ increase in yield strenglth.

Helium doping of niobium samples wils dane: creep tests gave results similar to those of undoped niobium. Doping increased the yicld strength of niobium/I-w1\% airconium speciniens.

We irradjated $\mathrm{Nb}$-Ti superconductors al $4.2 \mathrm{~K}$ to at fluence of $8 \times 10^{20} \mathrm{n} / \mathrm{m}^{2}$ : the sritical current decreased by $24^{t} \%$. This is a far grealer sensitivity to 14-meV neutrons than would be expected fiom using damuge-energy correlations and published dala on fission neutron effecls. Annealing at room temperature produced recovery to within $7 \%$ of un. iiradiated values.

The effects of 14-me"' neutron irradiation on lowtemperature resistivity were measured to gel data from which to develop models of the displacement process. Based on preliminary data on vasadium. niobium, and molybdenum, we reached a speculative conclusion that theoretical dumage ratios are about $20 \%$ higher than those meusured.

In a computer-modeling study of radiation damage, we completed a dynamic study of collision cascades in tungsten. 


\section{Tritium Technology}

Tritium control was studied as part of all our major reactor studies. Several new methods were considered and described for the Mirror Hybrid Reactor. We calculated that enissions can be kept to below $0.4 \mathrm{TBq} / \mathrm{d}(10 \mathrm{Ci} / \mathrm{d})$.

We made an economic study on a large scale $\left(70 \mathrm{~m}^{3} / \mathrm{s}\right)$ cleanup system using our oxidationabsorpticn models; data was nol sufficient to makc a proper choice from among alternative concepts. Experimental apparitus is being built for testing tritium cleanup using various catalysts and absorbents,

We are continuing our investigation of active metal "getters" for litium cltasup. We have studied uranium and cerium. With cerium the tritium concentration in a gas stream could ideally he reduced to less than $3.7 \times 10^{-12} \mathrm{~Bq} / \mathrm{rm}^{3}{ }^{3}\left(10^{-19}\right.$ $\left.\mathrm{mCi} / \mathrm{m}^{3}\right)$, ahout $\mathrm{i}^{2}$ times lower than that with uranium. Preliminary datu on cesium is encouraging.

\section{Author}

C. E. Taylor

\section{Superconducting Magnet Development}

During FY 1977 we disected our development program loward three main aims:

- Developing the conductor and designing the superconducting coils for the Mirror Fusion Test Facility (MFT5).

- Develoning inultifilamentary niobium tin $\left(\mathrm{Nb}_{3} \mathrm{Sn}\right)$ superconductors for large fusion devices.

- Building the High-Field Tes! Facility (HFTF) for lesting (a) the MFTF test coil and (b) $\mathrm{Nb}_{3} \mathrm{Sn}$ insert coils.

\section{MFTF Conductor Development}

A special cryostatically stabilized niobiumtitunium ( $N b-\mathrm{Ti}$ ) conductor will meet the needs of the MFTF magnet coils. We investigated two possibie fabrication roules: (a) a four-element type comprising an $\mathrm{Na}-\mathrm{Ti}_{\text {/ }}$ copper composite core soldered to three copper conductors, in which cooling channels have been rolled. and (b) one in which a wide stabjlizer strip (also in which cooling channels have been rolled) is wrapped around and soldered to a simitar superconducting core. The latter alternative, which proved to be more successful, was adopied.

Supplisrs extruded 250 -mm-diam billets of sample $\mathrm{Nb}$-Ti/copper composite material and drew them to the final size of $6.5 \times 6.5 \mathrm{~mm}$ for the super- conducting core. Performance of the wire from three of the four suppliers met or came close to meeling the preliminary specification of $11 \mathrm{kA}$ at $4.2 \mathrm{~K}$ and $7.5 \mathrm{~T}$. The MFTF Project sent the final specification for this material out for bids.

Airco developed the wraparound stabilizing process, building on their existing expertise and wrapping equipment. They set up an electroplating line to plate $\sim 0,08-\mathrm{mm}$ thick ness of solder (90 lead. 10 tin) onto the central core. The stabilizer was sepurately prepared by passing oxygen-[ree highconductivity (OFHC) copper $\sim 45 \times 4.5 \mathrm{~mm}$ through a series of rolling and punching processes, interspersed by some annealing. The two components were then brought logether in the final fabrication line. Flux was added, and the stabilizer wiss wrapped around the core, with the cooling channels against the cors, as the components passed through a series of forming rolls. A "Turk's head" sized the conductor before it continued into the furnace, where the solder wis melted. The conductor was compressed horizontally and vertieally by chilled catterpillar tracks, which maintained pressure until the solder froze. The conductor then wen through ultritsonic washing batths, drying and an $\mathbf{u}^{\text {l. }}$ trasonic bond-analyzing system before being coileó onto the supply reel. The ultrusonic detection system conlinuously monitured the quality of the solder bonds un all sides. It was typically set to sound an alarm when less than half a chevron was bonded. Figure I shows the stabilizer ready for wrapping around the core and the finished conductor.

Sample cors malerial $(\sim 2000 \mathrm{~m})$ is being stabilized and will then be wound in 18 pincakes to produce a coil $1-\mathrm{m}$ bore, $1.7-\mathrm{m}$ o.d. and $250-\mathrm{mm}$ long. This coit witl be assembled belween two similar-sized cuils already wound for HFTF (see iater). Heaters to produce controlled quenching and diagnostics to analyze propagation of the normal zones will be inserted in the test coill. Wc will use the test results on this coil to choose the operating curtent and current densityof the MFTF coils and other aspects of the coil design.

The conductor for the MFTF coil will need seversl hundred joints beciuse of the limited length that can be extruded and becuuse joints are required between adjacent pancake coils. The mechanical and electrical integrity of every one of those joints is vitally important, and a variety of possible joining rechniques have been considered and investigated. The lechnique we finally selected is to cold-weld the $\mathrm{Nb}$-Ti/copper composite core with a butt joint, then resolder the stabilizer back onto the core in this region. The strength of the cold-weld joint is clase 


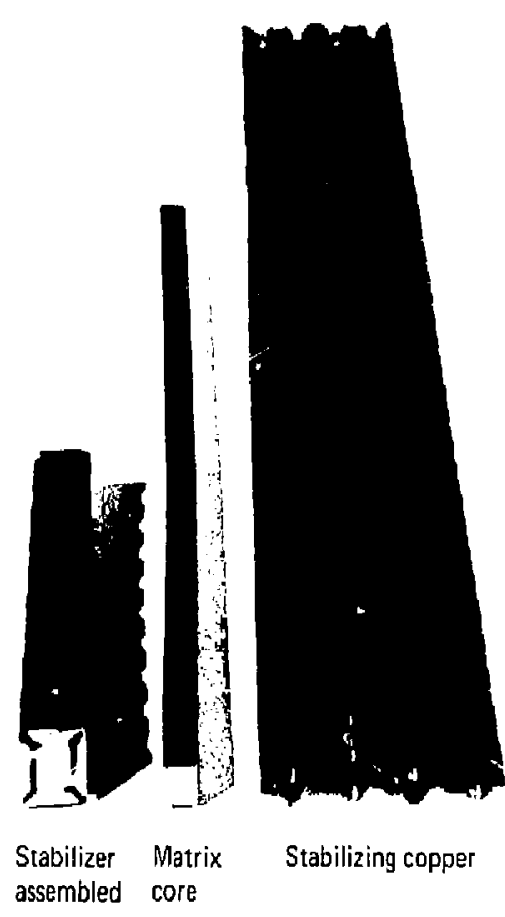

rig. 1. Wraparound copper stabilizer for saperconducling magnet. Hi soldered the copper to a niobium-tilanium/copper corc.

to that of the conductor itself. and the tecthnique, which uses a commercially available machine, is exIremely reliable. Virtually no preparation or skill is required to produte consistent results. Under operating conditions the joint will have some resislance. but it is an acceptable low value.

\section{Multifilamentary $\mathrm{Vb}_{3}$ Sn Development}

We investigated the relationship between muchanical strain and critical current in delail, using the cryogenic ensile-lest appiratus conslfucted over the past two years. The apparatus proved to be versatile and ideally suited for this ty? tion.

Wic made strain measurements on Airco malerial thal used either copper/10 who-tin or copper; 13 wiclin bronze and niobium filaments $-4 \mu \mathrm{m}$ diam. The bronze/niobium ratio was always $2.9 / \mathrm{l}$. All samples showed un initial increuse in critical current as load was applied. The critical current peaked at $\sim 0.3 \%$ strain: it only fell below its zerostrain level for strains $>0.6 \%$. The changes in critical current were always reversible for strain levels $<0.8 \%$, with permanent degradation occurr. ing at strains $\geqslant 0.9 \%$. This type of behavior wold bs explained by the $\mathrm{N}_{3} \mathrm{~S}_{n}$ being initially in compression due to the differential contraction between it and the copper and bronzc matrix. The initial anplication of external strain relieved this internat $\mathrm{Nb}_{3} \mathrm{Sn}$ compression. The peak in the criticul current corresponded to the $\mathrm{Nh}_{3} \mathrm{Sn}$ being stritin-lire. The application of either true tensile or compressive strain on the $\mathrm{Nb}_{3} \mathrm{Sn}$ thus caused a reduction of the critical current. A sertes of measurements, where we applied combined bending and tensile strains to the sample, further confirmed this explanation.

We used the results of the critical current-sitritin work as a basis to design a cryosiabilized $5-k \lambda$ comductor for the first $\mathrm{Nb}_{3} \mathrm{Sn}$ insert coils in MFTl: Fabrication of a prototype length of this eondutus will begin at Airco during FY 1974.

We conclude that theste "bronde prosess" nuttifilamentary conductors sun loletate high erough mechanical strain and have high enough current density to be useful in large. high field roilis. There are three remaining lusks

- Develop an ippropriale stabilizing schente (which may be different for eich applicition).

- Further develop the most simomical manufacturing technigues for large billets.

- Demonsirate satisfactory operalion of the cunductor when wound intu a coil.

Fabrication and operation of the HFTF insert coils should accomplish these.

The work associated with the ase of mutil-lont strain gages in temporary experinconcal imstullittions, such as for $\mathrm{Nb}_{3} \mathrm{~s}$ strain measurements, was completed. The extension of this work to permaneml installations, such as the MIFTF niagnt sistem, will be completed next pear as parl of the MFTF Pro. ject.

Manufacturing development work continued vier the past year al both. Birco and Stipercont, and a new progran was incbaled at Magnetic Corporilion of American $(\mathrm{NC} A$ ). The progesalm at dirbe in. cluded a study of alternalive Ianlalum-batries labrication techniques and the fahriation of a 3.5 . ki conductor with incrised copper contellt. The lantalum-barrier study included the assimbly of a billel. Which had seamla: and welded lanlalum rubes and wrapped tantalum foil as harriers This work was nor completed hesuse of problems in atcquiring suituble tantalum. A $3.5-\mathrm{k}$. conductur with 62 ' copper (rather than the standard 3.7") Wats produced but exthibited center-bursting problems during the linal drawing states. Airco solved this problem os a similar conductor by shanging the heal treatment and die schedules.

Supercon fabricaled a $3.5-\mathrm{kG}$ condustor using 
niobium tubes containing copper/13 wt\%-tin bronze. The fabrication process inyolved two 20-cm extrusion billets. After the second extrusion, the njobium lubes troke over most of the conductor cross-section. Altempls to measure the critical current of heil-trealed samples of this conductor were unsuccessful because of resistance at low current levels.

A program was initiated at MCA to investigate the manufacturing possibilities of the tin-infiltrated sintered-niobium process. A number of sintered rods are new being prepared for a triul $5 . \mathrm{cm}$ billet.

\section{High-Field Test Facility}

We made considerable progress on MPTF. A hitch wils built into the rnof of the eryogenics laboritory to allow the new 2-m-diam cryostat and the relligeralion urits released from Baseball II-T to be brought in. We insulated the cryostat with super-insulation, fitted it with liquid-nitrogen shields, leak-lested it, ther instilled it in the existing pit. The styrofoum heat plug. vapor-cooled highcurrent leads, and auxiliary tittings were fabricated and litted to the eryostul top plate; the whole ansembly is now rendy for its first cooldown to $4.2 \mathrm{k}$.

The Baseball II.T refrigerator, 10 000-lise liquidheliu in storage Dewar, and helium purifier were dis. mantled. reassembled, and commissioned in the tryogenics laboratory. New Iransfer tubes were fabricuted and filled between all the various units.

We wound the first two Nib-Ti backing coils with $15000 \mathrm{~m}$ of surplus conductor from Princeton. These eoils are each $1 \cdot \mathrm{m}$ bore, $1.7-\mathrm{m}$ 0.d., and 224 $\mathrm{nm}$ long. They will be assembled initially with the MFTF lest coil to enhance its maximum field. We urdered a further $23000 \mathrm{~m}$ of similar conductor trom Supercon to wind two similar, but $50 \%$ longer. cuils. After we complete testing the MFTF test coil, we will remove it from the assembly and assemble all four $\mathrm{Nb}$ - Ti backing coils to provide the background field for lesting $\mathrm{N}_{3} \mathrm{~S}$ insert coils.

We ordered and began assembling the power supplits. circuit breakers, protective resistors, and auxilary equipment and controls to operale the first two backing coils and the MFTF test coil.

\section{Magnetic-Field Computer-Code Development}

EFFI, a nsw computer cods, i. now aviilable for general use it calculates mugnetic-fiux lines, fields, forces, and inductances for an arbilxary system of coils made from circular arcs and/or straight segments of rectungular cross-section conductor bundle. In addition to printed output, one can also obtain pluts of forces, field contours, field profiles, flux lines, and field magnitude along a flux line.

\section{References}

These reforences provide further details of the above development work:

1. D. W. Deis, D. N. Cornish, D. G. Hireel, and A. R Rusduhl, "Strain-Critical Current Dista for I.arge Multifildment Nh, Sn Conductors," in Proce 7th Symp leng. Probs. Fusion Res. Knoxrille. Tenn. 1937 (Institute of Electrical and Electronics lingincers, New Yurk. 1977).

2. H. S. Frcynik, Jr., D. F. Roach, D. W. Deis, and D. G. Hir. zel, "Nickel.Chromium Strain Guges for Cryogenic Stress Anulysis of Supcrconducting Structures in High Magnelic Fields," in Proc. 7th Symp. Eng. ?"robs. Fusion Res., Krox. ville. Tenn. 1977 (Institute of Electrical and Electronics lingineers, New York, 1977).

3. D. N. Curnish, D. W. Deis, and J. P. Zbusnik, "Cold. Pressure-Welded Joints in Large Mullifilamentary Nb-Ti Superconductors," in Pros ?h Simp. Eng. Probs. Fusion Res., Kroxville, Tertin, 1977 (Institulc of Eleclrical and Elce. tronics Engineers, New York, 1977).

4. S, J. Sackell "EFFI-A Code for Culculaling the Elec. tromagnetic Field, Force, and Induelance in Coil Systems of Arbitrary Geometry," in Proc. 7wis Symp. Eng. Prubs. Fusion Res., Knoxille. Tema., 1977 (Institute of Electrical and ElecIronies Enginesrs, Naw York. 1977).

5. D. W. Dejs, D. N. Cornish, A, R. Rosdahl, und D. G. Hitz.t. "Mechanical Strain of Large. Multifilument Nb, $\mathrm{Sn}_{\mathrm{n}}$ Conductors for Pusion Magnets," in Proc. Sith Intl cimf.

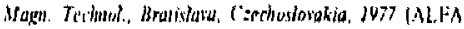
Publishing Compuny, Bratisleva, Ccecboslovakia, 1977).

क. D. S.Cornish, D. W. Deis, A. R. Harvey, D. G. Itirzel, J. L. Johnton, R. L. L ctwer, R. 1 ivelson, and J. P. Zbasrik, "Devclunment Wark on Supurcunducting Cuils for a Large Mirror Fusson Test Facility (MITF)," in Pro' hich saxi.

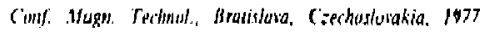

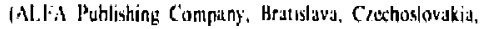
1977).

i. II.S. Ireynik, H., D. R. Roseh, D. W. Deis, and D. G. Hira.el, "levaluation of Metal-Foil Strain Gages for Cryogenic Applicutions in Magnetic Fields." in Pror. 2nd Imt.

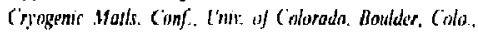
1977 (Pienum Press, New York to be published).

8. D. W. Deis, D. G. Hizel, A. R. Rosdihl. D. R. Rouch. 1), S. Freynik, Jr.. and J. P. Zbastrik, "Evalualion of Large, Multifitament $\mathrm{Nb}$, Sn Conductors with a Now 12-Tesli Tensile Test Apparalus," in Proc Ind Ind Cryogentic Mads. Comf. Linis of Colnradio. Bondder. Coltr. 1077 (Plenum Press, Niew York, to be published).

Author

Major Contributors

D. N. Cornish

D. W. Deis

A. R. Harvey

R. L. Nelson

S. J. Sackett

J. P. Zbasnik

\section{Direct Energy Conversion}

\section{Beam Direct Conversion}

In last year's annual report we described a prototype experiment at $15-\mathrm{keV}$ that proved the principle of inline beam direct conversion with electrostatic suppression of background electrons. During the 
past year we scaled up the $15-\mathrm{keV}$ experiment to a $120-\mathrm{keY}$ system and investigated magnetic suppression of electrons to overcome the electrostatic limitations due to beam-space charge. We recently reponed the engineering status of this work.

Magnetic Suppression of Electrons. The limits on beam density and thickness imposed by electrostatic electron suppression can be relaxed if the electrons are magnetically suppressed. We used our $15-\mathrm{keV}$ facility to test different magnetic-field configurations. In one approach we used an iron yoke and narrow pole pieces (Fig, I) is produce a localized field perpendicular to the beam. Figure 2(a) shows the location of the magnet relative to the collector. A plot of the magnetic field strength on the beam axis is in Fig. 2(b), We lound that a field of about $300 \mathrm{G}$ was needed to slop the electrons when the collector was biased positively.

Our present effort in this series of tests is being directed toward the understanding of mechanisms by which the magneticaly confined clectrons are arriving at the collector.

120-keV Beam Direct Conversiun. We construcLed a larger converter (Fig. 3) based on D, \&RT-code calculations and the $15 \mathrm{keV}$ prototype with electrostatic energy suppression. This system was in. stalled in the Berkeley 120-keV test stand (Fig. 4) and operated wilh a beam of maximum lotal power of over ! MW. Initial operation provided information on several phenomena requiring further work.

We determined that additional pumping speed would be reguired to allain high efficiency of beam direct conversion. The most critical gas-pressure requirement is imposed ay

- The power load resulting from the acceleration and collection of slow ions, and electrons produced by ionization.

- Charge-exchange of background gas and by the secondary electrons thus produced.

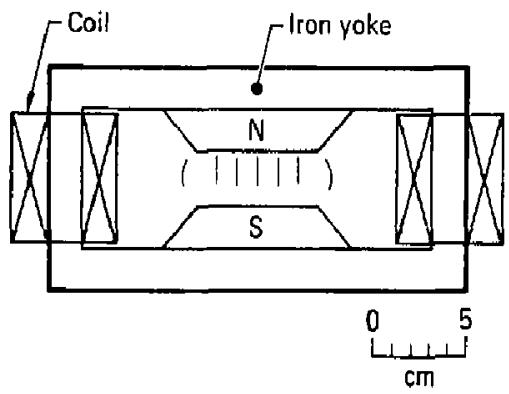

Fig. 1. Magnet used to produce a tield pependicular to the be art for magnetic electron suppressinn.
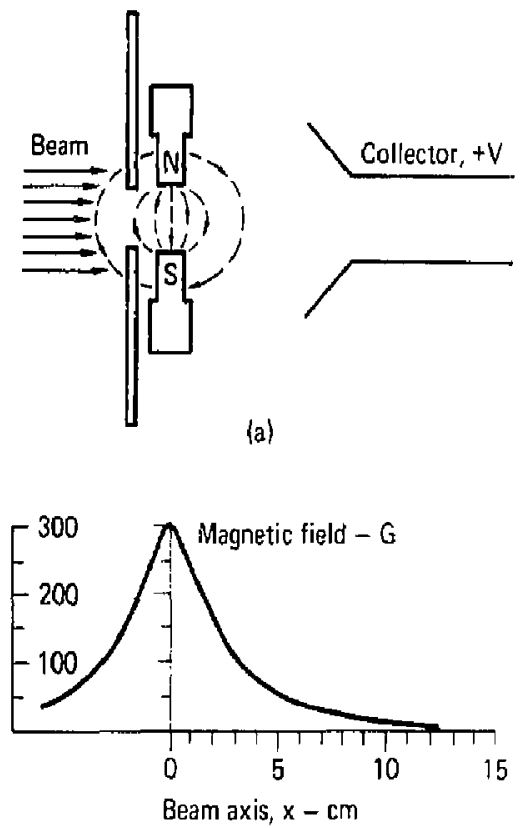

(b)

Fig. 2. (1) Acam Jireet converter sith a perpendiculitr magnetic field to suppiess the electrontion. (h) fisld strength allong the beank axis.

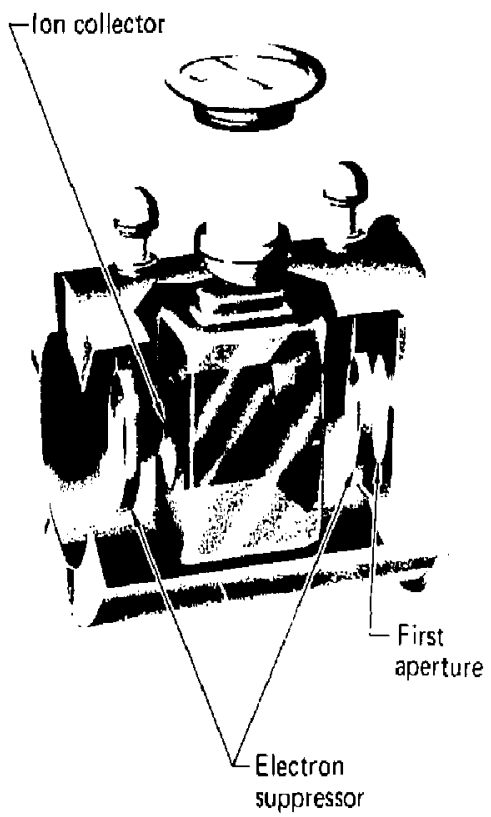

Hig. 3. Beam direct conterter clectrude assembly. 


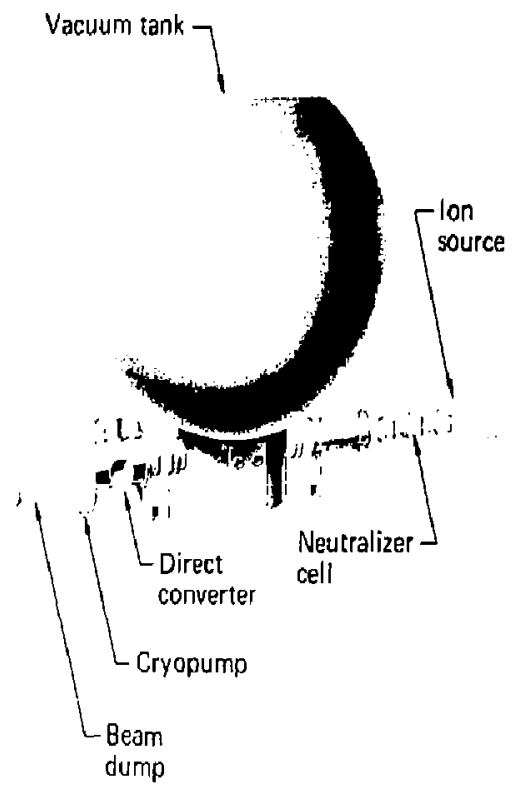

Fig. 4. I.Jarente Berkaley Ishuratory 121-keV test stand with the dirsst conterter and cryopump.

for this reason we started fubrication of a $150 \mathrm{ng} 0$ litre is eryopump to mainlain a pressure of $2 \times 10^{-5}$ Torr under a gas load equivalent 10 several amperes of ions and last beams atoms. The cryopump will be insialled in the position shown by Fig. 4 to pump the gas produced in the beam dump and in the direcl sonverter.

In uddition to the diffuse background gus that can be puinped a tay there will be a gas component. collisionlessly streuming from the neutralizer. We calculale that a drift space of about $50 \mathrm{~cm}$ between neutralieer and converter will be required to at. tchualc this streaming component and to provide space lor gus pumping.

The last series of 120-kV tests showed that the collecled ion current was able to bias the collector up to $10-\mathrm{kV}$ by the IR drop across a load resistor. This appiars io be limited by the $40 \mathrm{keV}$ and 60 . $\mathrm{keV}$ dissuciation products of molecular-hydrogen iuns, which are more abundant than the converter was designed for. Beam analysis has shown several amptres of such products in the Lawrence Berkelcy Laboritory beim.

The most certain way of eliminaling problems tialused by molecular jons will be to operale the beam on heliun gas rather than on hydrogen. It may ultimalely be necessary to use a helium cryotrap for this reason. There are other advantages to using helium ralher than hydrogen for high. energy neutral injection (e.g., deeper penetration into a confined plasma).

\section{Reference}

I. W. I.. Burr. J. N. Dogget, G. W'. Hamilton, J D. Kinney, and R. W. Moir, "Engineering of Beam Direct Cunversion

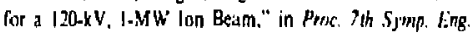
Irah. Fusich Res. Anoxille. Tetr , 1979 (Institute of Electrical and Electronics Engineers, New York. 1977).

\section{Authors}

W. L. Barr

T. C. Chu

G. W. Hamilton

R. W. Moir

\section{Advanced-Fueled Fusion Reactors \\ Suitable for Direct-Energy Conversion *}

We designed i 120-kV helium-3 neutral-beam injector for fueling and heating deuterium/helium-3 reactors. The design was an extrapolation from existing Lawrence Berkeley Laboratory (LBL) injuc. tors for deuterium. We paid special attention to (a) atlaining a 6-month operating life, (b) incorporating direct conversion and (3) adopting recently developed cryotrapping technology to the problem of pumping helium-3.

The injector is $6-\mathrm{m}$ long, the source ion aperture is $100 \times 7 \mathrm{~cm}$, and the $22-\mathrm{A}$ neutral beam has about an $88 \times 30 \mathrm{~cm}$ cross section when measured $10 \mathrm{~m}$ from the source. The injector employs conventional positive-ion accelerution (no satisfactory helium-3 negutive-ion sources have been demonstrated). We have concluded that sputtering is the tife-limiting process, and only by reducing the source's ioncurtent density (below the electrical-stress-limited value) $10108 \mathrm{~mA} / \mathrm{cm}^{2}$ and adding extra acceleralion grids can excessive spu'ter damage be avoided before 6 months pass. At this reduced current, elecIrical siresses are comparativaly modest. The grids require some form of active cooling (we have chosen to use heat pipes as grids).

Conventional hairpin filaments of the type used in experimental ion 5ources do not provide for 6 months of operating life. Instead we have incorporated an indirectly-heated. hollow matrix cathode of the type under devetopment jointly by Lawrence Livermore Laboralory and $\mathrm{LBL}$.

The gross input power to the injector is $5.1 \mathrm{MW}$. of this. 1.3 MW is supplied from the direct converter. The direct converter is a louvered design that was arralyzed with the DART code and found to

\footnotetext{
"Work sponsored by Electric Poner Restarch Institute under coniras No. RP645-2
} 
capture $89 \%$ of the incident ions. Injector efficiency is $63 \%$, assuming $90 \%$-efficient power supplies.

This project has supported, in part, the helium-3 cryotrapping studies that demonstrated success this year. Helium-3 vacuum pumping is a serious problem. Indeed, injector size is dominated by the required cryolrapping pantel area. Argon-sprayed, liquid-helium-cooled cryotrapping paneis $\left(11 \mathrm{~m}^{2}\right)$ surround the beam. Thirty argon atoms are sprayed on the LHe-cooled surface for every helium-3 atom removed. The enthaply change associated with the argon is the principa! refrigerant load; this makes the LHe refrigerator the principal cost item in the design. Further the additional argon causes the LHe panel to frost (to a 100 - $\mu \mathrm{m}$ thickness) in $4 \mathrm{~min}$ at high pressures $\left(1.5 \times 10^{-4}\right.$ Torr $)$. To allow the use of cryotrapping at these pressures, we exlended the normal LHe surface by a factor of 10 and postulated a short (10-min) defrost time. While otherwise satisfactory, the cryotrapping designs need to be improved to aroid the excessive frosting rate if used at pressures above $10^{-5}$ Torr.

Author

A. Blum

\section{NeutrakBean Conceptual Studies}

We completed two major s:udies of neutral-beam injectors. One injector, for the Reference Mirror Reactor, ${ }^{1}$ will deliver $1800 \mathrm{~A}$ of $150-\mathrm{k} \mathrm{V}$ neutral particles ai 81 \% efficiency; the other, for the Taridem Mirror Reactor, ${ }^{2}$ will deliver 122.5 A of 1.2 . $\mathrm{MeV}$ neutral at $73 \%$ efficiency. The beams in bolh injectors will originate as negative ions, formed in cesium double charge-exchange cells. The Reference Mirror Injector will use photodetachment to convert the negative ions to neutrals, where the Tandem Mirror will use a cesium plasma stripper. We presented information about these injectors at several meetings during the year. 3 -7

A third sludy, just completed, concerns an injector for the Hybrid Mirror Reactor. ${ }^{B}$ This unit wil] deliver $2600 \mathrm{~A}$ of $125-\mathrm{keV}$ neutrals at $60.5 \%$ efficiency. It will use a positive-ion beam, with a neutralizer formed from a cesium-vapor cell. The cesium vapor will reduce the area of cryopumps needed along the beam line by blocking the flow of low-lemperature gas. A favorable efliciency will be obtained by means of energy-recovery electrodes.

The primary objective of these designs was to evolve viable methods to generate the beams al reasonable efficiences. Reliability and long life also concerned us. We considered high-voltage asc suppression, ${ }^{9.10}$ continuous cryogeric pumping, grids designed for continuous operation, " shielding insulators from neutron bombardnent, and redundancy to obtain reliability. ${ }^{7}$ In addition. we conducied an experiment on a long-life cithods for the Berkeley-type ion source. ${ }^{12}$

\section{References}

I. J. H. Fink. W. I. Barr. und C. W. Hammlon, Fifficten light

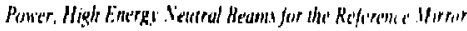

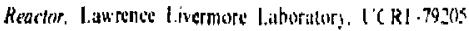
(1977).

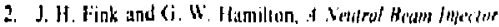

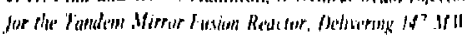

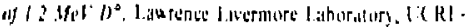
$794+3$ (1977)

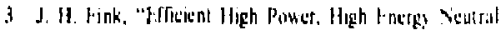

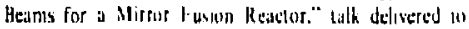

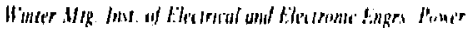

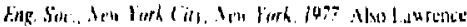
1. ivernure I ahoratory. I'CRI.-7K\$95 [1487,

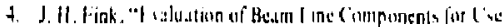

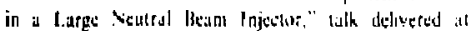

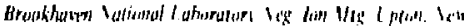
Fork 147 ?

5. J. H. Fink and (i. H. Hamilen, "L ficient Producllown of Neutral Beams ty Phulu-dsuchment af Sequatlue lonn."

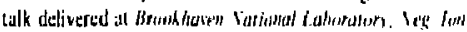

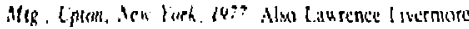
laboratury, LCR1 .796): (1977)

6 1. H. Fink, "Fueling with Yeul ril Beams." talk dellsered :

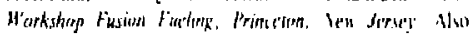

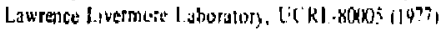

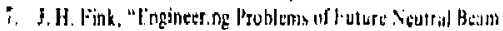

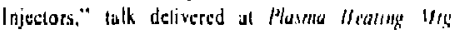

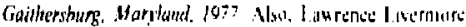
Laboralory. UCRL-80384 (1977).

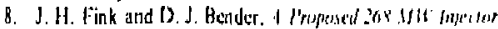

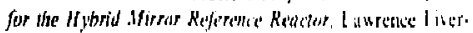
more Laboratory. LiCRI. rupi. in preparation.

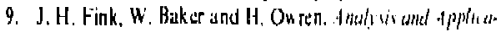

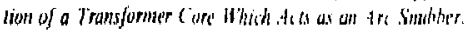
L.awrence Livermose Laborstory. UCRL.-740]1 (11)??

10. J. H, lïnk. "Arc Snubbers for Ven latice Steady Statc Neutral Beam Injectors as Requied by Nirror Reactions."

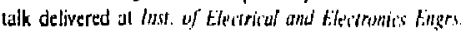

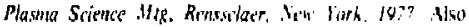
Lawrence Livirinort Latorsatory, L'CRL.79016 (1977).

11. S. R. Yosen, D. J. Bender J. H. Fink and J. D. I.e.

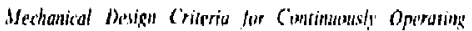
felural Beamr, Liwrence Iitumore Laboralury. LCRI. $79730(1977)$.

12. J. H. Fink and L. Bugig. "A Lang life cathode fur the Berkeley.Type Ion Soutce." posser scssion al Simp this

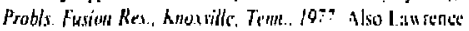
Litermore Laborilor: UCRI.-7970: 11977 )

Author

J.H. Fink *

On loun from Westinghuse Blectric Cotroration 


\section{Reactor Studies}

\section{Field-Reversed Mirror Reactor}

Our chief cffort in FY 1977 on the Field-Reversed Mirror (FRM) reactor was directed :oward completing the cunceptual design of the verliral-stacked mulicell reactor (Fig. 1). The final design was a 12. cell unit producing roughly 100-MWe net electric oulpul. ' Using design concepts developed for the tandem mirror study, we started a conceptual design of a modular, horizontal-axis multicell rtilc10r. This approach leads to simpler overall structure and serviceability, but involves more difficulty in changing the inner Joffe bar-mirror assembly, which may have to be replaced roughly twice as of ten as the blankel/iirst wall assembly. Effort on the horizontal design will continue in FY 1978.
In addition to the detailed designs, we continued to do parameter studies to investigate the sensitivity of our reactor cost estimates to various assumed input parameters. One effect neglected in the past was the healing of the plasmi by fusion products. Analytic estimates ${ }^{2}$ and computer calculations indicaled that 30 to $60^{\%} \%$ of the fusion alphauparticle energy could be retained in the plasma, depending on plasma size, temperaluse, and plasma conditions in the boundary region along the separatrix. A parameter study of the effect of alpha heiting on reactor cconomics showed that too much heating was uniavorable. Circulating power and beam costs would be reduced by retaining a large fraction of the alpha energy, but the clectron temperature and pressure would be driven up, requiring stronger and more cxpensive magnets for a given fusion power.

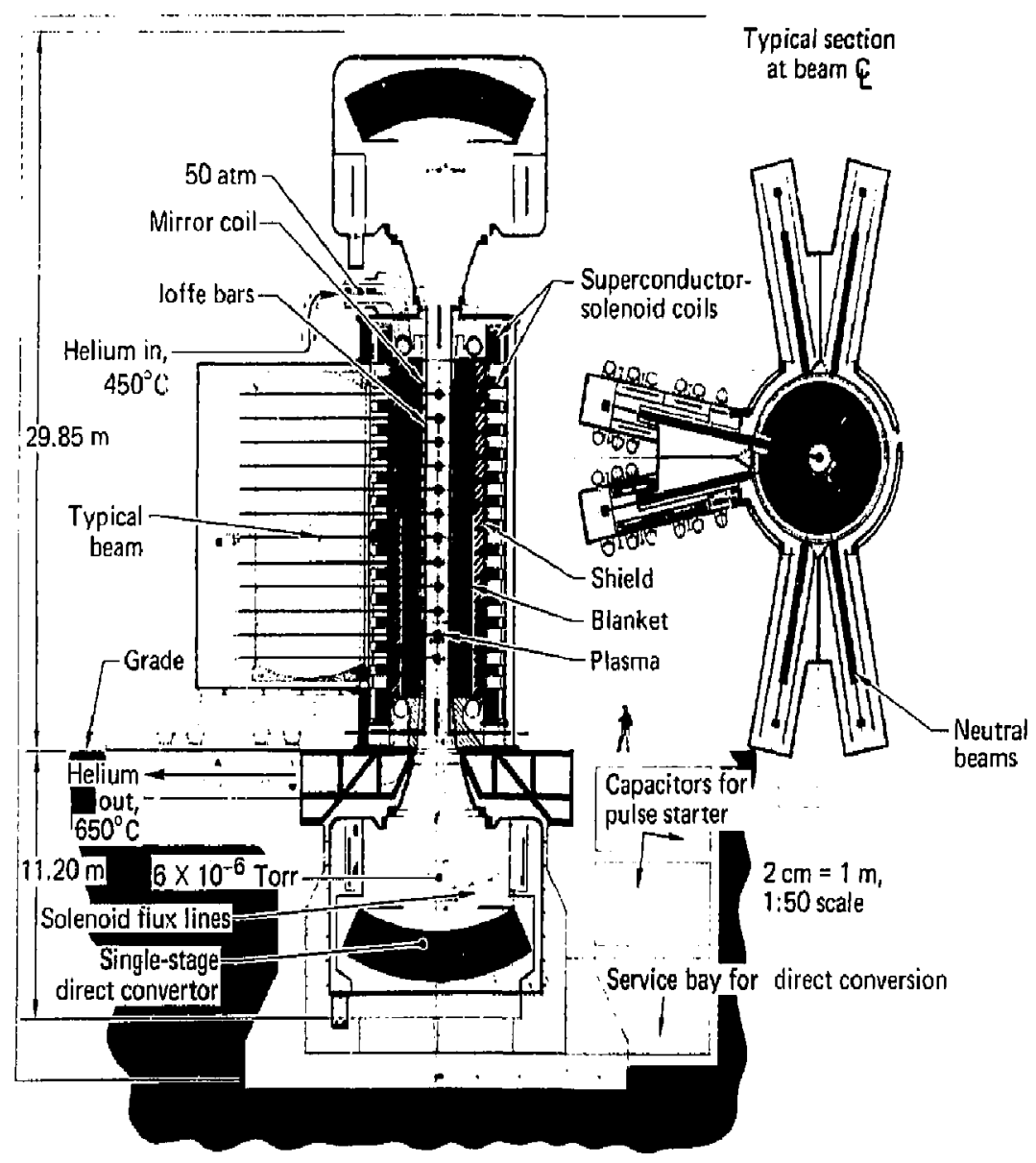

Fig, I. Our Field-Reversed Mitmor (FRM) texstor's fital cutceptual design features 12 cells stacked vertically. This multicell reactar will produce roughly 100 MWe net etcetric output. 
The optimum alpha-energy retention appeared to be about $30 \%$ (Fig. 2).

Parameter studies showed the reactor costs were relatively insensitive to assumptions about neutralbeam absorption (Fig. 3; "Plasma thickness" is the ratio of minor radius to beam absorption length). However, the costs are sensitive to assumed plasma pressure and higher ratios of plasma pressure to magnetic pressure (beta) are desirable (Fig. 4). Based on these findings, we decided not to devote a great deal of effort to neutral-beam deposition calculations: rather, we will concentrate, in FY 1978. on developing an accurate method for calculating plasma pressure.

Finally, we exumined several schemes for reactor
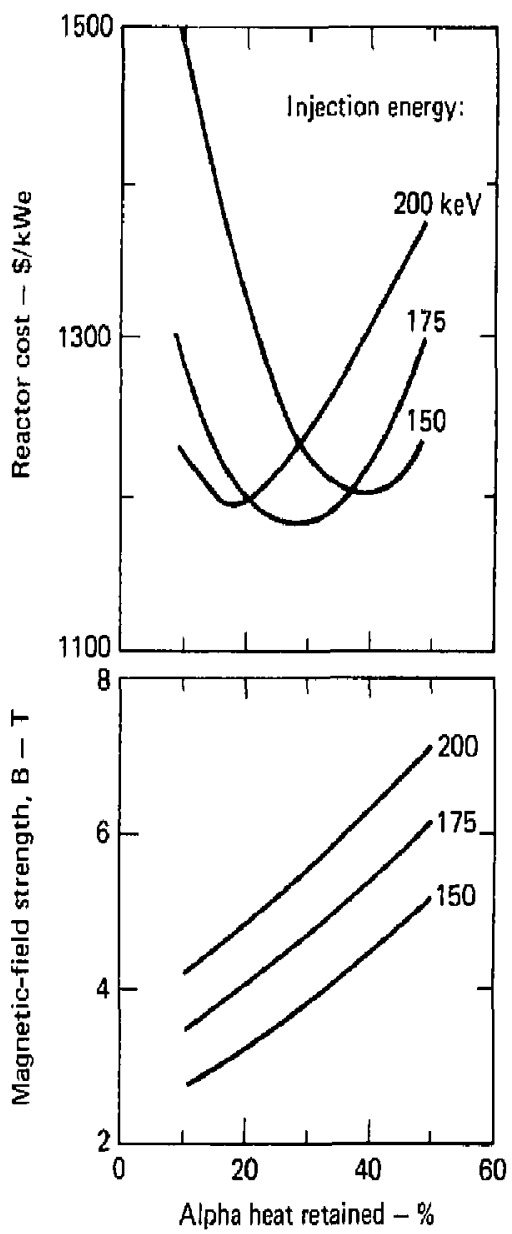

lig. 2. The effect of alpha heating on FRM reactor economics s. 10 s that too much heating is unfarorable. Optimum alpha-energy ictention apperes to be aboul $30^{\circ}$. startup. In-place startup was found 10 require an impractical amount of neutral-beam current. Wc also investigated a concept in which u field-reversed plasma is generated in an external chamher and moved isto place by pulsed field coils. This appea red to involve a small cost additional to the reactor; it is at present our preferred method of reactor sturtup.

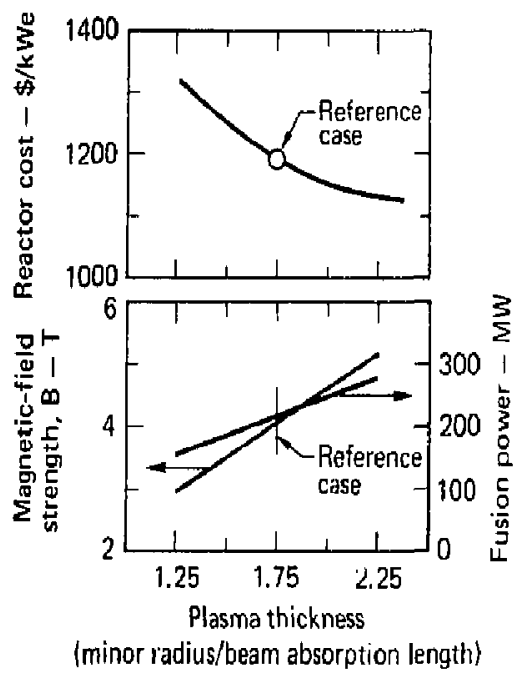

Fig. 3. Duta for an II-cell FRMI reactor shon that reuctor cons are relatiody insensitice to astumptions about neutral-besm ab-

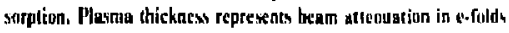
to the plasma's conter.

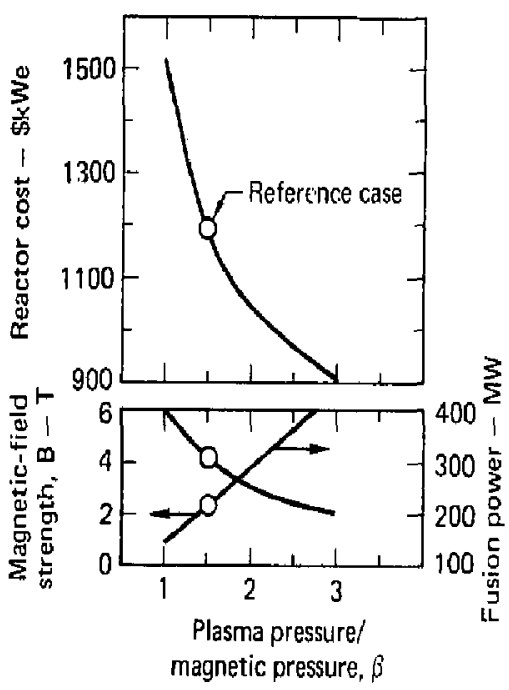

Fig. 4. logla for un I]-cell FRII reactor reseal thut hightr rution of beta ure desirable. 


\section{References}

I. N'. C: Cundit, (i A. Curlsun, R, S. Devolo, J. N. Doggeti, US. Suxf. Jr, and I. 1) Hansen. Pretiminary Dess"

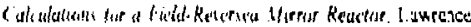

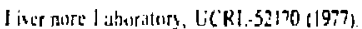

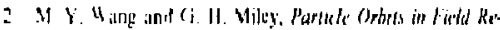

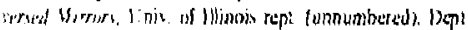

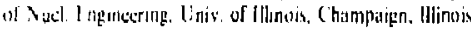
(1977).

Authors,

(i. A. Cirlson

II. C. Condit

R. S. D):voto

II. S. Siect, it

J. D. Hartson

Y) Y, Wang

1. C. Sunith

\section{Preliminurs Design Siudy of the} Tandem Vlirror Reactor

The sancept of the Tandem Nirror Reactor ITMR. is developed by Dimov, at al., 'and by louker and logean. 2 employs the positive elecIrovalate potential of two ordinary (standard) mirrors lo plug the loss of plasma from the ends of a ine silenvid. The combination resulls in 0 values of ; or wh where $Q=$ fusion power/injection mower s. whereas the standard mirror $Q$ is at most slyhtly nore thitl I. The cuncept looks sufficiently interesting for us to have initialed a major experiment alled the Tandem Mirror Experiment to cluck oul and explore the underlying physics ques(ivites.

1 reaclor hased on this concept produces f(100) MW and consists of a solenoidal magnet about 100-m lone, A cylindrical blankel is used for cheses resurery and tritium breeding. Thus the reactor uself is simple and of low technology. The end pluss, houever, are of high technology, having the high mignetic lields needed to confine the highpressure plasma and the high injection entergy ( 1.2 MeV) needed to achieve good magnetic confinement. The plasma densily in the plug $(-8 \times$ $\left.10^{14} \mathrm{~cm}^{-3}\right)$ is considerably higher than that in the antal cell $\left(-1 \times 10^{14} \mathrm{~cm}^{-3}\right)$ to provide a potential barrier at each end $\left(\omega=T_{0} \ln n_{\text {plup }} / n_{\text {solenoid }}\right.$. Because the function of the end-plug plasma is to provide a potential barrier and not to produce power, only deuterium (or even hydrogen) need be injucted. Therefore. neutron production in the end plugs is relitively low. The end-plug mugness are

"Participateng quesi from Pabific Gals \& Lectric Company. San Francisco. Calfornia. smull (the size of the Mirror Fusion Test Facility coil), but of high field strength (17 T). Thus what high technology is required for the TMR is concenlrated in the end plugs.

A detailed repurt ${ }^{3}$ describes how a $1000-\mathrm{MW}_{\mathrm{c}}$ TMR would look, based on our present un. derstanding. Because the design is based on rapidly evolving physics and engineering ideas, this report is a preliminary description of a TMR; we will address design problems in a later version of the design. For example. at the beginning of the study, we did not undersitand the problem of ash (helium-4) buildup: conseguently, we ignoterl this in most of the design. On the basis of much new underslanding of steady. state equilibrium concentrations of ash, as discussed in Ref. 3's chapler on physics (Ch. 3), we believe sicady slate may be possible from the ash-buildup point of vitw. The design consequences, however. afe as jut unknown.

\section{References}

1. Ci, I Dimov, V. V. Zakaidaker, and M. E. Kishneesks. ltathu Masma 2. 597 (1476): also C. 1. Dimow, V. V. Mikindakus, und M. F. Kishinewaky. "Open T rap wilh $\mathrm{Am}$.

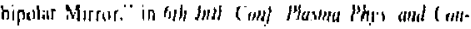

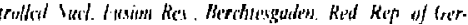

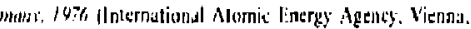
Ausiria, in prepsiralliom. paper (4).

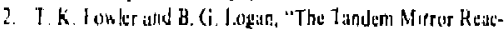

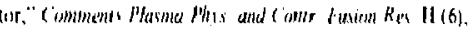
$1671[977)$.

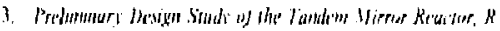

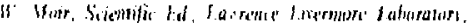

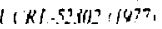

Authors

W. L. Barr

G. A. Carlson

W. L. Dexter

J. N. Doggell

J. H. Fink"

G. W. Hamilion

J. D. L.ee

B. G. Logan

R, W. Moir

W. S. Neef, JT.

M. A. Peterson

M. E. Rensink

\section{Fusion-Fission Hybrid-Reactor Studies}

Point-Design Studies. Our hybrid-reactor studies reached a milestone this year with the completion of a reference conceptual design for a fusion. fission hybrid reactor bused on a classically con-

\footnotetext{
On loan from Wortinghusse Electric Corporation.
} 
lined mirror plasna and a depleted uranium blanket. The design study, a joint activity between Lawrense Livermore Laboratory (LLL) and General Alomic Company (GA), culminated several years of research on the standard mirror hybrid. This research involved a series of iterations on point designs, optimization stud:es, and reactorsubsystem designs.

The major design choices for the reactor are in Table 1; the major reactor parameters are in Table 2. We optimized these reactor parameters for lissile-[uel production. Plutonium production of $1900 \mathrm{~kg} / \mathrm{y}$. resulting trom the neutron output of the 400-MW fusion plasma. is sufficient to provide make-up fuel for about six 1000-MWe light-water reactors. Figure I is a culaway view of the reactor. Its fusion components (magnel, blankel, and injectors) and its primary heat-transfer-loop components are mounted in a prestressed-concrete reactor vesscl; cnd tanks for plasma leakage are mounted abuve and below the confinement region. A report describing the details of the conceptual design is in preparation.

Table 1. Reference-mirror hybrid-reactor design choices.

- Mitimunt-B mirror confinement.

- Vin-yang cuil design, nubium-titanium supurconductor.

- Positive-ion injectors with direct recovery.

- Fastespecirum blanket neutronics.

- Singlestage, plasma direct cunverter.

- Cryocundensalion vacuum pumping.

- Blanket:

$U_{3}$ Si fucl (dupleted visnium),

Lithium bydios de tritiun brecder (nstural lithium). Inconol-718 struclural matcrial.

- Ifelicim primary healetensfer loop (PHTL).

- Prestressed-Concretu Reactor Vessel:

Mlagnel restrainl.

PHTL. cestrainl.

Blanket support and restraint.

- Stuam 1hemal-cunversion system.

Table 2. Refcrence-mirror hybrid-reactur parameters.

\begin{tabular}{|c|c|}
\hline Vruptriy & Vavi \\
\hline Fuxion powcr (MW) & 400 \\
\hline Thermal puwer, avg (NIW) & 3600 \\
\hline Injected ncutral power $(\mathbf{M K})$ & 625 \\
\hline Net electric-autput powsr $(M W\}$ & 525 \\
\hline l'irst-wdl 14-McV ncutton curen। $\left(\mathrm{MW} / \mathrm{m}^{2}\right)$ & 2 \\
\hline Annual fissile pruduction (kg) & 1900 \\
\hline
\end{tabular}

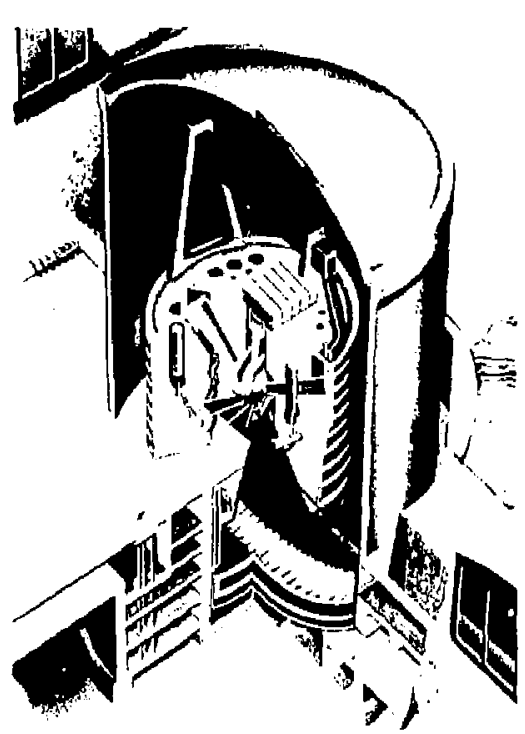

Fig. 1. The fusion camponents for this standard mirror hybrid reactor are mounted in a prestressed-concrete reactor vessicl. Find tanks for plasma leakagre sit above and helow the confinement region.

As an exlension of our inlerest in the hreeding of fissile fuel with hybrid reaclor, we undertook a preliminary evaluation of an alternate nuclearbreeding option, the accelerator breeder. This study resulled in the preparation of a conceptual ac celerator breeder-reactor design ${ }^{2}$

Activities. Fiscal year 1977 was one of increaned interest in the hybrid reactor conccpt as compused with pasl years. Two members of the mirror-hybrid design leam (D. J. Bender of LLL and K. R. Schult $\angle$ of GA) participated in a US/USSR workshop on hybrid-reactor studies in Moscow, where the mirror hybrid design was reviewed. "We learned that the hybrid reactor has become the near-term reactor goal of the Soriet fusion program. The LLL hyteridstudy group also participated in an evaluation of $R$ and Corporation of various nuclear brecding oplions, thich included the hybrid reactor and the accelerator brecuer reactor.

A summary of our reference hybrid reactor design was presented at the summer American Nuclcar Society meting ${ }^{f}$ al New York and the International Alomic Encrgy Agency Conference and Workshop on Fusion Reactor Design t at Macison. Wisionsin. Delaits of the design of selected reactor components were presented at the 7ih Symposium? on Engineering Problems of Fusion Research ${ }^{7}$ in Knoxville. Tennessee and the winter American Nuclear Sociely Meeting ${ }^{8,9}$ in San Francisco. We also participated in two workshops on hybrid reac. 
tors sponsored by the Division of Magnetic Fusion Energy, Department of Energy, ${ }^{10-12}$

New Directions. The concerns expressed by the surrent administration regarding the proliferation risk of the plutoniurit fuel cycle, as required for plutonium-recycle light-water reactors and the liquid-metal fast-breeder reactor, has prompted us to begin examination of alternaie fuel cycles incorporating the hybrid reactor. We completed a preliminary evaluation of a no-reprocessing sccririo based on uranium-233 produced in a mirror hybrid and burned in a high-lemperature, gas-cooled reactor ${ }^{13}$; it forms the basis for our studies for FY 1978.

Our parametric studies also indicaled that a plasma-confinement configurution exhibiting a higher fusion power/injeclor power (Q) than the classical mirror plasma would result in improved hybrid-reactor economics. Thus, we initiated a study of a hybrid based on a low-technology version of the tandem mirror reactor (Fig. 2). The reactor's parameters are in Table 3. This reactor requires neutral-beam injection at $125 \mathrm{keV}$ in the end plugs and central celf and a maximum magnetic field of $X T$, which results in a plasma with a $Q$ of 1.8 and a first-wall louding of about $3 \mathrm{MW} / \mathrm{m}^{2}$.
Table 3. Parameters of a tandem mirror hybrid reactor.

\begin{tabular}{|c|c|}
\hline Parameter & Value \\
\hline \multicolumn{2}{|l|}{ Pisssile-fuel-breceding cencral tedl: } \\
\hline \multicolumn{2}{|l|}{ Cylinưrical shepe } \\
\hline length $(m)$ & 27 \\
\hline autside radius (m) & 3.5 \\
\hline Magnetic-lield strength (T) & 3 \\
\hline $\begin{array}{l}\text { Neutral beam injection of deuterium \& } \\
\text { bricium (A) }\end{array}$ & 1070 a $125 \mathrm{kcV}$ \\
\hline Jiirst-wal ncutron logding ( $\left(\mathrm{MW} / \mathrm{m}^{2}\right.$ ) & 2.8 \\
\hline liusion power (MW') & 261 \\
\hline Blanket thermal pitwer (MW) & 1700 \\
\hline \multicolumn{2}{|l|}{ End plugs: } \\
\hline Spherical shape nutsite coil radius (m) & 2,0 \\
\hline Magneric-ficld strength (T) & 8 \\
\hline $\begin{array}{l}\text { Neutral-hram injection of deuturium }(T) \\
\text { into cach plug (A) }\end{array}$ & 42 (2) $125 \mathrm{keV}$ \\
\hline \multicolumn{2}{|l|}{ Performance: } \\
\hline Ouceall plasme Q & 1.8 \\
\hline Aterirculating power fraction & 0.29 \\
\hline Net elecriral us tpur (BWW) & 500 \\
\hline $\begin{array}{l}\text { Anmual fisile production, } \\
\text { Urasiem-233 (kp) }\end{array}$ & 1000 \\
\hline
\end{tabular}

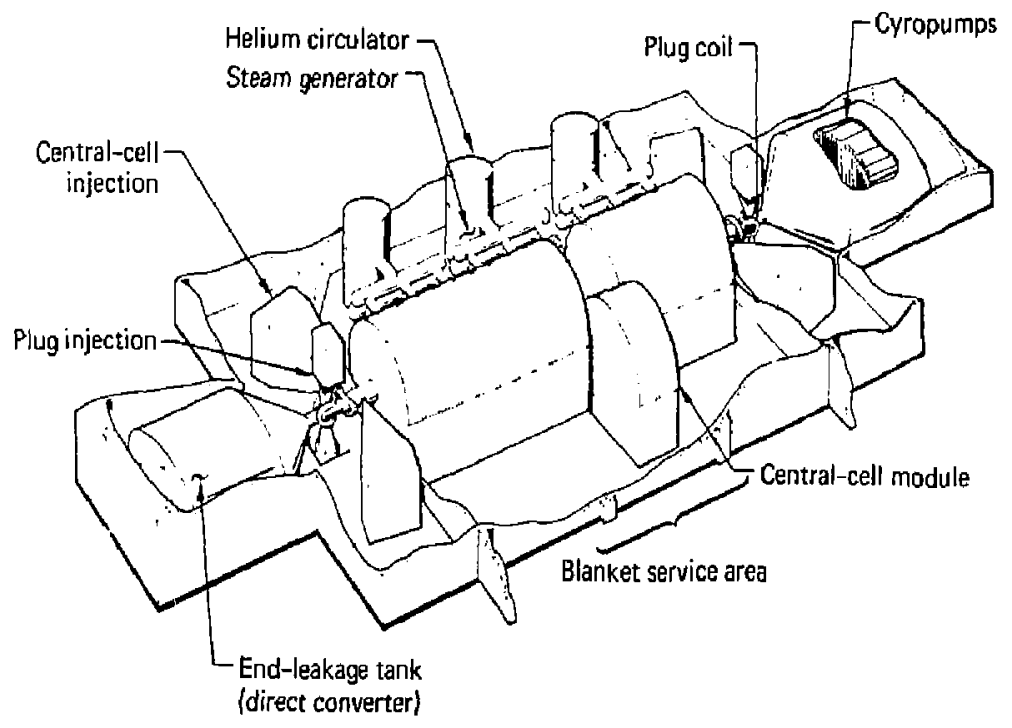

Fig. 2. This tandem mirror hybrid reactor requires ueutral-boam injection al $125 \mathrm{keV}$ in its end plups, Based on a low-technologs version of the indem mifror reactor, this hybrid requires a maximum magnetic field of $8 \mathrm{~T}$. 


\section{References}

1. D. J. Bendet, J. D. Lea, W. S, Neef, R.S. Devoto, T. R Gallowsy, J, It Fink, W. L. Dexter, K. R. Schuliz, D. W Culver, S. B. Rao. and S. R. Rav, Referenic Design far a Fusion Brecder HIIbrd, Reostor, La'difence Livermors Laboratory and General Atome Co.. sepl. in preparation.

2. C. M. Van Altd, J. D. L.ce and W. Heck rolls: The Flectrot

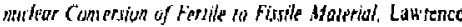
l. ivermore Laburutor), UCRL-52144 (1976).

3. D. J. Btnder, " $\Lambda$ Review of the Mirror Hybrid Reactor, "in Proc. LS/LSSR Warkshap Hybrid Reaciar Desigh, Muscen: CSSR W97T); also Lawrence Livermore J.uboratory, UCRI,79548 \{1977\}).

4. B. Augenstein. D. Dreysuss, W, Mooz, and P. Sher, 4n I. -

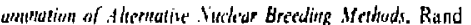
Corp. Santa Wunita. (alif., R-1267-leRDA 18977).

\$ D. J Bender. J. D. Lee. W. S. Neef. R. S. Devolo, T, R Golloway. W. L. Dester. M. A. Hoflman, J.H. Fink, K. K. Schull, D. Culver, S. K. Kao, S. B. Rus, and W. I: Kestenberg, "A Reference Misror Hybrid tousion-Fission Hesctor Design," Trams. Amt Nudt Sisc: 20, 55 (1977); also lakr nce livesnore Lahuralor, UCRL.79093 (1977).

6. D. J Bender, J D. I.e. W. S, Net, R. S. Devoto, T. R. Gallusaz, I I1. Fink, K R. Schuliz, D. Culver, S. R. Rao.

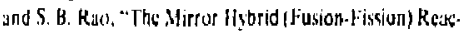

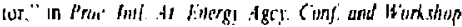

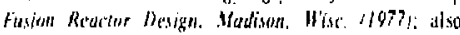
I.aurenes Iivermore l.abutatory. UCRL-80076 (1977).

7. 5. R. bisten. D) J Bender, J. H. Fink, and J. D. Lee, "Hechanical Denign Crileria for Continuously Operating Noutral Beems." in Proc. 7th Symp. Eng. Proh Fikfom Res. Am.sville. Tenn 1/477; also Lanrence Livesmure Loboratory. Lt RL-79730 (1977).

\&. D. J. Bender, J, D. L.v, K. R, Schulk, and S. B, Rao, "Fust Iesign Considerations for the Mirror thybrid Reatus," Trams ten its. fic 27,34161977 .

9. D) H. Culver an 1 W'. S. Nere, "Mechanical Structure of the

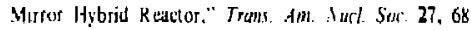
1]971)

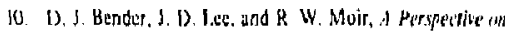

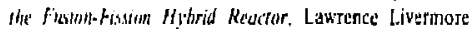
Laboualory. U(ID)-17622 (1977).

11. I). J. Bender. "M rror Hybrid Reactor Sludiss," in Prok

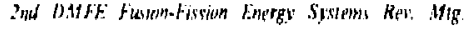
Washingeos, $b C^{\prime}$ 1937: also Lawtenet Livermore laboratory, UC RL-20694 in prepusation (1977).

12. J D. Let. "Nucledr Design of Ilybud Blankels." in Proc. Ind D.MFE Fuidn-Fussiun Energf Systems Rev. Wig.

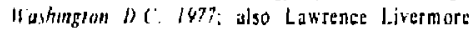
l.sburalory. UCRI.8065) in prepatation (1977).

13. D. J. Bender, J D. Lee. and R. W. Moir. Preliminary

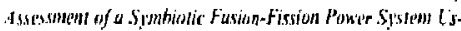
ing the $T h / C$ Regresh Fud Clote, Lawence Livermure taboratory, UCID.17607(1977)

Author

D. J. Bender

\section{Small Mirror Reactors}

We joined with General Atomic Company and Pacific Gas and Electric to work on a "small reaçtor" project lunded by the Electric Power Research institute. The objective of this project was to evaluate mirsor fusion concepts that might result in small tedators for the production of electrical power or fuels. The two-year program goal was to develop a conceptual design of a particular mirror concept that could provide a useful output from fusion and be buill and operuted in the late 1980's. Our first year's work (which officially began in May 1977) involved a scoping study of several reaclor options. The second year's work will consist of a conceplual design study of one selecled option.

One of the early accomplishments was the adoption by the three conlractors of a set of general guidelines for the project. We agreed that "small" meant physically sinall and low cost, and that the mirror reactors to be designed should be is small as possible consisient with a requirement for net product production and commerical upgrade potential. Recognizing the at iractiveness of a low-power commerical reactor, we agreed that commerical upgrade could be through replication of small units. addicion of modular elements, possible near-term advances in technology, or (as a last resort) scaleup beyond 100 to $200 \mathrm{MWe}$ or the equivalent. We also agreed that it would be highly desirable if the technologies to be incorporated into the designs be limited to those expected to be available by the mid1980 's, bused on presently committed restarch and development programs

For the period covered by this annual report. we directed our effort on the project mostly at paramuter studies of tinee basic mirror confinement concepts: the standard mirror, the tundem mirror. and the field-reversed mirror. In eich cisc our goial was the specification of a sel of plasma parameters and technological parameters (field strength, injec(ion energy. etc.) appropriate for design of the snall reactors.

Out previous studies indicated that for the standadd mirror to have a commercial fulure it nust be a fusion-fission hybrid. Our parameter studies thus concentrated on hybrid standard mirror reactors.

The proposed design for the small standard mirror hybrid is significanly different than that for previous standard mirror reactors (the magnet shape is cylindrical rather than spherical). The minimum-B magnelic well is provided by the combination of a pair of solenoidal magnels and four loffe bats. We believe we can design a smaller reaclor with this magnet than with the spherital fyinyang) magnet. We are designing this machine as a net-product producer (pown- generation by bred lissile fuel in fission reactor $>$ electrical input into hybrid) rather than a net-electric power producer.

The Tandem Mirfor Reactor we designed for the Department of Energy had high end-plug 
technology-1.2-MeV beams and 17-T rils-well beyond the goals of our presently commuted beam and magnet programs. Relaxation of the plug technology quickiy resulted in a system that didn't work for the mode of operation chosen, i.e., energetir: injection of the end plugs only. This led us to conside : in wher mode of operation-energetic injection of the end plugs and the central cell. We are now investigating the use of a $\mathrm{tw}$. smponent tandem mirror with central-cell injec . II as a basis for at small hybrid reactur.

For the field-reversed mirror (FRM) concept, we are investigating a single-cell version of the multicell FRM reactor design. Most of the work to date has involved incorporating various improvements in the parametric design code for the FRM (especially addilig "end effuts" so that it can correctly treat the one cell cases. Our conclusions are not yet final, but it appears that we cun still expect a high fusion power,injuctor power $(Q \sim 4$ or 5) for the FRM plasmia.

Author

G. A. Carlson

\section{Neutral-Beanı \\ Development and Technology}

\section{Introduction}

The injection of intense beams of hydrogen and deulerium utoms is at present the best way to heat and fuel mirror and tokamak plasmas. Experiments now operating, of under construction, require injection energies of 20 to $120 \mathrm{keV}$. Ten vears from now energies as high as I MeV may be needed. (Beam power from a single injector is in the range from 1 io 9 MW

The neutral-beam program to develop these injeztors has several elements, including

- Design, construction, and operation of test facillties.

- Det lopment ind testing of neutral-beam systems bast $f$ on the acceleration and neutraliza-

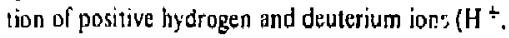
$\left.D^{+}\right)$.

- Development and testing of neutral-beam systems based on the acceleration and neutralization of negative ions $\left(\mathrm{H}^{-}, \mathrm{D}^{-}\right)$.

- Design and testing of prototype beam lines.

- Transfer of technology to industry.

\section{Test Facilities}

These continue to be the pacing items of the program, as we go to higher currents and longer pulse lengths. Table 1 lists the tes: stands suitable for development of high-power beams with energies of 80 to $200 \mathrm{keV}$. These test stands must have high pumping speeds to handle the gas loads from the ion sources and neutralizers. Because the accelerator strutures are relatively fragile and must handle very high power, one must use reliable diagnostic and control techniques to prevent damage to the injectors and experiments to which they are attached.

Test Stand IIIA. The only high-voltage, highcurrent, long-pulse operational neutral-beam test stand in the U.S., IIIA has been used for testing a variety of beam-line concepts and components for about a year. In the process, the viability of a new approach to the regulation and switching of the high-voltage power-supply output has been proven. Conventional designs require tubes that don't exist yet, but necessity led to the development of "shunt controlled" systems I using off-the-shelf silicon. controlled rectifiers (SCR's). The later IIIB and the Tokamak Fusion Test Reactor (TFTR) NeutralBeam System Test Facility high-voltage systems ${ }^{2}$ use the same basic design. The IIIB SCR swiches ${ }^{3}$ appear in Fig. I.

A second electronic innovation successfully tested on IIIA is a "nlagnetic core snubber." 4 Our tests show that injector performance degrades if more than a few joules of energy are deposited in the accelerator electrodes when a spark occurs. $4120 \mathrm{kV}$ the energy stored in the stray capacitance of the source, cables, and other electronics exceeds this limit by an order of magnitude or more. Figure 2 shows a circuit to limit the damage caused by a spark. The magnetic core snubber limits peak curtent during a neutral-beam source spark to $\leqslant 200 \mathrm{~A}$ and limits the energy delivered to such a spark to a few joules. The snubber absorbs the remainder of the stray-capacitance energy in core losses governed by time-dependent eddy-current and hysteresis processes.

Table 1. High-voltage test facilitics.

\begin{tabular}{|c|c|c|c|c|c|}
\hline \multirow[b]{3}{*}{ Incility } & & & & \multicolumn{2}{|c|}{ Vucuuin system } \\
\hline & \multicolumn{3}{|c|}{ Elcetronit's } & \multirow{2}{*}{$\begin{array}{c}\text { Deuterium-gats } \\
\text { vol (liots) }\end{array}$} & \multirow{2}{*}{$\begin{array}{l}\text { Punping } \\
\text { sperd } \\
\text { (limes/s) }\end{array}$} \\
\hline & $(k v)$ & (A) & (s) & & \\
\hline $\begin{array}{l}\text { Test Stand } \\
\text { III A }\end{array}$ & 120 & 20 & 0.5 & 170000 & 60000 \\
\hline $\begin{array}{l}\text { Iest Stand } \\
\text { III H }\end{array}$ & 120 & Bo & 0,05 & & \\
\hline High-Vultage & 80 & 85 & 30 & & \\
\hline Test Stand & 120 & 65 & 30 & 20000 & 650000 \\
\hline (HVTS) & 200 & 20 & $d c$ & & \\
\hline
\end{tabular}




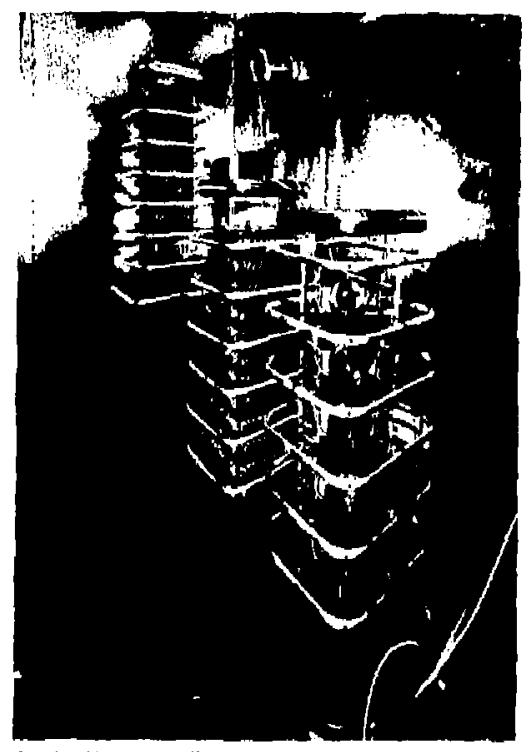

Fig. 1. Silicon-contralled rectifier switches for Test Stand III B (the IIl t syntent uses the same basic design). The scrics snitsh is an the right, lise shunt switrhes are center and loft.
The capability of our conputer ilszlallation to process diagnostiz data and control power supplies and other system components has been expanded considerably. Members of the Draper Laboratory. in cooperation with the Lawrence Berkeicy Laboratory (I.BL) Real-Time Systems Group, have developed soitware to optimize and condition injectors, 5 The computer has successfully interpreted diagrostic signals und has adjusicd powersupply controls, but has not yet been allowed wo "push the bution." This slep is inminem.

Test Stand IIIB. This test facility has the first all-solid-state, high-power neutral-beam system built. It became perational in the summer of 1977. powering and cuntrolling ouf first full-current TFTR source.

High-Voltage Test Stand. The neutral-heam High Voltage Test Stand (HVTS) neired completion at the end of the reporting period. Most components had been installed or Here being bench tested, and much of the stand had been tested in place.

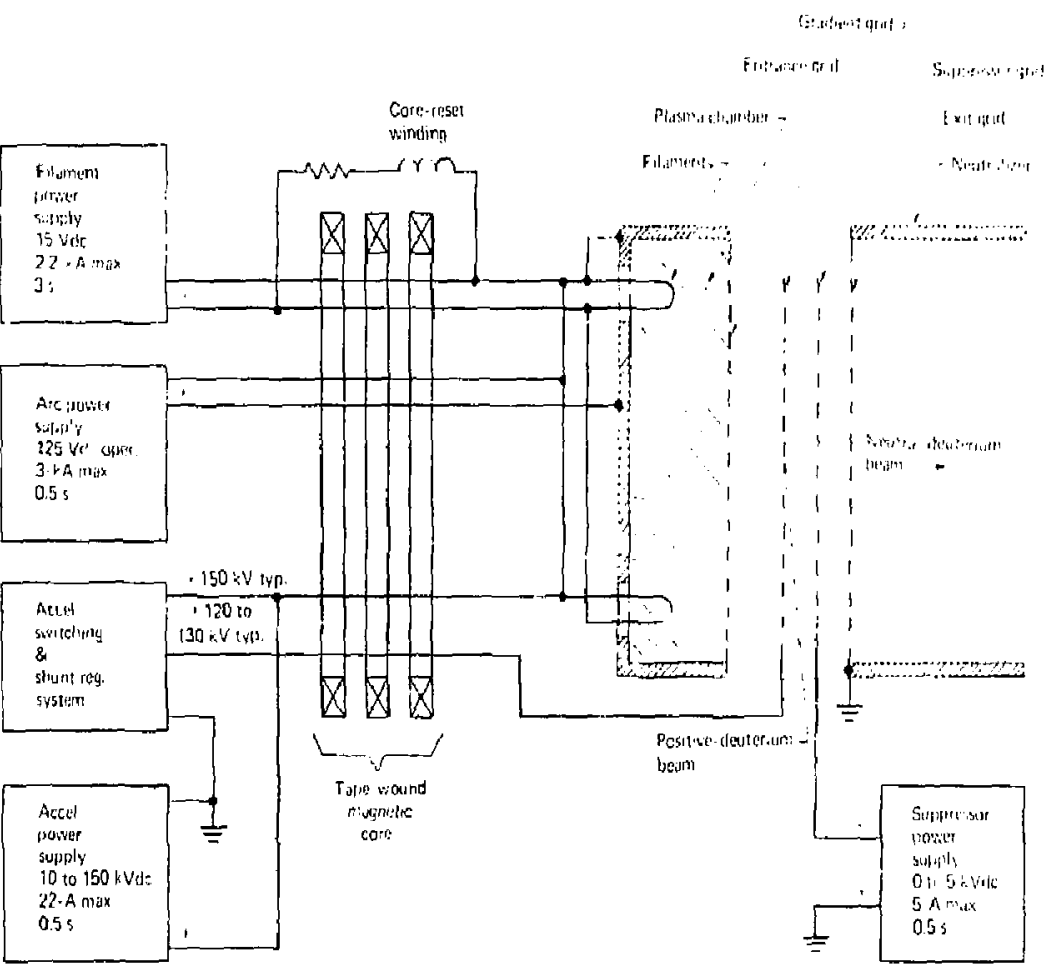

Fig. 2. "Magnetic core nubber" sircuit for limilimp spark dattage in neutral-beam injector. The snubber limits pesh curreti during a neutral-heam source spark to $\leqslant 200 \mathrm{~A}$. It also limits the energy delivered to such a spark to $\mathrm{fer}$ joules. 


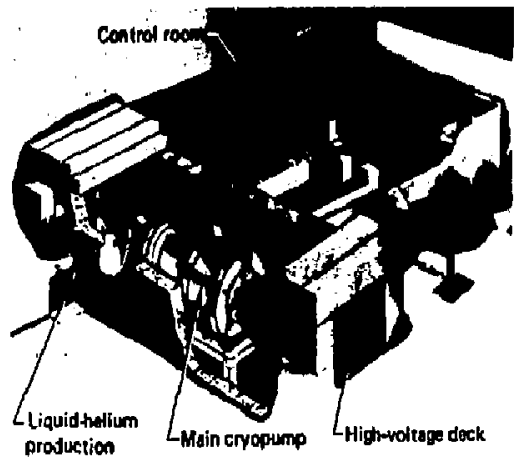

Fig. 3. High-Yoltage Tese Stand (IIVTS) for derelopment of high-poner neul ral beams. Tn shicld petsonnel firom neutroa radia* tion, we placed the bearn line in a conerete room. A hightroltege power supply (ant shown / sits in a pad area about, 30 mo to the left of the nasin styupump.

An arist's concept (Fig. 3) shows the beam line installed in a cuncrete room to protect personnel against neutrons from D-D reactions in the beam dump. A latge control room is adjacent to the shielded room. In a umaller adjacent room, we produce liquid helium for the cryopumps. Lowvoltage power supplies (arc and filament) are mounled on a high-voltage deck near the main cryopump. High-voltage power comes from a supply constructed in a pad asea outside the building.

Building modifications to accommodate the H'TS facility are complete and all major componerits are in place. The high-vacuum system, which combines cryopumping and high-speed mechanical pumping. is essentially complete and all components have been tested. The entire beam line has been ussembled and leak tested. Figure 4 shows the beam line during assembly.

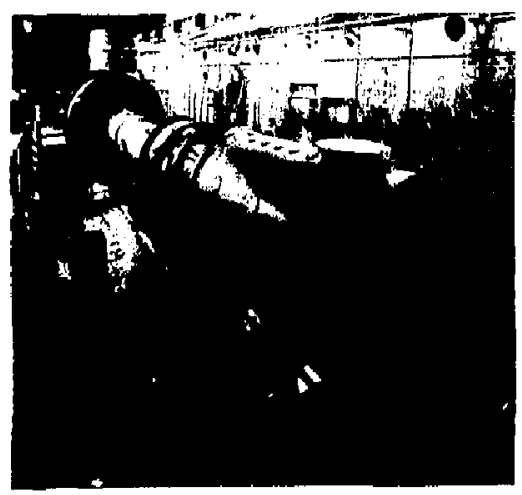

Fig. 4. Beam line for HIVT. The view shows the beam line during ussembly; the beam Jump is, mutunted in the open tank (right).
We operricd the main cryopump and its associated fefrigeration system for $\sim 1000 \mathrm{~b}$ without serious problems. Pumping speeds of the main cryopump for deuterium and hydrogen were meilsured on two occasions: these speeds exceeded the predicted value ( $\$ 00000$ litres/s for deuterium), although variations in gas pressure through the system made accurate measurements difficult.

We made liquid-helium boil-off tests on the main cryopump. Measurements indicated a heul lond of ut least twice the predicted load of $4108 \mathrm{~W}$. We could not explain this by poor estimates of surface emissivities. Visual inspection, during and after final assembly, indicated no glaring deficiencies. Since the system is operational and meets pumping requirements, the problem was corrected by increasing the liquifier capacity by adding a third compressor.

A thermal inertia-type beam dump was designed and is under construction, This consists of two large water-sooled copper plates in a V-type configuration having a variable half-angle of from 7 to 10 degrees. It will be instrumented with in array of thermistors into a computerized readout system yielding beam-profile information. The target is designed to hundle a pulsed beam loald of as high as $8 \mathrm{MW}$ for $30 \mathrm{~s}$.

A neutralizcr was fabricated and is curreitly mounted on the test stand along with a 20-kV source (Fig. 5). Preliminary testing with this source is underway.

The main power supply (Fig. 6) is designed for operation in three modes:

$$
\begin{aligned}
& 200 \mathrm{kV}, 20 \mathrm{~A}, \mathrm{dc} . \\
& 120 \mathrm{kV}, 65 \mathrm{~A}, 30 \mathrm{~s} . \\
& 80 \mathrm{kV}, 85 \mathrm{~A}, 30 \mathrm{~s} .
\end{aligned}
$$

Power can be provided wilh either polarity. We have completed the power supply and tested $\mathrm{i}^{\prime}$ at

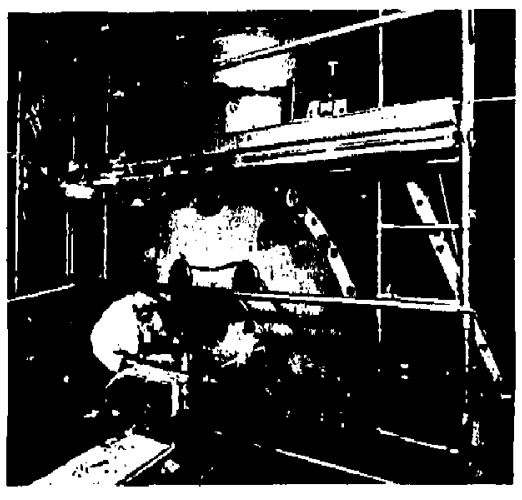

Fig. S. Neutralizer and 20-kV source mounced on HVTS. We began prelimioary testing Hith this source. 


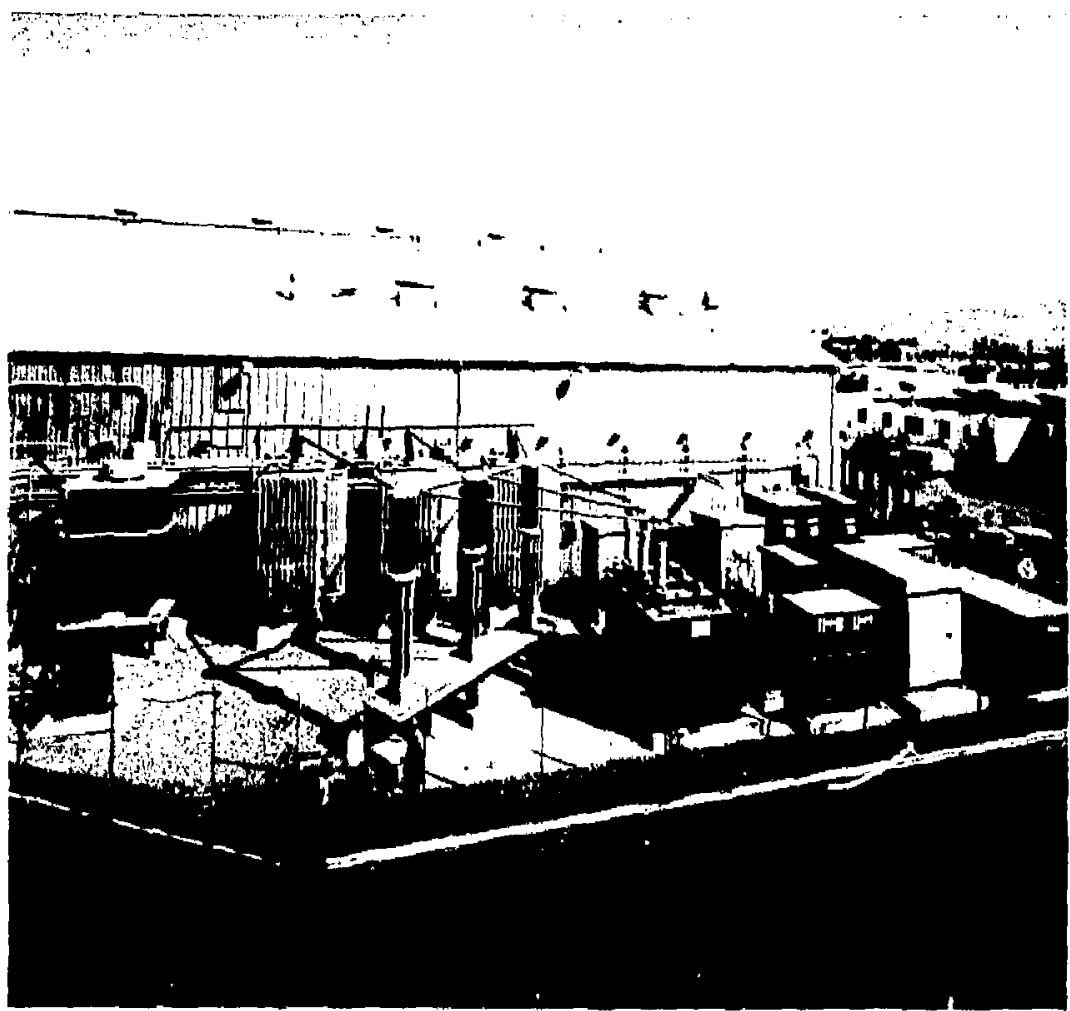

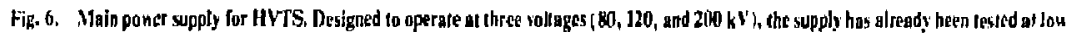
soltage.

low voltage.

Delivery of the newly developed switch/modulator was delayed by complications during construction at the factory. A lower voltage tube, usable to $40-k \mathrm{~V}$ source vollage. is being installed for preliminary operation.

We used are and filathent supplies to operate an arc in a chamber. The supply ratings are
filament:
12 V, $7500 \mathrm{~A}$.
Aic: $\quad 60 \mathrm{~V}, 7500 \mathrm{~A}$.

The supplies can operate at full load for $30 \mathrm{~s}$, with a duty sycle of $10 \%$ for cooling. Power comes from battery banks rated at $120 \mathrm{~V}, 200 \mathrm{~A}$-h for the arc and $24 \mathrm{~V}, 5000 \mathrm{~A}$-h fur the filament. Recharging is done belween operating pulses and/or during evenings or other test standdown limes.

\section{Positive-lon-Based Program}

We made a large. encouraging step upward in voltage and puise length by achieving successful operation of a fractional-area TFTR source. TFTR sources ase rated at $120 \mathrm{kV}, 65 \mathrm{~A}, 0.5 \mathrm{~s}$, deuterium.
To minimize cost and time, we do aur basic development with structures that correspond to the full-size sources in ill respects, excep! that they are reduced in one dimension (transverse in the beam direction). In this case. the fractional-ared source current (power-supply drain) is 12.1 .

With grids shaped to locus the heam $8.5 \mathrm{~m}$ from the sousce, we obtained aregular divergences. characterized by half-uidlth to the lie power puints, of $\pm 0.42^{\circ}$ partaltel and $\pm 1.28^{\circ}$ perpendicular to the long dimension of the accelerator slots.

These divergences, while acceplable for near-lerm applications [i.e.. TFTR. Doublet III tokamuk (DIII), Mirtor Fusion Test Facility (MFTF)], are somewhat larger than predicted from 20- and 40. $\mathrm{kV}$-source operation. A new spectroscopic technique $^{6}$ for measuring neutral-beam diverg.nces. species nixlures, and encrgies has given pretiminary evidence that the ungles increase as the beam transwerses the neulralizer: i.e., we may be seeing the resuit of a beam-plasma interaction. 
Figure 7 shows a fractional-area TFTR source, enclosed in a pressurized sulfur-hexaffuoride shroud and mounted on our IIIA test facility. A plasma source provides the ions for acceleration (Fig. 8). Figure 9 gives a cross section of the plasma source and accelerator structure.

Similar structures are being built and tested for MFTF $(80 \mathrm{kV}$, deuterium) and DIII $(80 \mathrm{kV}$, hydrogen) applications. The main differences are in the shapes and spacings of the accelerator electrodes.

We bujlt a full-scale TFTR source module and tested it to $60 \mathrm{kV}$. The accelerator structure (Fig, 10) uses epoxy insulators, which will be ceramic in the next model.

The plasma sources operate reliably and produce uniform, noise-free plasmas (Fig, 11), in part because they do nol have mags, , ic fields in the cen. ter. Unfortunately the atomic (most desirable) fraction of the hydrogen ions is approximately propor. tional to the are power. In the progression from 40to $120 \mathrm{kV}$ sources the atomic fraclion has dropped, parlly because of a deliberate decrease in ioncurrent density, and hence, arc power. We have shown previously ${ }^{7}$ that an extension of the scurce barrel (in the beam direction) can raise the atomic fraction from 65 to $88 \%$ and that the addition of multipole magnetic fields (to form a "MacKenzie bucket") can maintain the required plasma uniformity. The Oak Ridge National Laboratory Neutral-Beam Group has had good experience with these multipole arrays, and the Divertor and injecLion Tokamak Experiment (DITE) group at Culham also reports good preliminary results with sources of the general LBL configuration, but with MacKenzie-bucket magnets on the surface. In addi-

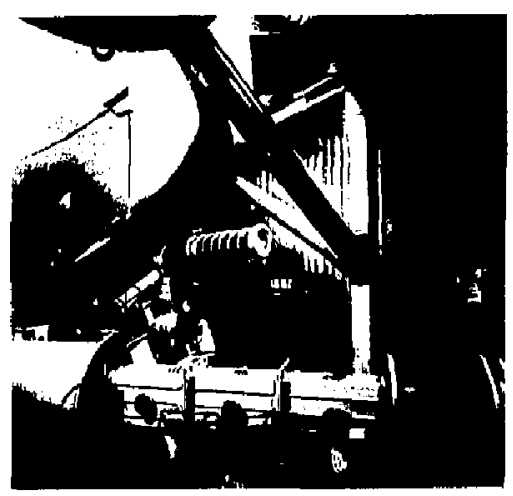

Fig. 7. One-half of beam line mounted on Test Stand IIIA. The sulfur-hexafluoride pressurized shroud (right) encloses a fractional-gren Toknmak Fusion Test Reactor (TKTR) 120-kV source.

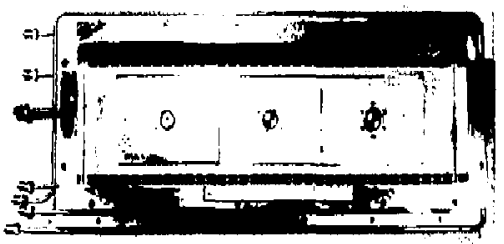

Fig. 8. Plasmn source for TFTR injector. This source provlds lons for acceleration.

tion to the possibility that the atomic species mixture may be bctter, we should be able to use fewer and thicker fildments or hollow cathodes (either one

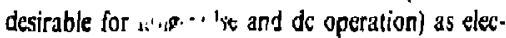
tron sourch. S. n ? intly, we have built a Mackenzie-b..k: 1 (....t , source (Fig. 12) to evaluale with ous il .0 -cm. 80- and $120-k V$ accelerator structures.

We tested several other neutral-beam-line design principles and components during the year. A cryopump was built and installed in the IIIA beam line to see if secondary particles from an intense. nearby beam would desort condensed gas ${ }^{8}$; no effect was obscrved. We prepared an experiment to expose this same pump to intense neutron and gamma liuxes at the pulsed Triga reactor of the $\mathrm{U}_{\mathrm{n}}$ iversity of California, Berkeley, Dept, of Nuclear Engineering.

We measured trajectories of the charged components of intense beams deflected by a sweep-magnet. These measurements were compared with calculations ${ }^{6}$ to determine if there are defocusing electric fields caused by incomplete space-charge neul ralizalion. No defocusing eiffects were observed.

\section{Efficient Beams}

Work continued on the efficient-beam (negativeion) program, whose purpose is 10 obtain intense, negative-deuterium beams: accelerate them to 10 to $200 \mathrm{keV}$; and strip the attached electrons to yield a neutral-deuterium $\left(D^{0}\right)$ beam produced at high power efficiency. $A 100 \mathrm{~mA}, D^{2}$ beam, produced by double charge exchange in cesium, was accelerated to $60 \mathrm{keV}$. $9-11$ We also worked on other beam-line components, on analysis of the beam, and on studies of a system using surface production of $\mathrm{D}^{-}$.

$1+k e V D^{+}$Source. As reported last year, ${ }^{12}$ 


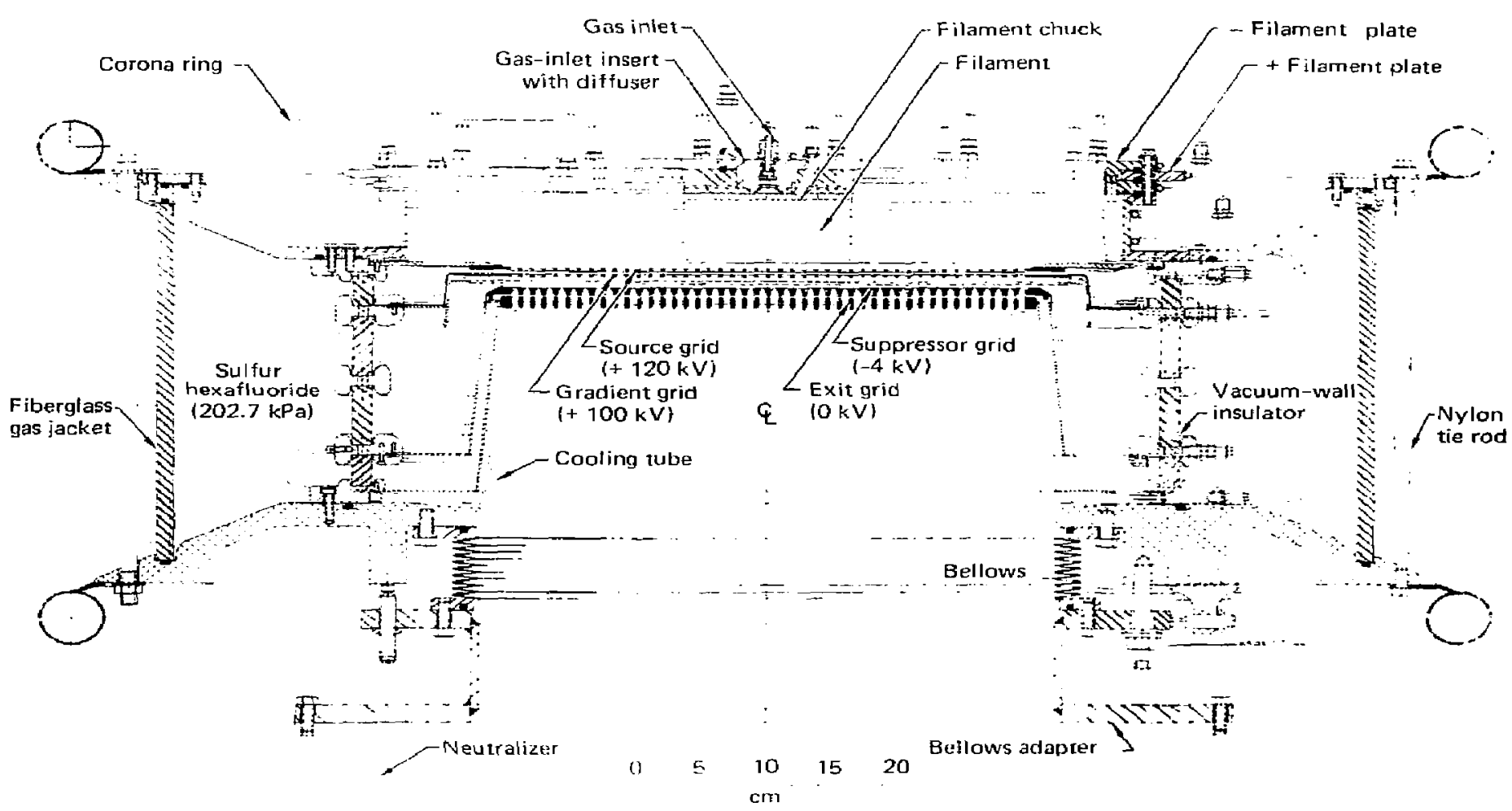




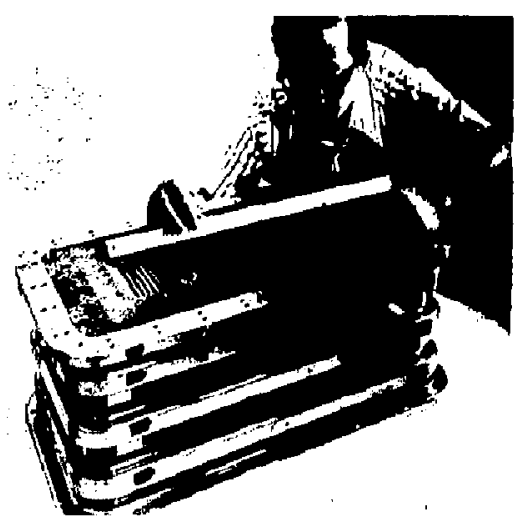

Hig, il). Full-sige accelergtor structure for TFTR. This structure uses epoxy inatators, which rill he ccramic in the next model.

20"\% ol a 1.keV D beam was converted to D - in csilum vapor. We used a modified LBL souree to obtain inlense ( ampere) $0^{0}$ beams at I keV. Since the eurrent densily increases with the voltage betweten the first and stcond grid $\left(\int_{\alpha} V_{12}{ }^{3 / 2} / \mathrm{d}_{12}{ }^{2}\right)$, we operalled the source in a strong accelerationdeceleration configuralion. In Fig. 13, a new grid,

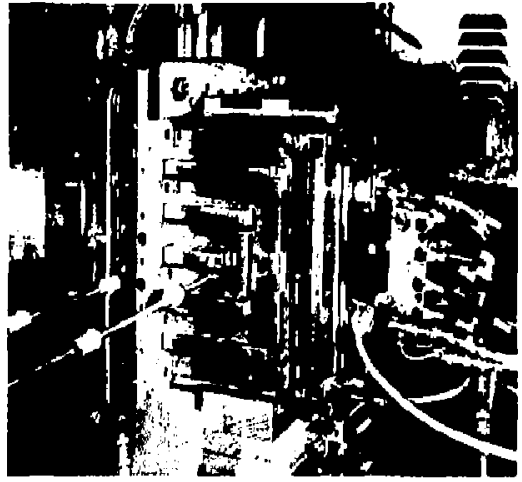

Fig. 12. "Mackenrie Bucket" plasma soure for 10.X-10-cm, RI- and 120-kV ion-source modules.

designed with the ajd of the computer code WOLF to optimize beam divergence, is sompared with the previous grid. For the configuration shown here, the ralculated beam divergence is $3.5^{\circ}$. better than that observed in the experiment. $\Lambda$ possible ex. planation for the poor beam divergence is that the beam must create its own background plasma for space-change neutralization, and at I keV this

Vertical profiles

Wall

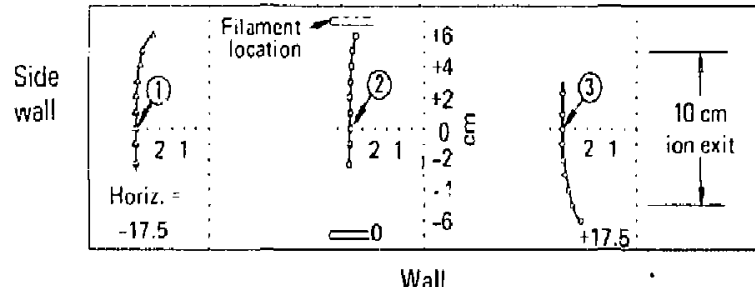

Horizontal profile
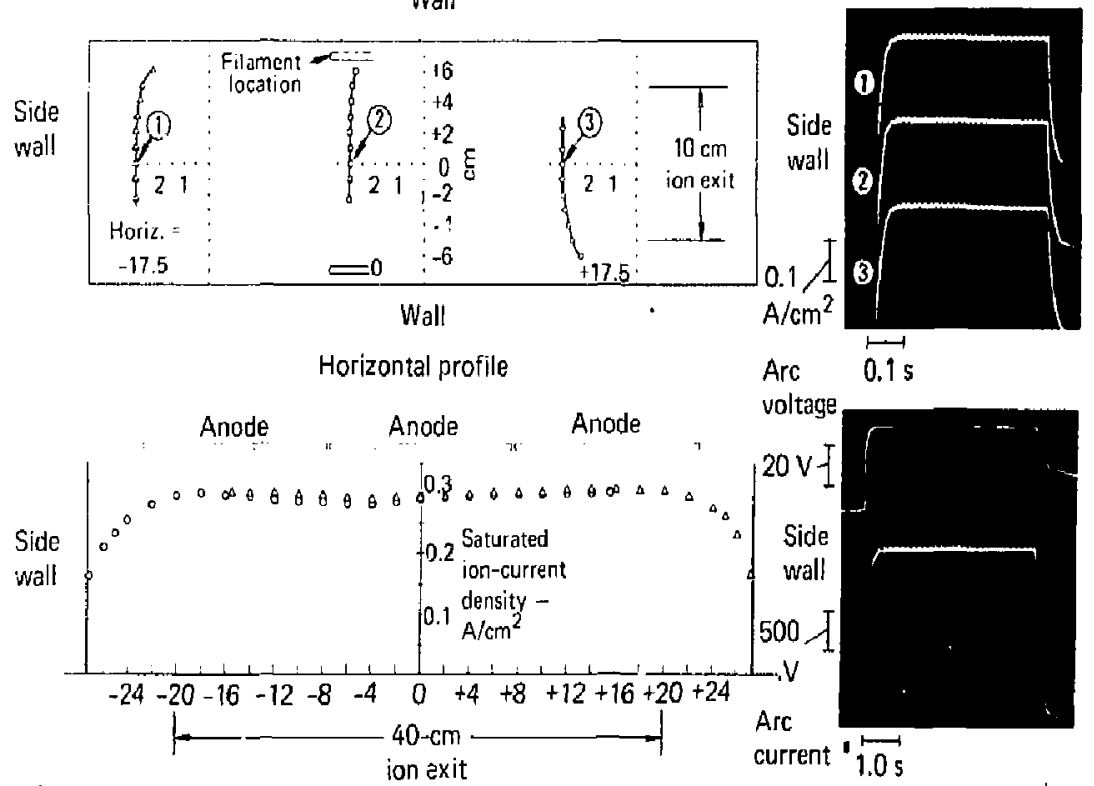

Fig. 11. lon-current density profiles for $10-x-40-e m$ extraction region. These profiles show that the current density is uniform to \pm 5 \& throughout the region. Oscilloxupe traces (lop right) indicate salurated-ion current wareforms of the three vertical probes. The boitcm right traces give the are wittage and current. 


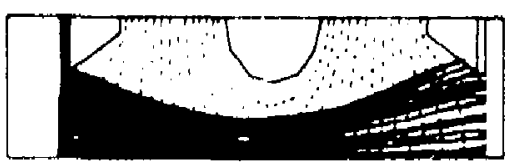

(i)

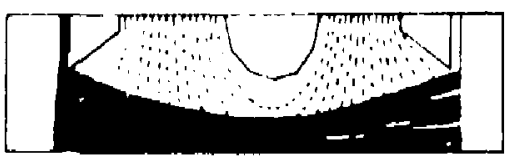

$(b)$

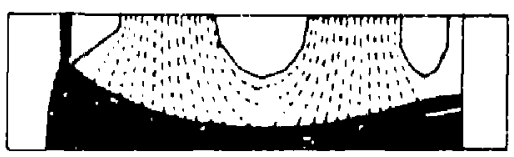

(c)

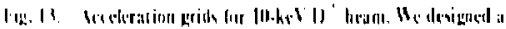

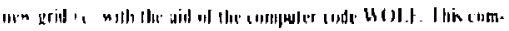

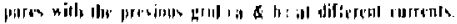

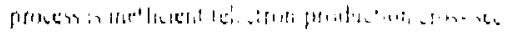

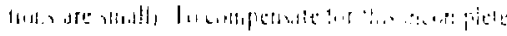

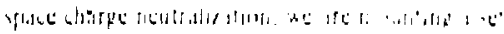

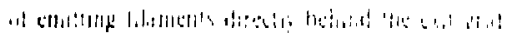

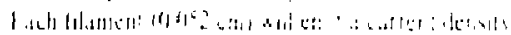

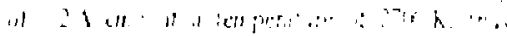

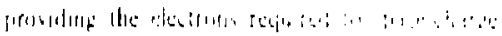

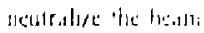

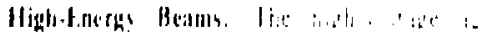

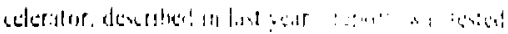

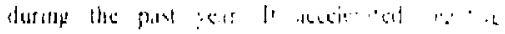

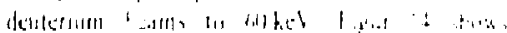

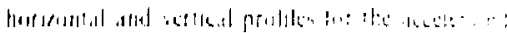

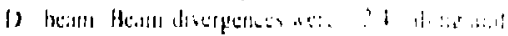

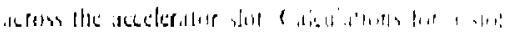

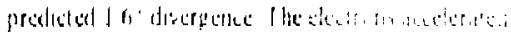

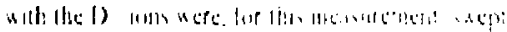

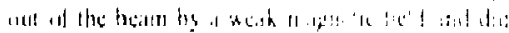

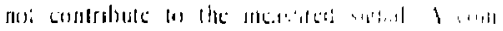

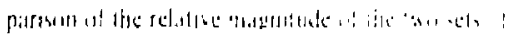

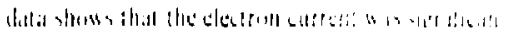

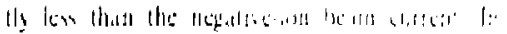

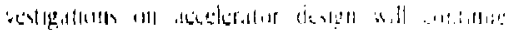
brouth like next !ce!t
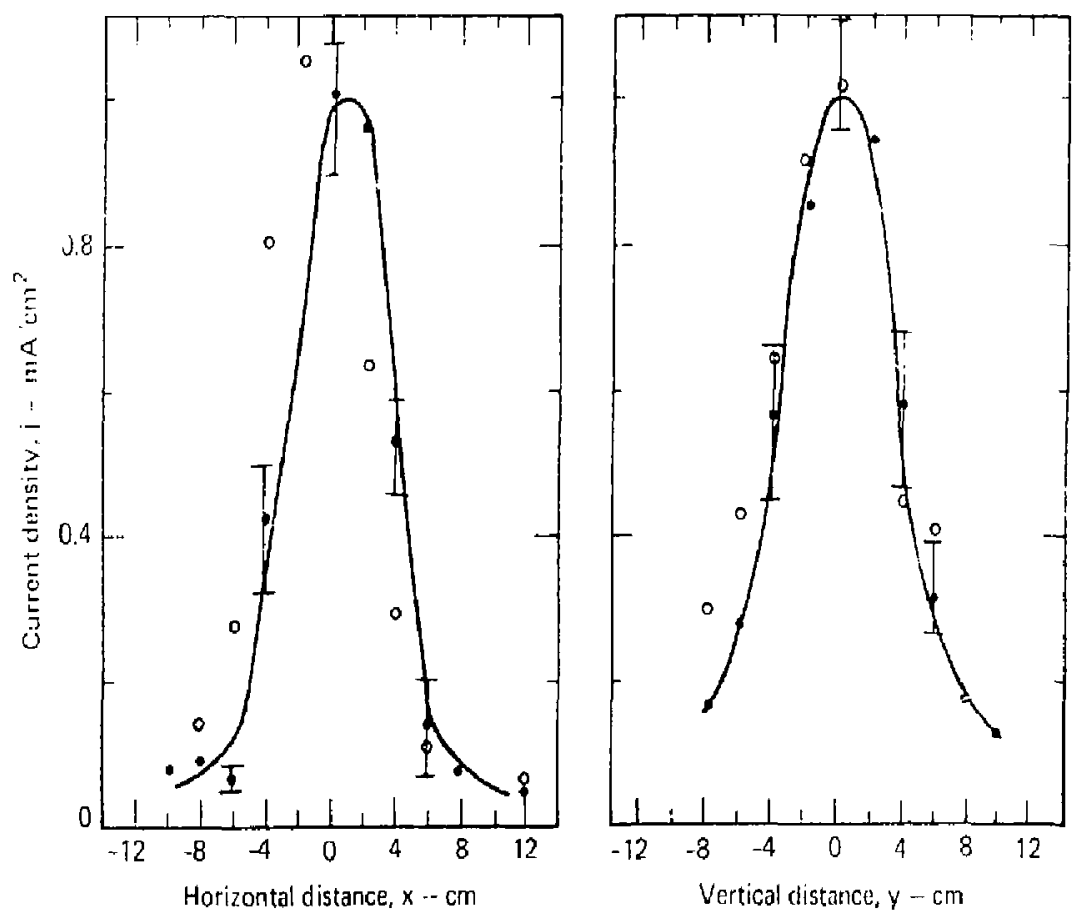

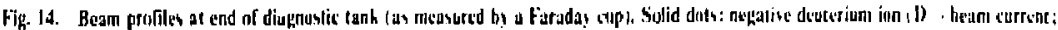

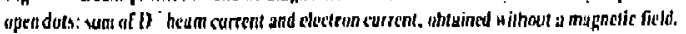


Plasma in the Negatikelon Beam. Backeround plasmat is essential to prevent space-charge blowup of the negative-ion hesm. We exlended the jon. dumensonil salculation of plasma now (reponed

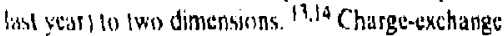
and sripping cells were modeled by an axial region of high gas pressure and ionization rate. The pressure outside the cell may be made low. corresponding to the region nesr a high-voltige ac. celeritor.

Typical computational results appear in Fig. 15. Vote that plasma density is high only in the region
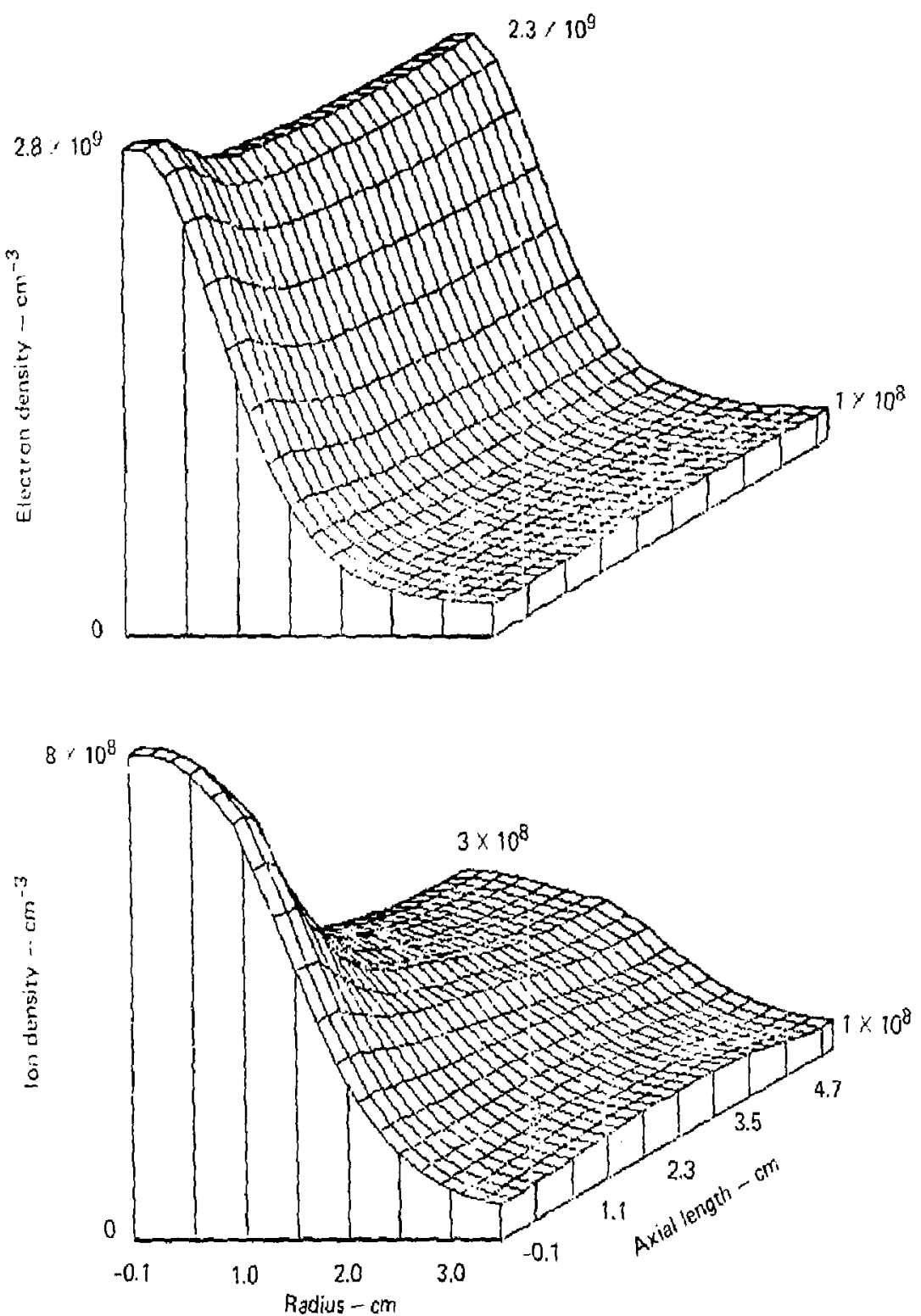

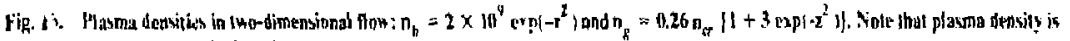
high onls in (he region of high ionjzation. 
of high ionization. Electrons and ions formed in that region escape to the walls within axial lengeths of a few beam radii. We used this transporl muchantism in the negative-ion experiment to limil electron current into the accelerator.

Similar results were seen in ti.e experiment. Figure 16 shows Langmuir-probe measurements; note that elestron density wals reduced to abous the beum density. As we calc lated, the electric field within the beam was small, which corresponded to the fat elecron profile. and the sesidence time of plasma : uns was long. which correspondud to a low production rate.

In this experiment, the low-energy (I-keV) $\mathrm{D}^{-}$ beam was required 10 , propagate $1.3 \mathrm{~m}$ from the cesium cell to the entrance of the high-voltage acceletator. The low-energy beum must be quiet in the region of the accelerator grids. We found that the background gas in the transport region must be greater than $\sim 4 \times 10^{-5}$ Torr of deuterium for stable propagation. Figuse 17 a and 1 ? 6 show Faraday-cup signals in the region of the accelerator entrance. In Figure 17a. here is a hackgrourid deuterium-gas density of $4 \times 10^{-5}$ Torr. Beam intensity is $3 \mathrm{~mA} / \mathrm{cm}^{2}$. and the beam is quiescent. Figure $17 \mathrm{~b}$ shows the $D^{-}$beam propagating in an ambicat background-gals densily of $\sim 1 \times 10^{-6}$ Torr. The average beam intensity is $-1 \mathrm{~mA} / \mathrm{cm}^{2}$. Noise on the beam has two "characteristic" Irequencjes: a high-irequency mode ( $\sim 3$ to $5 \mathrm{MHz}$ ) superimposed on the low-frequency mode $(200 \mathrm{kHz})$. These

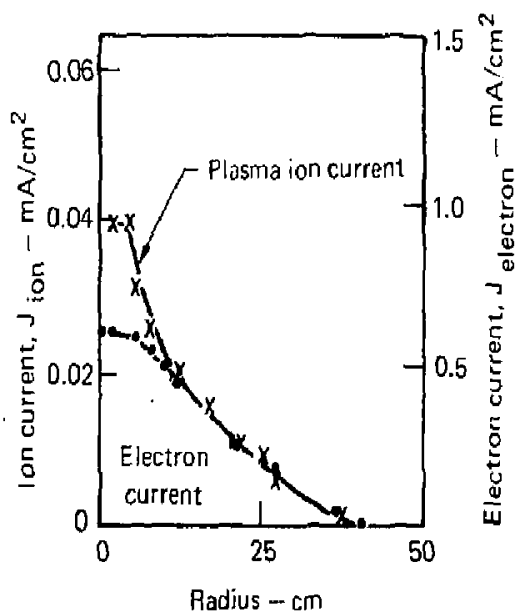

Fig. 16. Plasma densities ia a plasmu generated by a jokeY D beam. A shielded Lengmuit probe, which measured the densitics, was scanned radially $25 \mathrm{~cm}$ from the entrance of the drisi tank\}. The upper curve shous the ion current collected at - $30 \mathrm{~V}$ bias o seale on left: the lo her eurve shows the electron current collocted at $+5.5 \mathrm{~V}$ above the floating polential (scale on right). parasitic oscillations can be remuved simply by adding the appropriate amount of background gas. Preliminary analysis ${ }^{15,16}$ suggests that the unstable mode is an acoustic wave traveling almost transverse to the bean.

Jat Surface Conversion. We also sudied an alternate approach for making $D$ heams: the jet surfact-conversion system !? shown in Fig. It. Its essential feutuses are a supersonic jol of deuterium aloms and a separati. spetially trested cathode. The jel impinging on the cathode is converted $10 \mathrm{D}^{\text {- }}$ ions, which are acceleraled and neutratized is shuwn. A magnetoplasmady numic (MPD) arc ${ }^{14}$ and neulralizer ${ }^{17}$ efficiently produce the jut. Jor : calthode with an oplimum coating of cesiun, the surlace-conversion efficicncy $\left(D^{\circ}\right.$ to $D$ ) ) may approach 50\%, ${ }^{17}$ Relerence 19 discusses a method for producing and nasintining an oplimum citthode under working conditions. The acceleration grids. roughly indicalted in the figure, are similar to the TFTR grids being kested at L.BL: for a $200-\mathrm{k} u \mathrm{~V}$ system the current density would be aboul $0.25 \mathrm{~A} / \mathrm{cm}^{2}$.

Potentially, high powtr and gas efficiences may be possible for the overall system. ${ }^{17} \mathrm{~A}$ i present, $\mathrm{LBL}$ is conducting surface-conversion miasurements and LLL is tcsting an MPD are jet

\section{Prototype Beam Lines}

Protolype neurrat-beum lines, based on the positive-ion neutral-beum developmen and lechnology describud above. arc being built at LB! by the Engineering and Technical Survices Division. Members of LBL's Reswarch and Development Group interact on a regular basis with the engineering groups and with the staffs is Princeton Plasma Physics Laboratory. General Alonics. and the Departmenl of Energy's Division of Magnetic Fusion Energy.

\section{Technology Transfer}

Many fusion expe "ental devices and reactors will use lirge. multiple neutral-beam systens. A demonstrated industrial manufacturing capability is desired to determine reliable cost estinuttes and schedules. Three firms have completed indusirial manufacturing studies of 120-kV, 65-A, 0,5-s injector modules for us; we will receive hardwate for evaluation near the end of 1978 .

\section{Referentes}

1. D. B. Hopkins. W. R. Baker. and H. M. Orren. "A Shun Reguldtor for $150 . \mathrm{kt}, 20-4.0,5 \mathrm{sec}$ Neutsat-Besm Sourct PoH or Supplics," I, ith retice Berkelcy Laboratory, Herkeley. Calif., LHL-4152, presented at 9h Simp. Fus Tedind.

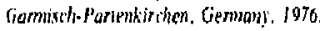




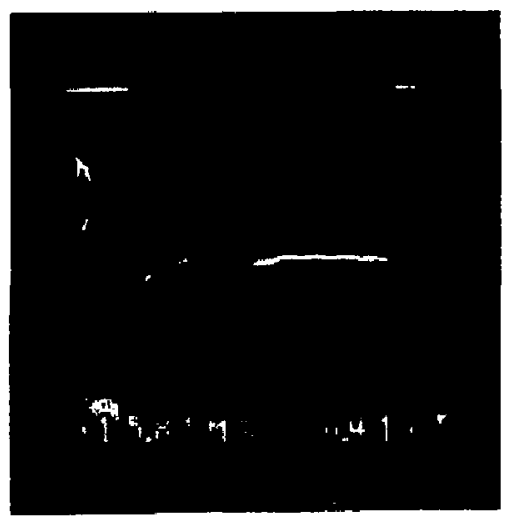

(b)

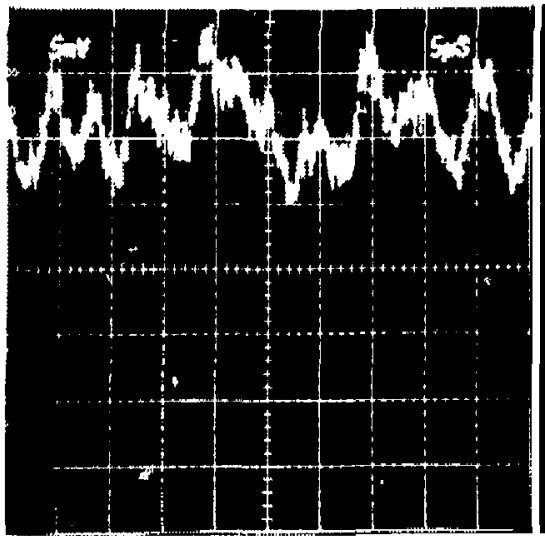

(c)

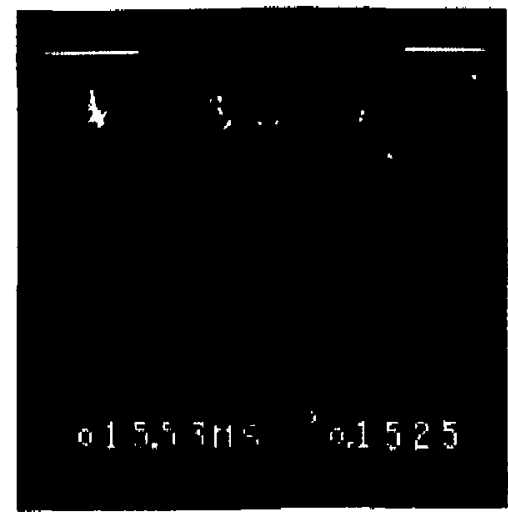

(b)

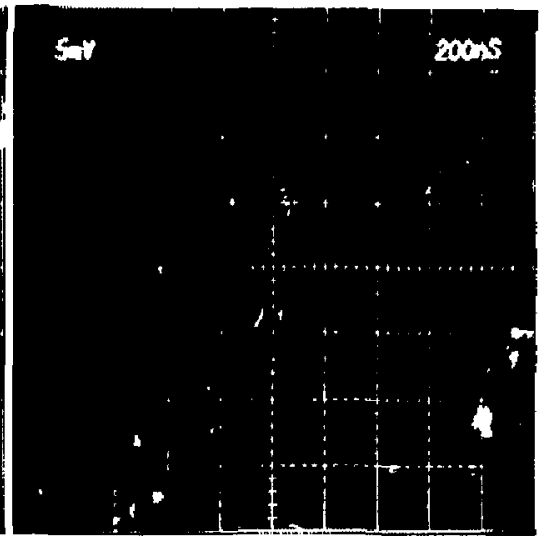

(d)

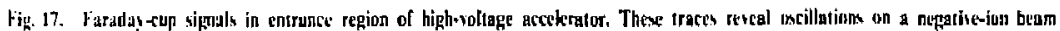

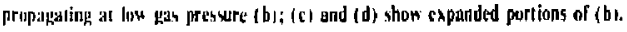

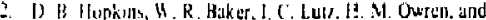

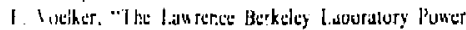

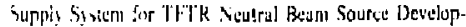

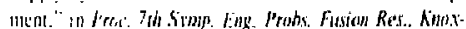

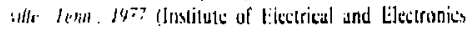
[ lugellets, Siew York. 1977).

1. I I I-ranth. A. A. Arthur. I.. A. Brusse, and W. Low, “, An

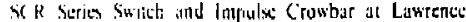
Berkeicy I anorilory for GTR Sieuiral Beam Sourot

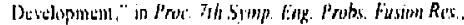

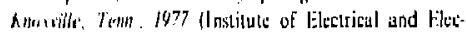
trunst Luginess. New York, 1977).

4. 11. R. Baktr and [J. B. Hopkins. "Present and Fiuture I tehnuloge af Itigh Voltage Sy stems for Neutril biam ln-

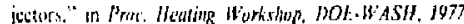
(1,S, 1) 1)

5. I. I. Shal $r$, K. H, Hevinger, and D. W. Kerne, "A Compuber Based Diagnoblic and Conteol Syslon for a $120 \mathrm{keV}$

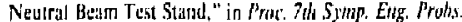

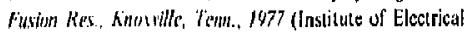
and Electronics lingineers, New York, 1977).

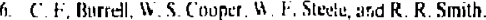
"Cadorimetric and Op'itorl Beam Iliagnosticy on the L.BL, 120-kel Neulal Beam Tes lateilty," in Mrik ith Symp.

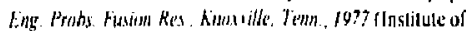
Electrical and I:Actronis linginecrs. Sce York. 1977).

7. I. G. Brown, K. H. Burkner, H. B. Kunkel. and R. V. Pyle. "10-imp Sisutra! Beam Sourct Lsing a Packet-Fence

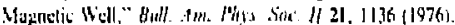

8, K. H, Berkner, P. K. I.au, R. V. Pyli, L. Ruh?. L. C. Pit tereer and I., V.. Valby. "Cryupusip. Neursal-Ream Conpatibilily Test.' Troms Am. bial Sis. 26. 73 (1977)

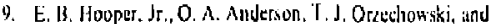
P. Poulsen, "Sixly-keV D" Beiluns L'siugg Double Cbargelexchange System," in Pros: Simp. Heg. Lon Bewms. Upton. New York. 1977 (Bruokhaten National Laboralory, Up. lont. Niew York. 1978).

10. O. A. Anderson and E. B. Hooper, Jr.. "Plasma Production and Flow in Negalive lon Beams," in Prac. Symp. Neg. Ion Beams, Uplon, New York, 1977 (Brookhaven National Laburatery, Upton, New York, 1978).

II. T. J. Orzechowski. O. A. Anderson, D. Birdsall, E. B. 


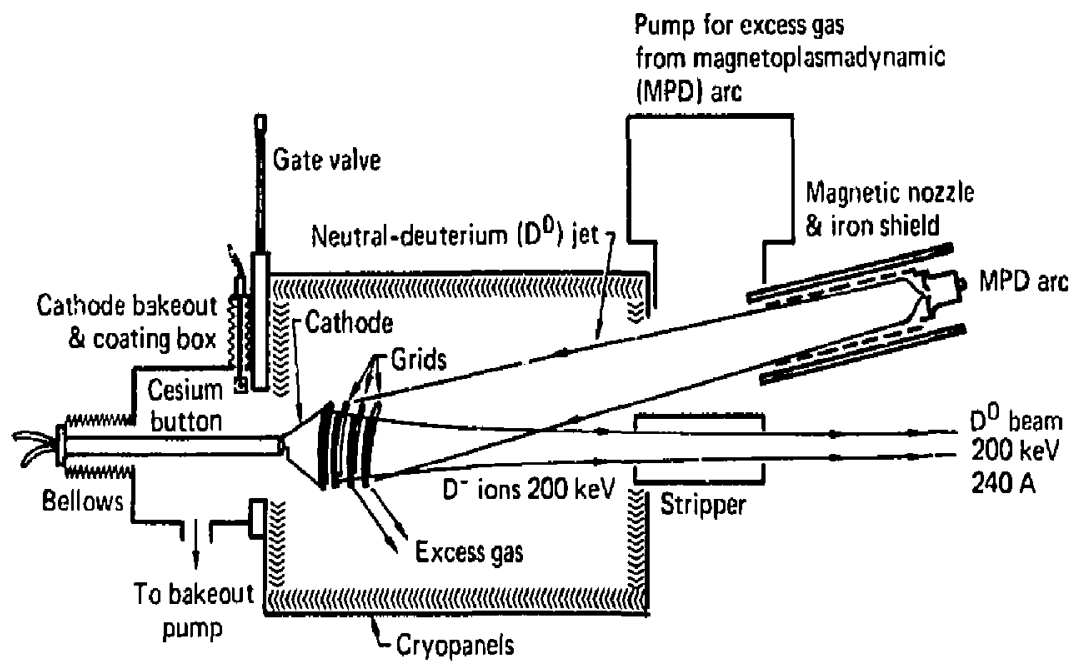

Hig. 18. Proposed neutral-beam system based on surface source of $D^{*}$ bons. It feutures a supersonic jel of deulerlum utoms (movinge from right to Ir't) and a specially tscated cathode (left of center).

Hooper, Jt., P. Poulsen, R. Spoerikin, and R. Turnbull. "Production of High Ënergy Negalive lon Beurns Using Double Charge Lxchunge," Bull. Am. Phys. Soc. 22, 1043 (1977).

12. Magnetic Fusion Energi' Annual Repond, Jidj 1075 throught September 1975, Lawrence L.jvermore Laboratory, UCRL. $\$ 0002-76(1976)$.

13. B. B. Houper, Jr. and P. A. Millmann, Plasma P'rudiction and Flow in ton Beans, Latrence Livermore Laboratory, UCID. 17559 (1977).

14. I. B. Hooper, Jr., O. A. Anderson, and P. A. Willmann, journal article in preparation.

15. F. B. Hoaper, Jr., Beam. Mlasing Imstability in lon Sy,sems L'sed in Netural Beam Generation, Lawrence Livernors Luborstory. UCID-17404 (197i),

16. R. J. Turnbull and E. B. Hooper, Jr., "Stabllity of SpucsChange Neutralized Beams," in Proc. Symp. Neg. lesn Beprns. Uplon, New York 1977 (Brookhaven National Laborutory, Brookhaven, New: York, 1978).

17. 0 . A, Andersun, Efficient, Eulerseric Nenural-Bean Source Using Surface Cansersion (1) $\left.100^{\circ}\right)$ of a JPI, Lawtence Livermors Laboralory, UCID.17282 (1977).

18. P. Poulsen and O. A. Anderson, Lawrence Livermore Laboratory rept. in preparation.

19. 0. A. Anderson. Cexiun-Tungsten Cathode for Surface Production of D", Lawrence Livermore Laboratory, UCID. 17583) (1977).

\section{Authors}

R, V, Pyle

E. B, Hooper, Jr.

\section{Rotating-Target Neutron Source-II}

Construction of the Rotating Target Neutron
Source-Il (RTNS.II) facility continued through FY 1977. This facility was an FY 1976 federal-budget line item to provide two $14 . \mathrm{MeV}$ neutron sources, each producing $4 \times 10^{13}$ neutrons/s for Division of Magnetic Fusion Energy (Department of Energy) investigation of fusion-reaclor materials. During FY 1977 we brought the new building that houses the neutron sources to $\sim 80 \%$ completion. Bids received during the phased-conseruction sequence were so favoratle that it was possible to expand the users work area of the facility by $150 \mathrm{~m}^{2}$ and remain within the original cost estimate for the building. Overall size of the facility (Fig. 1) is now $1800 \mathrm{~m}^{2}$ : occupancy by the project is expected before the end of calendar 1977.

During FY 1977 we focused the parallel R\&Deffort on performance testing of neutron-source components. After acceptance of the $400-\mathrm{kV}$ power supplies, high-voltage enclosures, and isolation transformers from the supplier, we assembled one complete prototype accelerator (Fig. 2) for tests with hydrogen-ion $\left(\mathrm{H}_{2}{ }^{+}\right)$beams. The modified high-voltage terminal ran at $400 \mathrm{kV}$ : the ion source produced 150 to $200 \mathrm{~mA}$ of magnetically separated $\mathrm{H}_{2}{ }^{+}$beams suitable for injection into the acceleration column; and all accelerator power supply, vacuum, telemetry, and control systems tested successfully at $400 \mathrm{kV}$. The acceleration colum is being installed for testing with the beam transport system in early FY 1978.

We built a full-scale tritium scrubber and tested it for efficiency, component lifetime, and likely failure 


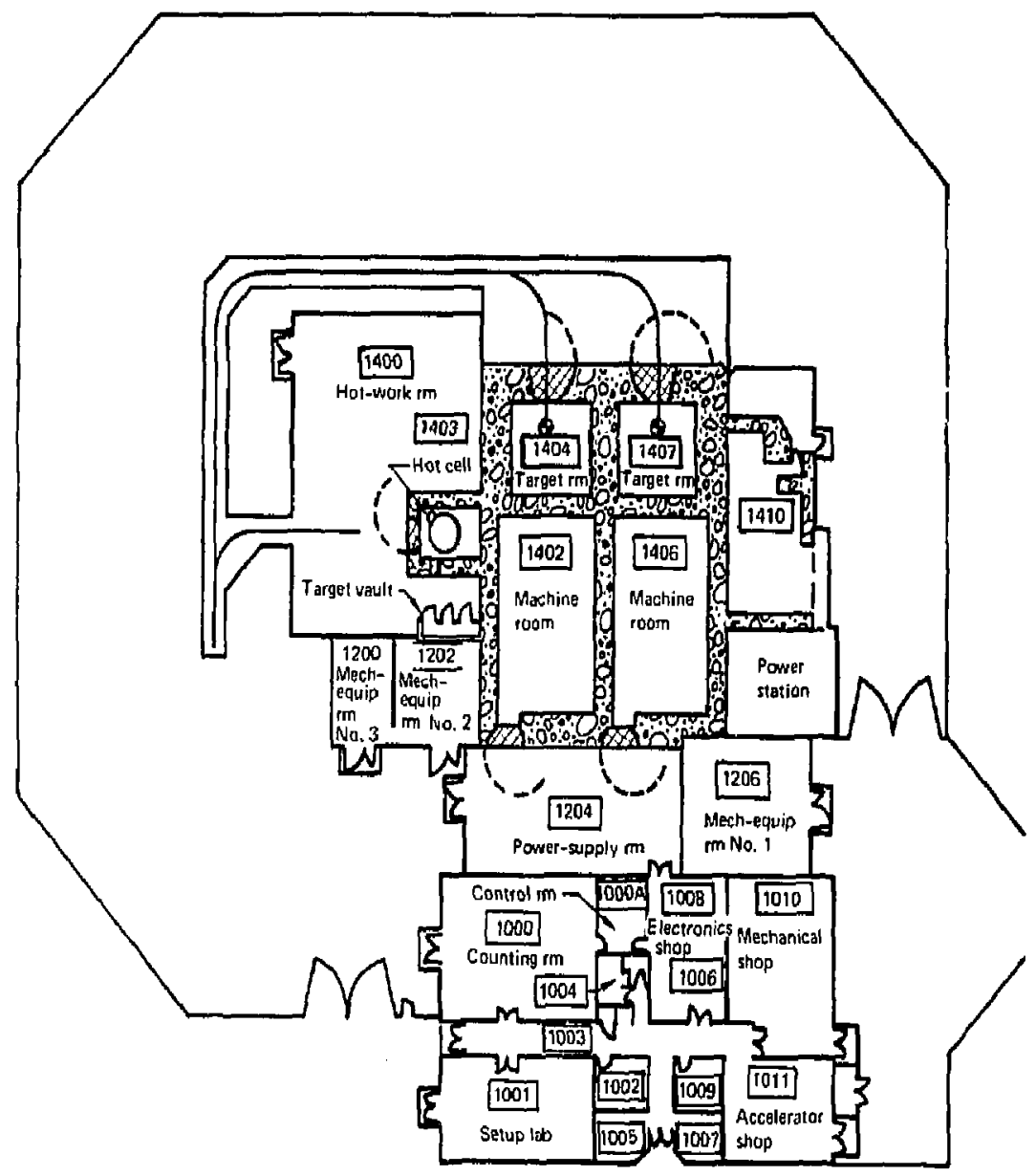

Fig. I. Rutatingt-Target Neutron Source-II (RTNS-II) facility in Building 292. We expcet to occupy this $18900-\mathrm{m}^{2}$ area before the end of ealendar 1977. The first neutren source (in target room 1404) will be operalional in late April 1978.

modes. Mechanical testing of a 5000-rpm, $50-\mathrm{cm}$ diam target also began. We used the RTNS-1 source to develop noninteractive beam-current and beamprofile devices.

Assembly of the neutron sources in the new building will require 4 to 6 months. The first source will be operational in Jure 1978. Initial experiments will begin in August 1978.

\section{Author}

\section{J. C. Davis}

\section{Radiation Damage}

\section{Correlation of Neutron Damage with Neutron Sources}

Introduction. The high-energy neutron sources ${ }^{\circ}$ planned for the radiation effects program ase the Rotating-Target Neutron Source-fl (RTNS-II), currently under construction at Lawrence Ljver-

\footnotetext{
"Fot this report, neutron rources that produce a spectrum with neutron energies $\mathrm{E}>4 \mathrm{MeV}$ are high-entergy neutron sources.
} 


$$
\text { 圈 }
$$


more Laboratory (LLL), and a lithium(d,n) stripping source, which is in the design stage. We expect these sources 10 provide a neutron flux of from $10^{17}$ to $10^{19}$ neutrons/m $/ \mathrm{m}^{2} \cdot \mathrm{s}$.

Presently, we are using low-flux prototypes of these sources:

- RTNS.I at LLL, which has a maximum Rux of $10^{16}$ neutrons $/ \mathrm{m}^{2} \cdot \mathrm{s}$.

- Beryllium(d,n) stripping sources. One of these, at the University of California at Davis (UCD), has a flux of $7 \times 10^{16}$ neutrons $/ \mathrm{m}^{2} \cdot \mathrm{s}$.

Radiation-damage experiments on these low-flux protolype sources cannot produce the high neutron Muence $\left(>10^{26}\right.$ neutrons $/ \mathrm{m}^{2}$ ) for evaluating the structural integrity of materials in a fusion reactor's first wall. They can, however, provide a basic un. derstanding of the nature and magnitude of highenergy neutron-damage effects. They also allow dircet comparison and correlation of high-energy neutron-damage effects with ion damage effects and fission-resctor neutron-damage effects,

This section reports the results of some exploralory studies on the naiure and magnitude of ridiation-damage effects produced by high-energy neulrons from RTNS and beryllium(d,n) sources.

Copper, Vanadium, and Niobium Irradiations. Results for the increase in yield stress vs neulron fluense for tensile specimens of copper, vanadium, and niobium irradiated with neutrons from RTNS, beryllium(d,il), and Livermore PoolType Reactor (LPTR) ${ }^{\dagger}$ sources appear in Fig. I. The neutron-energy spectra for the sources are in Fig. 2. Most of the strengthening results are for ambient irradiation temperatures of $25^{\circ} \mathrm{C}$ for RTNS and beryllium(d,n) and about $65^{\circ} \mathrm{C}$ for LPTR. We show some results for irradiation of copper at $210^{\circ} \mathrm{C}$ in the RTNS and LPTR spectra.

These plots indicate that high-energy neutrons from RTNS and beryllium( $(d, n)$ sources are considerably more effective than fission-reactor neutrons in strengthening copper, vanadium, and niobium at 25 and $210^{\circ} \mathrm{C}$. About 20 times more fission-reactor neutron ( $\mathrm{E}>0.5 \mathrm{MeV}$ ) fluence is required to produce the same strengthening in copper as is produced by fusion neutrons. If LPTR neutron fluence is expressed in terms of $\mathrm{E}>0.1 \mathrm{MeV}$, this ratio reduces to 10 . In niobium, the fluence ratios are $\sim 17$ for $E>0.5 \mathrm{eV}$ and $\sim 9$ for $E>1.0 \mathrm{MeV}$. For copper, vanadium, and niobium, the ratios of beryllium(d,n) to RTNS neutron fluence for the sarre strengthening are about 1.3.

When the strengthening results for copper are replotted vs damage energy (Fig. 3), the data for

\footnotetext{
$\dagger_{\text {Fission-neultón source. }}$
}

RTNS and beryllium $(d, n)$ irradiations fall on the same curve. This shows that strengthening scales directly with the damage energy of these two sources. Comparison with the results for LPTR irradiation shows that it takes about 2.3 times more damage energy from lission-reactor neutrons to produce the same increased in yield strength produced by the higher energy neutrons.

The nature and magnitude of radiation-damage structures are being compared by transmission electron microscopy. We show dark-field threedimensional stereo miscoscopy of the radiationdamage struclures for copper irradiated to a fluence of $3.3 \times 10^{22}$ neutrons $/ \mathrm{m}^{2}$ at $65^{\circ} \mathrm{C}$ in LPTR (Fig, 4) and for copper irradiated to a lluence of $1.27 \times 10^{21}$ neutrons $/ \mathrm{m}^{2}$ at $25^{\circ} \mathrm{C}$ in RTNS (Fig. 5). Electron microscopy observations reveal that LPTR, RTNS, and berylliun(d,n) sources produce the same kind of primary structural defects, i.e., vacancy and interstitial point-defect clusters and small Frank and prismatic dislocation loops.

Differences in radiation strengthering produced by high-energy and fission-reuctor neutrons appear to result from a greater rate of accumulation of those structural defects during high-energy neutron irradiation. Irradiation with high-energy neutrons from RTNS and beryllium( $(d, n)$ sources produces many high-energy cascades ( $>100 \mathrm{keV}$ ) that spontaneously create stable vacancy clusters. Fission. reactor neutron irradiution produces lew highenergy cascades, and the majority of structural defects form by diffusion-controlled coalescence of point defects. The fraction of displacement damagc at room temperature retained in the form of primary structural defects appcars to be greater during irradiation with high-energy neutrons. This is primarily caused by increased recombination of dif. fusing vacancies and interstitials during irradiation with fission neutrons.

Future irradiation, studies will be conducted on refractory metals and alloys at elevated temperatures and higher fluences.

Type-316 Stainless-Steel Irradiations. The Department of Energy's breeder reactor development program has provided considerable data on the behavior of stainless steels in a radiation environment, Consequently, stainless steels have been proposed as candidates for fusion first walls. We are investigating the behavior of stainless steel in a fusion-reactor environinent.

Specimens of annealed and cold-wcrked type-316 stainless steel will be irradiated at room temperature and elevated temperature at RTNS and the beryllium $(d, n)$ source at $U C D$. We will relate 

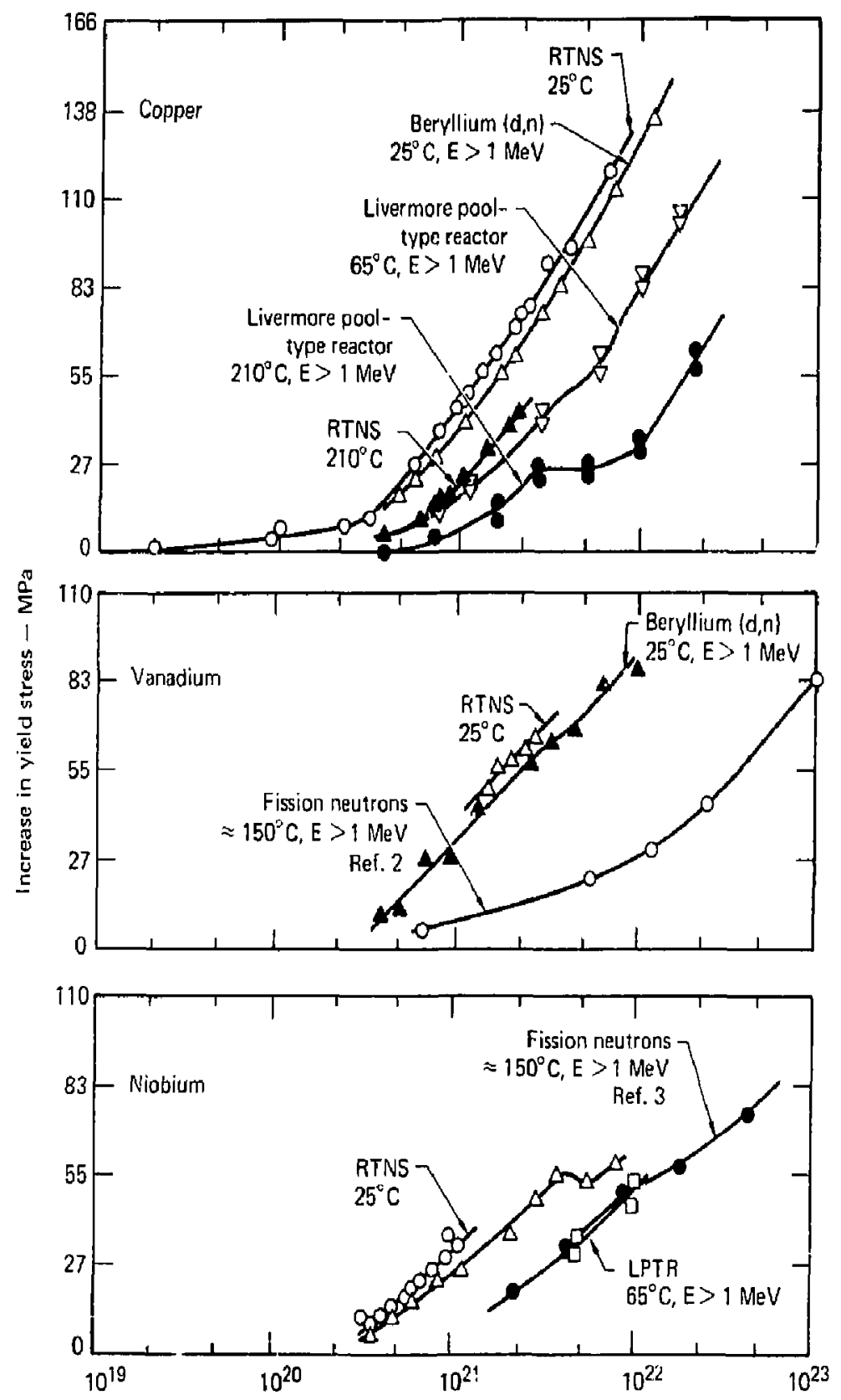

Neutron fluence - neutrons $/ \mathrm{m}^{2}$

Hig. 1. Increase in yied stress for copper, vanadium, and niobium irradiaced at various uculeon soutres. Temperatares reler lo irradiation

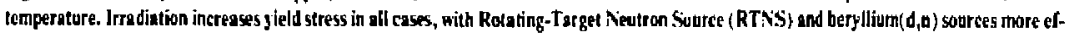
lective than the rission-sezctor source on an fuence basis. 


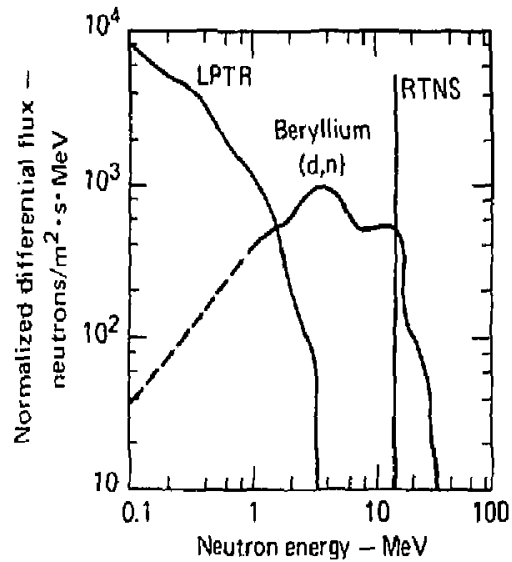

His. 2. Siscrial cumparisan of various neutron sources whed in radiution-damage cxperiments. RT.NS and berylliun(d, ni sources have a significant cumponcen ahowe $\mathrm{F}=4 \mathrm{McV} ; \mathrm{L}$. PTR and other fiskion ragceors do not.
Nuence and damage energy to changes in tensile properties and use electron microscopy to analyze the size, densily, distribution, and morphology of radiation-induced defects. Strengthening mechanisms governing deformation behavior will be determined and the results interpreted in terms of damage microstructure. Data from tensile tests and electron microscope studies of specimens irsadiated with high-energy neutrons will be compared with similar data from fission-neutron irradiation experimenss. We will then compare the relative damage effectiveness of neutrons from different radiation saurces.

Current Progress. We conducted tensile tests on type-316 stainless-stecl specimens irradiated with $14-\mathrm{MeV}$ neutrons at room temperature. Two types of material were tested. The first was cold rolled with $33 \%$ reduction in thickness; the second was annealed at $1050^{\circ} \mathrm{C}$ and water quenched. Table 1 gives the chemical composition of these muterials.

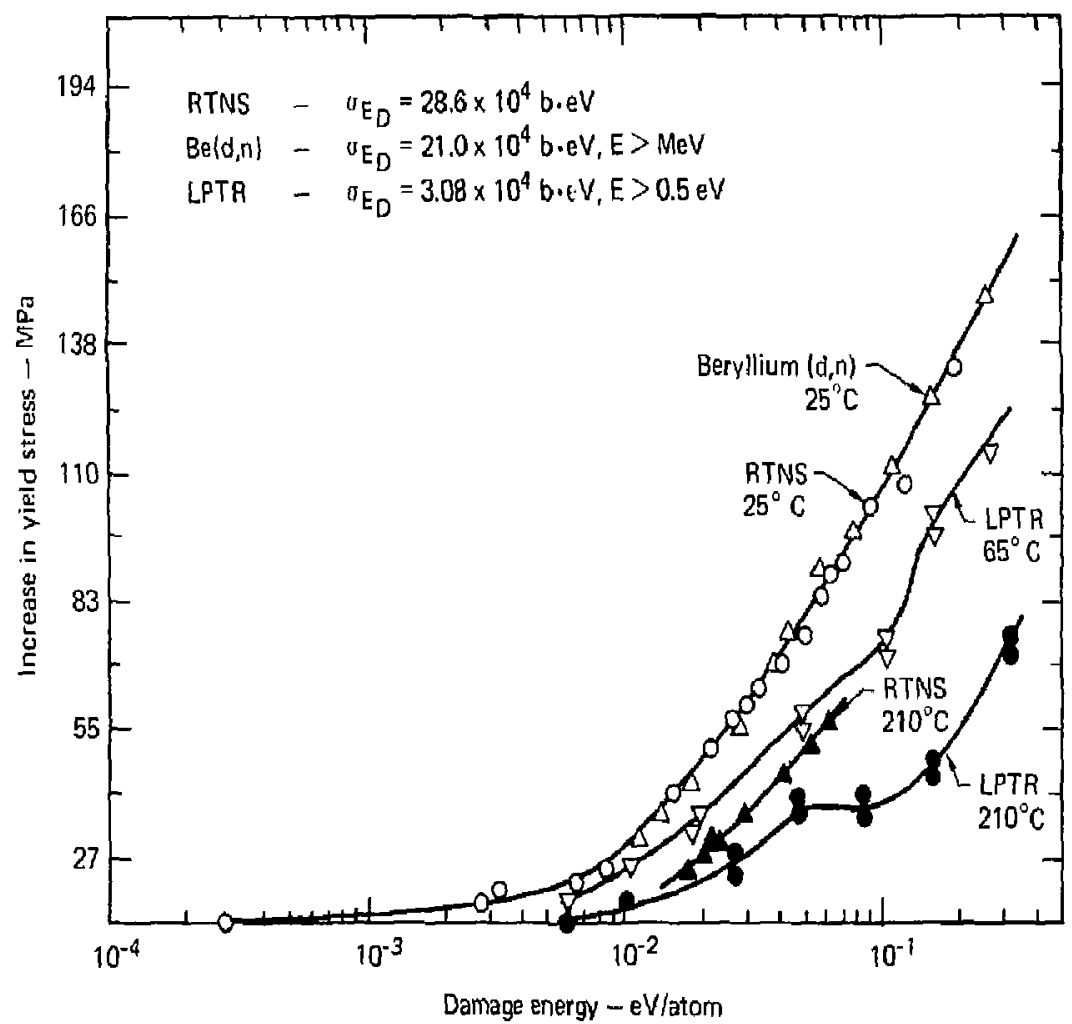

Fig. 3. Change in mectankal properties for irradiuted copper neplotted is damage energy. The data from RTNS and bery llium(d,n) irradiathons cosselate well on a damageenergy basis; the duk from LPTR imdinion do nol correlate with the olthers. 


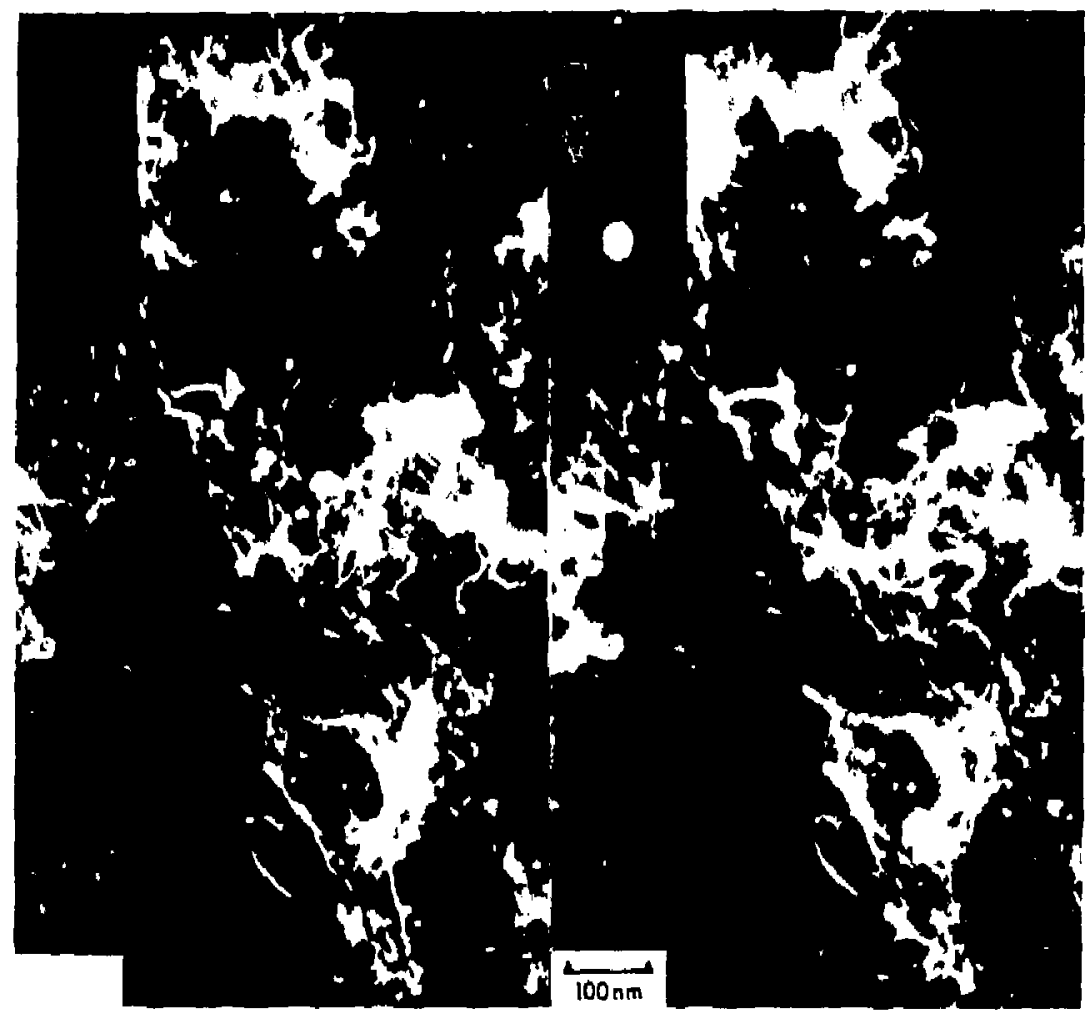

Fïg. 4. Transmission electron micrographs of rediation-damage structures produced in copper after I.FTR imsdiation to 3.3 $\times 10^{22}$ neutrons $/ \mathrm{mo}^{2}(\mathrm{E}>0,5 \mathrm{MeV})$. The micrographs are a three-dimensional pair produced by tilling the specimen slighily betwecn exposures. This allowed us to obtain depth perspective with the proper viewing equipment.

Stress-strain curves for cold-rolled material appear in Fig. 6. Irradiation increased the yield stress and ultimate stress of the cold-rolled specimen by about $5 \%$. Elongation decreased from 15 to $33.5 \%$ and reduction in areal decreased from 50 to $45 \%$ after irradiation to a fluence of $3.0 \times 10^{21}$ neutrons $/ m^{2}(E=14 \mathrm{MeV})$. Figure 7 has stressstruin curves for anneated material. inradiation produced much larger changes in tensile properties of annealed material than in cold-worked material. The yield strength of the specimen irradjated to a fluence of $2.5 \times 10^{21}$ neutrons $/ \mathrm{m}^{2}$ increased about $60 \%$; its elongation decreased from 70 to $47 \%$ after irradiution. The reduction in area of the irradiated specimen was $60 \%$ as compared with a reduction in area of $70 \%$ for the unirradiated specimen.

A fluence of $1.3 \times 10^{21}$ neutrons $/ \mathrm{m}^{2}$ also caused changes in the tensile properties of the annealed malerial. Thus, the threshold for irradiationinduced changes in strength and ductility of an- nealed Type-316 stainiess sleel is below a fluence of $10^{21}$ neutrons $/ \mathrm{m}^{2}$ for $14 . \mathrm{MeV}$ neutrons.

Higgy and Hammad reported the effect of fissionreactor neutron isradiation on the tensile properties of Type-316 stainless steel. " They irradiuted specimens at a temperature less than $100^{\circ} \mathrm{C}$ with fast-fission neultons ( $\mathrm{E}>\mathrm{|MeV}$ ). Comparison of tersile data from that study with our results showed that it takes $\sim 20$ times more fission neutrons than $14-\mathrm{MeV}$ neutrons to produce equivalent changes in tensile properties of annealed Type-315 stainless steel.

\section{References}

I. H. H. Higgy and F, H. Hammad, "Effecl of Fast-Nituron irradiation on Mechanieal Propertics of Stajnless Sicels: N151 Types 304, 316, and 347." J. Nud. Mater. 55, 177 (1975). 


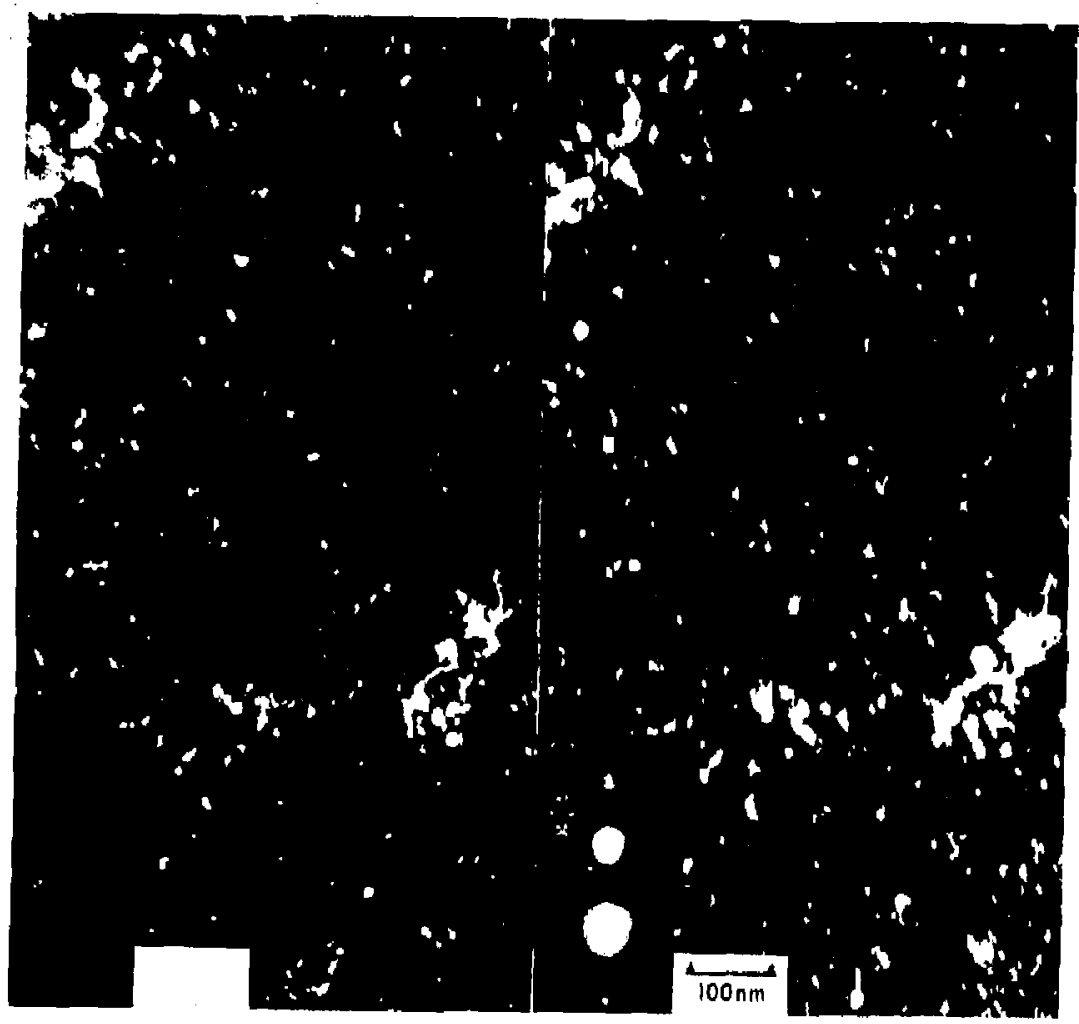

Fig. 5. Transmission election mlerographs of radiatlon-danage structeres produced in copper afier RTNS irnadiation to 1.27 $\times 10^{21}$ neutrons $/ m^{2}(E=14 \mathrm{MeV})$. Comparison nith Fig. 4 shows that the anpount of displasemeat damage rethined in the forth of primaay siructumal defects appetes to be grestet in the $14 \mathrm{MeV}$ metron case, The defects matked by cheles appear to be molsiple clusters originating from the sume neutron event. This phenomenon seems in decur mors frequently in highenergy neutron irradianions.

2. M. Boek, H. Bohm, and W. Schneider, "The Influence of Neutron Radiation on the Yield Stress and on Some Actival(ion Parameiers of Polyctystalline Vanadium," J. Nacl Mater. 40, (1971).

Table 1. Composition of Type-316 stainless steds used in radiation damage studics.

\begin{tabular}{|c|c|c|}
\hline Chemical element & $\begin{array}{l}\text { Commercial } \\
\text { Type-316 steinless } \\
\text { steel annealed at } \\
\text { [050 } 0 \text { and } \\
\text { water juenchesd } \\
\text { (\$6) }\end{array}$ & $\begin{array}{l}\text { Low-carbon } \\
\text { Type-3 } 36 \text { snainless } \\
\text { steel cold rolked } \\
335^{2} \\
\text { (\%) }\end{array}$ \\
\hline Copprer & 0.08 & 0.001 \\
\hline Chramium & 16.7 & 17.0 \\
\hline Njekel & 13.7 & 16.7 \\
\hline Molybdenum & 2.5 & 2.5 \\
\hline Manganeso & 2.1 & 0.03 \\
\hline Silicont & 0.9 & 0.5 \\
\hline
\end{tabular}

a Obuined from J. Stiegler (Oak Ridge National Laboratory).

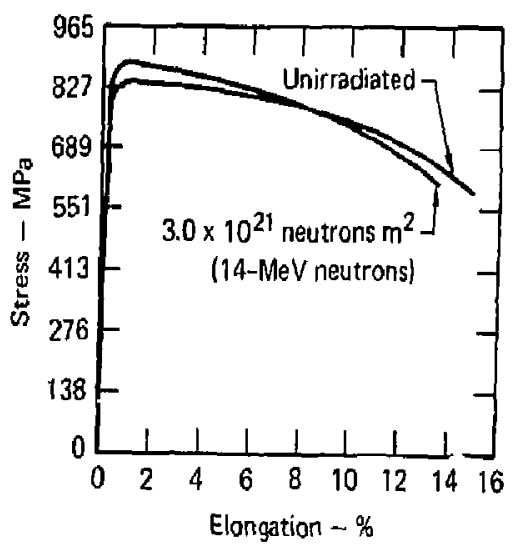

Fig. 6. Change in mectranical properties of cold-W orked Type-316 stainless sted alter irradiation $10,0,0 \times 10^{11}$ aeutrons $/ \mathrm{m}^{2}$ ( $\mathrm{E}=$ $14 \mathrm{MeY}$ ). After irmdintion, yipid strength increases 55 and elongation decreases 155 . Stmillar chunges are not evident when this material is ifradigted to this fuence level with fission neutrons. 


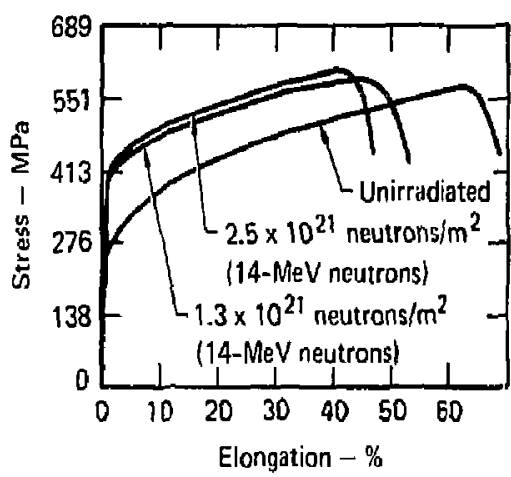

Fìg. 7, (hange in mechanical propertles of anneald Type-116 stuinless stecl after irndiationts $101.3 \times 10^{21}$ and $2.5 \times 10^{21}$ neulrons/ $m_{-1}^{2} E=14$ MeV), Al the latier fluence, yield stresy in-

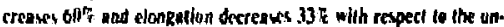

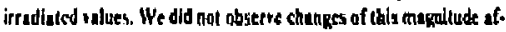
Ier irradiation to thess fuence lovels with fiscion neutrons.

3. K. P. Tucker and M. S. Wechsler, "Kadiation Itardening in Niuhium-Dependense uf the Y Yeld Steress on Neutron Dose," Rutidell biff 3.,73(1970).

Authors

J. B. Mitchell

R. R. Vandervoort

\section{Helium Effests on Mechanical Properties}

Introduction. High-ęnergy neutrons nol only do disnlacement damage, but also produce litlium iloms in metul matrices by interacling with melal atoms by means of the $(\mathfrak{n}, \alpha)$ reaction. Helium gas bubbles irapped and accumulating in the microstructure can alter the mechanical properties and lead to embrittlement. To separate and itudy helium effects on mechanical properties, we are doping niobium and niobium-1-wt\% zirconium (designated $\mathrm{Nb} \cdot \mid \mathrm{Zr}$ ) tensile and creep specimens with various concentrations of helium-3.

To do this, we dissolve tritium in niobium at $400^{\circ} \mathrm{C}$ and allow it to decay to helium-3. When a predelermined concentration of helium has been incorporated into the microstructure, the mobile tritium is removed by high-vacuum pumping at 400 to $550^{\circ} \mathrm{C}$.

Helium Doping of Test Specimens. Niobium and $\mathrm{Nb}-\mathrm{IZr}$ specimens are heated to $400^{\circ} \mathrm{C}$ under vicuum and then equilibrated with a predetermined volume or tritium so that a 1,3-k Pa equilibrium partial pressure is obtained. This gives a tritium-10niobjum atom rasio of 0.05 in the metal. The specimens are held at $400^{\circ} \mathrm{C}$ while the tritium decalys 10 helium-3. These experimental conditions produce about 7 atomic parts per million (appm) helium-3 each day in !he melal. When a predetermined amount of helium-3 has been "doped" into the specimens, the tritium is removed. The material is buked at $400^{\circ} \mathrm{C}$ for $16.7 \mathrm{~h}$ at $4 \mathrm{Pat}$, then at $500^{\circ} \mathrm{C}$ for $16.7 \mathrm{~h}$ at $13.3 \mathrm{mPu}$. This reduces the tritium in the material to a level we can safely handle in subsequent experiments.

We doped niobium and Nb-1Zr tensile and creep spainnens with from 1010500 appm of helium.

Creep Testing. We creep lested pure niobium in high-vacuum, high-lemperature units to get reference information of pure niobium. At $800^{\circ} \mathrm{C}$ under various stresses, we found the following stress dependence of creep rate: $i=\mathrm{K}_{\sigma}{ }^{10.0}$, where

$i=$ secondary (minimum creep rale).

$n=$ axial stress, and

$K=$ constint.

Crexp tests on niobium specimens doped wirh 25 uppm of helium- 3 gave creep behavior similar to that of the reference material (Fig l),

Tensile Testing. We compleied a number of 1 en. sile tests on $\mathrm{Nb} \cdot 1 \mathrm{Zr}$ specimens in a high-vacuun clamshell furnace.

Mechanical properties from baseline tests on annealed $\mathrm{Nb}$ - I Zre specimens and from lests on Nb-IZ,r specimens doped with 25 appm hellium-3 (Tablc I) indicated that yietd streng th of a doped specimen increased and elongution slightly decreasid. However, the effecis on the tensile properties were nol deleterious when we added 25 arpm helium-3 to the mircrostrueture of the $\mathrm{Nb}-\mathrm{ZZr}$ alloy.

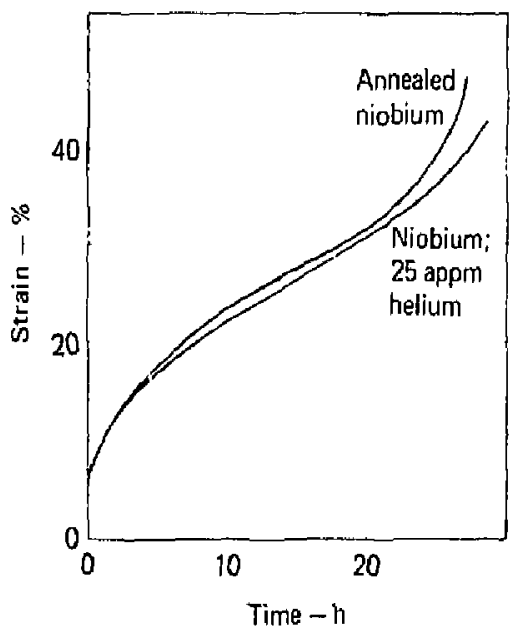

Fig. I. ('rcep behasios of niobium doped with 25 atomic parts per millian (appm I of luelium-3. This bethavior is compared with thet of undoped niobium of 8010' ${ }^{\circ}$ and a 65.12-118? load. Helium al the 25-appm leves appears to have litte effect an the crer; hething of niobium. 
Table 1. High-vacuum tensilc tests on Nb-1Zr.

\begin{tabular}{rcccc}
$\begin{array}{c}\text { Helium-3 } \\
\text { (appm) }\end{array}$ & $\begin{array}{c}\text { Temperature } \\
\left({ }^{\circ} \mathrm{C}\right)\end{array}$ & $\begin{array}{c}\text { Yield stress } \\
\text { (MPa) }\end{array}$ & $\begin{array}{c}\text { Uhimate stress } \\
\text { (MPa) }\end{array}$ & $\begin{array}{c}\text { Strin } \\
(\%)\end{array}$ \\
\hline 0 & 23 & 150 & 260 & 50.8 \\
25 & 23 & 165 & 279 & 46.4 \\
0 & 600 & 68 & 217 & 35.2 \\
29 & 600 & 85 & 218 & 32.8 \\
0 & 800 & 60 & 199 & 32.0 \\
25 & 800 & 78 & 221 & 27.0 \\
\hline
\end{tabular}

Authors

W. L. Barmore

R. M. Scanlan

R. R. Vandervoosl

\section{Radiation Damage in Superconductors}

Introduction. To properly design the magnot shielding for maguetic fusion reactors now in the planning stages, one must know the effects of radiation on candidate superconducting materials as a function of Nuence. Present reactor designts use either niobium-litanium ( $\mathrm{Nb}-\mathrm{Ti}$ ) or niobium tin $\left(\mathrm{Nb}_{j} \mathrm{Sn}\right.$ ) as the superconducting material. Calculdtions for a tokamak reuctor predict a total neutron fux of between $4 \times 10^{12}$ and $4 \times 10^{13}$ neutrons $/ \mathrm{m}^{2} \cdot \mathrm{s}$ and a $14-\mathrm{MeV}$ neutron flux of between $10^{! !}$and $10^{12}$ neutrons $/ \mathrm{m}^{2} \cdot \mathrm{s}$, depending on the reactor parameters chosen. Calculations for a mirror reactor predict a total neutcon flus of $3 \times$ $10^{14}$ neutrons $/ \mathrm{m}^{2}$. $s$ and a $14-\mathrm{MeV}$ neutron flux of $6 \times 10^{12}$ neutrons/ $m^{2} \cdot 5$ at the superconductor, In both cases, we based flux calculations on uniform shielding. As we make more refined calculations, which incorporate neutron-beam injection ports and vacuum ports, the calculated flux values at localized areas of the magnet will be higher. It is es. sential that the magnets be used for many years. Also, the radiation tolerance of the magnets may be an important factor.

We presently know that a catastrophic reduction in $\mathrm{Nb}_{3} \mathrm{Sn}$ critical cursent $\left(\mathrm{I}_{\mathrm{c}}\right)$ occurs at fluences greater than $3 \times 10^{22}$ neutrons/m ${ }^{2}$ (fission-reactor neutrons) at an irradiation temperar se of $60^{\circ} \mathrm{C}$ and with an applied field of $4 \mathrm{~T}$. We de not know the corresponding fluence at which such a reduction might occur under fusion-reactor conditions of 4.2. $K$ operating iemperature, applied fields to $12 \mathrm{~T}$, and neutrons having energies up to $14 \mathrm{MeV}$. Such measirements have not been performed, and the theory does nol exist to make accurate predictions. However, one can infer from present knowledge that these conditions are likely to be more severe in every case.

The response of $\mathrm{Nb}$-Ti to irradiation differs from that of $\mathrm{Nb}_{3} \mathrm{Sn}$. Degradalion in $\mathrm{Nb}_{3} \mathrm{Sn}$ critical curtent is altributed to a degradation in the intrinsic properties $T_{c}$ (transition temperature) and $\mathrm{H}_{\mathrm{c} 2}$ (upper critical field), which in turn affect $I_{c}$. The degradation in $\mathrm{I}_{\mathrm{c}}$ for $\mathrm{Nb}$-Ti is uttributed to a modification of nux pinning by irradiation. Experiments have shown that $I_{c}$ degradation for $\mathrm{Nb}$-Ti is gradual rather than catastrophic; the threshold fluence for $I_{c}$ degradation, however, is lower for Nb-Ti. Low-temperature irradiations of Nb-Ti with fission neutrons have shown ${ }^{1}$ a threshold of $\sim 10^{2}$ neutrons $/ \mathrm{m}^{2}$ for $\mathrm{l}_{\mathrm{c}}$ degradation. Our irradiations of $\mathrm{Nb}-\mathrm{Tj}$ with $14-\mathrm{MeV}$ neutrons at $4.2 \mathrm{~K}$ show a threshold for $I_{c}$ reductions of $\sim 2.5 \times 10^{20}$ neutrons $/ \mathrm{m}^{2}$.

The magnitude of the decrease in $I_{c}$ under: irradiation depends on irradiation temperuture. Socll ${ }^{2}$ found that multifilamentufy Nb-Ti irradiuleo at $5 \mathrm{~K}$ to a fluence of $7,5 \times 10^{22}$ neutrons $/ \mathrm{m}^{2}$ underwent a fwofold decrease in $I_{c}$ After annenling. only $15 \%$ reduction in $\mathrm{d}_{c}$ remajned; this is consisteni with Parkin and Schweitzer's ${ }^{3} 12 \%$ reduction in $I_{\mathrm{s}}$ in $\mathrm{Nb}$ Ti irradiated at $60^{\circ} \mathrm{C}$ to the same fluence. These results show that it is important to evaluate Nb-Ti, as well as $\mathrm{Nb} \mathrm{Sn}_{\mathrm{n}}$, under fusion-reaclor operating conditions.

Our work in progress has the following thret ob. jectives:

- Determine the effects of neutron irradiation (from about 4 to $14 \mathrm{MeV}$ ) on the critical current of $\mathrm{Nb}_{3} \mathrm{Sn}, \mathrm{Nb}$ - Ti, and other superconductors at liquid. helium temperatures and. in the presence of marnetic fields up $1012 \mathrm{~T}$.

* Correlate the electrical properties of these lititerials with both initial microstructure and radiation-induced changes in microstructure.

- Measure the recovery of the changes in the critical current during annealing at teinperatures up to room temperalure.

Current Progress. Two samples of Nb-45-wt $\mathrm{Ti}$ superconductor were irradiatec at $4.2 \mathrm{~K}$ for 2 weeks at our Rotuting-Target Neutron Sourse. The critical current of the samples was measurcd periodically during the irradiation. At the end of the irradiation we measured the critical current as a function of annealing tempcrature.

At a maximum fluence of $8 \times 10^{20}$ neulrons $/ \mathrm{m}^{2}$ critical current decreased by $24 \%$ (Fig. 1). Published data for fission-neutron irrudiation of $\mathrm{Nb}-\mathrm{Ti}$ at $5 \mathrm{~K}$ showed a decrease in critical current of $25 \%$ a! a fluence of $4.5 \times 10^{22}$ neutrons $/ \mathrm{m}^{2}$ ( $\left.\mathrm{E}>0.1 \mathrm{MeV}\right)$. The large difference between the fluences of fission 


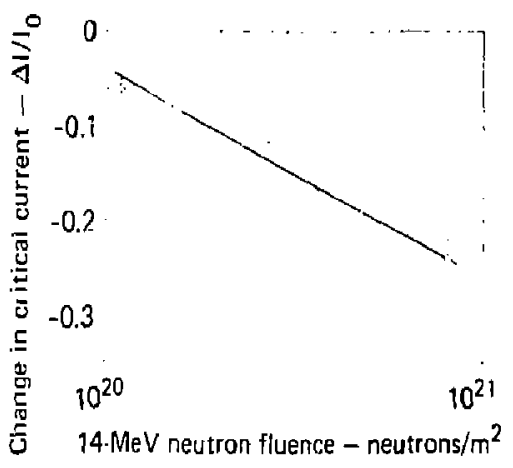

Fig. I. Siendy dectease in tritical rurrent for nimbiem-litanium

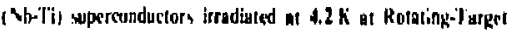

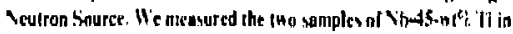
an $8-T$ magnetic field.

and fusion neutrans required for a similar change in critical curtert (i.e. a factor of 50 ) is surprising. On the basis of damags-energ\} calculalions by Parkin and Goland, "he would expect about a tenfold dif. ference in the fluences required for similar changes. One possible explination for this distrepency is that the particuler property being measured (i.e., criticil current) is sensitive only to changes produted br high-energy primary recoils, which are much mor: numerous for $14 \mathrm{MeV}$ neutrons than for a fissionneutron spectrum. Microstructural characleriation by trunsmission electron microscopy (TEM) is presently underwiy to identify the defects tesponsible for the tritical-current changes. The TEM resillts maly also aid ir. explaining the observed change in critical current.

After irradiation we annealed the samples to $273 \mathrm{~K}$ and found that critical currents recovered to within $7 \%$ of the unirrudiated values. This recovery was consistent with the behavicr four 1 after lission. neutron irradiation. This result was encouraging from the standpoint of fusion-reactor operalion: it showed that a reactor with an Nb.Ti magnet could he warmed periodically to ambient temperature to recover the critical-eurrent carrying capacity.

\section{References}

1. W. Cuvich. 1. Puulut, and E. Bonjour, "Lffects af Fist Siculron Itradiation at Jow Temperiture on the propertits oN Nb.T Supercunductor Wires," IFtK Trams . Lagn 11170 (1975).

2. M. Soull, C A. M. Yander Klein. H. Bauer, and Ci. Yopl, "The Inlluence of Low Temperalure Neutron Irradiation os" Superconducting Magnet Systems for Fusion Rtuatiors," IEFF Trans. Afapn. 11178 (1975),

1. D. M. Purkin and D. G. Schueitzer, "tffects of Neut,un Irradiation on the Supercunducting Broperties of $\mathrm{Nh}-\mathrm{Ti}$

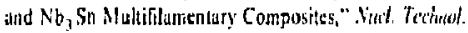
22, $108,(1974)$.

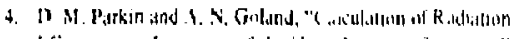

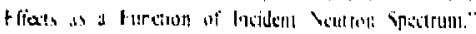
Radiar. Afl 28, "? (1976).

\section{Author}

\section{R. W. Scanlin}

\section{Resistivity Mtisurtements of Radiation-[Jamage Rutes}

Introduction. The medsurement ul resistivity al low temperatures can provide a bas for colmpering the lot:ll number of delects produced by varitis sl irsadiation sources. We hope lo bse the data from

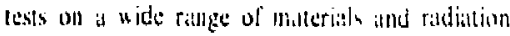
sources to dowelop madels al the displiacement process

The rosults prosented here are part of an in-

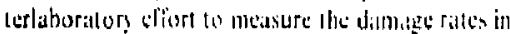
dibute alloss of rirconium in batiadium. niothium.

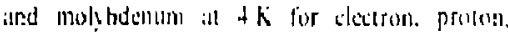

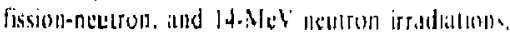
A list of parricipants and specificillons lor sample prepuralion appeitrs elsewhere Olik Ridge

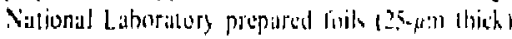

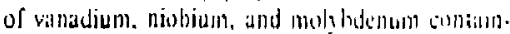

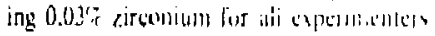

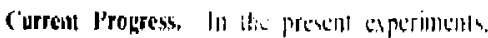

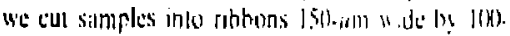

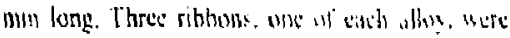
wound onto is sample loblder in the lorm of a helis

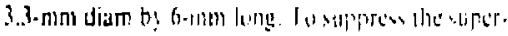

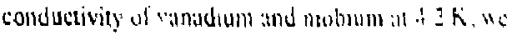

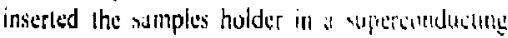

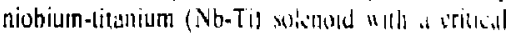
curtent of $12.35 \mathrm{~A}$ at $1.2 \mathrm{~T}$. Durilly irridiallon the assirnbly was inmersed in linuld helium. Ficlus at $0.275 \mathrm{~T}$ and $1.1 \mathrm{~T}$ respestively, were applied a the

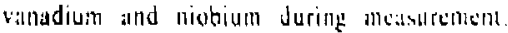

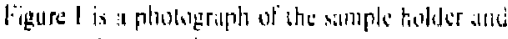
supercunducl as: solsmoid.

He insered the sample holder .lld whlentid in a

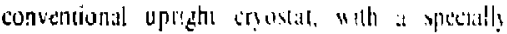

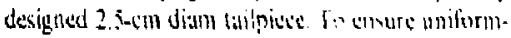

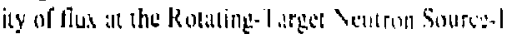
(RTNS-I), Ne continuously Jsillated he sartiples. and solenoid back and forth $36\left(l^{\text {th }}\right.$ tout then ales during irradiation. W' used con contichall de putenliomelric echniques with a somsil. it! of $\pm 10 \mathrm{nt}$. The medsuring current was $100 \mathrm{ml}$. Solsi lesels

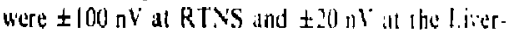
more Pool-Type Rewetar (L.PTR).

To check out the system, we ireadiuted vandodium and nolyhdenum for 11 h a RTNS. All L hrec alloys were irradiated for $55 \mathrm{~h}$ in the stcond experimeill. Following this second irrudiution. Ut mainatined 

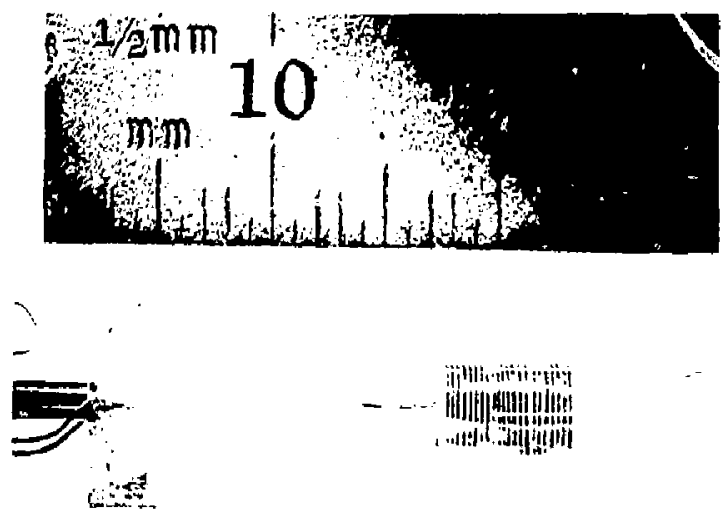

(a)

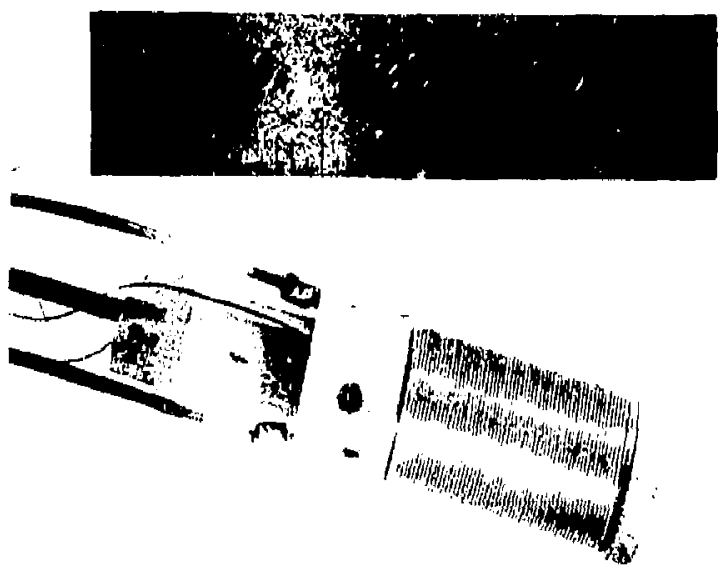

(b)

Fig. 1. Sample holder with spiral resistivity specimen (a) . A 1.2-7 supercondusting solenoid (b) slides orer plu: resistivity specimens. To ensure uniform expasure, this unil allows specimeas to be rotaled at $4.2 \mathrm{k}$ uring irradiation. 
the samples at $4.2 \mathrm{~K}$ and moved the cryostal to LPTR. An incremental irradiation of $28 \mathrm{~h}$ was carried out with the samples $25.4 \mathrm{~cm}$ from the fis. sion plates in the Fast- Neutron Irradiation Facility10 (F NIF-10).

Neutron Fluences. A। RTNS. $16 \mathrm{~mm}$ from the source, the neutron spectrum is newrly mono. energetic, with an average energy of $14.9 \mathrm{Mat}$ ? Relative fluences during the runs were monitored with a fixed-geometry proton revil counter. We determined absolute fietrees after the runs by measuring the activation of the niohium samples from the niobium-9.3 in. ?njniobium-92m reaction. We used an atctivation eross section of $458 \mathrm{mb}$ for this reaction. ${ }^{3}$

Al I.NIF-10 the neutron speetrum is is parlially moderated fission spectrum ${ }^{4}$ The iron-st

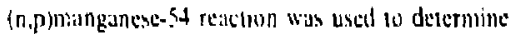

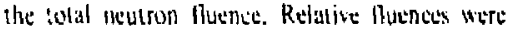
inonitured by a delisyed neutron counter. The Muences are reported as 1: $>0.54$ "2" for which the

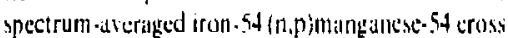
section is $32.3 \mathrm{mb}$ (Ref. 5\%.

Resistivity Changes. The vanadium. niobium, and molybdenum simples have resistance rattios of 110,68 , and 88 . The inilial resistivity at $4.2 \mathrm{~K}$. $8 \mathrm{~s}^{2}$. change in resistisily. Sp. lotal Ruence, Jo, and

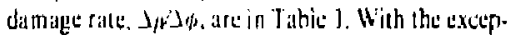
tion of the steiond RTSS irradiation of molybdenum. we shoreded no detetable thange in damage rates. With mulyhdenum the damage rate decreased $3 \%$, for a total resistivity change of 8.60 ncutruns $\cdot ! \cdot \mathrm{cm}$.

The relative precision of the damage-rate measurements is lot for molybdenum, 2? for vanadium, and 6 f for niobium. These ire thout the

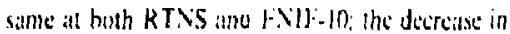
noise level at LITTR compensaled for the smiller resistivily shenges. The poorer precision fer niobiun results from its large mingetoresistance coefficien and its snaller overall chlmper in resistivity.

Damays Ration. The ration of experinnemsal damage riltes at R [.XS-1 to thouc at 1. VIf .10 are in Table? lor the second set of simples. The uncerlainties sesull from meitsurentent erros and uncer-

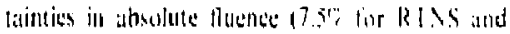
I(1)\% for I:RNII - IO)

Theoretical dimlatge rations hased (an) dimitateenergy crons-xition taikulations with the DON Code" laise been mide for bolh RISSt l and

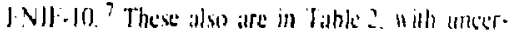

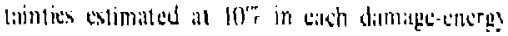
cross setion.

With the exception of niahium the comploriwon w

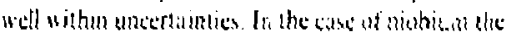
bounda just miss arerlipping.

Taken as a whols the theoretical diunitge rittion

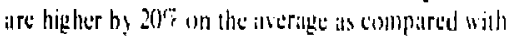
thase ntialsured it $+k$. This might ind citte that the

Falle 2. Damage ration.

\begin{tabular}{|c|c|c|c|}
\hline \multirow{3}{*}{$\frac{\text { sinnle }}{M a+11032 \operatorname{tr}(2)}$} & \multicolumn{3}{|c|}{ RIS5-1/4.411-10 } \\
\hline & \multirow{2}{*}{$\frac{1 . y \text { prinstim }}{+.23 \cdot 11.53}$} & \multicolumn{2}{|c|}{ llienn } \\
\hline & & +1.5 .4 & $11,6+$ \\
\hline$V-(1, n), K, \mathrm{r}(2)$ & $3,648+0,47$ & 4,23 & $\|4\|$ \\
\hline N|lo, $0, \cdots(2)$ & $4.2 \mathrm{~B} \cdot 0.65$ & 5.78 & 11.32 \\
\hline
\end{tabular}

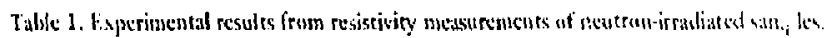

\begin{tabular}{|c|c|c|c|c|}
\hline Sinures: sianple & 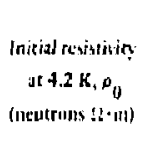 & 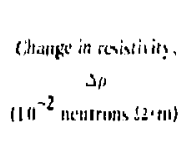 & 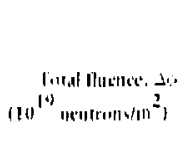 & 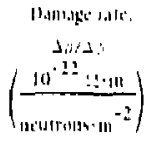 \\
\hline 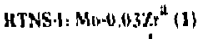 & 0.734 & 2.364 & $2.3: 3$ & 1.111 \\
\hline RTNS I: V.0.1737. & $1.87 \mathrm{~B}$ & +.517 & $2,3,34$ & 1.23 \\
\hline RTNS-I : Ma-0.037r (2) & 0.711 & 8,604 & $8,4,311$ & 0.1447 \\
\hline$F+17-10: M(0-0.103 \%$. (2) & - & 0.176 & $0.44 n$ & 11.2 .30 \\
\hline RTNS-1: V.0.03Xri? & 1.865 & 16,370 & $8,(1,3)$ & $1.84 \%$ \\
\hline FNIF=IO: Vन-1).05ZR (2) & - & $10.38-1$ & 10.746 & 11.515 \\
\hline RTNS.I: Nh-0,0J7/r $(2)$ & 2.173 & 0.717 & 8.630 & 1.136 \\
\hline PNEti- JO: Nh-0.03Zr (2) & - & 11.196 & 0.746 & 40.20 .5 \\
\hline
\end{tabular}

\footnotetext{
"Malybdenum-0.03-wt\% aireonium.

banadium·0.03-wr\% zircunium.

'Niobium-0.03-wro zirconium.
} 
moderated fission-spectra neutrons are somewhal more eflicient than fusion neutrons. Al the present lime. howeve:, this conclusion could only be regarded as speculative because of uncertainties in the measurements, spectra, and damage-energy cross suctions.

Current Plans. A similar set of experiments his been completed at the University of California, Davis. cyclolron with neutrons from a $30-\mathrm{MLV}$ beryllium(d.n) source. The resulls will be reported when final spectra evaluation and dimage-energy calculalions are complete lalte this year further axperiments are planned un a series of face-centered cubic melals.

\section{References}

I K I. Reesl, 1. 1. Kl.humde. J K. Redman, and R. R.

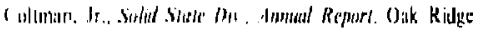

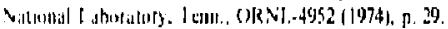

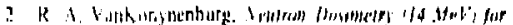

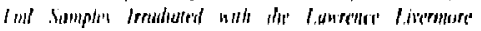

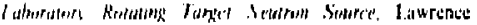

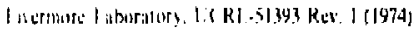

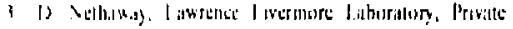
Cismumum, Itusn a $1 \mathrm{~mm}$,

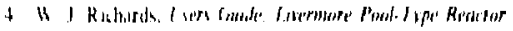

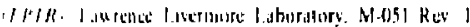
$(1,1,-2)$

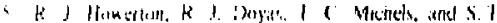

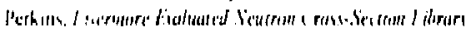

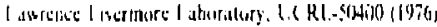

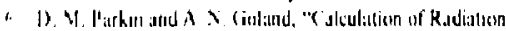

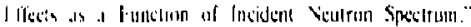

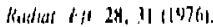

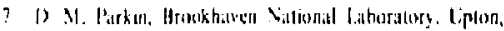

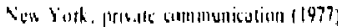

Authors
11. W. Guinan
C. I:. Violes

\section{(ompuler Mlodeling of Radiation Damage}

Introduterion. Modeling the production of displacement dimage plays an important role in the ancall cllort to corralate radiation damale produced in diflierine environments. The successful simulation uff. or exirapolation to. Pusion-reactor comblitions will depend on a reasonable understanding of the processes involved in a highencegy collision sustide.

Our modeling etforts imvolve the study of

- Delect propertics. such its mobilily, displace. ment hlicshulds, and stithility.

- The interactions ol defecls with impurities and transmulation products.

- The production and distribution of defects in energetic collision custscades.
Current Progress. Wu completed a fully dynamic sludy of $2.5 \mathrm{keV}$ collision cascades in lungsten. Preliminary results of the study were presented at the American Nuclear Socicty annual meeting in Toronto, 1976.

Sixteen cascades with random primary-knock-on (PKO) directions were initiated in ad crystal contain. ing $\sim 4000$ atoms $(13 \times 13 \times 13$ body-centered cubic ecells with periodic boundary conditions. Since this work was primarily undertahen to study the inlluence ol transient thermal effects on final defect configurations. we applied damping to the bouldary latyer to simulate the cooling of the cascade region by the surrounding lattice. The damping consiant was chosen to mateh tooling ritts obsurved for small crystals imbedded in a larger malrix. The tungster-lungsten polential is the samte as thite used in previous studies of displacement thresholds ${ }^{2}$ and defett diffusion ${ }^{3}$ in lungsten.

Al high-energy transfers, damage production is considerably more complicited than that oceurring near the damage threshold. PKO atom produces il cistialde of secondary knock-ons as it collides with surrounding atoms. Tloc lime development of such a sollision cascade can be sepilfuled into two relitively distinte time stales. D platements are produced for ahout $10^{13} \mathrm{~s}$. at which time notic of the resoiling aloms have sufficitn energy left to creale addilional displatements. Ni this point the collision cescade has produced what is known as a displatement spike.

He produced a large number ol displistments, not all af which nere stable, ill a relalively smill volums. Jisplacement spikes vere studied extensively, using the binary collision approxinalion in which the cascade wals treated as a series of sequential two-body collisions. We coullin ued the sequence until displacements coused, at which point the calculation was terminated and unstable pairs s'i,inimated

The development of the cisciade. however. is not yet completed Only - 10 ; of the PKO energy wits tited up as potential encrgy of the stable frenkel pairs. The remiainder of the energy eased at state ol intense agitation in the casciade region. which gradualiy coulsd until thermal equilibrium with the surrounding latlice was reached. This portion of casciade development is oflen refered 10 as the thermal spike. Tinies of the order of $10^{-12}$ s are required to reach locil thermal syulibrium. During this lime the energies are loo low to be trealed by binary models and the lattice too disturbed to be treated by equilibrium thermodynumics. The initial phase of the thermal spike must be trealed by many body dynamics methods. The two regines are seen clearly 


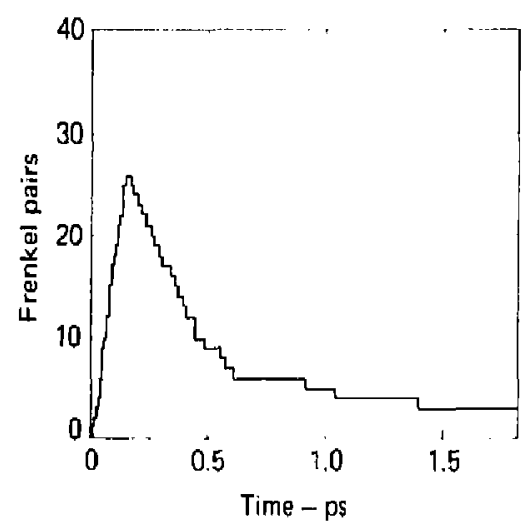

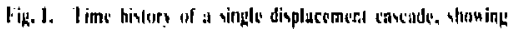

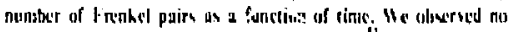

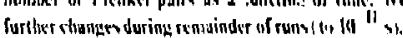

in Fig. I, in which we plot the number of frenked pairs an a funclion of lime.

Dynamic Inany-hody calculations can he compared with the binary-collision nodel by noling the defet cunfiguration at the end of the displasement spike. Consible pairs tan then he manually climimaled using an appropriate slat ic secomhinaIan volume as is dome in binars calculations.

In Tible I us compare the present resulis for 2.5 . ket collision cilscides in tungsten wilh lle hinary calculations of Beeler and Bescot sote the eflect ol choositen diflerent bislues for the recombination volume The 53-sile secombinalion region is the correct one for the presem potenlyil," The harger cascade sire and number of stable finkel pairs in the hinary calculation are the direct result of longer replasiment seyuencen. Whether this reflects the somew hat sofler potential of Beeler and Besco or the nandling of replacement sequences in the binary calculation remains to be seen.

Al the end of the thermal spike, only 3 to of the stable pairs ereated survive. The observed defecl

Table 1, Camparison of $2.5 \mathrm{kcV}$ collision cascades is tungsten.

\begin{tabular}{|c|c|c|c|}
\hline & & $\begin{array}{c}\text { Binar' } \\
\text { cullixian } \\
\text { model }\end{array}$ & $\begin{array}{l}\text { Jyonimic } \\
\text { many-hady } \\
\text { model }\end{array}$ \\
\hline Canzade vulume & & 670 & 540 \\
\hline Initial displacemsnts & & 23 & 25 \\
\hline \multirow[t]{3}{*}{ After recumbination: } & 31) sitcs & 14.5 & 10 \\
\hline & 52 sites & 12 & 9 \\
\hline & Q0 sites & 8 & 1.5 \\
\hline lind displaccmer.s & & - & 3.3 \\
\hline
\end{tabular}

trantiport is moes than an otode of magnitude grealter than sexpected from the know n' equilibsium transport coefficients. This survival rase in the therrlal spike appears consistent usth recent sxperimenlal work.'

\section{References}

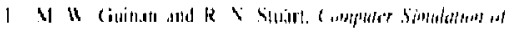

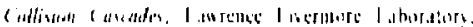

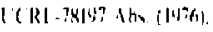

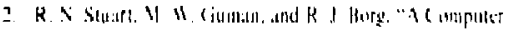

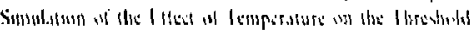

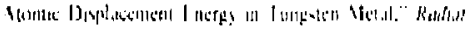

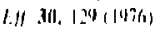

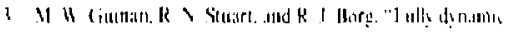

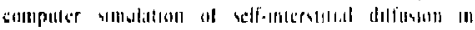

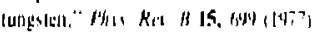

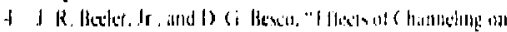

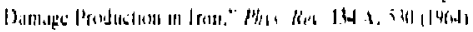

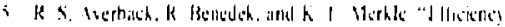

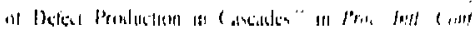

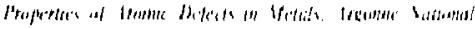

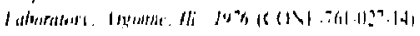

\section{Luthors}

\section{N. H. Gumaln}

R. Y. Stuirst

\section{Rotaling-Iarpet Veutron Souret-1 Irradiations and Dosineetr!}

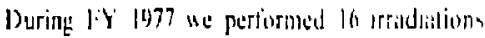
with $35 \%$ simples. The irradiallons supposted rescarcli on the elfects ol 14.8-110 neturons hy 16 indiriduals representing cight inslitusions. IJthough most of the cxperiments utre carricd out at

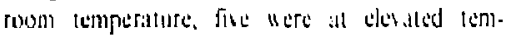
peralure (up $10600^{\circ} C^{\circ}$ ) and Hor were at eryugentio ta:mperaltures. Maximum flux ate ally of lat roum lemperature runs was $9 \times 10^{11}$ neutrens emo sor st 80-h rutr.

Irtudialled malterials included the lollowing elsments. allose and compounds:

\section{1.lemems}

vickel

Sinbium

Pyrographile

Alloys

Siainless siets

Siubiun-1-41" fiscontium

Niobiunt-tilanium

Compounds

Cilcium hluorde 
Nluminum oxide

Mapnesium oxide

Yturium aluminum gatrnet

Spime]

Silicil supriail

Niubium-lin

Vathadiutio-pallium

Ne designed the experiments to study the effects a) $14.8-\mathrm{MeV}$ neutroms on mechanical propertics, critical parameters ol superconductors, defece production adialion-enhanced diffusion. microslructural features, and helium gentration. laperimental lechmigues included tunsile lesting, Iransmission electron microstopy, oplical absorption. dilianotry, electrical resistivity, mass specLromelry, and ganma spectroscony.

The niobium-9.3(n. 2n) niobium-92n reacion was used ta determine 14.8-Mev neutron fluences, for cisch irradiation the exporimbuters received al report detioling experinental conditions and irradiation hivwrs as well as individual sample dosimetry.

Iullur

S. Hisl.tin

\section{Tritium Handling and Control}

\section{Tritium Containment and Blankct Designs for a Mirror Fusion ('entral Pewer Plant}

Introduction. A long-term goal in the fusionreactor engineering community ${ }^{\prime}$ is to reduce the tolil tritium loss to the environment to below $37 \mathrm{GBq} / \mathrm{d})(\mathrm{l} \mathrm{Ci} / \mathrm{d})$. The accumulated tritjum emissions from the 1500 1-GW fusion power plants that mght be built in a world fusion economy by the yeit 2025, would not significantly $(\sim 10 \%)$ add to the present tritium buckground. But by the 2050, with 10000 1-GW plants, the emissions per plant would have to be $3.7 \mathrm{GBq} / \mathrm{d}(0.1 \mathrm{Ci} / \mathrm{d})$ to stay safely below the ralural tritium production of 400 to $80 \mathrm{TBq} / \mathrm{d}$ (10 to $20000 \mathrm{Ci} / \mathrm{d})$ [Ref. 2].

For a reaclor vessel of about $350000 \mathrm{~m}^{3}$, losses could only be kept to such a low level ir tritium concentration within the gas cover (area between blanket and containment vessel) were kept low. For this reason we are investigating ways of removing tritium from the gas cover and reducing tritium losses from the blanket and coolant to low levels.

Current Progress. In one conceptual design of ours there is air between blanket and vessel. A continuous cataly lic-oxidizer/molecular-sieve adsorber cleanup system maintains a $14.8 \mathrm{MBq} / \mathrm{m}^{3}(40 \mu \mathrm{Ci})$ $\left.\mathrm{m}^{3}\right)$ tritium icvel $\left[1.9 \mathrm{MBq} / \mathrm{m}^{3}\left(5 \mu \mathrm{Ci} / \mathrm{m}^{3}\right)\right.$ of tritiated water vapor (HTO)] against $6.7 \mathrm{TBq} / \mathrm{d}$ [180 Ci/d) leakage from reactor components, energy recovery systems, and process piping.

In this design the blanket contains submodules with a lithium beryllium oxide-beryllium mixture ( $\mathrm{Li}-\mathrm{Be}_{2} \mathrm{O}_{3}$ - $\mathrm{Be}$ ) for tritium breeding and submodules with beryllium for mostly energy production. We ohtain tritium by seavenging the containers that hold the breeding material with lithium-vapordoped helium gas. The container consists of molybdenutn alloy (TZM) tubes and tube sheets. The breeding material is packed and sintered in the shel] surrounding the tubes. Potassium-vapor (also lithium-foped) coolant passes through these tubes to recover the heat at $900^{\circ} \mathrm{C}$. Tritium leakage from the scavenging helium into the potassium vapor within the blanket submodule can be reduced to $133 \mathrm{TBq} / \mathrm{d}(3600 \mathrm{Ci} / \mathrm{d})$ for the TZM case. This leakuge after an iniermediate TZM exchanger wauld result in loss into the stream by means of Haynes-25 alloy/boiler (potassium boiling) of $25.9 \mathrm{GBd} / \mathrm{d}(0.7 \mathrm{Cl} / \mathrm{d})$. We use a moving getter bed to recover the Iritium from the lithium tritide (LiT and $\mathrm{Li}_{2} \mathrm{~T}$ ) scavengers in both the helium-blankel scavenging flow and the potassium-vapor coolent. The increase in leakage fesulting from repluccment of the TZM with niotium is being examined.

\section{References}

I. J. D. I.te. W. L., Bitrmure, D. J. Bender, J. N. Doggell, and

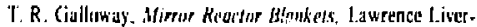
nlore labbiralury, (K(I)-17(tk3 (1976).

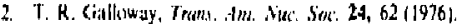

\section{Author}

T. R. Galloway

\section{Tritium Control in Mirror Hybrid Reactor}

Introduction. Tritium control in the mirme hybrid reactor is possible with emissions to the thvironment below $0.4 \mathrm{TBq} / \mathrm{d}(10 \mathrm{Ci} / \mathrm{d})$, while still mainlaining worker safety and cost effectiveness. We employed a number of new methods to achieve such low levels in a near-term ,nachine wilh today's technology. Figure I summarizes the various tritium leak-source lerms and the associatec processing loops.

Current Progress. The tritiumbreeding pins, designed as tritium-combainment ressels fllied with lithium deuteride, are constructed of a special low: permeability, high-temperature strength aluminum allay. In the hybrid reactor these tritium breeding pins are "harvested" with the plutonium pins. Tritium is extracted from these tubes in-plant, and the lithium deuteride-filled tubes are remanufacsured and reinstalled for the next cycle. A breeding. 


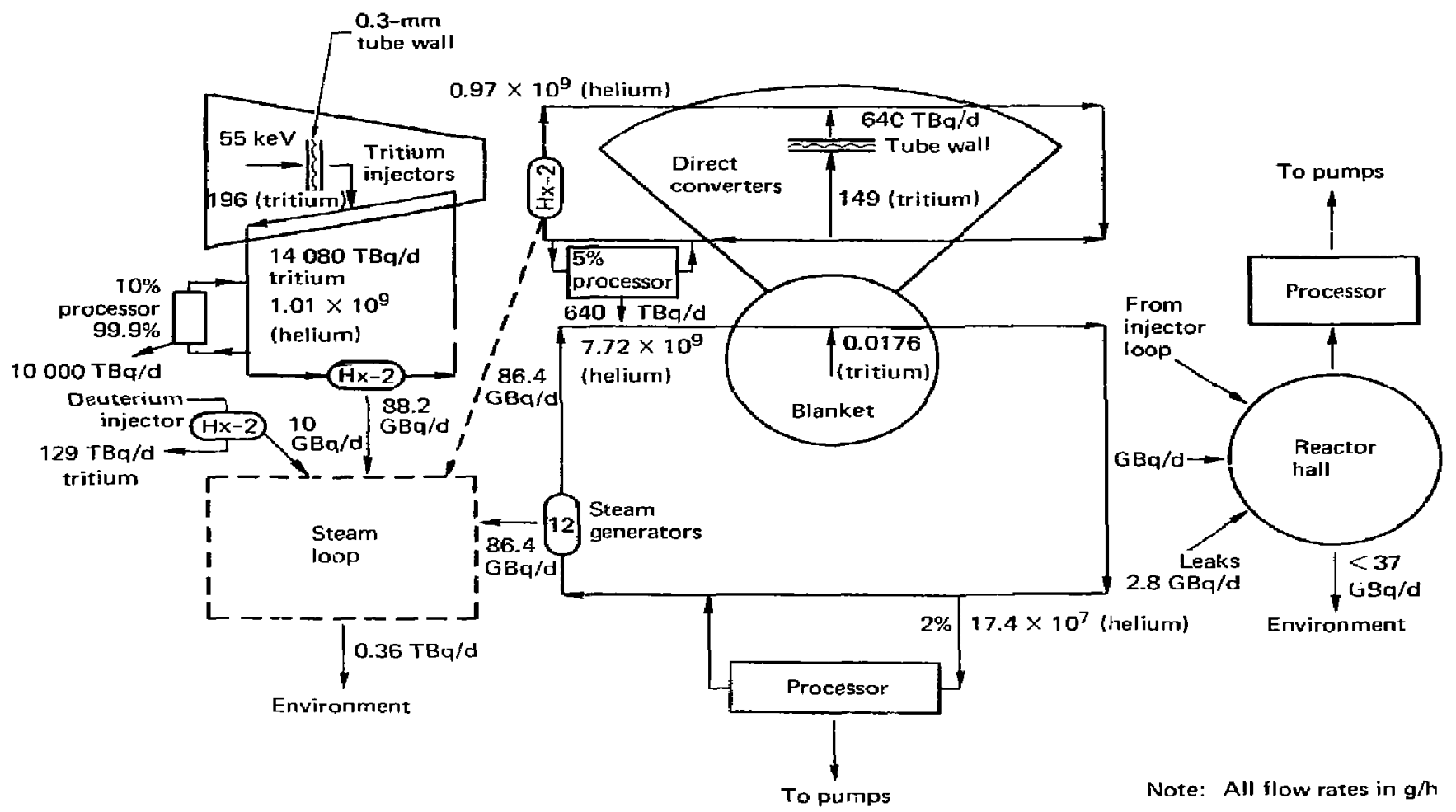




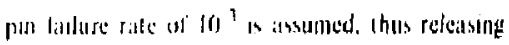

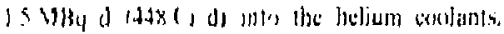

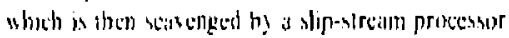

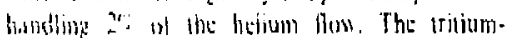
sontaminaled helium will permeate about 90 (il3y:d 3 ( Ci/d) into the steam generators, which is low to the soling ances and then wo the environ. ment.

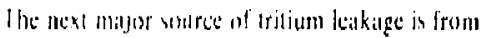
trolum neulral-batm injectors. where $5.5-\mathrm{kic}$

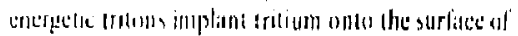
the clectrode whine. Ones whin the lubs, metat permeatom produce a flur of Irthum ind the cict-

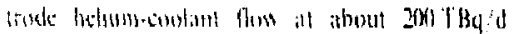

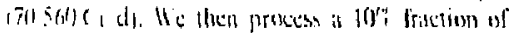

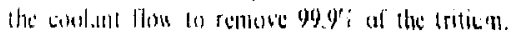

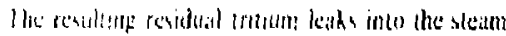

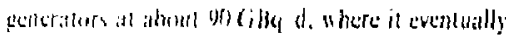
pianes mist the sumling water and then we the tor.

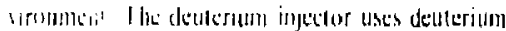
sall it manuman l', tritium impurily level: it

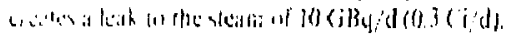

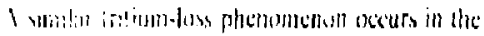

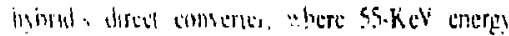

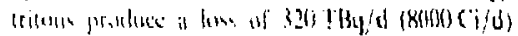

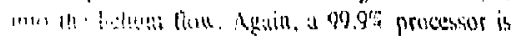

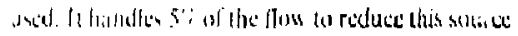

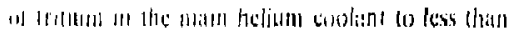
Mitiky d.

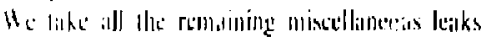
from the process sepuipheme and pipsng or ciucting

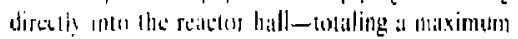

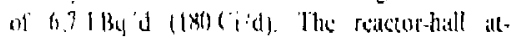
moplore in procensed and kep all low hemidity to

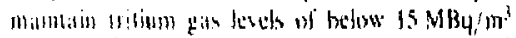

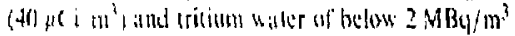

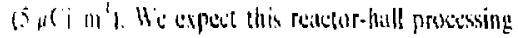
desten lo resull in routine at well als creditsle acci-

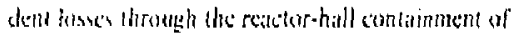
less that 37 (itheid $(1)$ (i)d).

In this waly trititin loss to the environment is designed to be less than $90 \mathrm{GBq} / \mathrm{d}$ from breeding pin losses. $90 \mathrm{GBq} / \mathrm{d}$ from injectors, $90 \mathrm{GBq} / \mathrm{d}$ from the difector converter, and less than $37 \mathrm{GBd} / \mathrm{d}$ from seictor-hull contatinnent permeation. This is sontc 40 limes lawer than that required by Nuclear Regulatory Commission regulations for all nuclear fuel cycle operations, but about the level suggested by the ALARA (As Low As Reasonably Achievable) cosl/benefit analysis (an expenditure cut off it the $\$ 66000$ levell). We found that no further reqductions in emissions could be eccomplished by such an expenditure.

\section{Author}

T. R. Galloway

\section{Tritium Processing and Control Systems}

Intraduction. Proposed rusion reactors call for a large tritium inventory. Containment and cleanup systems will be needed to limit personnel exposures and population dose. Miso. fusion research facilities presently being designed will require tritium clalnup systems. Tritium can be removed from er. fluent air by catalytic oxidation followed by water adsorption. Available performance characteristics and hasic data for the design of tritium/air cleanup syetensh, however, are indequate. Our program secks 10

- Develop malbemicical rtodels for the enginesing dexign of iritium cleanup systems.

- Obtain ditt on the kinetics of oxjdation and adsorplion-bed dynamics.

- Develop instrumentation for real-time dis. crinination of tritium gas and tritiated water vapor.

('leanup-System Concepts and Calculations. 1.quipmeni size and cost were astimated for a la rgescalts $\left(70 \mathrm{~m}^{3} / \mathrm{s}\right)$ tritium cleunup system using oxidation-adsorption models previously described. I We prepared these ualculations for a metling at the Silvinnahl River Pan!. Savannah River is considering a large-scalc processing system to contain accidental spills. Various processing coneepts were dicussicd: onlint rontinuous, ance-through standhy, and vacuum-lank holdup with su asequent tow-flux-rite teyclo processing. Attendes tortcluded that datat are insufficien to permil rational choice of a costerffective concent for tritium remotial from air

Cast-Benefit Model. One must ask how much investment is justilied to prevent (contain) a postulaled accidental release or wo reduce a continurus relcuse. Assuming that onsile personnel ex pusure is not significant, the problem reduces to at estimation of the maximum pernissible dose to the oflsite population. For the re:case of tritiated water vapor, the calculation is complicated by metcorological parametors. The effect of gas release is easier to estimale. assuming eventual dispursion over the Northern Hemisphere, Our wlculations show an es. timaled justiftable investment of $\$ 70 / \mathrm{TBQ} / \mathrm{lo}$ provent is single release and $\$ 540 /(\mathrm{TBq} / \mathrm{y})$ lo prevent at concinuous release of tritium as gas. We primarily based the method of estimation on Bennells? model for aritium dose cue to atmospheric production.

Bench-Scale Experiment Design. We are design ing experimental apparatus and related instrumentution to test calaiysts and adsorben beds for tritium sleanup. Component design and fabrication are nearing completion, and exerimentation will begin early in 1978. Two Belatec tritium monitors 
with dual 2-liter ionization chambers were calibrated electronically with a picoammeter source. The in itruments gave a stable. reproducible, nearly linear output over the six-decade range $(\sim 10-5$ to $10 \mathrm{GBq} \cdot \mathrm{m}^{3} \mathrm{l}$. Calibration with Iritium gas remains to be done. The insuments, with associated flowthrough bellows pumps and plumbing, were prepured for installation in the experimental area.

\section{References}

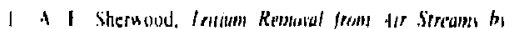

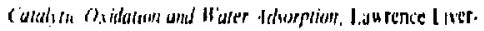
mofe 1 shuratoty. [ ( $\mathrm{KI}-7 \mathrm{KI} 73$ \& 197\%).

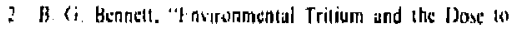

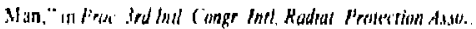

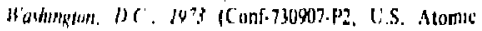

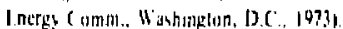

Author

\section{A. E. Sherwood}

\section{Tritium Processing and (ontrol I sing Active Metal Getters}

Introduction. Our investigation is directed toward stecting and characlerizing the hydriding behaviur of suitible getter malesials. Many metals. intermetallic compounds. and alloys form hydrides. Their hydrogen dissocialion pressures and capacitics vary widely. We are interested in selecling and sludying the behavior of the hydride formers lhat would best fulfiil Lawrence Livermore Laboratory magnetic fusion energy requirements for tritium cleanup. For easy recovery of the tritium. the hydride should have a low dissociation pressure ( $\angle 0.3 \mathrm{mPa})$ al hydriding temperatures and a high dissociation pressure $(>100 \mathrm{kPa})$ at a moderately elewuled temperature.

Currem Progress. Usanium is a getter used for years to collect. store, and purify tritium gas. Uranium metal is accivated by heating with hydrogen to form uranium hydride, which is a finely divided powder. The hydride is then heated to $400^{\circ} \mathrm{C}$ in vacus so it can decompose to uranium powder. This hydriding/dehydriding cycle can te repealed indefrnitely with no deleterious effect on the reactivity or capacity of the uranium for hydrogen. For uranium hydride the dissociation pressure of hydrogen is $<0.3 \mathrm{mPa}$ at room temperature and $\sim 100 \mathrm{kPa}$ at $700 \mathrm{~K}$ as shown in the pressuretemperature-composition diagram (Fig. 1).

We sludied uranium hydriding behavior under varying flow conditions, using a specially designed uranium trap to prevent channeling and promote maximum reaction rates with the gas. To test the trap we used mixtures of deuterium in argon at room temperature at several concentrations and

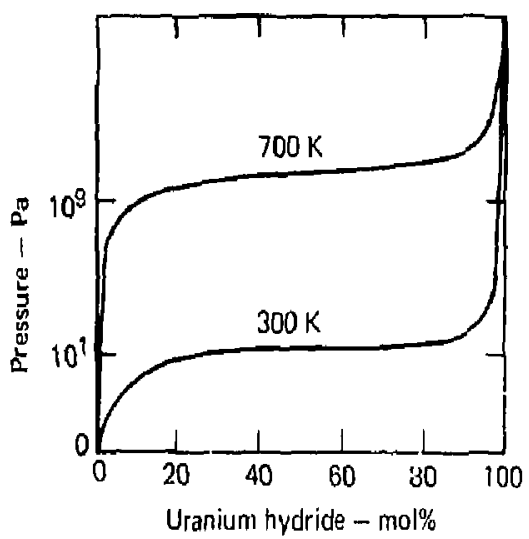

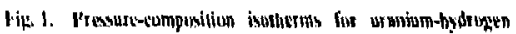

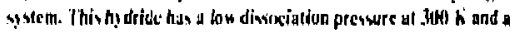

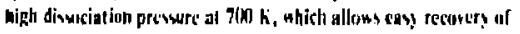
hydtugen (ot sf tritium l.

flow rates. The concentrations of deuterium in the argon stream above and below the trap were measured by mass spectrometry (Fig. 2). Results were expressed as the purification faclor, which is the ratio of deuterium concentration at the inlet of the uranium trap to the concentrution at the outlet. We found purification factors to vary inversely with both the alom: iutio of decuterium to uranium already contained in the trap and with the rate of now of gas through the trap. These purification factors, however, appeared to be independent of deuterium concentrations in the ranges studicd! (0.1 10 5 vol\%).

Uranium sludies form the basis of our currenl inrestigalions into suilable getiers for tritium cleannp. We selected cerium as the second metal to test mainly because it hats a low dissociation pressure? for tritium at temperutures between 25 and $250^{\circ} \mathrm{C}$ $\left(10^{-33}\right.$ Pu al $\left.25^{\circ} \mathrm{C}\right)$, By using cerium we could ideally reduce the tritium concentration in a gas stream to $<1 \mathrm{pBq} / \mathrm{m}^{3}$, whereas the lowest achievible concentration using tronium would be $370 \mathrm{MAq} / \mathrm{m}^{3}$. Corium also reacls rapidly with tritium. has lafge trilium capacity, ind is reasonably cheap and available. It is, however, highly pyrophoric in air and reacts with nitrogen, carbon monoxide, carbon dioxide, and water. Because it could be poisoned by exposure to these gases, it must be hundled in an in. ert atmosphere.

We purchused powdered cerium and prepared it for use by clcaning with organic solvents, vacuum drying to $400^{\circ} \mathrm{C}$, and grinding $10 \sim 200-\mu \mathrm{m}$ particle size. All handling was done in an argon glove-box. Characterization included vacuum fusion. spec- 


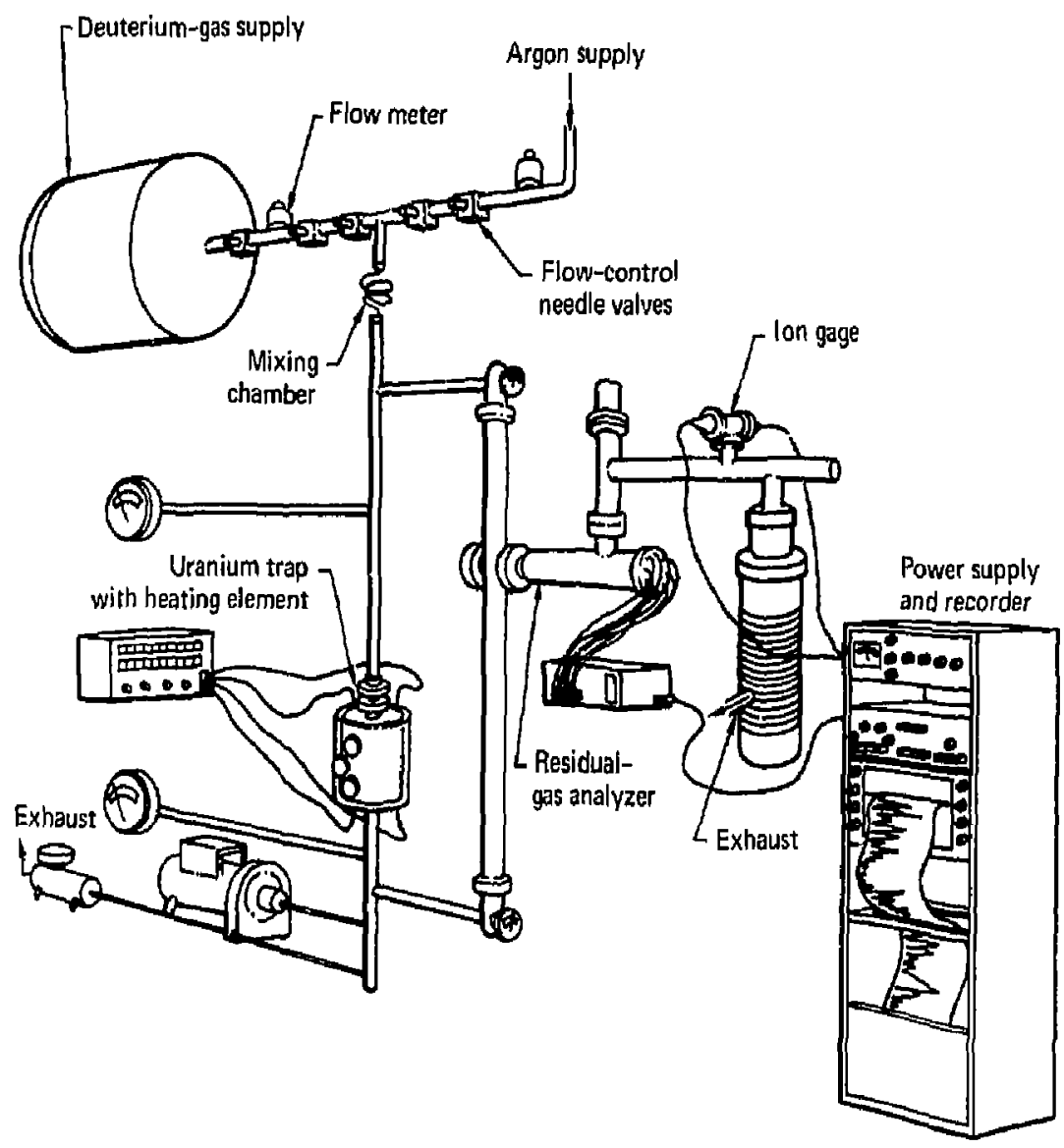

Fig. 2. F.xperimental mpparalus for measuring deuterium removal from an argon stream. The specially designed uranium trap prevents channeling and promotes maximum reaction rates between getter and gas stream.

trochemical, x-ray diffraction, differential thermal, and photomicrograph analyses. The principal impurities appeared to be hydrogen, oxygen, and nitrogen in the amounts $9.6 \%$ cerium oxide, $7.5 \%$ cerium dihydride, and $1.2 \%$ cerium nitride. All other impurities totalled about $250 \mathrm{ppm}$.

A trap containing $699 \mathrm{~g}$ of cerium was both assembled and welded under argon. Our initial experiments used the same apparatus described for the uranium work. When the trap was in place in the system, we heated it to $400^{\circ} \mathrm{C}$ for $4 \mathrm{~h}$ to activate cerium for rapid reaction with hydrogen. We added deuterium to the trap to bring the deuterium/ cerium atomic ratio to 0.20 ; the reaction went to completion immediately. Subsequent hydriding experiments were at 200,100 , and $2 \pi^{\circ}$. No temperature dependence was noted in the bydriding behavior in the first series of runs (deuterium/cerium < 0.6 ).

Preliminary results ase encouraging, but we do not have sufficient data to draw any definite conclusions. Although at one point the cerium became passive to deutêrium, we achieved reactivation by heating to $400^{\circ} \mathrm{C}$ in vacuo. Some purification factors attained were greater than our experimental limits of detection (core in/core out $=30000$ ). We can presumably improve the !imits of detectability by using Iritium instead of devterium in the argon stream and by measuring the concentrations above and below the trap with high-sensitivity ionization chambers. ${ }^{3}$ These ionization chambers have been fabricated, a:d we are in the process of remodeling the system for tritium use.

Since cerium forms a eulectic with iron at $595^{\circ} \mathrm{C}$, 
we are conducting some compatibility studies with stainless steel (Type 316) to determine the limits to which cerium can be heated in this trap. Cerium powder was sealed under argon in stainless-steel containers and heated in a resistance furnace to $600^{\circ} \mathrm{C}$. The two samples prepared so far were hested for $10 \mathrm{~min}$ and $6 \mathrm{~h}$, respectively. Pholomictographs of the samples show some small reactions at the cerium-sleel interface. Microprobe scans, being prepared, will help us determine the extent of this reaction. The sample heated for 6 h showed signs of some cerium-steel container inveraction. A photomicrograph of a cross section of this sample and the container shows the change in character of the cerium at the interface and along the side of the sample area (Fig. 3). We are also considering possible new trap designs and materials.

\section{References}

1. C. L. Folkers and M. R. Singielon, Collection of Deuterium on a Lrausum Geller During Dynanic Flow Conditions, Lawrence Livermore Laboratory, UCRL-76734 (1975).

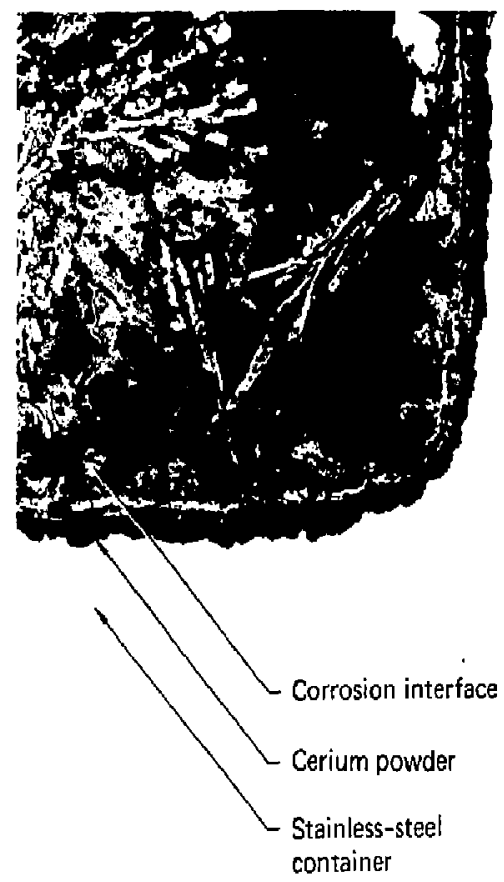

Fig. 3. Photomicrograph ( $100 \times$ magnification) of cerium ponder in stainless steel, heated $10600^{\circ} \mathrm{C}$ for $6 \mathrm{~h}$. The change in appenrance of the cerium adjaccnt to the stainless steel (the corrosion interface! indicated an interaction with the stainless-steel conminctín
2. 1. L. Maienschein, Applicability of Chemical Getter Beds to Scarcigc Tritium from Inen Gases. Luwrence Livermore Laboralory. UCRL-52034 (1976).

3. C. A. Colmenires, "Bakeable lonization Chamber for LowLevel Tritium Counting," Nac. Iasirum. Methods 114, 269 (1974).

Author

M. F. Singleton

Improved Equipment and Production

Procedures for Rotating-Target Neutron Source-II Tritide Targets

Introduction. Analysis of production and opera. tions data for Rolating-Target Neutron Source (RTNS) targets (fabricated by Oak Ridge National Laboratory) was terminated early in the fiscal year. We revived developmental efforts later in the year. with an emphasis on producing several high-quality, internally cooled titanium tritide targets for use on RTNS.II, Primary goals are to produce targets haying (a) more repeatable operating characteristics than the one currently used and (b) a long life $(\sim 100 \mathrm{~h})$. Such an effort should provide for higher average neutron strengths and less downtime for target changes.

Current Progress. Target substrate labrication, titanium evaporation, and tritium loading will be accomplished by Lawrence Livermore Laboratory. The first target is scheduled for production during mid.FY 1978. Special emphasis will be on keeping the evaporated titanium film clean and active before tritiation. To reach this goal we took certain precautions in system design and fabrication procedures. Such an approach includes using ultrahigh vacuum compatible hardware for construction, keeping the titanium layer under good vacium or high-purity inert gas, and minimizing time need from initial titanium evaporation to final tritium loading. The target will be exposed to air anly during a short time between its removal from the titanium evaporation system and encapsulation in a transfer container.

$A$ detailed log of each target's production and operating history will be kept. Also, considerable metallographic microscopic and surface analytical data will be collected for further correiation with target performance.

Author

S. A. Steward 


\section{SECTION 3. RESEARCH}

\section{Theory and Computations}

\section{Introduction and Summary}

This year has seth the mirfor program focus on ino alternite mirror paths. the landem mirror and the field-reverted mirror. Consequently there has becll it moderate change in emphasis in the theory program. The face that single-celt mirror physics is contmon to both paths necessilates comtinued studies in this ared. which is now refered to ats standard-mirror theor.

In this artat we have siten improvements in the lintar theory of drift cyclotron loss cones (DCI,C) and the concomitunt quasilinear theory. This Jatter study assumes that diffusion dus to fluctuations leads lo stochatstic hehavior. An in-depth study of che ctlects of waves on particles has produced relined conditions, vis-it-vis wave amplitude, for the olise of stochasticily. Along these same lines a general liornalism hals heen develoned that delermimes audatalic invariants and generates tequalions that determint the magnitude of torakdown of these sume invariants. Since, in mitror configuriltion. conlinenent relies on the presence of adiabatic invarianls, such analyses leved ultimately 10 configurahional linitations.

In the tandem mirror area we completed a delailed proposal in which we delineated the majur problen artas in theory and performet first-cut analysis of many of these. Since that tine we performed further work in such areas as ficld design and rolitional inslability. Further studies of the limitation of anisolropy due to the Alfuen ioncyclotron (AIC) mode in the central cell were compleled.

ficld-reversal studies have led to an un. derstanding of the role tlectron currents play on the buildis 10 and maintenance of this configuration. Finully there have been continuing studies ol negative-deuleriam-ion formation on alkali-coated surfaces.

We primarily devoted our computational activity to understarding the 2XIIB Experiment, with emphasis on continued exploralions of field reversal. modeling for the Tendem Mirtor Experiment (TMX): and some work on the Mirror Fusion Tesl Facility (MFTF). The primury codes used were SUPERLAYER, Fokker-Planck, and McGus (a 3-D magnetohydrodynamic equilibrium code).

A large effor went into SUPERLAYER for modeling if drift-cyclotron loss-cone (DCLC) diffusion. The basic quasilinear description was assumed, and a Monte Carlo technique for randow scallering of the particles in $v_{1}$ was implemented. The presence of diffusion was absolutely esseritial for SUPERLAYER to produce iorl-velocity dis. tributions peuke "near the beum-injection energy (as observed in 2XJJB). With no if diffusion, a dragdominated ion elistribution would have resulted. which was clearly not occurring in $2 \times 118$.

Using rl diffusion and a proper beam-deposition algorithm, we underlook a variely of parametric stuáier in accurately model $2 X I I B$ and to delermine model sensitivities. Cumparison with $2 X \mid I B$ stilt showed marked differences in such grusss features as plasma length and achicved field depression for a given beam current and electron $t$. sperature. We believed these differences could not be explained by inaccuracies in the present model. i.e., numerical errors. This negative result strongly indicated the importance of physical effects not yet in the model: it clearly pointed out that we did not yet completely understand the physics that delermines the scaling of the presen $2 X I 1 B$ regime to higher beun currents and etectron teniparatures.

As part of our ongoing thecoretical effort to bet ies understand the 2XIIB Experiment, we continued to design and impliment new particle-sjmulation algorilums to stud; low-frequency phenomena in magnetiaed plasma. We appliad these algorithms to the exumination of microinitabilities and the buildup of plasma currents related to reversal of the magnetic fielis in a mirror plasma. For particle simulition of high-beta (plasma pressure/magnetic pressure) mirror plasma with no closed magnetic ficld lines, we demonstrated that SLIPERLAYER II provided a salisfactory physics description of the sclf-consistent magnetic and inductive electric fields and ion motion. To this simulation model we added an exlernil-guadrupole magnelic field consistent in magnilude with 2 XIIB.

We made further progress on the development of physics models and new simulation melhods that describe important electron physics features in a high-beta plesma. We introduced a new family of algorithms for quasineutral. hybric (particle ions and fluid electrons) simulutions. This model was thoroughly tested for a variezy of linear enamples; compressional Alfven waves; electrostatic instabilities with some rinite-beta effects, e.g., the DCLC made; and elect romagretic instabilities, e.g. the Alfren ton-cyclotron (AIC) mode. The model produced new results for firite-geometry stabilizing efforts on the AIC mode. We also studied the excitation and relaxation of electron-return currents by means of the excitation of compressional Alfvén 
Waves when a weak current is injected perpendicular to an exiernally applied magnetic field in a cold, uniform plasma. Our tesults agreed well with theory. Some results were also obtaincd for targenamplitude currents.

Using a 2.0 mullispecies Fokker-Planck code (HYBRID (I) we underlook a number of studies en tandela mirror systems. Detsiled resuits involved effocts of adyanced fuel cycles (c.g., catalyzed deutsrium-deuterium), electron heating. two. component operation, and helium injoction in the solenoid for field-reversal experiments.

The bounced average Fok'ker-Planck code was partially rewritten in a $\mu-J$ form.

A large effort went into cantinued investigation of DCLC quasilinear studies, We investigated in detiil the effect of the radial-density gradient uriv. ing loam and its stabilization, caused by combining the plasma streum with elcetion damping/or outgo. ing wave damping or both. This work vied fixed spatial-gradien code: and a self-consistent radially dependent cods.

Flectron heuting stabilized the DCLC instability in is couple of experiments. We studied the conversion of electrun-beam energy into a hot distribution of electrons by means of beam-plasma instability and quasilinear diffusion of the electron beam.

We converted the axial flow code for the plasmit stream to un implicit different scheme so at could bs efficiently coupled to the quasilincat code.

We sxtended the Monte Carlo scheme (used to simulite the effects of DCLC curbulence on the phase-space arajectories of andividual particles in SUPERLAYER ') to two dimensions in both velocily and configuration space, Spatial diffusion is now properly calculated. We incorporate this spatial scteme in a Monte Carlo version of the 1-D quasilinear tratsport model of Berk and Stewarl: it qualitalively reproduced their results. This cour demonstrated the computational feasibility of determining turbulence level self-consistently in a particle code such as SUPERLAYER (which made it possible to put the Monte Carlo diffusion scheme in energ)'-conserving form).

We thoroughly applied the 3-D guiding-center nuid-equilibrium code, McGus, to studies of MFTF, the TMX plugs, and several reactor designs. We lad two inain results for TMX:

- A good magnctic well was preserved up to the design $B$ (magnetic-field) values for the experiment. This magnetic well ensured gross stability of the linked mirror plasmas.

The 2-D equilibrium esde C Y LEQ was applied to field-reversed and near-hield-reversed equilibria at parameters close to 2 XIIB. The qualitative connec- tion betwees the code and the experiment ugreed with the conclusion that 2 XIIB was close to, but not al, a field-reversed staic with the beam current usis so far.

We completed initial versions of Monte $C_{i:} \cdot 10$ codes for neutral particle tiansport.

Other work this year included

- Development of a MACSYMA progria i tor generalized adtabatic invariants.

- Developnent of an incompletc Cholesky conjugate-gradiemt 3-D Poisson solver.

- Adaptation of a luid sode to the modeing of negarive-jon beams.

- Examination of stochascic behavior resulting from collisionicss motion of a particle in the presence of two waves.

\section{Reference}

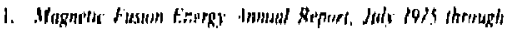
Gepesthor 10\%. l.awrense liverntore labofaloty. LCRI. $50003.76,(1976)$.

Nuthors

1. 1). Pcutstuin

1. A. Bys":

\section{Quasilinear (udes for lim}

Trunspont in Mitrors

This year we continued development of the quaslinear codes that fescribe the salturation of the drift-cycluten loss-cone (i2CLC) instibility and of the associteted ion transport. We nou hilte thres codes thit somplement each other in the serite of mitking different approximations. The codes ats ilse I.D in $v_{1}$ velocity spate the 2-D in $v_{1}$ and $v_{11}$ velocity space, and the $2-1)$ in $v_{1}$ velocily space and radial position r. Liss year's annual report give: our :ulis for the first two cudes.

$A$ major accomplishenent this year was the developnent of the $\left(v_{1}, r\right)$ code 10 the point where it produced quasifineur marginal stability that included self-consistent spatial diffusion. The equation solved by this code for the ion-distribution function $F$ is

$$
\begin{aligned}
& \frac{\partial t}{\partial t}=\left(\frac{2 m \omega_{c i} \partial}{\partial v_{l}^{2}}+\frac{\ell}{\omega_{v i}} \frac{1}{r} \frac{\partial}{\partial \tau}\right) D\left(u_{i}^{2}, r\right) \\
& x\left(\frac{2 n \omega_{c i} \partial}{\partial v_{\perp}^{2}}+\frac{\ell}{\omega_{i i}} \frac{1}{\partial \mathrm{r}}\right) \mathrm{J} \\
& +\nu_{D} \frac{\partial}{\partial v_{\perp}^{2}}\left(v_{l}^{2} l \cdot\right)-v_{L} l+Q\left(v_{l}^{2}, r\right)
\end{aligned}
$$


This first term on the right is due to quasilinearwave diffusion in velocity and in radius, where $\ell$ and $\mathrm{n}$ are the azimuthal and harmonic mode numbers, resjectively. The last three terms are electron drag, finite transit loss in the unconffined region of phase space, and an external-sou:ce term due to neutral. beam and stream injection. Figure I shows rtsults from a typical run of this code.

The influence of the spratial-density gradient is destabilizing. This effect tan be modeled approximately in the two velocity-space codes by adding terms representing a fixed gradient in the growthrate expression and in the of diffusion operator. All the codes confirm that the density-gradicnt term causes the DCLC to be more difficult to stabilize than in the case when the gradient is neglected. In fact, when we obtain the wavenumber of the unstable made by solving the dispersion relation: : detail, the if potential grows to a large level. The distribution is driven lo a Maxwellian form for these high if diffusion levels. We found, however,
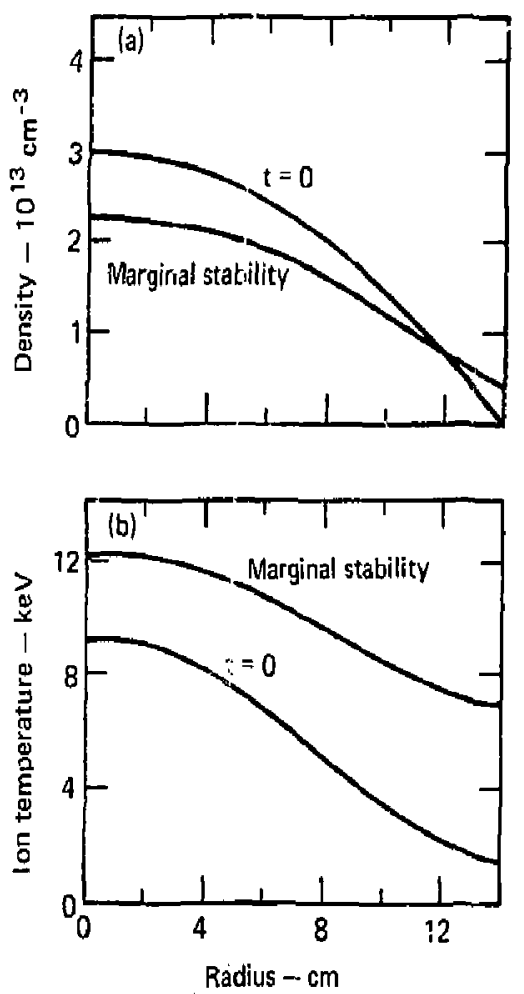

Fig, 1. Typical resulss from 2-D $\left(v_{+}, r\right)$ quas sillines code showing (a) radial density and (b) sadlat jon-temperature profiles initiolly $(t=0)$ and at self-consistent majginal strbility. The of couses the densily proflde to fintten and the ion-temperature gradient to persist.

that only a small amount of additional damping of the DCLC mode gives results in line with the 2 XIIB Experiment. The case shown in Fig, $t$ has an added damping of $0.1 \omega_{\mathrm{c}}$, We considered several mechanisms that can give this amount of damping, including outward-going waves at the end of the mirror machine, electron damping due to classical collisions enhanced by large radial wavenumber. and nonlinear electron damping. The $\left(v_{\perp}, r\right)$ code indicales that the shape of the radial eigenfunction also has a imporlant effect on tinal stability, Models for these damping mechanisms will be investigated in detail during FY 1978. In addition, the $\left(v_{\perp}, r\right)$ code shows the development of a self-consistent tempcrature gradient; its effect on stability will also be studied.

Another area of investigation concerns the phenomenon of of bursting. The if potential observed in 2XIIB is often characterized by periodic pulsations instead of a steady of level. We also found this type of behavior in the quasilinear codes. There is a threshold that depends on neutial-beam current and the magnitude of the growth rate. This oscillatory nature of the linal stale, obtained using quasilinear theory, is an interesting departure from the usual case of a time-independent final statc.

in relation to using the codes for predicting the detailed behavior of the Mirror Fusion Test Facility's mirror machine, we verified that the approximale way in which the dispersion relation is solved in the codes is an accurate representation of the more rigorous solution. Our quasilinear codes assumed that the most difficult modes to stabilize were those nearly at the ion-cyclotron harmonics. Exact solutions to the dispersion relation have shown this to be a good assumption.

\section{Reference}

1. Maguesic Fusion Energy dintual Report, July 1975 dimugh Seplenaber 1976, Lawrosce Ljvermore Laboratory. UCRL. 50002.76 (1976).

Authors

H. L. Berk

Y. Matsuda

T. D. Rognlien

\section{Marginat-Slability Studies of Drift-Cyelotron Loss.Cone Mode}

In the previous annual report ${ }^{1}$ we discussed the effects of warm plasma and orbit diffusion on stability boundaries. Stability boundaries were seen to be strongly modified by ion-orbit diffusion due to the highly resonant nature of the mode. This great sensitivity was soriewhat disquieting since the non- 
linear theory from which this term arose was not rigorous; thus these distortions were only reliable in a qualitative sense. More recent studies included the effects of orbit distortion on these resonant modes. These distortions are important since at marginal stability the modes are so resonant ( $\omega \approx \pi \omega_{\mathrm{ci}}$ ). How one includes this effect is sketched below.

First, break up the response of the plasma into its asymptotic and nonasymptotis pieces so the differential equation along a field line ${ }^{2}$ can be written

$$
\frac{1}{g} \frac{\partial}{\partial s} g \frac{\partial \phi}{\partial s}+q_{a ; y m p}^{2} \quad(s) \quad \phi=F n \phi
$$

$$
\begin{gathered}
\left\{\int_{-\infty}^{\infty} d v_{0} f(v) i \omega \int_{-\infty}^{t} d t^{\prime}\right. \\
\left.\operatorname{cxp}\left[-i \int_{t^{\prime}}^{t} d t^{\prime \prime} \mid \omega-n \omega_{c}\left(t^{\prime}\right)\right]\right] \\
\left.-\frac{\omega}{\omega-n \omega_{c}(s)}\right\} \equiv \Lambda(s) \phi(s) .
\end{gathered}
$$

In this expression we removed $\phi(s)$ from under the integral because the perturbation slowly varies compared with the exponential. Note that $q^{2}$ con'dins the asymptotic response of the ions, the form standardly used, and that rhs vanishes in the asymptotic limit. Near marginal stability the modes occur at the harmonics of the central cyclotron frequency. Consequently, except near the midplane, the rhs vanishes. That is, $V(s)$ is a sharply peaked function of short range [compared with $\phi(s)$ ]; consequently

$\left\lfloor\frac{1}{\phi} \frac{\partial \phi}{\partial s}\right\rfloor_{s=0}=\int_{-\infty}^{\infty} \Lambda(s) d s$

and the lhs is computed by setzing the fhs of $\mathrm{Eg}$. (l) equal to zero. For a parabolic well $(B=\mathrm{Bo}[\mathrm{l}+$ $\left.S^{2} / L^{2}\right]$ ) we have

$$
\begin{aligned}
\int_{-\infty}^{\infty} \Lambda(s) d s & =L \frac{\omega}{n \omega_{c i}} \sqrt{\pi i} \int_{0}^{\infty} \frac{d \tau}{\sqrt{\tau}} \\
& \exp \left(i \frac{\omega-n \omega \omega_{c i}}{\omega_{c i}} \tau\right) \\
& \times\left[\left(1+i \frac{\tau^{3} \rho_{l}^{2}}{n^{2} L^{2}} \frac{T_{11}}{T_{1}}\right)^{-1 / 2}\right]
\end{aligned}
$$

The $\tau^{3}$ term contains the transiting-orbit distor(ions (both dispersive and dissipative). Competition between this negative dissipation and electron Landau damping (outgoing waves) provides the stability boundaries.

In Fig. I we show critical radii in terms of the Larmor sadius as a function of plasma pressure/magnetic pressure $(\beta)$ and density for a spherical plasma. Figuse 2 plots the magnitude of warm density transiting the Tandem Mirtor plugs (subscript $w$ ), required for stability, in units of hot density for two hole sizes $\left(T_{\text {hole }} / T_{\text {hot }}\right)$. In all cases the density in the solenoidal region is $30 \%$ of the plug density, All other parameters reier to the plugs.

\section{References}

I. Magnetic Fusion Energy' Anmugl Refwr, July 1975 through Sepjember 1976, Lawrence Livermore Laburatory. UCRI. S0002-76 (1976).

2. H. L. Berk, L. D. Pearlstein, and J. C. Cordey, "Critical Lengths for Mirror Machines." Physs. Fluids 15, 891 (1972).

Author

L. D. Pearlstein
Major Coniributor

N. Maron 
Plasma pressure/magnetic pressure, $\beta$

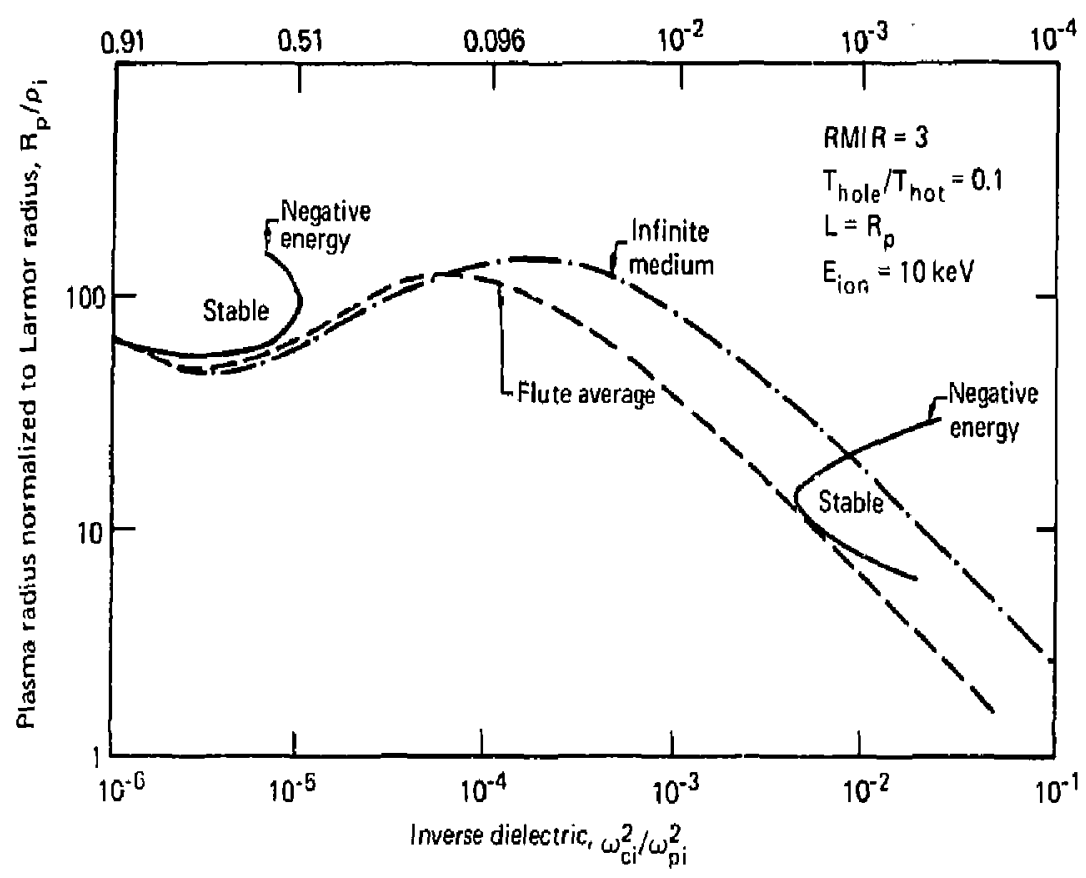

Hig. I Critical madi for a spherical phama. We ploted these redit in lerms of the larmor radius as a tunction 3 ar densily. 


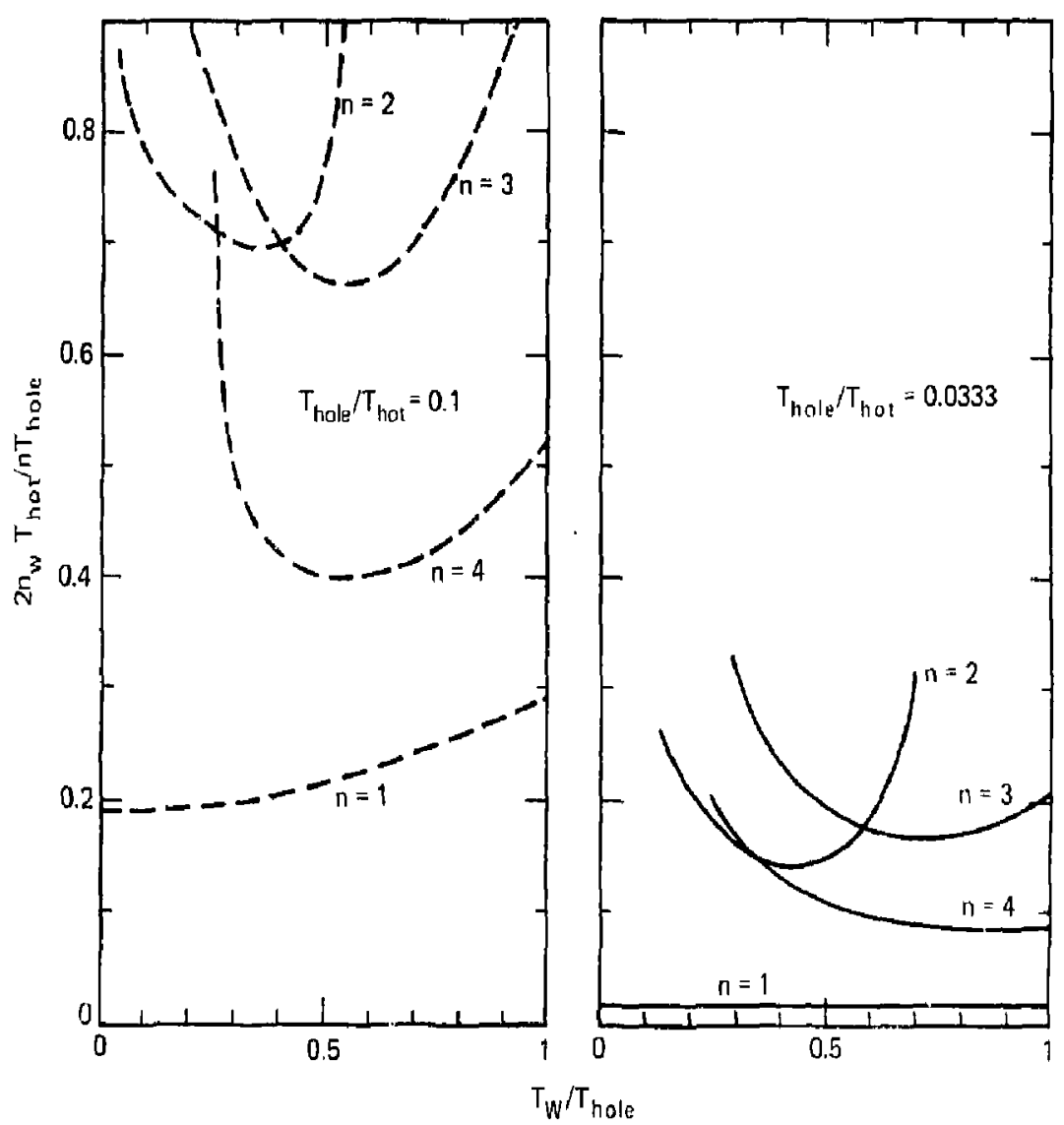

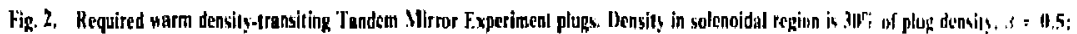
mir rer ratio $=1.5: \mathbb{K}_{\mathrm{p}} / \rho_{\mathrm{i}}=3 \mathrm{i}$ axial scale length $/ p_{\mathrm{i}}=4 \mathrm{i}$ rentral-cell density/plup densil! $=0.3$. 


\section{M = 1 WOBBL.E Instability \\ Driven by Rotation}

In theta pinches and in the central cell of a tandem mirror, rotational inst abilities are expected to be one controlling factor for allowable equilibria. Recent theta pinch experiments ' show that an $\mathrm{m}=$ I (aximuthal-mode number) rotation ("WOBBLE") is a common occurrence. Farly calculations ${ }^{2}$ shew that the most difficult mode to stabilize is the $m=$ $2, n=0$ (rudial-mode number) rotating flute. The $\mathrm{m}$ $=$ I rigid displacement is marginally stable (consequence of angular momentum conservation). More recent numerical calculations ${ }^{3}$ show that a departure from flute perturbations $(k \cdot B>0)$ relaxes this later constraint and that an $\mathrm{n}=0, \mathrm{~m}=1$ rotational instability sels in when the ions are rotating.

Here the propertics of this mode are solved analytically: the resultant dispersion relation follows:

$$
\begin{aligned}
& 1 .=\ln \left(\Omega_{1} \Omega_{2}+n\right), \\
& f^{\prime}(1 .)=-1,
\end{aligned}
$$

and

$$
\begin{aligned}
& \left(\omega^{2}+k^{2} V_{n}^{2} \beta\right)=\frac{k^{2} V_{u}^{2}}{2} \ln \left(\frac{u_{1} s_{2}}{k^{2} V_{a}^{2}}+\beta\right) \\
& x\left(\frac{1}{1-\frac{\pi \operatorname{sign}\left(\Omega_{1}\right)}{\ln \left(\frac{n \Omega_{1} \Omega_{2}}{k^{2} v_{a}^{2}}\right)}}\right)
\end{aligned}
$$

\section{References}

1. B. J. Commisso, C, $A$, likdahl, $k$ B. Fresse, $K, t$, Mekenna, and W.C. Quinn, "Solid End Plus Experiment on a I Pinch," Mhiss. Rev. L.ett. 39, 137 (1977)

2. M. N. Kosenbluth, N. A. Krall, and N. Roshker, "Finile l.umor Rudius Stabilization of 'Weskly' Unstable Confined Plasmia," Nitht. Fusion Sunpl. P1. 1, 143 (1962).

3. J. P. Freidberg and J. A. Wesson. "Instability of the $m=1$

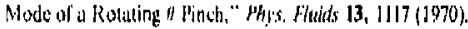

Authors

L. D. Pearlstein

J.G. Freidberg *

* Los Alamos Scientific I_aboratory.

\section{ETectron Effects in Ion-Current Field Reversal}

Existing calculations of magnetic-field reversal using an ion current injected with neutral beams have neglected all electron effects other than drag. Because ion orbits are generally comparable with plasma dimensions, while the electron orbits are small. onc assumes the generation of a current by ionization of neutral-beam atoms results from the charge separation induced by the magnetic field. In this picture, all plasma currents are carried by the ions. More realistically, electron currents can be generated by two means:

- The electron-ion drag tends to squalize the ion and electron average velocities, partially cancelling the ion current. This mechanism is particularly effective at the field null.

- Radial electric fields can be set up either by the charge sepuration that results upon ionization or by nonequal transport rates. In the presence of these fields, electrons can drift in a way to cancel the ion current.

We calculated electron currer,ts in the presence of assumed ion species of charges $\boldsymbol{Z}_{\mathrm{j}}$ and average velocities $v_{-i}$, using a niadel of simple electron momentum bulance

$$
\begin{aligned}
& D=t(1)+\frac{1}{i} y_{c} \times(3)+\frac{1}{\pi_{c}} \nabla P_{r} \\
& -\frac{n_{u} u_{c i}}{n_{i}} \sum_{i} n_{i} z_{i}^{2}\left(\underline{v}_{i}-z_{v}\right) .
\end{aligned}
$$

where

$v_{i j}=\frac{ \pm}{3} \sqrt{\frac{2 \pi}{m_{c}}} \frac{m_{c} c^{4} \ln A}{\mathrm{j}_{i}^{3 / 2}}$

is the electron-ion collision frequency. The following are our general conclusions for an axisymmetric configurations:

- The existence of a field null in steady state requires a net current at the null, This may be accomplished in a plasma composed of more than one ion species having different charges and average velocities, Most simply, a non rotating species offers a resistant background so the electrons cannot accelerate to nullify the current of a rotaing ion species. In an experiment this nonrotating species may be present in the form of impurities or may be supplied directly. In a reactor $\alpha$-particles might play the same role. 
- Away from a field null an azimuthal electrondrift velocity arises only because of a rudial electric field. The magnitude of this field is detormined by both the neutral-injection profile and the transport. - On open magnetic lines eleciron endconduction to grounded boundaries constrains the variation in potential across the magnetic flux to the ordet $T_{t} / c$. The resulting acimuthal electron-drift currents are small compared with the ion current; so calculations neglecting electron currents are jusijiced on open lines.

- On clused magnetic lines large potentiu. : vin develop between magnetic llux surlaces. and the possibility exists for significant cancellation of the jun curren! by drilling electrons.

A quantitative calculation of these effects requires inclusion of a prescription for calculating electric fields in ion-particle codes, such as SUPIERLAYER al Lawrente Livermare Laboratory. This inclusion is eurrently being inplemented.

Author

D. F. Baldwin

Major Contributor

M. E. Rensink

\section{Reassessment of Requirenents 10) Ohlain Fituld Reversal in Mirrur Machines;}

Hi: re-cxamined requirentents to obtain ficld rotersal by neutral injection. Our approach look acecount of a cancellation of currents all a ficld null calused by sestron-ion collisions that drag the secetrons along with the moving ions. We found that for calses ot interest exen a small admixture of higher- $Z$ ions generales a residual current (Ohkawal current) sufficiont to maintain field restsal in steady state with is lifetime comparable to the usual magneticdiffusion time. An approximate presicription was given for buildup to such a state: namely. the neutral injection currenl had to be sufficient to reduce the field to zero on axis with open confinement for an initiul plasma radius of $r_{1}=4 r_{1 . j}$, where $r_{l . i}$ was the ion-Larmor radius in the vacuum field. Again, high-Z ions were needed to bring about the transition to a field-reversed state, $\tau_{l}=4 r_{1-i}$ being the initial radius that minimized the injection current needed to do this for a reasonable higher $-Z$ ion content ( $10 \%$ helium, or less of a higher- $Z$ gas). Since $4 r_{\mathrm{Li}}$ was about wice the radius in past $2 X I I B$ txperiments, we concluded that either the injection current or the energy confinement time had to be substuntiaily increased, by about a factor of three if field reversal was to be achieved in 2XIIB. Auxiliary injection by pulsed ion sources or plisma guns might reduce the current requirsmems significantly if $2 \mathrm{~kJ}$ of energy could be deposted in the plismat.
Iuthor
Ilajur contributur
D. l:. Haldwin
T. K. louler

\section{Theory for Tundem Mlirror Experim it Proposa]}

The Tonden Mirror I:perimsme (TWK)

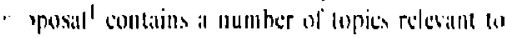

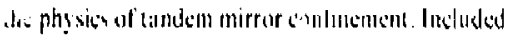
are studits of clissical energetion. microstibilit?.

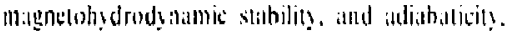

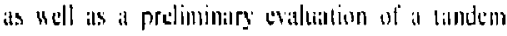
mirror deuterium-Iritium reitutor.

The TMIX experiment hils been decigned so that. in ils initia: mods of operation, its plugs operitle as

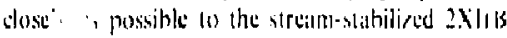
operattor in this mode the snd-|ass current lrome the sentrai wolendoid will sipply the sream mecessis!

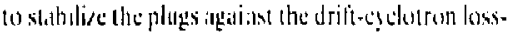
(o) me mode.

All tandem mirear milghetic fields hatre regions of

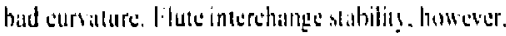
is strongly inlluenced fand usulall! insured, its in TMX) hy the hightepressure minmum-B plags. A curvalure-driven bathoming isterchange sets 3 .

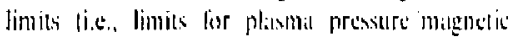

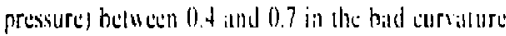
regions. Rolational insubidities draten by radial clectron licids would be poiential problems for a er: long solenoids. although not for lengths slach in thitt for TIIX or current conceptuat reiteturs.

\section{Reference}

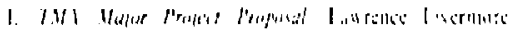

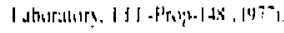

Author

D. E. Billain

Major Contributors

R. II Cohem

R. P. Iriss

B., (i. loggin

1. D. Pcarlstein

R. I. Port

\section{Monte Carlo Neutral-Transport cide}

We wrote a Monte Carlo code lo study the ransport of neutral particles in mirror-manthine plasmas. Veutral particles emitted hy simulated neutral-beim sources were followed in three dimensions through a larget plasma assumed to he in al sleady state consistent with the neutral-betm ifoput. We simulated ionization and chargetinchanget events using Monle Carlo kechniquess. Descendent 
generations of incident neulaal particles werc followed until losi cilher through ioniration or escape from the plasma.

The code presently uses a SUPLRLAYFR Heidy-stite distribution of $\sim 20000$ individual superparticles ats the target plasma: but an arbitrary target. gis suther in particulale or distributionfunclion form, can be used.

Prescolly anailable diagnessiles include

- Veutral density as a function of the cylin. dricill conrdinates $(r .$,$) .$

- Mein neutral energy as al funetion of $(r, r)$

- lilux of neutral particles emerging from the plasma in any particular direction as a function of posilion.

- Mcan energy of the cmerging lux as al lunction of position.

- lraction of inpul poher from neutral beams deposited in the plasma.

- Jrixtional atlenuation of incident neutral heitms.

We are presenlly using the code to inlerpret the neutral analyzer, beam altenuation, and other measuriments used as diagnostics in the $2 X I 1 B$ lixperiment.

.iuthor

T. H. Kutser

Monte (arlo Simulation of the Effects of I) rift-( Yyclotron Loss-Cone Turbulense on Single-Particle Orbits

We extended so two dimensions (in both velocily and configuration space) the Monte (arlo scho' $10^{1.2}$ used to simulate the effects of driftcyclolron loss-cone (DCLC) turbulence on the phase-space trajectorics of individual particles in SI JPERIAYLR. This generalized an earlier trealment that considered only diffusion in particle tenergy. Polariziltion of the Lurbulent electric ficlds that san be treated was gencralized to include linear as well as gyrotropic distributions of k-vectors. The turbulence level can now be self-consistently determined from the ion distribution function and from the linear dispersion relation: or it can be fixed arbitrarily at a predetermined steady-stite value.

Using this scheme, our inclusion of the effects of DCLC lurbulence in SUPERLAYER resulted in inproved agreement between the plasma steady stites predicted by the code and those observed in the 2XIlB Experiment. Detailed comparisons of code results with experimental observations are discussed in the section "Computer Calculations of 2XIIB Field-Reversed Mirfor configurutions".
Although the Monte Carlo scheme has thus far been used to simuliate the effects of only the DCLC mode, it is applicable in principle to magnetized plasma in the presence of weak flute-type electrostatic turbulence of arbitrary origin. The basic approach follows. ${ }^{3}$ We used the fully 2-D (2-space, 2-velocity) quasitinear kiretic equation to derive the probubility density governing the evolution of the four-dimensional phase-space trajectory of a single particte. This probability density (the Green's funclion of the kinetic equation) served as the basis of an intrinsically stochastic particle pusher. We simplified the kinetic equation by exploiting the fact that the diffusion timescale is much longer than the gyroperiod. This made possible a multipletimescales expansion. The result of this andlysis was that on the fast (gyroperiod) limescalc a particle's initial conditions were consected ulong the unperturbed orbit: on the slow (diffusion) timescale the phasc-space coordinates of a particle diffused away from the convected initial conditions in a manner determined by the fast-timescale-averaged quasilincar diffusion tensor.

The structure of the gyroperiod-averaged diffusion tensor depended on the detuils of the electriclield fluctuation spectrum and on the parlicular choice ol phase space coordinates. If coordinates $\left(x_{k}, y_{g}, v_{1}, \phi\right)$, where $\left(x_{g}, y_{g}\right)$ was the position of a pirticle's guiding center, $v_{\perp}^{2}=v_{x}^{2}+v_{y}^{2}$ and $\phi=$ TAN $N^{-1}\left(v_{y} / v_{x}\right)$, were used, it turned out that for"at least two polarizations, the gyroperiod-averaged diffusion tensor was diagonal. This had the imporlant consequence that the random perturbations in different coordinates were mutually uncorrelated. The cuses of interesl were

- A distribution of k-vectors rutationally symInelric about the magnetic field.

- All k-vectors parallel or antiparallel to some fixed reference direction.

An interesting finding of this work was that spatial diflusion was not correctly simulated by simply propagating the stochasticity resulting from velocity diffusion through the equations of motion 10 a particle's position courdinates. In the coordinates $\left(x_{g}, y_{g}, v_{\perp}, \phi\right)$. for example. such a scheme would result in no spatial diffusion at all, while in other coordinate frames, important correlations represented by off-diagonal elements of the diffusion tensor would be neglectew.

We incorporated this diffusion scheme in Monte Carlo version ${ }^{t}$ of the ]-D quasilinear transport model of Berk and Stewart, ${ }^{5}$ which also includes neutrat-beam injection, electron drag. end loss, and low-energy stream. The turbulence level can be self-consistently determined as a function of 
time from the ion-distribution function. The growth rate can be obcanned from the linear dispersion relation or fixed arbitrarily at a predetermined sleady. stale value. When run in the self-consistent mode. the code reproduced the results of Berk. Rognlien. and Stewart ${ }^{6}$ depending on the value of a critical parameter, the lurbulence level reached either a state of marginal stability or one with largeamplitude oscillations (bursts).

The above behavior is illustrated in Figs, 1 and 2 , which give the time dependence of the turbulence

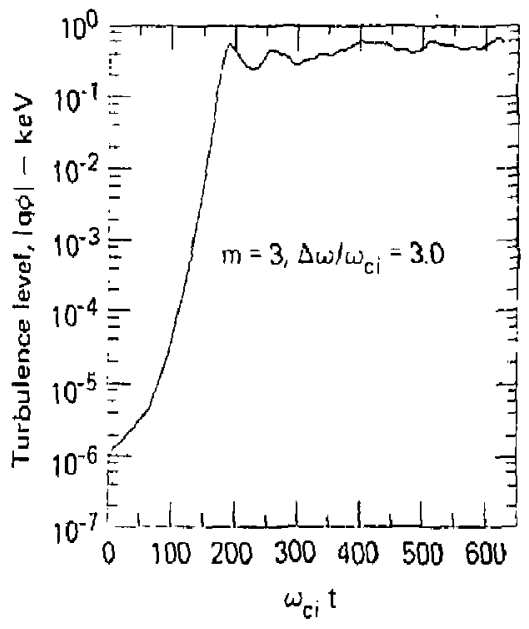

Fig. I. Slone (aslin simulation of drifteryciotson lass-contc (1)( I. () turbulence for a marginally stable stced! state. This plot gives the time dependence of the curbulence letel $\mid$ ad $\mid$.

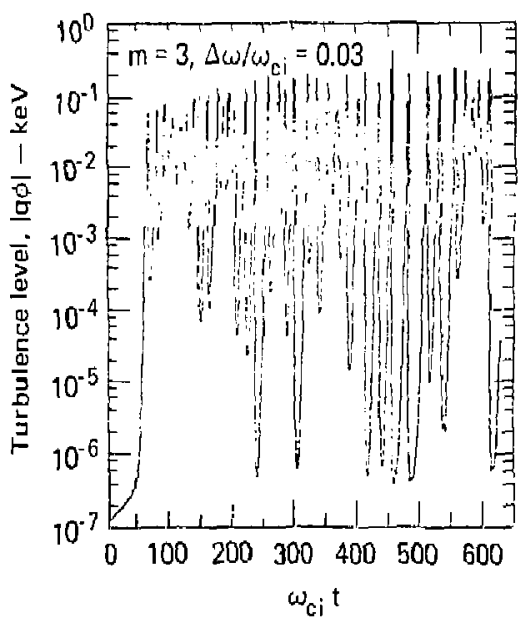

Fig. 2. Monte Carlo simulation of DCIC erbulence for a timeasymptotic slate with lerge-amplitude oscillations (busis', This plot gives the lime dependense or the turtuotence le vel, $|q 4|$. level, $|q \psi|$. Figure ! shows a marginally stible steady state, while the time-asymptotic itute in Fig. 2 e: hibits bussting. When operatiod in this mode the code demonstrates the computalional feasibility of self-consistently dotermining the turbulence level in a particle code such as SUPY: LAYER. This means that the Monte Carlo diffision scheme in such a code san be put in eslergyconserving form.

An illustration of lle strong eflect lurbulence has on the ion-distribution function appears in t.ies. ? and 4 , which plot the ion perpendicu!aresilter! distribution. In fige. 3 we set the turbulence level at a value typical of that observed in the 2Xllh lixperiment. Figure 4 combares the 2 XI1B chargecxchange energy speciram with the result ol it SUPERLAYER code run identical w that in lig. ?. except that we sut the turbulence level to dia.

\section{References:}

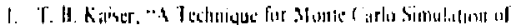

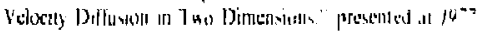

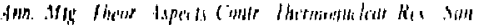

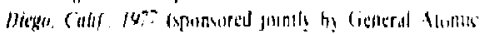
and Science ipplicatioms. Jac ।

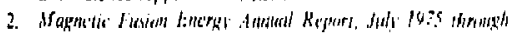

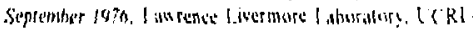
5000276 (1970).

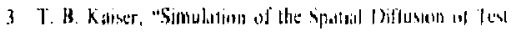

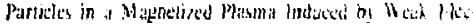

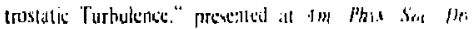

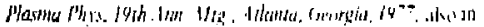
Bull sin thes Sin 22, 1175 197?.

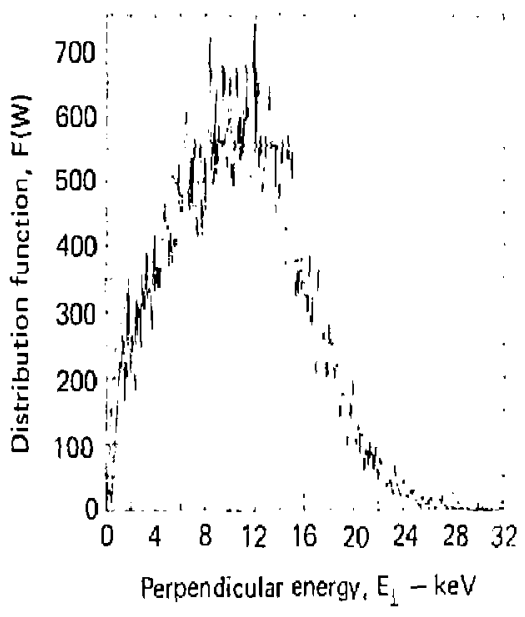

Fig. 3. lon petpendicular-encrgy distribution shows lurbultonce lesel typical of that observed in the 2XIIB experiment. The solid curve gives the ion distribution generated by the SI PHEL.AYAR cods; the dashed curre is an energy spectrum obluined from the 2XIH charge-sychage analyzer, normatizes to the same area. 


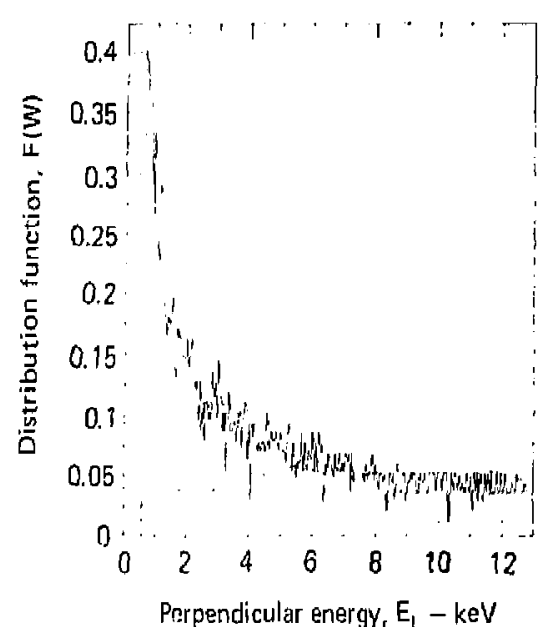

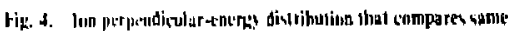

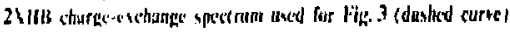

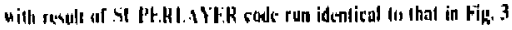

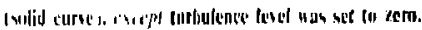

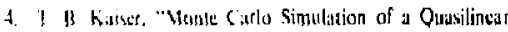

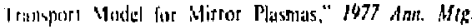

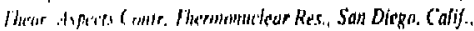

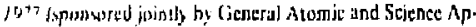
plistitions. Inc.).

5 H. 1. Berk alld J. J. Sluwart, "QHaslinadr Tsanspors Model

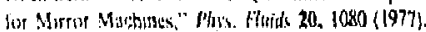

6. If. I. Berk, I. D). Kognlien, and J. J. Stewart, "Pulsation of

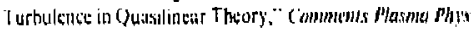
(indr. Jumm 3, 95 (1977).

Anthor

T. B. Kaiser

\section{Adiathaticity in Tandem Mirror Systems}

The advent of the landem misror eoncept has motivated both applied and basic work on magnetic-moment jumps. The plugs, being conventional mirror machines, cun be studied using the theory described previously.' In particular, the plugs in the Tandem Mirror Experiment (TMX) are adjabalic due to the small radial size of the plasma.

The seentral cell is quite different from a conventional mirror machine. Its field strength, in particulur, is nearly constant near the middle; hence, in contrast to the usual situation, magnetic-moment jumps may be expected near the ends, rather than the middle. of the cell. Several questions arise: for a cell of fixed length and tolal mirror ratio, how does changing the shape of the field profile affect the number. location, and size of magnelic-moment jumps and is there an optimally adiabatic shape for which nonadiabatic are minimized?
To probe these issues we considered a model field of the form

$$
\underline{B}=\mathcal{E} B(z)-\mathcal{e}_{r}\left(d B_{d} / d r\right) r / 2 .
$$

where

$$
B_{z}=B_{i)}\left[(R-1) \frac{\tanh \frac{z^{2}-z_{0}{ }^{2}}{\Delta^{2}}}{\tanh \frac{z_{0}{ }^{2}}{\Delta^{2}}+k}\right]
$$

and where $z_{0}$ and $\$$ are constants related to cell length and shurpness of the field change. respcc. tively. Plots of $\mathrm{B}$, for several values of $z_{0} / \mathrm{J}$ are in fig. 1.

According to theory, near the axis the jumps are governed by the iocation of the zeros of $B_{Z}$ in the complex 2-plane. Mort direce informalion can be gained by localing the zeros in the upper-talf com. plex " plane. where

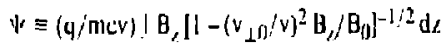

is thr lawest order approximation to the gyrophase. The jumps are proportional to expli $\forall(\mathbf{B}=0) 1$. Figure 2 shows a plol of the zeros as a function of $z_{0} / 1$. Based on this figure, one may piedict the following:

- A single magnetic-moment jurnp per machine tronsit, at the midplane, lor small vailues of $z_{0} / \Delta$,

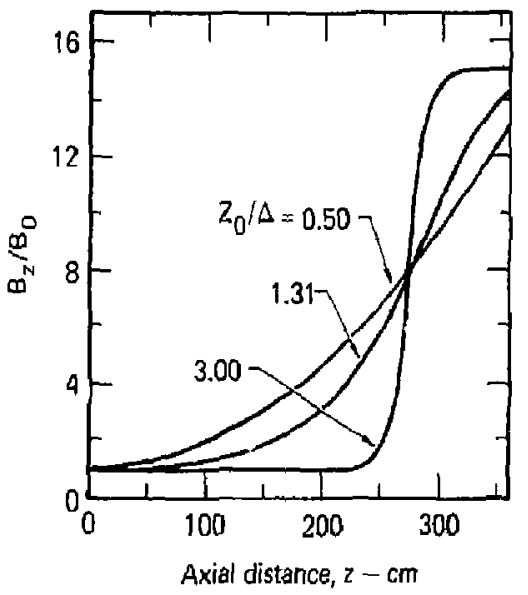

Fig. 1. Plots of axiyl field profile $B_{2}(z)$ for model magnetic field, with $R=8 \mathrm{arg} I=275$. The Iarpe $z_{0} / \Delta$ corresponds to a flatbottomed well. 


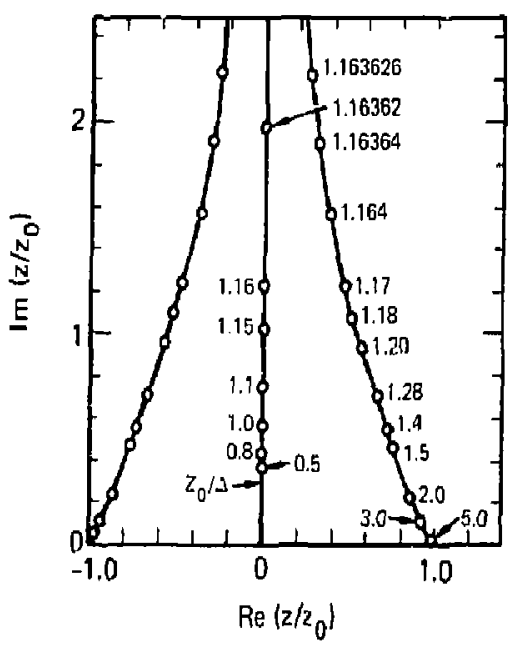

Hig. 2. Zetoce of $B$ in complex z-plane for $B=8$. The urro is af io for $z_{0} / \triangle=z_{0} / \Delta_{0}=1.1636258$...

where there is or $y$. single zero of $B$.

- Two jumps for large $z_{0} / \lambda$, where these re (wo well-separated $(|j \Psi|>2 \pi)$ zeros.

- A transition from one jump to two at $\lrcorner \sim \mathcal{J}_{0}$. where $J_{0}$ is the value of $\psi$ such that the two zeros are separated by $|ذ \Psi|=2 \pi$.

- A pronounced minimum in the magneticmoment jump size at the value of $A$, where $\operatorname{lm} \psi(B$ $=0$ ) is maximum.

- For $\perp \sim \Delta_{1}$, nulls in plots of $\left|\Delta_{\mu}\right|$ vs v, due to destructive interference of the two zeros.

- When there are two jumps, they occur at predictable positions, namely, where $\Psi=\operatorname{Re} \Psi \Psi(\mathrm{B}$ $=0)$ ].

These predictions have been verified by comparison with resulls from the TIBRO orbit code. Quantitative agreement with theory on the size of jumps has been fair (good for purposes of determining adiabatic energy limits, not so good for ${ }^{\prime} \mu$ values). This agreement should improve when the analytic expression for finite midplane guiding. center radius $r$ is evaluated. So far, only the $r \rightarrow 0$ version of the theory has been used.

Adiabaticity is an issue for the central tell of a tandem mirror only for species with energies above the confining potential energy, e.g., hot ions injected to provide supplemental heating to the central cell or alphas produced by fusion. In the latter example, it may be advantageous to arrange the field so that alphas are strongly nonadiabatic (by making the field steep-edged, i.e., $x_{0} / \Delta$ is large'. Using a one-dimensional (pitch angle) kinetic coude, we find that, with minor modifications, the tandem

mirror reactor design given in the TMX proposal ${ }^{2}$ could be made to nonadiabalically lose $80 \%$ of its alphas.

\section{References}

1. R. H. Cohen. G. Rowlands, and J. H. Foote. "Nonadiabaticily in Mirtor Machines," Phis Mask 21, 627 (1978). Also Law rence I.ivermore l.abortiory, UCRL-78g89 (1977).

2. THA Project Propusal, Laurence livermore lahofatong, L.I.L. Ptop-148 (1977)

Author

R. H. Cohen

\section{Potentigl-dided Confinement in Mirror Machines}

We considered the basic problem of purticle endloss in a magnetic mirror field that has an electrostutic confining potential, This is a subject of interest in the context of the tandem mirror machine.

Two analytic approaches to the problem appeared in the literature. Both were direcled at finding the solution to the high-velocity expansion of the lineirized Fokker-Planck equation that vanishes at the loss boundary. Pastukhov' constructed loss-rate expressions from an approximate solution that vanishes on a surface that matches the position and radius of curvature of the (hyperbolic) loss boundary at its vertex (minimum-energy poinl). Chernin and Rosenbluth ${ }^{2}$ replaced the loss boundary by one consisting of line segments of constant pitch-angle of energy: they approximately matched solutions in different regions of velocity spacc. Pastukhov's expressions were derived for electioslatically confined electrons in the presence of in singly charged ion species; Chernin and Rosenbluth's result applied to a singly charged electrostatically confined ion species. Both calculations were done for square-wel! fields.

We extended both calculations ${ }^{j}$ to apply to any electrostatically confined species in a multispecies, multicharged plasma. This extension was achieved by carrying an extra constant that multiplied the pitch-angle tern in the Fokker-Planck equation through both calculations. Additionally, we generalized the Pastukhov approach to apply to the bounce-averaged Fokker-Planck Equation, allowing consideration of arbilrarily shaped magnetic wells.

We also treated this problem by using three m:lltispecies Fokker-Planck codes: A nonlinear 2-D $(v, 0)$ code; a linearized 2-D cade, in which a tenuous test-particle species interacts with a lixed Maxwellian background; and a lin arized I.D code, in which the pitch-angle distribution is assumed to be 
lhe losest normal mode. We considered the nonlincilt conde is a test for the (faster) linesr 2-D code. Sie lound that they angeed well when the contining poismial entegy was more than about twice the spsciss temperiture.

(vinpiring the 2-1) codes with the other upproaches, we lound that the closest agreement was with the generillized Pasilukhov results. Vulues of $\pi$ r agreal wilhin lo (1) $20 \%$ over a wide range of confining polelitiats and mieror ratios. for hoth electron and ion problems. The mosl glaring discrepancy was that the generalided Pastukhow result variod more slowly with mirror ratio thari with code result. The Chernin-Rosenbluth nt valucs Here consisiendy lower. by as much as a factor of two. and the 1-D coude values were higher, by a factor of about inv.

He made it ereits of tests lo estimite the errors in the l okker.l'linek codte dut of the finite-mesh

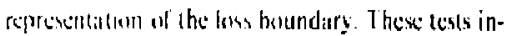
buled ratrong the mesh spicsing and making small shangen in the mirrer ratio and potential (to look for juntip in the ats the loss boundary crossed a gerid poml o 14 c comstuded that the uncertainly in the wole salus us abrut $\pm 10 \% "$.

\section{Reflerinters}

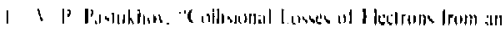

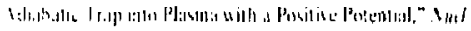

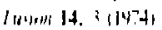

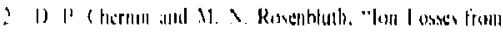

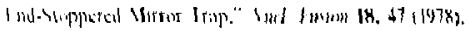

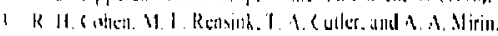

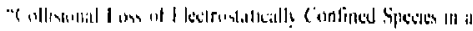

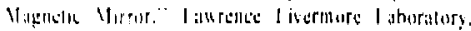

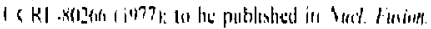

futher

R. H. (ohen
Mlajor Contriliutors
T. A. Cutler
A. A. Mirin
M. (C. Rensink

\section{Pandem Mirsor Rale Cide}

We developed a fast-running rale code for tandum mircor systems. Electrons and thernalized untar-coll ion specist were described by generalied Pastuklose expressions lor number and encreg endloss rules.

The code describes plug ions by assuming they are draged by electrons from their injection energy Io an energy proportional to $\mathrm{T}^{3} r^{2} / E_{p}^{i}$, at which point thiy are lost due to pitci-angle scattering. An option is provided where the plug loss rate in enhanced. if necessary, to provide marginal slability lor the drift-cyclotron loss-cone mode (partially stabilized by center-cell endloss). The code also provides for injeclion of ions (e.g. fusion-produced alphas) in the center cell above the ambipolar energy: Charge exchange is included but is presently described only by contslant cross sections.

Wic compured this code with results from a code in which ion species are described by coupled Fokker-Planck equations and alectrons are deseribed by generalized (bounce-averaged) Paslukhov expressions. We found the results to be in good agrement for steady-slate and time. dependent test cases.

The code was used to study (a) buildup of thermalised alpha particiss in a tandem mirror reactor and (b) cyclic schemes for limiting the alpha population. We had three principal findings:

- Q (liusion power/injection power) was drastically reduced (from $\sim 8$ to $\sim 1$ for the calse considured) us alphas built up from a steady state in which they were artilicially sliminated.

- Pulsed-mode purging schemes helped somew hat (time ilveruge $Q \equiv Q_{\mathrm{j}}-2$ ).

- Llimination of $80 \%$ of the alphas by nonadiabalic loss in combination wilh running the code in pulsted node helped more $\left(Q_{i b} \sim 4\right)$.

The code will he used to study sturtup modes for the Tandem Mirror Experinent.

\section{Relerenco}

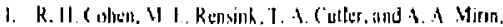

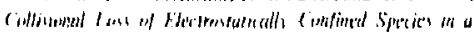

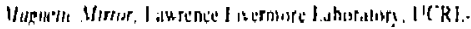

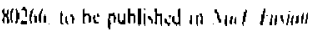

Authort

R. H. Cohtr

\section{Basic Studies of Dynamicu] Systenss}

Plasmas of interest in Lawrence livermore Laboralory stagnetic fusion energy program fresquently have the following characteristics:

- Particle motion is ncarly collisionless.

- Instabilities ciasse cortujn waves to grow to large amplitides.

Thus, we often study the collisionless motion of parlicles in lie presence of one or nore waves. The sing. plest problsm of this type is one-dimensional norotion in the presence of two waves.

We curried out a numerical study' of this problem for a particular ratio of the amplitedes of the two waves. We varied iwo parameters, related to the ratio of the wivelenglhs and the difference of the phase velocilies of the lwo waves, to determine the nature of the particle motion. Stochasic motion. which can have important physical consequences, was observed rather often. Certain resoninces, not necessarily those expected initially, were quite prominent. Our understanding of this 
simple problem aids us in our work on the more complicated dynamical systems in the magnetic fusion energy program.

\section{Referense}

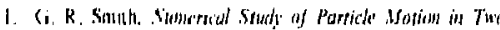
1Fare, l.anrence livermere lahortary, LCRI.80121 (1977)

Aulhor

G. R. Sinith

\section{Axial Flow Code for Wasm Plasma} in a Mirror Machine

$W^{\prime}$ used the time-dependent axial flow code PHLOW to model the flow properties of warm plasma fornied by the gas box in the 2XIIB Experiment. The model was improved to include the following effects:

- A rate equation that describes the ionization of the neutral gas in the gas box with electsonemperature-dependent ionization rute.

- A spitially dependent electron-entegy equation,

- Modilication or the magnetic-ficld profile by a high-beta hot plasma.

- A source term at the end walls that cun accounc for reflux of neutruls off the walls.

We coupled the axial flow code to the HYBRIDII Fokker-Planck code. At each time-step, the PHLOW code calculated warm plasma current, flowing axjally, which was fed into HYBRID II as a low-energy source of particles, Likewise. HYBRID II fed back to PHLOW the level of hot plasma density. This density level acted like a putential barrier

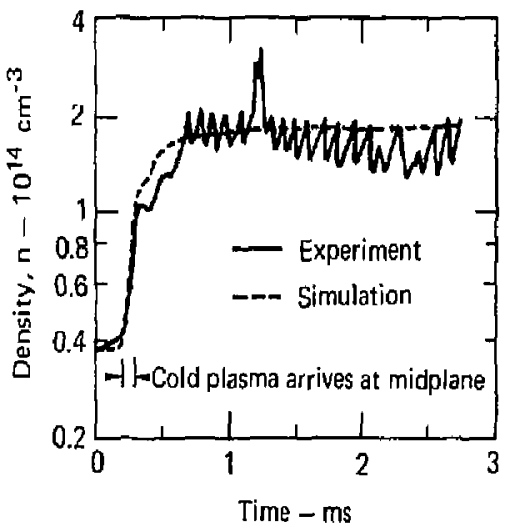

Fig. 1. Comparison of meastued and calculated temporal evolu tion of plasera density at the midplane for 2XILB experiment. Computed curve is from the coupled HYBRID-Il and PHLOW codes The sudden increase in ptasma density is due to the arrival of gasbox plasma. for warm ions flowing axially. As an example of output from the coupled codes. Fig. I shows the measured temporal evolution of density in $2 X 11 \mathrm{~B}$ for a large gas-box-current case and compares it with the computed results. For this case, warm plasma current was large enough for the driftcyclotron loss-cone to be stable.

In combining the PHLOW and HYBRID-II codes, we found that the PHLOW code actually look a majority of computer lime. This occurred because PHLOW was written in an explicit type of numerical algorithm: it thus required a small timestep to prevent numerical instability.

We are rewriting the code, using an implicit numerical algorithm that will be much faster. During FY 1978 we also plan to investigate the effect of includitig a modified Poisson's equation. This equation, which would adjust Debye length to the order of grid size, would help us determine if sheath-like shocks form. Currently, the code uses an artificial viscosity to allow for shock formation.

Author

Major Contributors

T. D. Rognijen

T. A. Brengle

T. A. Cutler

\section{Monte Carlo Simulation of Neutral Particles}

We developed an efficient Monte Caflo method for sreating neutral particles in cylindrical plasmas. ' Our primary objective was to couple the Monte Carlo code with the radially dependent quasilinear code so we could include the physica? processes associated with neutral particles, e.g. neutral-beam injection and charge-exchange loss.

The Monte Carlo method is well-suited for treating an arbitrary number of generations of neutral particles produced by successive chargeexchange collisions. Employing the sampling technique for calculating mean free paths, one can use our method to treat any plasma velocity distribution, such as a loss-cone distribution with an arbitrary spatial dependence, in an efficient manner.

We developed a code based on this method. Our numerical results agred well with analytical results, verifying our method and the code. Figure I show's the results for neutral-beant injection.

\section{Reference}

1. Y. Mutsuda and H. L. Berk, "Wonte Carlo Approach for Neutral Purticles in a Mirror Machine." pressented al 1977 Alur. Mig. Theor, Aspects Conir. Thermonud. Res.. Sua Diego, Calif. 1977 (General Alomic Company and Science Applications, Inc.. Sun Diego, Calif.. 1977) 


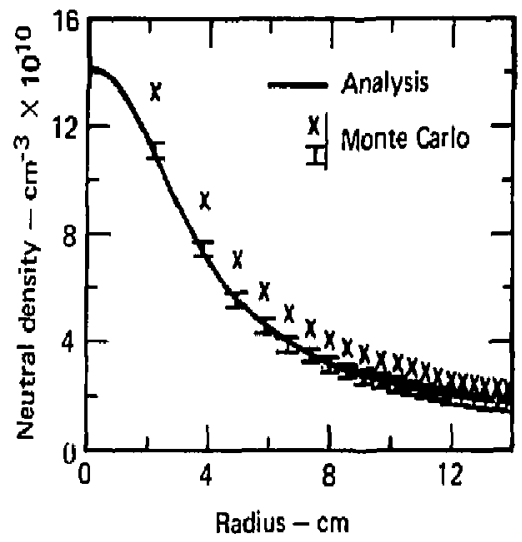

Fig. I. Comparison of neutral densitles obtuined from analysls and the Monte Carto code, We Injected a neutral bean of 18 keY into a plasma with a parabolic radlal profite and densly $3 \times 10^{13}$ $\mathrm{cm}^{-3}$. The analytical result and the Monte Carlo rewil represtated by the symbol "l", for the case lgnorlog secondary charges exchange collisions, show good agreement. The synbol " $X$ " represents the Monte Carlo mesult, including all mulliple churges exchange collisions.

Authors

Y. Matsuda

H. L. Berk

\section{Adiabatic Invariants by Lie Transforms}

We applied the modern technique of Lie transforms to a description of adiabatic invariants, their behavior around resonances, and their breakdown at large amplitudes of the perturbing forces. The essential results are in a few simple formulas. 1.2 Given a Hamiltonian dependent on a small parameter $c$ in the form of a series expansion:

$h(p, q, \epsilon)=\sum_{0}^{\infty} \frac{e^{n}}{n !} h_{n}(p, q)$,

where $t_{0}$ represents a soluble problem with periodic orbits, then a further constant of motion, $K$, can be calculated. This can be given in terms of the Poisson bracket [,]

$$
[h, K]=\sum_{n=1}^{n}\left(\frac{\partial h}{\partial p_{n}} \frac{\partial K}{\partial q_{n}}-\frac{\partial h}{\partial q_{n}} \frac{\partial K}{\partial p_{n}}\right)
$$

and in terms of the averaging and integrating operators, $\because \wedge$.

$$
\bar{h}=\operatorname{Lim}_{\mathrm{T}+\infty} \frac{1}{\mathrm{~T}} \int_{0}^{\mathrm{T}} \text { hdt and }
$$

$h=\int^{t}(h-\bar{h}) d t$

where the integrals are taken along the orbits of the lowest order Hamiltonian, $h_{0}$

The invariant is

$$
\begin{aligned}
& K=K_{0}+c\left[K_{0}, \hat{h}_{1}\right]+i / 2^{2}\left[\hat{h}_{1},\left[\hat{h}_{1}, K_{0}\right)\right] \\
& +e / 2^{2}\left[K_{0},\left(\hat{h_{2}}+\left[\widehat{h_{1}, \hat{h_{1}}}\right]+\left[\hat{h_{1}}, \hat{h}_{1}\right]\right)\right]+0\left(c^{3}\right) \cdot(5)
\end{aligned}
$$

For a charged particle in an electromagnetic field there are up to three ways in which the particle may execute periodic motions or experience oscillatory forces. When two or more oscillations resonate, the integrations implicit in Eq. (5) give resonant denominators that can be removed by careful choice of the zero-order invariant, $\mathrm{K}_{0}$. The canonical coordinate transformations used to generate series like Eq. (5) are expressed in terms of the Lie-transform generators, $W$, given by

$g / \partial \in p(P, Q, t)=[p, W(P, Q, t)], \partial q / \partial t=[q, W] .(6)$

When $W$ is independent of $a$ the transformations and their inverses can be expressed as the operator equations

$$
\begin{aligned}
& p=-[W] \cdot p(P, Q, \epsilon) \text {. } \\
& P=e^{e W(P, q) \cdot]} \cdot p(P, Q, c) \text {. }
\end{aligned}
$$

These simple types of Lie transform can be used to investigate the trapped orbits around a particular resonance or 10 generate the superconvergent series of Kolmogorov. The advantages of the Lie method are that the development of series solutions of mechanics problems can be developed by recursive processes at each order and that the transform generator, $W$, can be used to transform any function of the phase space variably to or from the averaged variables with equal ease.

The averaged Hamiltonian for the invariant in Eq. (5) is

$H=h_{0}+\bar{h}_{1}+\epsilon^{2} / 2\left(\bar{h}_{2}+\overline{\left.\left(\hat{h}_{1}, h_{1}\right]\right)}+0\left(\epsilon^{3}\right)\right.$,

and the corresponding transform generator is

$\epsilon W=\hat{h}_{1}+\epsilon^{2} / 2\left(\hat{h}_{2}+\left[h_{1}, \hat{h}_{1}\right)+\left(\hat{h}_{1}, h_{1}\right]\right)+0\left(\epsilon^{3}\right),(9)$ 
which transforms a function $F=F_{d}(P . Q)+\epsilon F_{1}+$ $2 / 2 F_{2}+\ldots$

to

$$
\begin{aligned}
F(p, q)= & F_{2}+\epsilon\left(F_{1}+\left[F_{0} W\right]\right)+\epsilon^{2} / 2\left(F_{2}\right. \\
& -\left[W_{1},\left(2 F_{1}-\left[W_{1}, F_{0}\right]-\left[F_{0} W_{2}\right]\right)+0\left(\epsilon^{3}\right)\right.
\end{aligned}
$$

These are the key formulas and definitions of a powerful mathematical tool that we also implemented on MACSYMA. ${ }^{3}$

\section{References}

1. B. McNamara, Super Convergem Adiabatic Invariants with Resonant Denominations by Lie Transforms, Lawrence Livermore Laboritory, UCRL-7984] (1977).

2. B. McNamara, R. J. Faleman, and B. Char, "Resonant $t$ Nim-Resconiant Adiahatic Intariamts Gencrated by MAC. SY'Ad," Bull. Am. Phis Sor. 22, 1122 (1977).

3. B. Char, LILPROG; A MACYSHA Progrom for Lis Transfums and adiaha!.t Imrarions of Simple Hamillonian Systems. Lawrence Livermore Laboratery, UCRL sept. in preparation (1978).

\section{Aurhor}

Major Contributors

\section{B. McNamar:}

B. Char

R, Fateman

\section{Tandem Mtirror Studies}

To study plasma confinement in a tandem mirror system we developed a computational model based on the 2-D multispecies Fokker-Planck code, HYBRID II. ' The main features of the model are

- Spatial square-well profiles for $B(s)$ and $\phi(s)$.

- v-(l) velocity space for magnetically confined ions in the plugs and for both magnetically and electrostuically trapped ions in the central cell.

- Maxwellian electrons with rate equations for determining electron temperature and the selfconsistent ambipolar potential.

\section{Results}

For deuterium-rritium reactor studies ${ }^{2}$ this model was primarily used to generate a few reference cases. We subsequently used these to calibrate a simple rate-equation model for making extensive parameter surveys.

For dueterium-deuterium (advanced fuels) reactor studies ${ }^{3}$ we surveyed the $\mathrm{Q}$ (fusion power/injection power) of the central cell as a function of the positive-deuterium-ion injection energy and the plug-10-central cell density ratio. Our results appear in Fig. I. The strong dependence on injection energy was primarily due to the variation of the

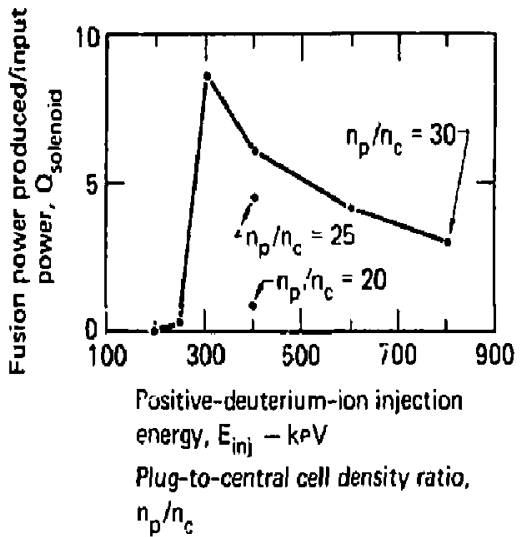

Fig. t. Survey of $Q$ (fusion pouncr produced/input pawer) for central cell of deuterium-deuter|um reaclors shaws strong dependence in iujectlon energy. Ourcalculations assumed rehjection of tritium and helium-3; we also accountec for mdial alphis diffusion.

deuterium-deuterium fusion cross section.

We also used our code for modeling the Tandem Mirror Experiment (TMX). Our work included regulation of the central-cell gas feed so the escaping plasma just stabilizes the drift-cyclotron losscone mode in the plugs. Results are in the TMX proposal. "For neutral-beam injection into the cen. tral cell, we determined the form of the anisotropic ion-distribution function and used it in an analysis of the Alfuén ion-cyclotron mode stability. ${ }^{5}$

We investigated the trapping and energy deposition of alpha particies in the ceniral cell of a tandem mirror reuctor. Results are in Figs. 2 and 3, Our analytic estimates ${ }^{6}$ did not include the effect of a loss boundary in velocity space. We incorporated these data in the simple rate code used for reactor parameter surveys.

The confinement of electrons and ions by ambipolar potentials in a magnetic mirror was in. vestigated in detail. We compared two analytic theories 7.8 with results of the 2-D code and a simpler I-D code. Results appear in a paper to be published in Nuclear Fusion.?

\section{References}

I. J. Killeen, A. A. Mirin. and M. E. Rensink, m, Methods in Compulational Physics 16, J. Killeen, Ed. (Academic Press, New York, 1976), p. 389.

2. R. W. Moir, scientific editor. D.T Tandon, Murrof Reactor Design! Study. Lawrence Livermore Laboralory, UCKL. \$2302, to be published.

3. B. G. Logan, "Prospects for a [1.D Tandem Mirrur." picpared fur Electric Power Res. Insi. Rev. Mtg. Adi. Furi Fusion, Unir: of Illinois al Lirbana-Chompaign. Fusion Siludies J.ab. 1977. Also Lawrence Livermore Laboratory, Rept. UCRL-79641 (1977). 


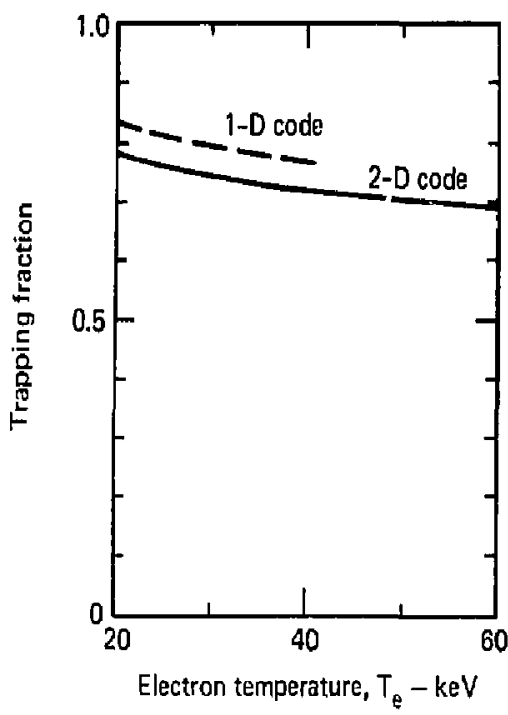

Jig, 2. 'Trapping Iraction for alpha particles in the centeral cell of y landem mirsur reactor shows weak dependence on electron temperaturs. Ion deusity, $\pi_{c}=10^{14} \mathrm{~cm}^{\text {"R }}$; ion temparature, $T_{c}=$

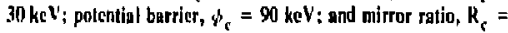
10.
4. TISR Major Project Proposal. Lawfence Livgrmote L-athorutory, Rept. L.L..-Pfop.148 (1977).

5. D. C. Watson and D. I: Baldwin, Alfrén-lon-C 'joloton Itstability in the Central Call of Thu', l.ilwrence l.ivermore Laboratory, Rept. UCID-17495 (1977).

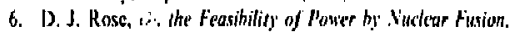
Oak Ridge National Laboratory, Tenn., Rept. ORNL.TM. 2204 (1968).

7. R. H. Cohen, M. I. Rensink. T. A. Cutter, and A. A. Mitin, Collisional toss of Electrostaticalily Comfined Speries in a Magnetic Mfirm, Lawfence Livermore Laboratury, UCRl. 80266 (1977). Prepared for Aved. Furiom.

B. B. P. Ghernin and M. N, Rosenbluth, Yucl. Fusium 18,47 (1976).

Author

M. E. Rensink

Major Contributors

T. A. Cutler

B. G. Logan

A. A. Mirin

- - Analytic estimate

2-D Fakker Planck

- 1-D Fokker Planck
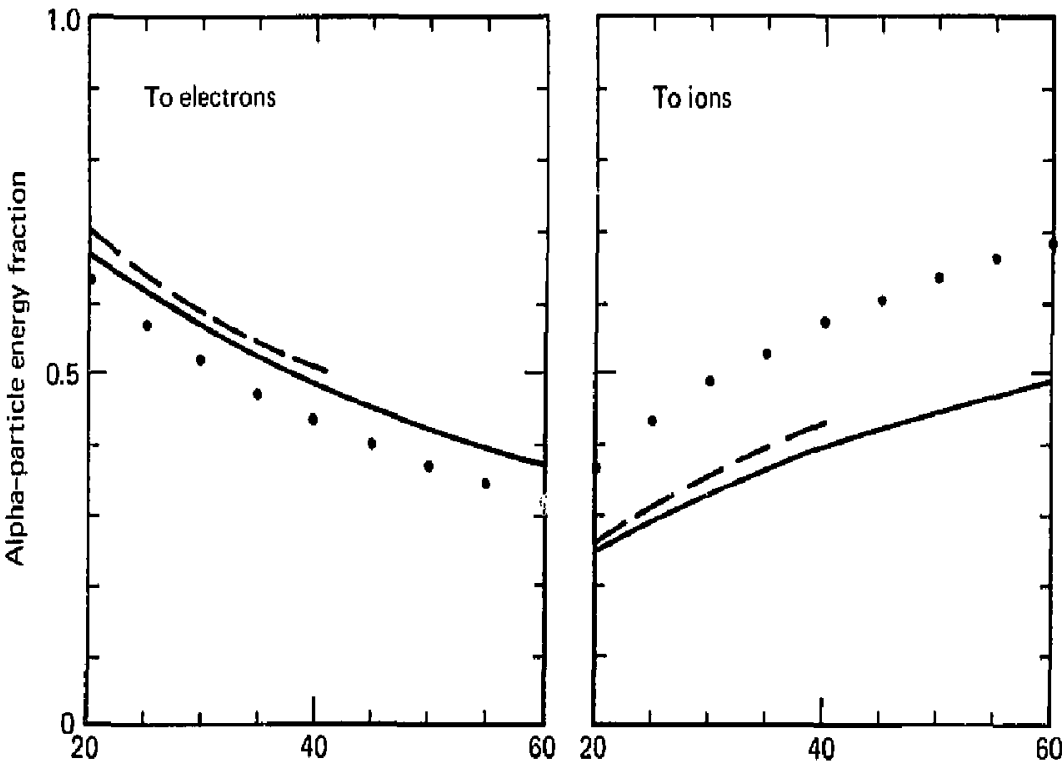

Electron temperature $-\mathrm{keV}$

Hig. 3. Fractional alpha particle energy deposited in the central cell fons and elcel rons of a tandem mirtor reactor depends on elcetron tcmperature. Some of the energy eseapes with untrapped alpha particles. 


\section{Conversion of Bounce-Average \\ Code $10 \mu \mathrm{J}$ Space}

We partially rewrote the bounce-average Fokker. Planck code to have the adiabatic invariants $\mu$-J as independent phase-space variables replacing the velocity and pitch angle ( $\mathrm{v}-\theta)$. We made this change of independent variables to eliminate a numerical instability for high-beta runs. This instability arose from the field update, which uses the long thin approximation, and from the convective terms used to maintain $\mu-\mathrm{J}$ invariance. (The mapping of $\mu-\mathrm{J}$ contours ontu y." space is shown in Fig. I. A typical distribution funclion for conventional mirrorconventional mirror-confined ions is shown in $\mu-J$ and $y-1$ phase-space by Figs. 2 and 3.1

Conversion to $\mu$-J space appeared to have been satisfactorily made; convective terms were eliminated. The annoying numerical instability,

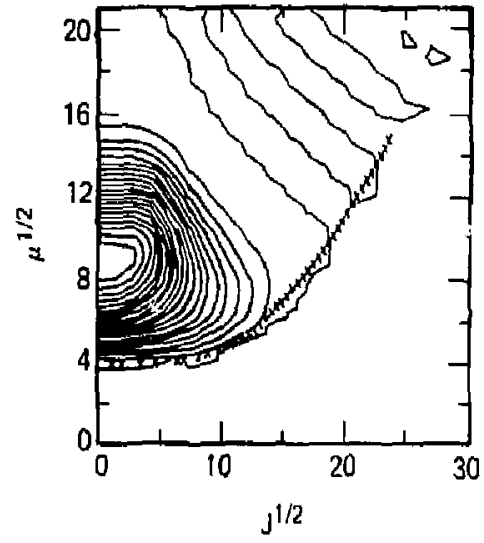

Hig. 2. Contour plol of ion distribulion in $\mu^{-J}$ space with $\mathrm{X} s$ marking the loss-boundary curve each time it crosses a grid liac in v-li space. These points delermine the loss boundary in $\mu \cdot S$ space.

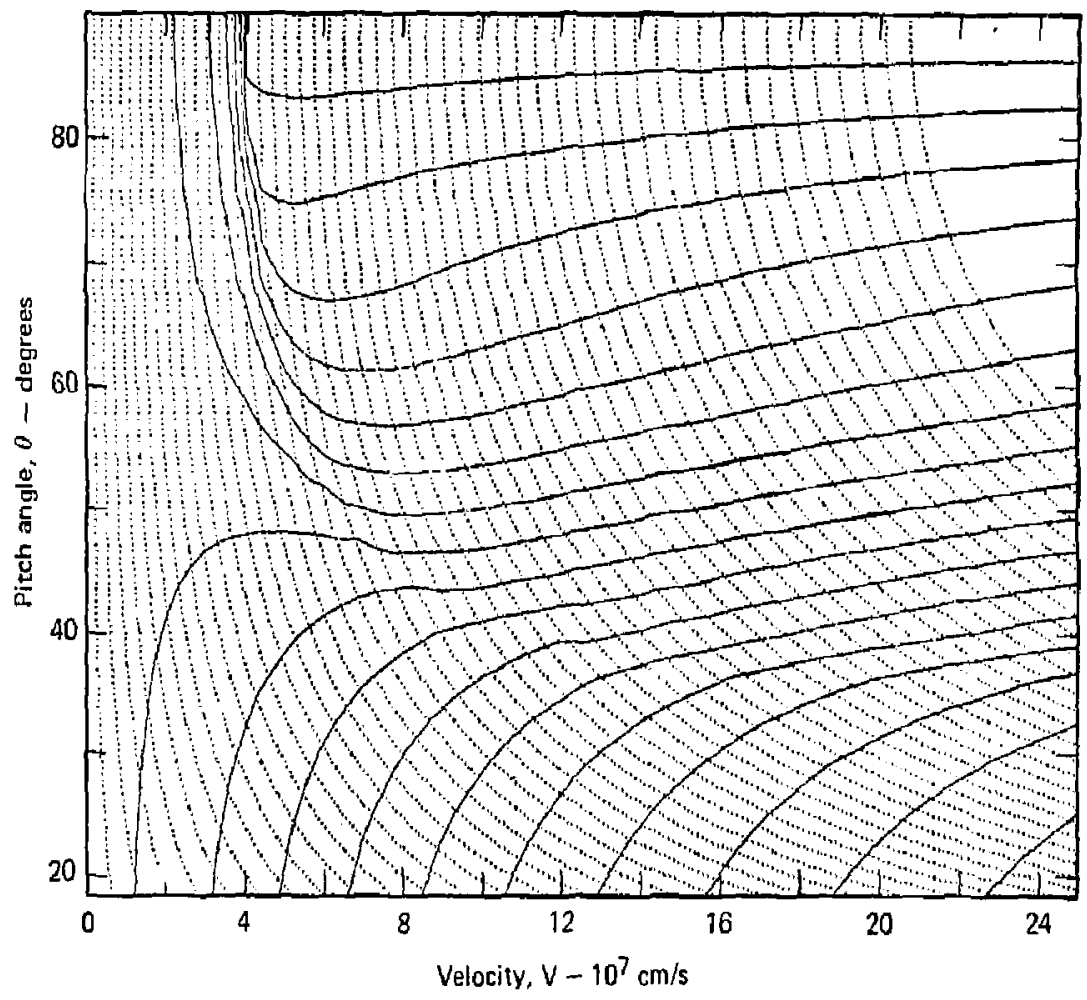

Fig. 1. The $\mu$-J grid mapped onto $\mathrm{r}-\mathrm{fl}$ space. The dotted lines represent the constant magnetic moment ( $\mu$ ). The solid lines represent the constant Jongitudinal invarianl (J). 


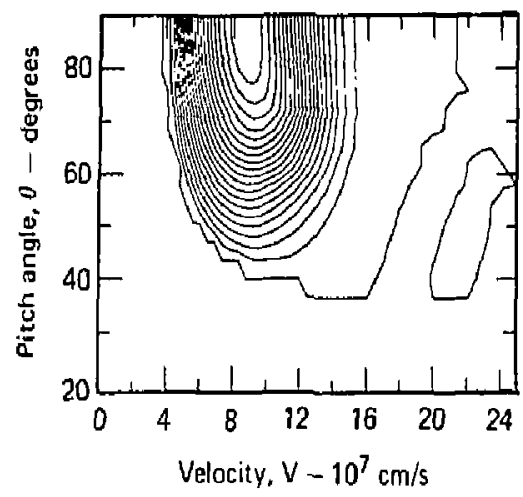

Fig. 3. Same ion distribution as in Fig. 2, but contoured in r.ll space.

however, still remained, driven by the field-update calculations dependence on past quantities, We are looking for a compulationally feasible remedy.

Author

Major Contributors

T. A. Cutler

L. D. Pearlstein

M. E. Rensink

\section{Magnetohydrodynamic Equilibrium and Stability of Minimum-B Mirror Traps}

I $(\psi, \alpha)$ are normalized flux coordinates $(\nabla \psi \times \vee \alpha$ $=2 \pi \mathrm{B}$ ) in a volume containing a mirror-1rapped plasma with anisotropic pressure components $p_{\perp, \| l}$ $=p_{\perp, \|}(\psi, B)$, necessary and sufficient conditions for the magnetohydrodynamic stability of equilibrium against perturbations localized within a small tube of force are the nonexistence of solutions of the Euler-Lagrange equation

$$
\begin{aligned}
& \mathrm{b} \cdot \mathrm{V}\left\{( \mathrm { h } / 2 \pi \mathrm { B } ^ { 2 } ) \left[(\mathrm{W} \psi)^{2}+2 \alpha(\nabla \psi \cdot \nabla \alpha)\right.\right. \\
& \left.+\mu^{2}\left(V(x)^{2}\right](b+v \hat{b})\right\}+(\gamma / B)\left(\mu{ }^{2}(\underline{x} \times \underline{b} \cdot \gamma)\right. \\
& +\mu(k \times \underline{\sim} \cdot \psi]] \hat{\psi}=0 \hat{\phi}(1)
\end{aligned}
$$

Here $b$ is the unit vector along a line of force; $h(\psi, B)$ and $\Upsilon(\psi, B)$ are functions defined in terms of the pressures $P_{\perp}$ and $P_{\mid}(r$ is proportionat to $\left.\partial p_{\perp, 1} / \partial \psi\right)$ such that $h, \partial h / \partial B$, and $\uparrow$ are all positive for a well-de:igned and well-injected mirror trap; $k$ $=\mathrm{b} . \nabla \mathrm{b}$ is the field-line curvature; and the modenumber ratio $\mu$ is an arbitrary constant relaled to the transverse structure of the flux-localized perturbation. The nonnegative scalar $\theta$ is always stabilizing; its two prescribed values distinguish the necessary and sufficient conditions. In the largeaspect-ratio (small-curvature) limit, $\theta \hat{\phi}$ vanishes compared with the term proportional to $\hat{\phi}$ on the left of tq. (1). The two conditions then coalesce.

Al finite plasma pressure the difficulty of applying Eq. (1) lies in the determination of the truc flus coordinates, $(\psi, \alpha)$.

With large aspect ratio in the straight-axis mirror trap, the introduction of cylindrical $(r, 0, z)$ coordinates permits the introduction of a single function $P(\psi, i), 2)$. This coordinate potential fully defines the finite- $\beta$ geometry, Both $\psi$ and $\alpha$ can be determined from P. Specifically

$$
(1 / 2) r^{2}=P_{B}, \alpha=2 \pi B P_{t}
$$

and

$$
\mathrm{B}_{2}+2 \pi \mathrm{p}_{1}(\downarrow, \mathrm{B})=\mathrm{B}_{\mathrm{v}}^{2}
$$

where the subscripts $\theta$ and $\psi$ denote partial derivatives in mixed $\left(\psi,(1,2)\right.$ coordinates and $B_{v}(2)$ is the (known) vacuum induction on axis. In general, $P(\psi, \phi, z)$ satisfies a rather complicated fourth-order nonline'dr partial differential equation that requires numerical solution. However, if we go to the limit in which the pressures have an explicit dependence upon $\downarrow$ only within a boundary layer $\psi<\psi<\psi+$ $\perp \Psi$. then throughout the bulk of the plasma,

$$
P=(\psi / 2 \pi \mathrm{e}) \arctan (\mathrm{e} c \tan (l), \psi<\psi
$$

Here, $c(z)$ is an unlisymmetric scalar function of $z$ alone, which is determined self-consistently by the quadrupole component of the yacuun field and the currents flowing along the lines of force in the plasma boundary-layer. Within the boundary layer, the equation for the coordinate potential $\mathrm{P}$ is also considerably simplified. In the limit of small plasma pressure, it can be solved analylizully. In this case the important result is that the variation of the second llux coordinate through the boundary layer is given by

$a_{\psi}=-\frac{1}{2}(\sin 2 a) \int_{0}^{2} d c_{1}(\cosh c-\sinh c \cos 2 a)^{-3}$

$\int_{z_{1}}^{\infty} d z_{2}(T / B)\left|\left(B_{z} / B\right)_{z} \sinh c-c_{x x} \cosh c\right|$.

Author

L. S. Hall 


\section{A b linirio Multiconfiguration/ \\ Self-Consistent Ground-State-Potential Finergy Curves}

We evalualed the ly+ ground states of lithium hydride ( $\mathrm{LiH}$ ), sodium hydride ( $\mathrm{NaH}$ ), and cesium hydride $(\mathrm{CsH})$ and the ${ }^{2+}$ ground stales of $\mathrm{LiH}^{-}$. $\mathrm{NaH}^{-}$, and $\mathrm{CsH}^{-}$(as well as the ${ }^{2{ }^{+}}$ground state of $\mathrm{CsH}^{+}$) over a wide range of internuclear distances. Multiconfiguration/self-consistent-field wave functions were obtained with the optimized-valence configuration approach to the description of chemical bunding. Four conligurations for the neutral molecules and seven for the negative ions provided satisfactory descriptions. All the negativemolecular-ion ground states are altractive: all huve lower potential energies that the neutral-parenthydride molecules over the internculear distances studied. Molecular-clectron affinities at the equilibrium internuclear separations were $0.283 \mathrm{eV}$ (LiH), $0.278 \mathrm{eV}$ ( $\mathrm{NaH})$. and $0.357 \mathrm{eV}(\mathrm{CsH})$

Authors
A. M. Karo
M. A. Gardner
I. R. Hiskes

\section{Formation Processes and Secondary-Emission \\ Coefficients for Negative-Deuterium lon \\ Production on Alkali-Coated Surfaces}

Negative-ion formation by deuterium collisions on cusium-conted surfaces was considered in the limiting cuses where the resident cesium was cither in the purely ionic state or in the purely atomic stale.

The secondary-emission coefficient for negativeion production is a product of the backscattering coefficient, the formation probubitity, and the survival fraction for negative ions moving awisy from the surface. We calculated the survival fraction using a melhod of complex eigenvalues. For oplimum cesiun coverages, the survival fraction may be near unity for bombarding energies between 10 and $100 \mathrm{eV}$. Similarly, this is true for lormation probability. In this energy range the secondary: emission coefficient is then given appurimately by the backscaltering coeflicient; it is expecied to be as large as 30 to $50 \%$.

\section{Huthor}

\section{J. R. Hiskes}

"ironu the beginning

\section{Radiation Losses in 2XIIB Using the Promo Source}

It was proposed to use a $2 \cdot \mu \mathrm{s}, 10^{5}-\mathrm{A}$ source of neutral deuterium and carbon for injection into the 2 XIIB device. This source was recently developed by Dan Prono. As much as one-third of the beam might consist of neutral carbon. We want to know how serious the radiation loss would be because of trapped carbon. During the injection pulse (and provided the electron temperature was maintained above $100 \mathrm{eV}$ ) radiation losses would exceed $100 \mathrm{MW}$. This would be mainly due to the heliumlike $\mathrm{C}^{4+}$ ion. Although such losses would be large we would, generally sperking. expect the energy. transfer rates from the irapped ions to the electrons to exceed these loss rates by a large factor.

Author

J. R. Hiskes

\section{Computer Calculations of 2XIIB}

Field-Reversed Mirror Configurations

Introduction. We compared the tesults from the particle simulation code SUPERLAYER with some recent 2 XIIB experiments. Our purposes were (a) 10 determine how well SUPERLA YER performed as a predictive tool to optimize experimental parameter and (b) to verify experimental resulls.

The code has the following features:

- 2-D (R,Z) Plasina (azimuthal symmetry assumed).

- Self-consistent magnetic (B) fields.

- Charge neutrality.

- Darwin model for fields.

- 3-D neutral beams (with charge exchange and ionization).

- If turbulent diffusion (based on quasilinear theory).

- No electron dynamics (electron temperature. $T_{s}$ an input parameter used in ion-electron drag term).

Results. Four experimental setups were concentrated on: they were characterized by the vacuum $B$ fields, the measured electron temperitures, $\left(T_{e}\right)$. and input neutral-beam current $\left(\mathrm{I}_{b}\right)$ and geometry. (See Fig. I for the two geometries.) The resultant quantities used for comparison at steady state were the average ion energy $\left(E_{i}\right)$, the peak ion density $\left(n_{1}\right)$, the resultant $B$ ut $R=0, Z=0$ due to the ion currents $(\Delta B)$, the peak value of plasma pressure/magnetic pressure $\delta\left(\beta_{\max }\right)$, plasma radius $\left(R_{p}\right)$, the hals length in $z\left(L_{v}\right)$. Table 3 summarizes the results. (The columns labeled Code-limiter will be explained later.) 
Table 1. Comparison of experimental vs calculaced rssules for fout experiments.

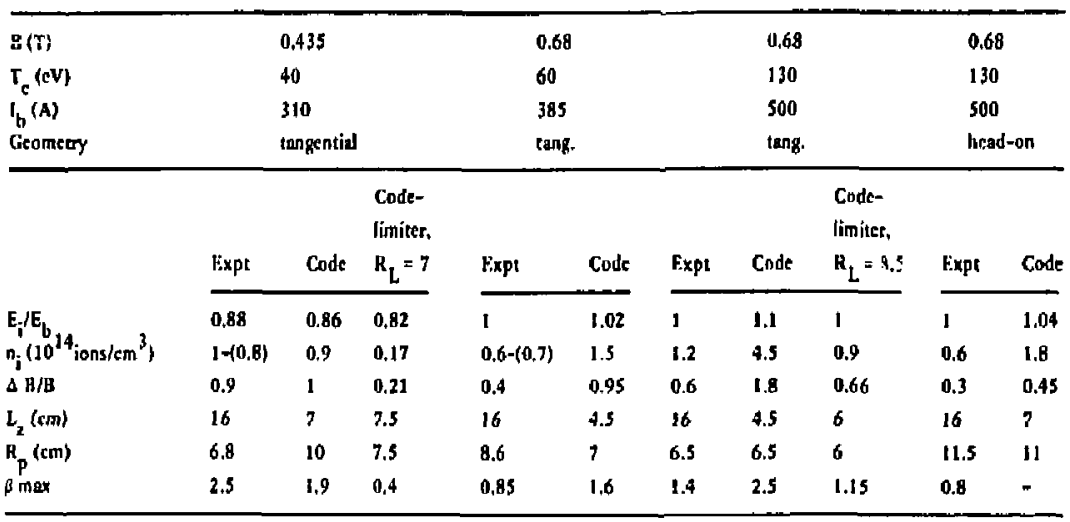

The results show the following:

- For $B=0.435 T$ calculation and experiment agreed for $n_{i}$ and $\triangle B / B$.

- For all ather cases calculation gave a larger $n_{i}$ and $\mathrm{IB} / \mathrm{B}$.

- For all cases calculation gave smaller plasma half-lengih $L_{2}$ (by a factor of $1 / 2$ to $1 / 4$ ).

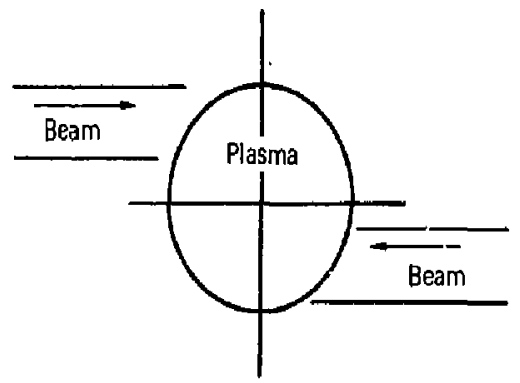

Tangential

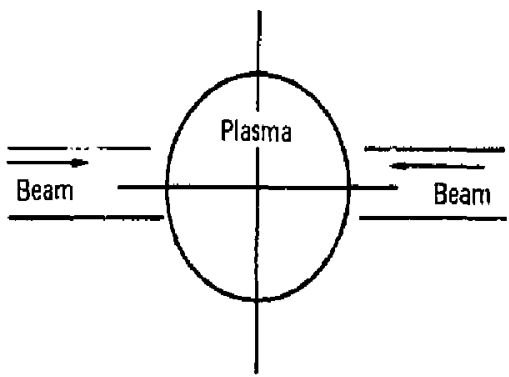

Head-on

Fig. i. Nlidplane schematic of beam-plasmn peometry.
- We forced the calculated $E_{\mathrm{i}} / \mathrm{E}_{\mathrm{b}}$ to agree by adjusting the rf-diffusion coefficient. The of electric fields implied by this, however, agreed with the experiment.

Some of the code-model limitations that might contribute to the disagreement with the experiments are considered in the following discussion. Before proceeding with that we want to point out that although our talculations do not include electron currents, this should not be a serious effect for these results because the experiments are open-field configurations $(\triangle B / B<1)$, and electron currents only become significant in closed-fjeld regions.

Axisymmetric Magnetic Fields. Our calculations assumed axisymmetric B fields, whereas the experiment had a 0-dependent quadrupole vacuum field. Preliminary results from a arate calculation, 1 which includes a quadrupole field, gives $\sim 20 \%$ increases in $\mathrm{L}_{z}$ for 2 XIlB conditions.

We introduced a lengthening effect in the axisymmetric model by amplifying the spread in the initial velocity in the $z$ direction $\left(V_{2}\right)$ for the injected neutral beam. We found, for the case $B=0.68 \mathrm{~T}, T_{\mathrm{e}}$ $=60 \mathrm{eV}$ (whete $\theta_{\max }=\sin ^{-1}\left[V_{2 \max } / V_{\mathrm{h}}\right]$ ) that $\theta_{\text {muk }}$ $= \pm 26^{\circ}$ gave a plasma half-length $L_{z}=13 \mathrm{~cm}$ (Table 2). Note that this 2.9-fold increase in $\mathrm{L}_{2}$ only reduced $\triangle B / B$ by $\sim 30 \%$.

Table 2. The cffect of increased initial $z$ velocity in the neutral beam.

\begin{tabular}{lcc}
\hline${ }_{\max }$ & $\begin{array}{c}\text { Pincma half-tengeh, } \mathrm{L}_{7} \\
(\mathrm{deg})\end{array}$ & $\Delta 8 / \mathrm{cm})$ \\
\hline \pm 6 & 4.5 & 0.95 \\
113 & 5.5 & 0.90 \\
\pm 26 & 13 & 0.70 \\
\hline Notc; $\theta_{\text {max }}=\operatorname{Sin}^{-1}\left(\mathrm{~V}_{z_{\text {max }}} N_{\mathrm{b}}\right)$. &
\end{tabular}


Accelerated Time Scales. We used accelerated time scales (T.i.le 3) to limit the computer running tirte and the number of simulation particles necessary for a given problem.

Source and sinks (neutral-beam cursent, electronion drag rates, $\mathrm{r} f$ diffusion) are accelerated by an arbitrary factor $K$ (typically $\approx 100$ ); however, the ion equations of motion are not accelerated (i.e., the ion-cyclotron period is not accelerated).

To test the effects of these modified times scales requires a longer running, larger capacily program. This is now in progress.

Radio-Frequency Diffusion. In the present model, if lurbulent electric fields are not computed self-tonsistently. Their effects ure represented by a velocity-space diffusion coefficient calculated from quasilinear the r.y. ${ }^{2}$

The resulis stow a strong dependence on of effects. If $r f$ is not included. the disagreement between the calculated solutions ind the experimental results increases (excepl for $L$ ). This is scen in Figs. 2 through 5 , which tompare results for the case $B$ $=0.68 \mathrm{~T}_{1} \mathrm{~T}_{\mathrm{t}}=60 \mathrm{eV}$. These results support the conIention that the present rI model is a step in the right direction (but more improvement is needed).

Radial-L.imiter Fffects. Experimentully, increased beam current and $T_{\mathrm{e}}$ resulted in a smaller radius plasma. This suggested the possibility that

Table 3. Tims-scale comparison (for $n_{i}=10^{14}$ ions/c $\mathrm{cm}^{3}$, $\left.T_{c}=60 \mathrm{cV} \mathrm{K}=100\right)$.

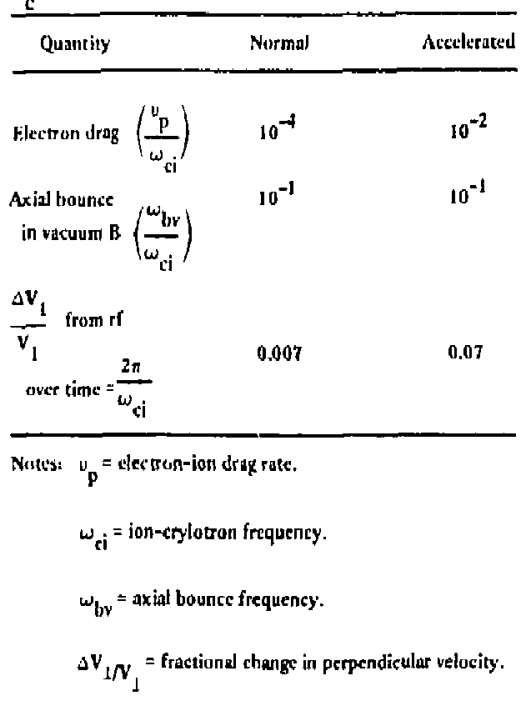

some external effect (such as cold gats) acted ils a radial limiter, To simulate this effect we ran the code with a condition that removed any particic if its radial trajectory exceeded a fixed pisameter, $R_{1}$. The results are shown for two cases in the columns; in Table 1 labeled Code-limiter, $A$ is is evident, the limier improves the ingreentent for the cilse $B$ $=0,68 \mathrm{~T}, T_{\mathrm{s}}=130 \mathrm{et}$; it, however, reducs the agreement for the case $B=0,435 \mathrm{~T}, \mathrm{~T}_{\mathrm{c}}=40 \mathrm{cH}$. $\mathrm{T}_{\mathrm{c}}$ make this approach anylhing nore than speculation at this point would require experimeital widence that cold gials was important in the ane ceist and not the viner.

Summary. In general (three oul of four cases) the calculations over predict the peak ion density and the reversal parameter $\triangle B / B$ and underpredict the axial length. To improve these cesults we are aiming at improved models for if turbulstice tself. consistent), refinement of present if-diffusion coutficients, reduction of aceelerated time seales. and cold.gas models. Note that the calculationtil model assumes a slable plasma, and if the experiment hali some instibilities present thist could plity a large part in the discrepuncies.

\section{References}

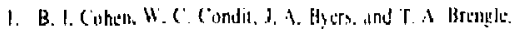

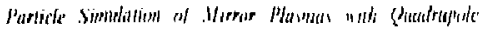

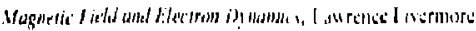
Lihuratury. LiCRL.-79841 Abs (197?)

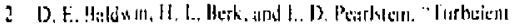

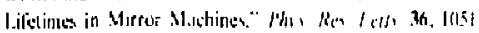
(!976).

Authur

R. P. Fre.s

Major Comtributors

J. A. Byers

R. M. Glater

T. B. Killiti

S. I. Rominel 

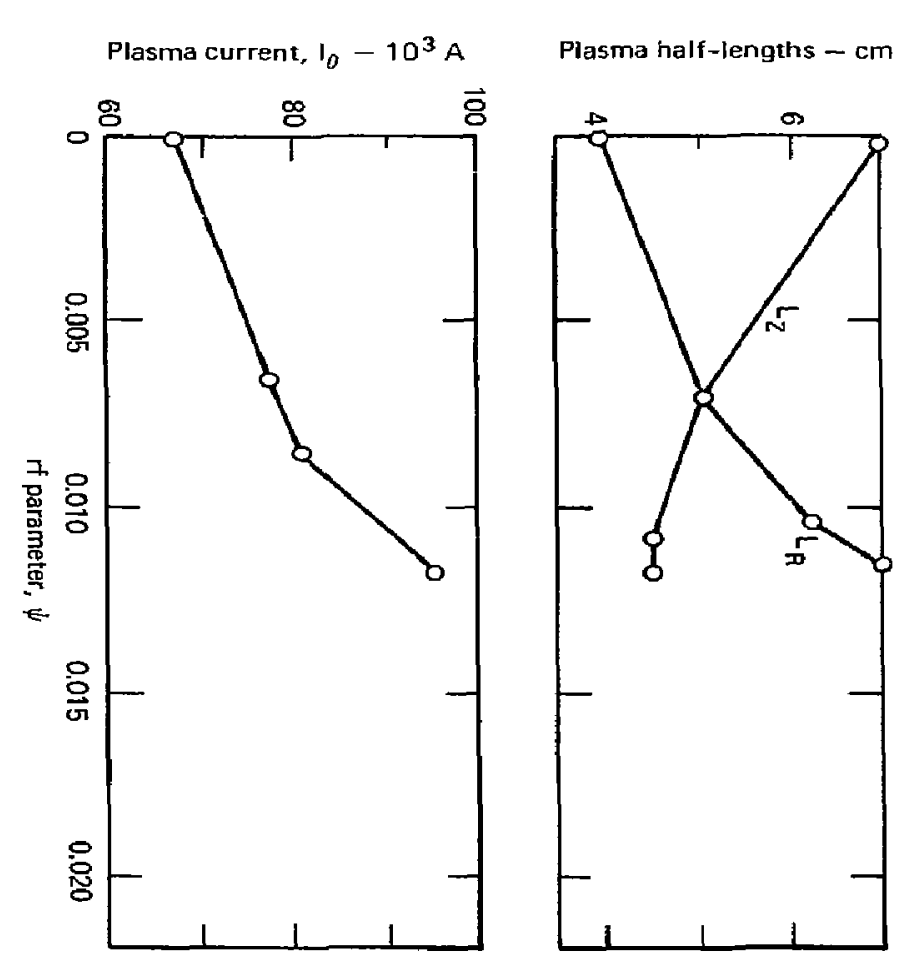

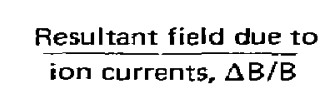

욤

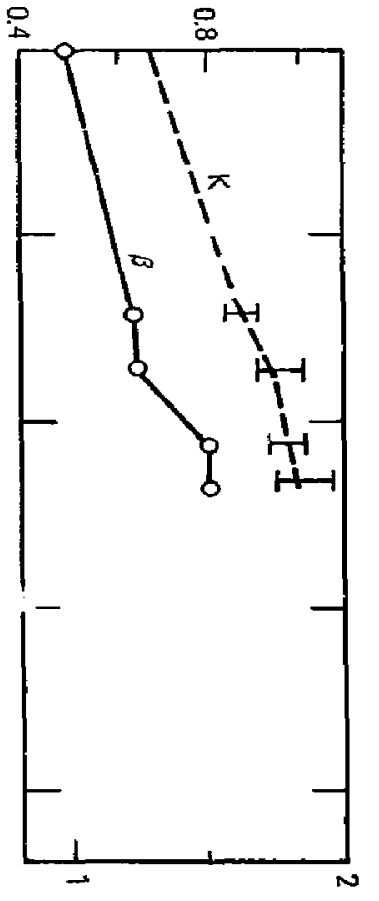

Plasma pressure/magnetic pressure, $\beta$
Average energy, $E_{i} / E_{b}$

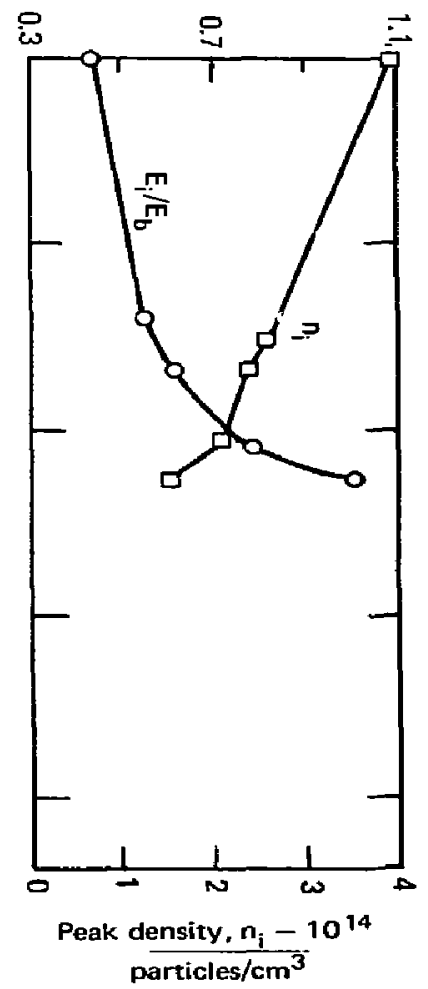




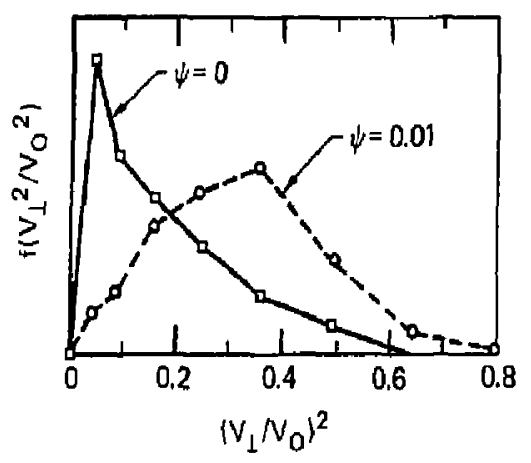

Fig. 3. Particle distribution fonction of th of $(\psi=0.01)$ and

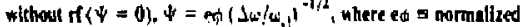
energy in of field and ${ }^{w} w$ corratalion frequency.

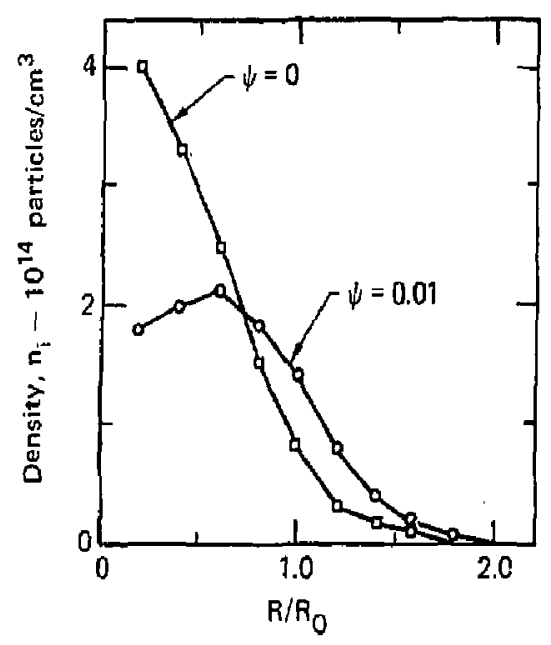

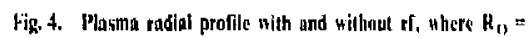
$5 \mathrm{~cm}$.

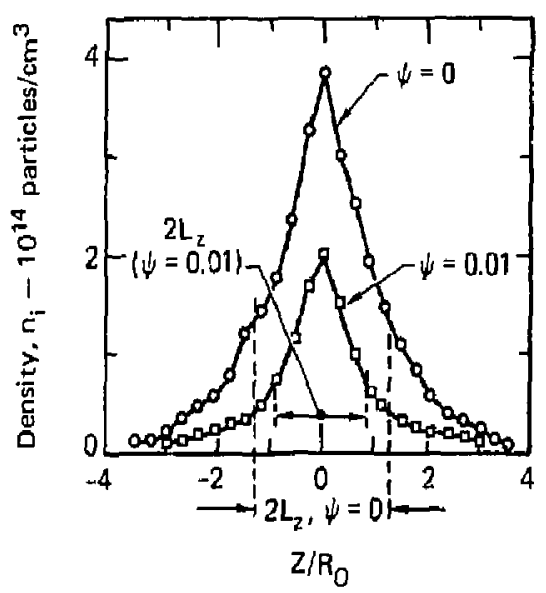

Fig. 5. Plasma axial profile with and Hitheut rf, where $R_{0}=$ $5 \mathrm{~cm}$. 


\section{Tokamak Microins/ability}

He completed a two-dimensional siudy of the nonlinear saturation of the dissinative rapped-ion mode. 'This low-frequency drift wave is expected to be unstithle in tokamak device like the Princeton I.arge Torus, T-10, and the Tokamak Fusion Test Reactor. Wo expect the drift wave to make an importunt contribution 10 anomelous particle and energy losses in these devices. The situration scheme investigaled involved the lapping of avatainle chergy sinks, as described by linear kinetic theory, by mesus ol the nonlinear $1: \times 3$ coupling of unstible modes to stable ones. Two dimertsional effects not sensidered in previous I-D mods-coupling theor: played an essemtial role. One-dimensional nondincar cequilibria scre unstable to radial pertur. billon. He lound new equilibria explicity including 2-I) clifuts. Tlase equilibria could sarurate at sienticimly somaler amplitudes of the electrostatis potenlial and trinsport than in the J-D case. We in-

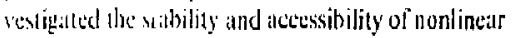
sitlurited utates io ascertilin their relevance.

\section{Rolorentes}

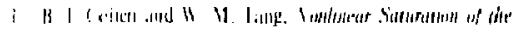

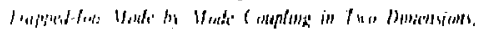

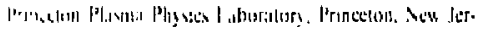

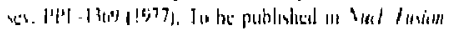

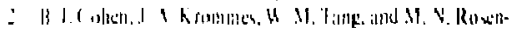

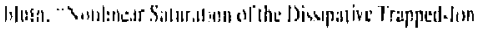

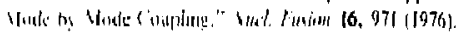

Alithis

B. 1. Cobin

Viajor Conirihutor

W. M. Tang"
In progress is a further extension of SLPERLAYER II in which the quadrupole selfCields are calculated, and in which we included a general, but limited, superpesition of Fourier modes to describe azimuthal variation.

There was further progress on the development of physics models and new simulation methods that describe important electron physics features in a high-beta (plasma pressure/magnetic pressure) plasma. We introduced a new family of algorithms for quasineutral, hybrid (particle ions and luid elextrons) simulations. ' The electrons are described by their momentum equation, witii inertial effects ignored:

$$
\begin{aligned}
& 0=-\operatorname{en}_{\mathrm{t}}\left(\mathrm{E}^{\prime}+\dot{v}_{\mathrm{c}} \times \dot{B} / \mathrm{C}\right)
\end{aligned}
$$

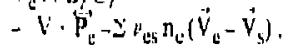

The ions are ad vanced at each time step, using partiwe equations of motion. Muxwell's equations arc solved in the Durwin (nonrudiative) ipproximation and with the assumplion of quasineutrality:

$$
\begin{aligned}
& V \times B=4 \pi c^{-1}\left(j_{1}-n_{c} c \ddot{V}_{s}\right)^{l} \text {. } \\
& V \times H_{1}^{-1}=-n 13 i / c a t
\end{aligned}
$$

$$
\operatorname{lif}(\phi)=0 \text {. }
$$

and the added relations

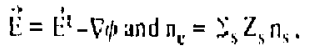

We continued ta design and implement new partide simblation algorithms to study low-frequency phenomenat in magnetized plusma. We applied these algorithms to the examination of microinstabilities and lhe buildup of plasma currents to reversal of the magneric field in a mirror plasma. For particle simulation of high-beta mirror plasmas with no closed magnetic theld lines, we demonstrated that the SUPERLA YER-II code provided a satisfaetory physics description of the self-consistent mugnetic and inductive electric fields and the ion motion. To this sim ation model we added an external quadrupole magnelic fieid, consistent in magnitude with the 2 XIIB Experiment, as part of a continuing thoorctical effort to betler understand that experiment.

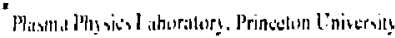

where the $t$ and 8 superscripts indicate transverse (divergence-free) and longitudinal (curl-free) vectorfield compenents und the sum over $\$$ indicates that the possibility of more than one ion species is admitted. We successfully applied these algorithms to the simulation of compressional Alfvén waves (Fig. 1): electrostatic instabilities with some finite-bela effects, e.g., the drift-cyclotron loss-cone mode (Fig. 2): and electromagnetic instabilities, e.g., the Alfvén-ion-cyclotron mode (Fig. 3). We also studied the relaxation of electron relurn currents by means of the excitation of comptession Alfuén waves upon injection of a weak current perpendicular to an externally applied magnetic field in a cold, uniform plasma. Our results are in good agreement with the theory of Betk and Pearlstein. ${ }^{2}$ We 


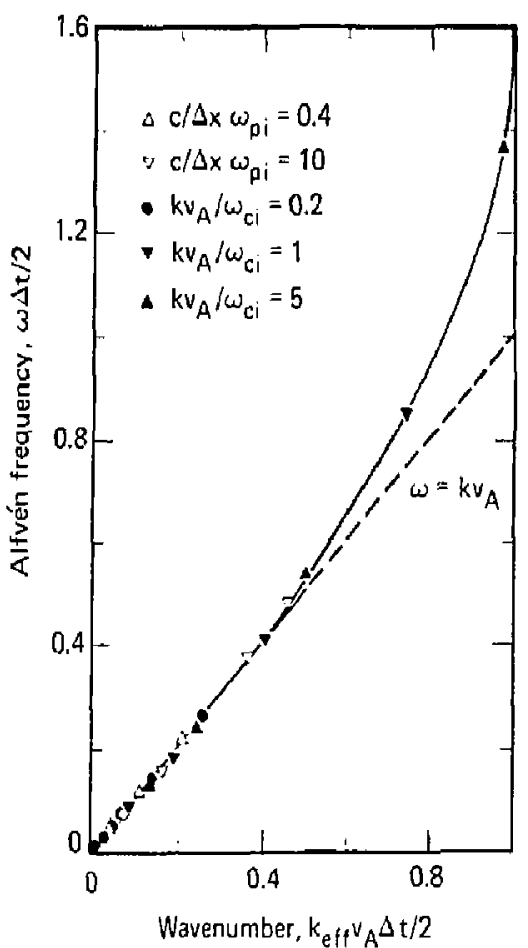

Hiz. 1. Thenretical dispersinn retaliun for sompremsiunal Alsín Hater wilh space-time mesh corrections deduced lor a camminicalmontentum-cumeriting aldorithm. This establishss aceurus, and confidence limits in the nee algorithmo, the desthed line is for $3 x=$ it = 0; the solid curne includes the modifications due to finite dif-

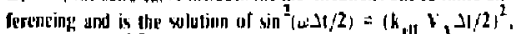

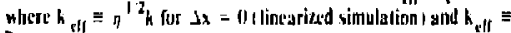
$\bar{k}$ for $\mathrm{J}_{\mathrm{s}}=0$ (fully ronliness. Sinuldion data are shoun in

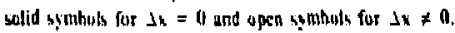

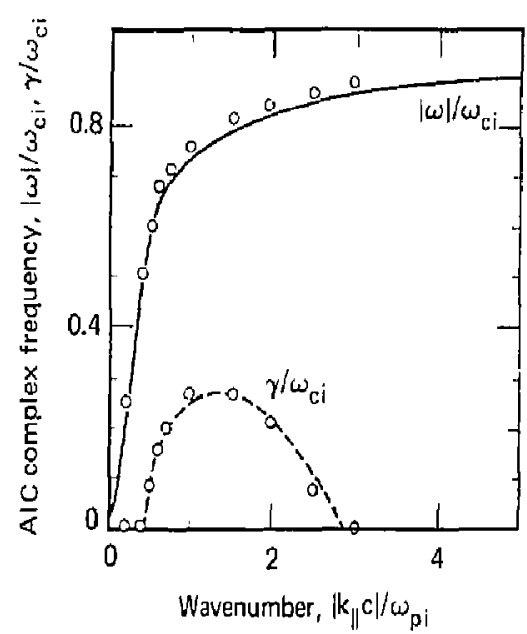

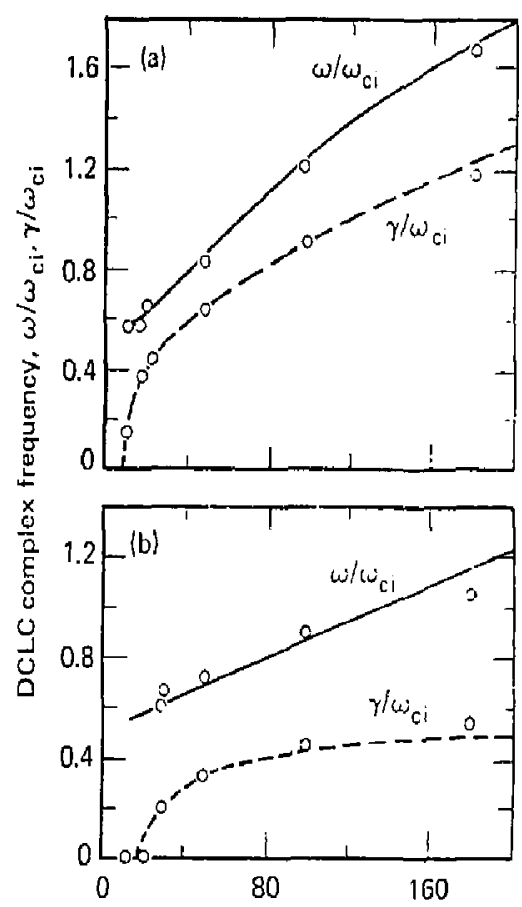

Wavenumber squared, $k_{?}^{2} a_{i}^{2} / 2$

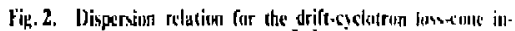

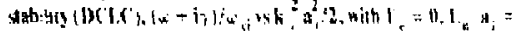

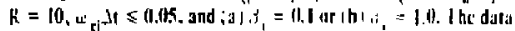

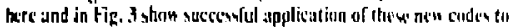

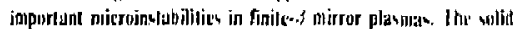

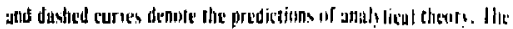

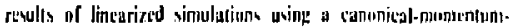
conserening algurithm are inticated by the data puists

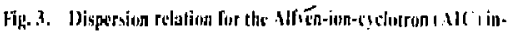

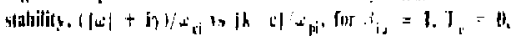

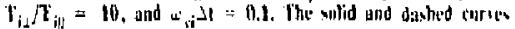

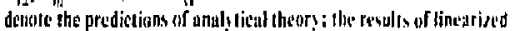
simulution using a predictor-sorrector scheme uppeur as daria points. 
more recently extended these methods to the simulation of field-reversed configurations for which the electrostatic polential on open field lines is deternined by end loss and on closed field lines by $l \cdot j=0$.

\section{References}

1. J. A. Bers, B. I. Coben. W. C. Condit, and J, B. Hanson,

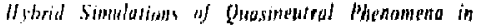

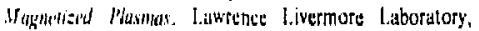

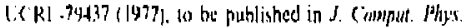

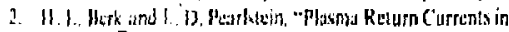

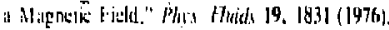

Authors

\section{Major Contributors}

B. I. Cohen

J. D. Hanson

J. A. Byers

T. A. Brengle

W. C. Condit

\section{1.aser Interattions with Plasma}

He cominued our study of some aspecti of laserplasma inceractions, In collaboration with $\mathrm{Allan} . \mathrm{N}$. Kaulman lliniversigy of california and Lawrence Berkeliy lathoratory) we extended un analysis of the resomiant excitation of a large-amplitude plasma wase" 10 inchude the back-reaction of the plasm: wits on the driving fore for the specific case of stimulatw Raman scallering. ${ }^{2}$ Such scallering is of intersis for plasmi-trealing applications and Masma-bast amplification: it could be Jeleterious in luture lastr-peilet fusion and laster-heated solenoid experiments.

The interation is described by the following coupled-mode equations:

$$
J_{1}: J_{t}=-\left(i_{i} i_{2}\right)\left(w_{p i}^{2}: \omega_{b}\right)\left(\tilde{n} / n_{(j)}\right) u_{2}
$$

and

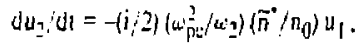

where $u_{1}$ and $u_{2}$ irs the slowly varying (complex) amplitudes of the transverse oscillation velocities of iwo transterse waves with frequencies $\omega_{1}$ and $\omega_{2}\left(\omega_{1}>\omega_{2}\right)$ and $\hat{n}$ is the amplitude of the associated densily nerturhation. of the beal-wave. These waves resonandy excite a plasma wave through their nonlinear $\vec{V} \times \vec{B}$ force [derivabla from a ponderomotive potential whose amplitude is given by $\bar{\phi}_{0}=(\mathrm{m} / \mathrm{e})$ $\left[u_{1} u_{2}^{\prime \prime}\right]$ if $\omega_{1}-\omega_{2} \approx \omega_{n \omega^{*}}$ We directed particular attentjon to the effects of electron trapping in the beat. wave. To this end we married the couple-mode equations to an electrostatic particle simulation code. We did this to perform efficient numerical calculations on the plasmi-frequency time scale, in which large-implitude plasma waves are excited and considerable trapping occurs.

Figures 1 and 2 illustrate typical results, Trapping causes the plasma wave to become heavily damped, and the scaltering continues at a reduced, but finite rale. In this example $90 \%$ of the energy in the highrequency wave is depleted over eight bounce periods of the trapped electrons, with a fraction, $\left.w_{p e} / w_{1}\right)$. going through the plasma-wave channel into the plasmi as kinetic energy. This result is encouraging for plasma healing and laser. amplificution applications; it is possibly discourag. ing for laser fusion where Ruman backscatter could lead 10 large reflectances and hot electrons.

Wc undertook further research in collaboration wilh Claire E. Max (Lawrence Livermor Laborato:y) to theoretically study the linear evolu. tion in space and time of slimulated Brillouin scal. tering, indaced scattering by ions. and illamentation of laser light in a uniform, underdense plasme. These instabilities could be extremely deleterious

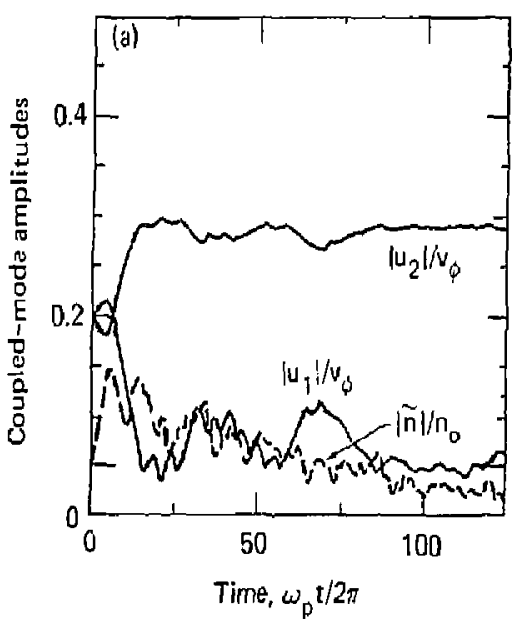

Hig. $t$, Shas the elficient conwervian of the high-frugucney clec. tromagnetic wave into the lover frequency rave and a plasma Have. This figure slows data from a simulation of the resonant response of a Maxwellian efectron plasma [thermal specd $v_{\mathrm{r}}=$ $(\mathrm{l} / \mathrm{m})^{1 / 2} \mid$ to a ponderomotive planc-tave driping force, of froquency $w_{0}$ (chosen equal to $\omega_{p}$ ) and phase belocity $\omega_{0} / k_{n}$ ( chosen equal io 3r $)$, induced hy the $\vec{F} \times \vec{B}$ coupling of iwn opposed eleztromapactic wares with oscillation relocity amplitudes $u_{1}$ and $u_{2}$ (chosen initially equal to $0.2 \omega_{0} / k_{0}=0.6 v_{e}$ ). Initiolly the linesi momal-mode frequency is $R e \omega_{i}=1.17 \omega_{\mu}$ and the linear Ladau damping rate is -Im $\omega_{1}=0.03 \omega_{\text {we. }}$. The transwerse waves have irequencics $\omega_{1}=5 \omega_{p c}$ and $\omega_{2}=\omega_{1}-\omega_{0}=4 \omega_{p e}$. Showr as functions of time are the magnitudes of the coupled-mode amplitudes $\left|u_{1}\right| / v_{\psi_{1}}\left|u_{3}\right| / v_{s}$, and $\mid$ 可 $/ n_{0}$ where $v \phi \nexists_{u_{0}} / k_{0}$. 


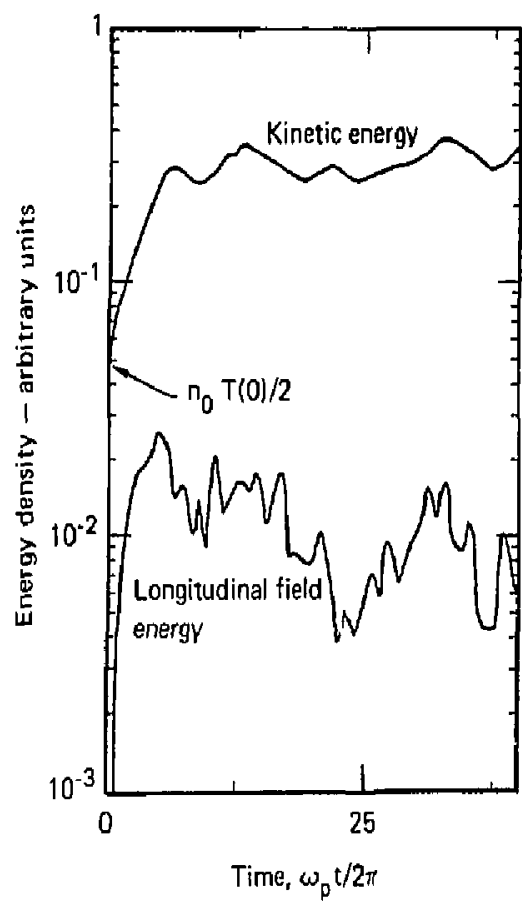

Fig. 2. Shows that, of the exergy andiable to the plasma, most of it is deposited into plasma linetle energy (beating) and ant inlo coherenl-thate energy. The spatially suenged longitudinal kibetic

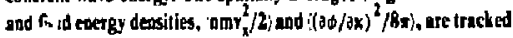
in time ( initial therntal finctuation level for $\left.i(\partial \phi / \partial x)^{2} / 8 x\right)$ bs less thas 0.25 $\times 10^{-2} \mathrm{n}_{0} \mathrm{~T}(0)$

for laser-pellet and laser-solenoid fusion schemes. Large reflectantes ( 50 to $70 \%$ ) as the result of Brillouin scattering have been experimentally observed. We calculated Green's Iunctions for the pulse-response problem, which clarified the competition of these parametric instabilities; absolute and convective instabilities were distinguished. Unless filamentation is preferentially initialized, stimulated Brilloujn scaltering dominates filamentation in a uniform plasma wilh $T_{e}>T_{i}$ for $T_{i}$ $-T_{j}$ induced scaltering and filamentation are both convective and have competitive growth rates.

\section{References}

1. B. I. Cohen and A. N. Kaufman, "Nonlinear Plasma Waves Excited Near Resanance," Plibs. Fluids 20, 1113 (1977).

2. B. I. Cohen and A. N. Kuufman, "Effects of Heal-Wave Electron Trapping on Stimulated Raman and Thumson Scatlering." Phips. Fluids 2I, 404 (1978).

Author

B. I. Cohen

\section{Alswén Ion-Cyclotron Made}

The theory of the Alivén lon-Cyclotron (AIC) mode $1-4$ described in last year's annual report ${ }^{5}$ has since proceeded in several directions.

One mude of operation of the Tandem Mirzor Experiment (TMX) involves neutral injection in the cent:al cell. ${ }^{6}$ We have shown that the anisolropy inherent in the magnetically confined hot-ion distribution does not cause absolute instability." Specifically, the combined electrostatic and magnetic confinement of ions in the central cell is such that high-energy ions experience a loss-cone of semi-angle $18.4^{\circ}$. This satisfied the condition for absolule ${ }^{6}$ AIC: stability, which is that the cone excised from !ile high-energy part of the ion-velocity distribution shall have a semi-angle less than $30.9^{\circ}$. This figure is arrived at by considering : 1 wocomponent model. with a Maxwellian cool component and a loss-cone-Maxwellian hot component chosen to approximate the outpul of Rensink's Fokker-Planck computations. The effect of the cell's finite width is evaluated by inserting a nonzuro $k_{1}$. Convective growth is shown to rcquire more than $950 \mathrm{~cm}$ for seven e-foldings (a thousandfold amplitude increase) when the loss-cone hals the $18.4^{\circ}$ semi-angle?

A request for computer time and scientific collaboration was received from anuther group working on the AIC mode. These persons were studying the spatial vasiation parallel to the magnetic lield of the AIC mode in a finite machine. In the course of evaluating their request. we discovered that their second-order differential equad. tion was incorrect and that. in any case, the fourthorder differential equation was required for an addquate description of the unstable eigenfrequency problem. We further found that the correct equation would not yield jump conditions.

Byers ${ }^{9}$ has reported stabilization of the AIC mode by finile length in particle simulations. The simulations in question ${ }^{10}$ are one-dimensional (along the magnetic field) and linearized. In equilibrium, $B_{0}(z)$ is a constant, so there is no deluaing of the mode by variation in $\alpha_{\mathrm{cci}}$. The ion.s are confined by an effective potential that is parabolic, so there is no dephasing of the mode by variation in the ion-bounce frequency chi-

We derived the integro-differential cquation describing the spatial variation of the complex amplitude $E(z)$ of the mode field. Rather than solving the complete spatial problem, we ser up a simple dispersion relation as follows. We assumed it single spatial-frequency electiomagnetic wave and found the response in the form of a (spatially varying) plasma current. The wave and current logether were 
required to satisfy Maxwell's equations at the plasme nidpoint. Dispersion diagrams based on the dispersion relation show resonances at a' irequencich $\omega^{\prime}=\omega_{b 1} \pm 2 n \omega_{\mathrm{ci}}$ is expected ${ }^{l 1}$ (Fig. 1).

We obtained a series of dispersion diagrams for plasntar of fixed length and increasing anisotropy. Restriching ourselves to rail wavenumbers such that a half-wavelength lits in the plasina length, we found stabilisation of the AIC mode vecurring at antisatropics al $\dddot{i}_{L} \mathrm{~T}_{\mid 1}=10$ lo 20 for short plasthas al lengeth the orciar of the ion-I.armor radius. Including the ian bounse molion in the dispersion relation could inersiss: the anisotropy aliowed at marginal slatility hy a fictor of i wo. Stabilization at these andolropics lor short plasmas was consisene with the lincariod particle simulation of Butro,

\section{Ruferences}

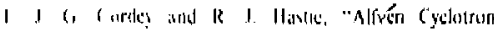

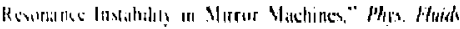
15. $2901+1973$.

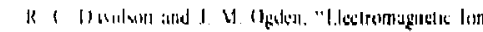

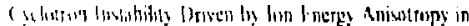

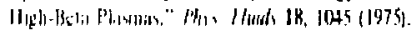

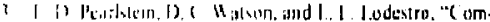

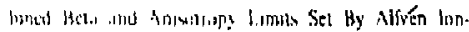

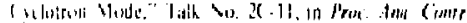

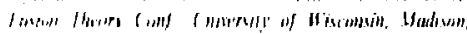

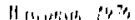

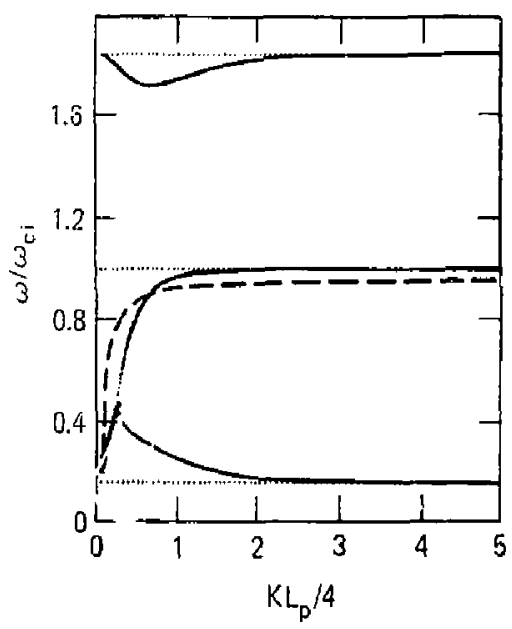

lig. 1. AIC bounce-niade dispersion relation. I,ight continuous line is real frequency corresponding to teal wayenomber. Heary line, which is the real part of a complex frequency. dexotes instability. Washed line is infinite-mediun dispersion curve. J'arar to are $\omega_{b i} / \omega_{d}=0.42 ; T_{i} / T_{1}=10: d_{1}=0.75$ : and $I .,=1.16 \mathrm{a}$. Note the resonancs structure as indicated by the dot. ced lines.
4. L. D. Pearlstein, D. C. Watson. and L. L. Lodestro. "Firite-I.ength Stubilization of the lon.Cyclotron Mode," biull. im. Phy's. Soc. 21. I106 (1976).

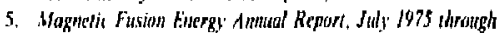
Sepiemher 1976. Lawrence Liveruore Laboratory, UCRL. 50002-76 (1976), p. 103.

6. TMl. Major Project Proposal. Lawrence Livermore I ahoralury. I.1.L. Prop-14k (1977). p. 14.

7. D. ( . Wiation and D. I. Haldain, "Aifuten lon-Cyclotron Instability in the C'entral (ell of TMX." Talk No. F20, in Proc anm Contr. Fissom Theor, Conf. San Diego. Calif. 1917

8. R. J. Briges, Eloctram-Siream Intracioms with Plasmas (M.I.T. Prouss. Cambridgu, 1964).

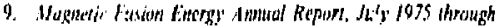
Scpiember 1976, 1.awrence livermonc Laboratory. UCRL. $50002.7611976)$. ก. 109.

10. J. A. Byts. "Cumputer Sunulalion of Fiald Reversal in Mireor Machines." Phy.e. Ker. I.ell. 39, 1476 (1977).

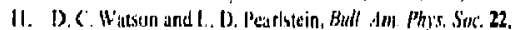
$114511977 \%$

Authar

Major Contributor

D. C. Watson

T. D. Rognlien

\section{3-1) (alculations of Mirror}

F.quilibria with the Finite-Elemen!

Vector-Potential-Equilibrium Code (VEPEC)

We perieeled a new version of the VFPEC ' code that calculates mirror equilibria rapidly and accuraleiy in the finite-element (cubic spline) formulation of Ampure's lizw, Presently, for the guiding. centur fuid model, it calculates equitibrium conligurations ;or be, as (plasma pressur:/ulagnetic pressure) less than the mirror-mode limit after lirst sttermining the equilibrium at the mirror-mode threshold, Figure I plots the mirror-rutio enhancement factor for the long-thin model.

$\frac{k_{k}}{k_{v}}=(1-\beta)^{-1 / 2}$

and its generalization,

$\frac{k_{v}}{k_{v}}=\left|\left(1-\beta_{l}\right)-r^{2} \frac{\partial k}{\partial r}\right|_{0}$

$$
\left.\left(\beta_{1}+\frac{1}{4}\left(\beta_{1}+\beta_{i}\right)\left(1-\beta_{1}\right)\right)\right]^{-1 / 2},
$$

suitable for field lines with small curvature (name'y. the $2 X I 1 B$ Experiment) $v$ s the actual VEPEC results for several different beta values. 


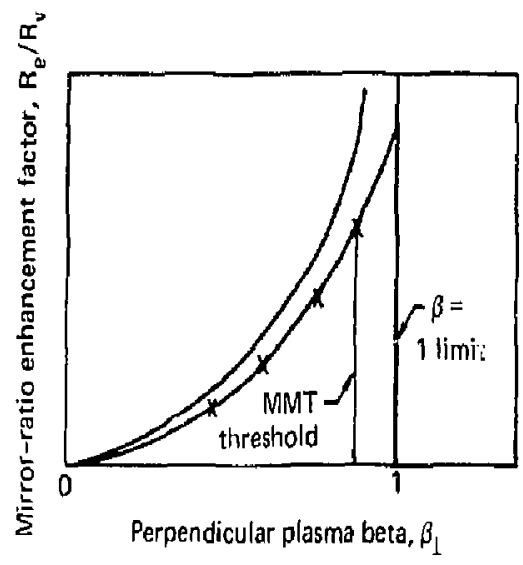

Hig. d. The girfor-etatio enhuncemenl factor $\left(\mathrm{Re} / \mathrm{K}_{\mathrm{r}}\right)$ is plottes an a function of the perpendicular plasma bele $\left(\alpha_{1}\right)$ to The tho ruress are fur the simple lonp-thin formula (uppor) and the firsturder modified leng-thin formula. Vertical lines indicale the

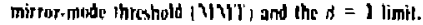

We further discovered that the onset of the mirror mode (at the machine midplane on axis) always coincides with the onsel of bad curvature, Later this effect was analytically proven. The converse is not true-bad curvature does not guarantee the mirror mode.

The present guiding-center model is only applicable to cold plasmas in 2 XIIB and not to the prevailing experimental hot plasma. New models for the plasma, which allow large gyroradii and field reversal, are required to make VEPEC equilibria more realistic. When there are new models the modular structure of VEPEC will easily allow their incorporation.

Solution of the nonlinear-uector Poisson's cquation

$$
V^{2} \underline{A}=(4 \pi / C) \underline{]}(\underline{A})
$$

is presently carried out by the Douglas-Gunn alyorithm ${ }^{2}$ applied to the difference scheme derived from the finite-element expansions. An incomplete Cholesky conjugate-gradient algorithm ${ }^{3}$ (ICCG) will be used to replace the slower Douglas-Gunn algorithm. Equilibria thal now require severa! minules $(\sim 10)$ for solution will be obtained in less than I min on the Lawrence Livermore Laboratory Magnetic Fusion Energy Division's CDC-7600 computer.

The spatial trunciation errors in $A$ for the solution to Eq. 3 are 4 th order in space. A typical finitedifference method would have third-order errors.

\section{References}

I. D. V. Anderson, J. Breizeal, and C. B. Sharp, VEPEC: $A$ 3-p Vector Polential Equilibritum Code for Hign Bpia Minimulis \& Plarme Confinemenr. Laurence Livermore Laboratory, UCRL rept. to be published.

2. J. Douglas. Jr. and J. E. Gunn, "A General Formulation of Alternaling Direction Methods." Nimser, Math. 6, 428 (1964).

3. D. S, Kershaw .7le Incomplerc Sholssky. Conjugale Gradirnt Wethad for the herative Solution of Sysengs of limear Equalions, Laurence Livermore Laboratory, UCRL.983,3 (1976).

Authors
D. V. Anderson
C. B. Sharp

\section{Preliminary Planning for a 3.1) \\ Multinuid Magnetohydrodynamic . Mirror-Plasma Simulation Code}

Programmatic needs and the promise of greater computer power with the aquisition of the CRAY computer suggest that a large-scale 3-D nuid simulation code for mirror plasmas may be a realistic 1ool for understanding plasma dynamics (as well as stcady stiltes) in a mirror plasnia.

Short time simulations need to be performed to follow the evolution of various magnetofhydrodynamic (MHD) instabilities. Long time simula. tions are also needed to undersland the evolution loward and the maintenance of a stendy p'asma configuration. Whether one code could operate one code on both timescales is being investigated: if true, savings of unnecessary duplication might be had.

Fur'her incentives to underlake this work huve been provided by severill recent breskithroughs in numerical analysis. Here we refer to the application of finite-element models to fluid equations' and the incomplete Cholesky conjugate-gradient ${ }^{2}$ method. These together form a synergislic relationship that allows fast, accurate solutions of the Muid equations on uneven coarse grids.

Many peculiar fealures of mirror plasmas (including large anisotropies in flow, pressure, and heul flow) dictate :hat existing 3.D MHD models bised on isotropy will not be sutisfactory.

\section{References}

I. P. M. Grusho and R. L. Lete. "Modeling the Plinetary Boundary Laver Using the Galerkin Rinite-lilemtent

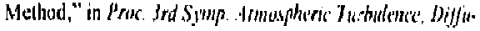
sion. and Iir Quality. Ralcigh. North Carolina. 1976 (Americun Meteorological Society, Buston. Mass. [976).

2. D. S. Kershiw, "The Incomplete Cholesky-Cunjugute Gradient $M_{\text {. }}$ hod for the Iterative Sulution of Systems of Linear Equations," \&. Compul Phys 26, 43 (1978).

\section{Authors}

D. V. Anderson

B. McNamara 
Accurite Single-Particle Orbits in

\section{Realistic 3-D Minimum-B Mirror Fields}

Three-dimensional cubic spline representations of gridded mirror fields were used to calculare trajerlories of particles in the ORBXYZ code.! This code is a considerably more accurate generalization of the familiar TIBRO ${ }^{2}$ and TIBROX ${ }^{3}$ codes.

We undertook two major applications of ORBXYZ, These were calculations of

- Low-beta (plasma pressure/magnetic pressure) plasma shapes and sizes in the vacuum fields for the ZXIIB and Mirror Fusion Test Facility (MFTF) experiments.

- Super-adiabatic phenomena using both gridded realistic fields as well as idealized analytic fields.

For the first application we calculated plasma axial half-lengths for e-folding $(13.5 \mathrm{~cm}$ and $22 \mathrm{~cm}$. respectively, for $2 \mathrm{XIIB}$ and MFTF). These were derived from the alignment of the neutral beams producing the plasmas.

The second project, still underway, has shown that the stochastic variations of the magnetic mo. ment, $\mu$, are often much less than lirst estimaled. Particularly, after a full drift period, we sometimes find $\mu$ coming back quite close to its initial value. Simulations of the particie resonance effects thought to be seen in RECE-BERTA at Cornell University (and that might occur in $2 X I 1 B$ as well) are now being performed with analytic fields. $A$ wealth of diagnostics pertinent to these resonances and to the adiabatic theory is evaluated in the ORBXYZ code, making it particularly well-suited for this study.

\section{Reforences}

I. D. Y. Andersos. B. M. Johnston, and C. B. Sharp, ORH.XY: A Carresian Orbit Code Using A's and B's and (uhir Spline Imlerpolation, Luwrence Livermore Laboratory. UCRL rept. to be published.

2. J. H. Foote, R. P. Fretis, and D. Fuss, Controlled Ther mamurlear Research Annual Reporl. Lawrense Livermore Lisborilory, UCRL-50002-67 (1967).

3. J. D. Hanson and R.S. Devoto, TIBRO-X: A Code ro Compure Trajectories of Charged Panicles in Mognesic Fields. Liwrence Livermore Laboralory, UCRL-52189 (1976).

Authors

D. V. Anderson

R. H. Cohen

C. B. Sharp

Y, Lee

Parameter Studies of Axisymmetric

Reversed-Field Vlasov Equilibria

for the 2 XIIB Regime

with the CYLEQ Code

The simple double-delta function

$$
f=c_{l} \delta\left(E-E_{0}\right) \delta\left(P_{c}-P_{c v}\right)
$$

was taken to be the Vlasoy equilibrisum-distribution function for our study. We plotted various measures of field reversal vs many parameters that determine $c_{1}, E_{0}$, and $P_{c 0}$ in the distribution function. For the dependenl parameters we chose

$$
\begin{aligned}
& R_{p}=B_{c q}(0,0) /\left(B_{\text {vac }}(0,0)=\right.\text { reversal on axis. } \\
& V_{c i n}=\text { volume of closed field lines. } \\
& F_{c n}=\text { fraction of the plasma volume in } V_{c i n} . \\
& \beta_{p k}=8 \pi n k E / B_{v a c}^{2}(0,0)=\text { peak beta. }
\end{aligned}
$$

Many possible sets of independent parameters were used. Primarily we studied

$$
\begin{aligned}
& \mathrm{E}=\text { total energy. } \\
& \mathrm{I}_{0}=\text { total } \text { - }^{-2} \text {.muthal current, } \\
& \mathrm{r}_{0}=\text { inner turning radius, }
\end{aligned}
$$

These in wrn are related to other parameters of interest, both from a theory and an experimental viewpoint. We used

$$
\begin{aligned}
& P_{c} \quad \text { = canonical angular momentum. } \\
& N \text { = total number of plasma ions. } \\
& A_{T}=\text { inverse aspect ratio. } \\
& L=\text { axial half-length of the plasma. } \\
& E_{t h}=\text { thermal energy at the vortex. } \\
& \text { 6 = eccentricity of the cross-section, } \\
& c_{d m}=2 \pi \int J_{0}\left(r_{1}, 0\right) d r=\text { midplane cutrent. } \\
& R_{\text {thk }}=R_{p l}-R_{0}=\text { radial thickness of the }
\end{aligned}
$$
plasm?.

Obviously these are not all independent of each other. From hundreds of various equilibria calculated by CYLEQ we plotted elsewhere' all the various dependencies indicated above.

\section{Reforences}

I. D. V. Anderson, M. E. Rensink, and R. F. Post, Rerersed Field Vlasav Equilibria and Orbits in 2-IJ Axisymmetric 2XI10 Configurations. Lawrence Livermose Laboratory. UCRL. 79844 (1977).

\section{Author}

D. V. Anderson

\section{Calculation of 2XIIB Self-Fields from Experimental Data}

We developed severai models of the plasma current profile for calculating the self-fields in the 2XIIB Experiment. The code CYLEQ was adapted to calculate the selfofields from these models, assuming the plasma current and sel? fields to be axisymmetric. Rigidly rotating ion plasmas with both gaussian and radially humped densily profiles were used as well as some models where the plasma was differentially rotating. We calculated the notmalizalion of the density and the rotation frequencies so the measured total magnetic moment and line den- 
sities were satisfied. Then we performed a parametric search of the axial and radial scale lengths to obtain a best fit to the measured off-axis self-fields.

Profiles were found best fitting the famous April 14th 2 XIIB runs, which were intended to approach field reversil, Comparing the different density and rotation models we calculated field reversal at $\mathrm{JB} / \mathrm{B}=0.9 \pm 0.2$, showing a dependence soniewhat independent of the model chosen. Other measurements support the conclusion reached here than the field is almost reversed but still short of producing any closed lield lines.

\section{Authors}
D. Y. Anderson
D. L. Correll, Jr.
W. E. Turner

\section{2-D Axisymmetric Fluid Simulation of} Plasma Production and Flow in Ion Beams

Extensive modifications were made to the multifluid $r, 2$ magnetohydrodynamic code PLASFLOW to study the interaction of the ion beam with the background plasma produced by the beam.

The code presently represents three ion or neutral fluids as well as electrons treated in the quasineutral limit. All three components of the magnetic field, electric field, and velocity fields are included. Very general boundary conditions may be imposed by the algorithm, including shealh boundaries. Source and sink lerms in the various fluid equations allow the inclusion of chemistry. which was essential in modeling the plasma production.

This code could also be used to study the roles played by the Ohkawa current and the "bootstiap" current in reversed-field mirror conligurations.

\section{Authors}

\section{V, Anderson \\ E. B. Hooper, Jr. \\ P. A. Willmann}

\section{Implementation of Incomplete Cholesky-Conjugate Gradient Method}

We significantly reduced the running time of HYBRID-II (a major production code) by converting to the incomplete Cholesky conjugategradient (JCCG) algorithm. ${ }^{1-4}$ The amount of reduction was problem-dependent, but the least we observed was a factor of five. With stiff problems. the reduction was three or four orders of magnitude in running time. At the same time the accuracy of results improved markedly. Other codes in our group should benefit similarly from ICCG methods.

ICCG is a method for solving large. spurse, linear systems of equations. Such systems, in particular, include the difference equations arising from the numerical solution of partial differential equations. This new method, which is iterative, is economical in its storage and arithmetic operations. It can much more effectively get at exact solutions to a given set of difference equations than can alternating direction implicit (ADI) or operator-splitting methods in terms of computer time and accuracy. This is especially true for stiff problems in which the fastest time scale is much shorter than the time scale in which the interesting physics lakes place. Direct methods of solving for the set of difference equations are competitive with ICCG anly fe $\mathrm{T}$ problems with a modest number of data points.

Prompled by David Kershaw's success with $I_{C C G}{ }^{2}$ in the Laurence Livermore Laboratory laser-fusion production code, LASNEX. we coded the nonsymmetric version of of ICCG in to software packages that solve for the nine-banded matrix that arises from a ninc-point, 2-D difference operator. We incorporaled these packages into the FokkerPlanck code. HYBRID-1I, ${ }^{4}$ Our savings in computer running time and the improved accuracy were clear.

Runs with a confining clectrostatic potential, applicuble to the Tandem Mirror Experiment. are extremely stiff. They greatly benefit Irom the implicit solution allowed with ICCG.

We used a 3-D, seven-point symmetric version on Poissun's equation. Rapid convergence wals obtained, even when the charge density was made il nonlinear function of the potential. We also tested a five-point, nonsymmetric version, Both of these efforts applied to mą̧netohydrodynamic equilibria.

\section{References}

I. J. A. Meijetink :nd H. A, Van der Vorst, An Iterarive SoldJion Method for Linear Systemer of which the Caefficient Matrix is a Symmetric M-natrix. Academic Computer Cen. Ire, de Lithof-U1recht, the Netherlands, Tech. Rept. TR.] (1976).

2. D. S. Kershuw. "The Incomplete Cholesky-Cunjugate Gradient Method for the lteralive Solution of Systems of Lineur Equations," J. Comput. Phys. 26, 43 (1978).

3. T. A. Culter und D. S, Kershaw, "The First Fully Implicit 2D Fokker-Pianck Solver Using ICCG Algorithm." Inth. ifig. Theor Aspects Conir Thernumut. Res, presented at San Deigo, Culit., 1977 (sponsored joinlly General Atomic and Science Applisations, Ins.).

4. A. A. Mirin. H'aR/O-II. A T'o-Dimensional Multispecies Fokker-Planck "imputer Code. Lawrence Livermore Laburalory, UCRL-51615 Rer.1 (1975).

\section{A tuthors}

T. A. Cutlei

D. V. Anderson

B. McNamara 


\section{J-D Plasma Equilibriun}

We applied the McGUS ${ }^{1 \cdot 3}$ equilibrium code to several different magnetic geometries. Our primary effort was directed at magnetic geometries from the Fusion Engineering Research Facility (FERF), hybrid-reactor design, loffe-coil reactor design, and the Tandem Mirror Experiment (TMX). Each of these designs yielded a distinct magnetic field and correspondingly different equilibria. The central distinguishing feature among the four fields was the variation of curvature along field lines.

The FERF coil set consists of a long yin-yang coil pair, which results in a small radial-well depth and field lines having very little curvalure. For the basic design, which has a coil sweep angle of $85^{\circ}$, McGUS yielded an equilibrium at beta (plasma pressure $/$ magnelic pressure $)=\left(8 \pi p_{1} / B_{v a c}^{2}\right)=0.56$. Modified coils with sweep angles of $65^{\circ}$ and $75^{\circ}$. wiile having a diminished field line curvature, gave only slightly reduced beta values.

The hydrid-reaclor design consists of two sels of yin-y ang coil pairs, nested inside each other. The cuils are positioned to provide a nearly sphcrical conlinement scgion in contrast with the elongateo FERF design. Consequently, there is a greater radial-well depth and greatly enhanced field-line curvature. For optimal pressure profiles with various injection lengths, we computed equilibria, with beta between 0.8 and 0.9 . The beam injection of the hybrid design was tailored using a FokkerPlanck code. To incorporate the parallel and perpendicular pressure corresponding to the FokkerPlanck calculated distribution, we modified McGUS to accept pressure as a tabulaled inpul in uddition to the standard procedure of using an analytical formula. For the hybrid design the use of the Fokker-Planck pressuie proved successful in the low-beta regime. Closer to the stability limits. noisiness of the numerical data generated convergence problems that are being examined.

The basic loffe lield was generated by a system of two loops and four quadrupole-bar currents. For a given device length and loop radius there wite two fundumiental design decisions remaining. First the bar coil may or may not be split at the end or position where the bar coil meets the loop coil. Second the ratio of bar current to loop current must be specified. For the split-end cise with a bar-to-loop current tatio of 2, a Baseball-like field stru.ture is generated. In this case. $r(\gamma)$, the radial distance of a fieid line from the $z$ axis, is a monotonic function of the distance along the field line, $C$, In other words, in the region of interest, as $f$ varies, a field line in a symmetry plane either fans out or compresses in toward the $z$ axis. For a general bar-10-loop current ratio, a fanning field line has an $r(f)$ that incresses, decreases, and then increases. The region of decrease occurs when the ficld line goes under a loop. This nonmonolonic behavior causer a had curvature region along fanning vield lines near the loop coil. The effect of increasing the bar-to-loop current is twofold. First the bad curvalure region is accentuated since $r(\eta)$ increases more rapidly for a fanning field line moving toward a loop: thus $\mathrm{r}(\mathrm{l})$ has a more rapid decrease region. Second the saddle point of the magnitude of the magnetic field moves generally in a radially increasing direction. The position of the saddle point proves to be important for the separable pressures used by the McGUS code since it is necessaly for the average driftsurfacte adtion function $\overrightarrow{T^{\prime}}=! \hat{\mathrm{P}}_{||} \mathrm{d} / \mathrm{B}$, to be monotonic, a general requiren:: of of stuble equilibrium. ${ }^{4}$ is the saddle point is too near the axis. $\bar{T}$ is nonmonotonic in the region where plasma exists. This places a restriction on the plasma radius. To increase the plasma radius the bar-lo-loop current ratio must be increused: this action. however, adversely affects stability since it accenluales the bad curvature region. Our compromisc for a device with length equal to 2.8 limes the loop radius was a plasma radius equal to a quarter-toop radius with a bur-tu-loop eurrent of 1.5 . We obtained betas belween 0.5 and 0.6 with and without split-end coil configurations.

The TMX ficld geometry is gencrated mainly by a central group of loop coils and two end-plug coil sets. An end plug consists of a Buscball-iike coil and several C-shaped coils. Eirrlise work has shown that the omigenily property is muintained in a variely of yin-yang and Baseball coils:" The end plug is of this type. Its field, however, is perturbed in an uissymmetric fushion by tne added TMX coils. To determine whether or not purticles with different pitch angle drift on the same surfice. we used the MAFCOIl ${ }^{6}$ code to culculate guiding-center trajectories. In all cases omnigenous drift surfaces werc genterated. With this assurance we used the McGl's code to construct finite-beta equilibrium. The pressure-weighted stability of the TMX device was then exannined by considering the radial behavior of $\bar{\Gamma}$. In the end plug. $\bar{\Gamma}$ was computed in the finitebeta magnetic field: in the central TMX region, $1=$ I d/B wis culculaled with the MAFCO76 code? The stubility index was then the radial variation of $\bar{l}+a l$, where $\alpha$ is the pressure ratio belween an end plug and the central cell. On this basis, in the predicted operating regime. TMX was sarisfactorily stable to interchanges.

\section{References}

I. J, K. Boyd, L., S, Hall, B. Me Yamiara, and C. A. Wijpus. 
Three-Pimensiomal Anicolrupic Pressure Eqmithrium in Ifirm Itachines, Lat rence Livermore Laboratory. UCRL. 77977 (1976).

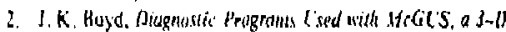
Ifirror liquilibrian (onte. Latwrence Livermore Laboralory. UCID) 17650 (1977)

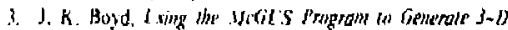
Viens fyulbrim. Iowrence liwernose laboratory. $1: C 10.17651(1977)$

4. 6. A. Hall and B. MeNomara, "Three Dimensional lquilibrium of the Ailisultopic, linito-Pressure Guiding Center llasna: Theort of the Magnelin Plasmu," Mhis. Huidu IR, 55 ? (1975).

5. I. S. Hall. B. Msivamaria. J. K. Boyd. C. A. Finan. D. Juss and (. A. Wilgus, "Theoretical Siudies of Plasma Con line. misnt in Mignetic Mirrors." Conf. Plama Phys, and in Proe

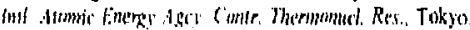
Japian, 1974 (Internationil Alomic Finergy Agency, Vienuia 19751.

4. II A. Parkins and D. Fuss, Hafw H-1 Comp for

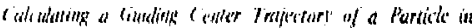

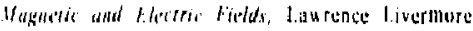
l.aboralory. lickl. 30438 (1968).

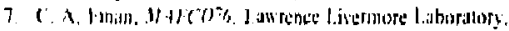

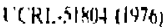

\section{Authors}

J. K. Boyd

l. S. Hall

B. Metimaris

\section{Exploratory Conceptsi Intense Pulsed Inn-Neutral Source (IPINS)}

\section{Introduction}

Altaining a field-reversed configuration in the 2Xil8 confinement exporiment is a major objective of Laurence Livermore Laboralory's mirror program, To date, achievemen of this goal appears to be thwarted due to insufficient input neutral. beam energ)' or energy confinement time (see 2XIlB section) or both. Thuse experiment limitations cause the contained plasmi cnergy to be less than the energy that would allow field reversal to occur. In the most simple form, 2XIIB fieid reversal would be accomplished by injecting and trapping sufficien beam encrgy to substitute the magnetic field energy. Thus

$$
\mathrm{Q}_{\mathrm{B}} W_{\mathrm{G}} \approx \xi \cdot \mathrm{B}^{2 / 2} / 2 \cdot \chi \cdot \text { volume of plasma. }(1)
$$

where $Q_{B}$ is the injected beam charge al energy $W_{B}$ $\xi$ is the degree of field reversal $(>1)$, and $X$ is the swelling factor of the plasma volume. For 2 XIIB parameters. $Q_{B} W_{B} \approx 5 k J$. The purpose of this $e x$ ploratory concepls program is to determine if a new technology' can develop an Intense Pulsed Ion. Neutral Source (IPINS) capable of furnishing the beam parameters necessary to attain field-reversa! requirements for 2 XIIB.

\section{Approach}

Past Livermore experiments * have shown that the new technology of intense-ion diodes was characterized by the following parameters:

- Particle enetgy $>100 \mathrm{keV}$

- Ion current density $>2 \mathrm{kA} / \mathrm{cm}^{2}$.

- Pulse duration $50 \mathrm{~ns}$.

Since this early work other researchers ${ }^{d}$ have demonstrated intense-ion diode operation al higher voltages (i,e, 500 or $800 \mathrm{keV}$ ) bul with similar pulse durations and current densities.

These operational parameters, allhough in. teresting, are insufficient for Livermore's objectives in two areas. First, for ion orbits to be contained by the existing coninement experiments magnetic ficld and to allow for the high-intensily ion beam to be atomically neutralized (lo avoid injection problems across the nitror magnetic fields) the ion-buam energy must be lowered to 50 to $100 \mathrm{keV}$. Lowering $W_{B}$ meant :itu $Q_{B}$ must substantially increase: to deliver the necessity $Q_{B}$ in the customiary ion-diode pulse time of 50 ns would require low-impedance generutor curren is of unwieldy proportions (severa 10s of MA). To avoid this difficulty one should ex. tend the intense-ion-flow pulse duration from $50 \mathrm{~ns}$ $10>1 \mu s$. Thus. Fy 1977 uctivily in this exploratory concept program concentrated on these major objeclives:

- Investigate whether intense-ion-dinde nows of energies $₹ 100 \mathrm{keV}$ were possible.

- Determise if alomic neutralization ol the ex. tracted high-intersity ion beam could occur.

- Determine ir one could extend the time duristion of the intense-ion pulse to $\$ 1 \mu \mathrm{s}$.

- Ir results are encouraging, fabricate an experimenlal facility whose performance is expeced to be within a factor of two of the requirements for 2XIIB application.

\section{X ccomplishnents}

We addressed the first three rescarch issues on it small test stand built to determine if ion-diode technology could be so advanced. Accomplishments of the test stand 1.5 appear below:

- Developed intense-ion-flow diodes of 1.2 25 .

- Generated ion-current intensity of $200 \mathrm{~A} / \mathrm{cm}^{2}$. Limitations on this cutrent intensily were power-supply designs (high impedance).

- Developed stable diade voltage of $75 \mathrm{kV}$ lasting a rull pulse duration. 
- Accomplished atomic neutralization of the ion beam by using thin carbon foils. Because of the high ion intensity, customary gas-cell neutralizers were unfeasible.

- Extracted the neutral beam and propagated it $1.2 \mathrm{~m}$ to a diagnostic target. Beam divergence was $\pm 3^{\circ}$.

Because of these encouraging results we completed fabrication of the larger experimental facility (last major objective) at the end of FY 1977. We began efforts to make this facility fully operational. Advancements in power-supply design and improvements in diode construction should improve cfliciency and increase our current density by over an order of magnitude. The key issues for FY 1978 research are (a) improving where possiole the beam fluence (further increasing diode efficiency) and (b) more importantly, decreasing the beam divergence. If both these research issues proceed favorably then the experimental facility will be within a factor of two of 2 XIIB requirements.

\section{References}

I. D. S. Prane. J. M. Croedon, I. Smith, and N. Bergstrom. "Mutitiple Recltections of Elecirans and the Passibility of Intense Positive-lon Flow in High $0 / \gamma$ Diodes, " $J$, Appl. Phys. 46, 3310 (1975).

2. D. S. Prang, J. W. Sheser, and R. J. Briges. "Pulsed lon Diode Experiment," Phys. Rev. Lell., 37, 21 (1976).

3. J. Golden, C. A. Kapentanukos, S. J. Marsh, and S.J. Slephanakis, "Generation of 0.2 IW.Pralan Pulses," Phys, Rev. Lell., 38, 130 (1977).

4. D. S. Prono and R. J. Briggs, "Intenje Pulsed Ion Nieutsal Source (IPINS)," presented at tm. Phyr. Soc., Aslanso. Geargia. 1877.

5. D. S. Prono, H. Ishizuka, and R, J. Briggs, Imense Pulsed fon-Neural Source (IPINS). Lawrence Livermore Laboratory, UCRL-79965 (1977),

Author

D. S. Prono 


\section{SECTION 4. TALKS AND PUBLICATIONS}

\section{Talks}

Eighteenth Annual Meeting of the Division of Plasma Physics of the American Physical Societ;. San Francisco, C...'Smia, November 15-19, 1977 [Published in Bull. Am. Phys. Soc., 21 (1976)].

D. V. Anderson and M. E, Rensink, "3D Calculations of High Beta Mirsor Equilibria," p. 1 I65 [UCRL78503 Abstract (1976)].

O. A. Anderson and E. B. Hooper, "Propagation of Dense Negative Ion Beams," p. 1102 [UCRL-78534 Abstract (1976)].

D. E. Baldwin, "End Loss Processes in Mirror Machines" [UCRL-78584 Abstract (1976)].

J. A. Byers, "Field Reversal by Neutral Injection in Mirror Machines," p. 1106 [UCRL-78512 (1976)].

J. Clauser, C. Gormezano, W. Nexsen, T. Simonen, and W. Turner, "Electron Temperature and Scaling in the 2XIIB Plasma," p. 1143 [UCRL-78545 Abstract (1976)].

R. H. Cohen and J, H. Foote, "Nonadiabaticity in Finite-B Mirror Fields," p. 1187 [UCRL-78505. (1976)].

R. Cohen and L. S. Hall, "Nonadiabaticity and the Mirror Mode," p. !998 [UCRL-78507 Absiract (1976)].

D. L. Correll, O. A. Anderson, D. H. Birdsall, E. B. Hooper, and D. S. Prono, "Negative lon Beam Produc. tion Efficiencies," p. 1102 [UCRL-78536 Abstract (1976)].

T. A. Cutler, A. Mirin, D. Pearlstein, and M. Rensink, "Bounce Average Code Mirror Plasma Studies," p. 1187 [UCRL.78529 Abslract (1976)].

C. C. Damm, J. H. Foote, A. H. Fulch, R. K. Goodman, R. S. Hornady, J. E. Osher, and G. D. Porler, "Streaming Plasma Measurements in the Baseball II-T Mirror Experiment," p.1164 [UCRL.78543 Absiract (1976)].

R. Devoto, J. Hanson, and W. Condit, "Parametric Survey of Field-Reversed Mirror Reactor," p. 1193 [UCRL-78508 Abstract (1976)].

J. Foote and J. Wyrick, "Ions From D-D Reactions As A Monitor Of Plasma Density," p. 1099 [UCRL78502 Abstract (1976)].

A. H. Futch, R. Fries, and A. Mirin, "Plasma Buildup Calculations of Neutral Beam Injection With A Radially Dependert Fokker-Planck Code," p. 1182 [UCR L-78540 Abstract (1976)].

L. S. Hall, "The Magnetic Plasma," p. 1105 [UCRL-78557 Abstracl (1976)].

C. W. Hartman, J. Eddleman, and K. Struve, "High-Density, Finite-Larmor Radium Stabilize Z-Pinches and Reactor Possibilities," p. 1171 [UCRL-78533 Abstract (1976)].

E. B. Hooper and P. A. Willmann, "lon/Neutral Beam Effects in Charge Exchange Cells," p. I102 [UCRL78535 Abstract (1976)].

B. G. Logan, "High-Beta, Gas-Stabilized Plasma in 2XIIB Mirror Machine," p. 1142 [UCRL-78526 Abstract (1976)].

B. G. Logan, T. K. Fowler, A. H. Futch, JT., A. A. Mirin, and M. E. Rensink, "The Tandem Mirror ConcepL", post-paper [UCRL-78761 (1976)].

Y. Malsuda, J. Sampson, H. Okuda, and P. H. Rutherford, "Guiding-Center Calculation of Beam Ion Diffusion in a Tokamak."

B. McNamara, J. K. Boyd, and L. S. Hall, "Mirror Equilibria and Reactor Design," p. I 105 [UCRL-78539 Abstract (1976)].

A. W. Molvik, J. Clauser, F. Coensgen, D. Correll, W. Cummins, C. Gormezano, B Logan, W. Nexsen, T. Simonen, B. Stallard, A. Stark, and W. Turner, "Measurements of Stabilizing Warm Plasma," p. 1143 [UCRL-78547 Abstract (1976)].

W. E. Nexsen, J. Clauser, F. Coensgen, W. Cummins, B. Logan, A. Molvik, B. Stallard, W. Turner, D. Correll, T. Simonen, and C. Gormezano, "Limitation of Peak Density in 2 X11B oy Stream Slarvation," $p$. 1143 [UCRL-78524 Abstract (1976)].

J. E. Osher and G. D. Porter, "Laser-Pellet Target Production in the Baseball II-T Experiment," p. 1/64 [UCRL-78542 Abstract (1976)]. 
L. D. Pearlstein. D. C. Watson, and L. L. LoDestro, "Finite-Length Stabilization of the Alfvén-IonCyctatron (AIC) Mode," p. 1106 [UCRL-785II Abstracl (1976)].

D. S. Prono, J. W. Shearer, and R. J. Briggs, "A Pulsed, Intense Neutral Beam Diode System," p. 1030 [UCRL-78528 Abstract (1976)].

M. E. Rensink, "Beta Límits for Mirror Confined Plasmas," p. 1187 [UCRL-78510 Abslract (1976)].

T. Rognlien, H. Berk, and T. Culler. "Effect of Wide Angle Neutral Beam 'njection on a Microinstability in a Mirror Machine," p. II44 [UCRL.78531 Abstracl (1976)].

J. W. Shearer, "Steady State Calculations of Reflex Diode lofl Sources," p. 1030 [UCRL.78504 Absiract (1976)].

T. C. Simonen, C. Gorm zano, B. G. Logan, A. W. Molvik, W. E. Nexsen, B. W. Stallard, and W. C. Turner, "Trapping Efficiency of Tangential Neutral Bcam Injection in the 2XIIB Magnelic Mirror Device," p. 1143 [UCRL-78555 (1976)].

B. W. Stallard, F. Coensgen. C. Gormezano, W. Nexsen, T. Simonen, W. Turner. "Calculation of Neutral Beam Plasma Buildup in a Mirror and Comparison With the 2XIIB Experiment." p. II43 [UCRL-78525 Abstract (1976)].

W. C. Turner, H. L. bisk, and J. J. Stewart, "Measurement of Turbulent Ion Diffusion in a Mirror Machine," p. 1143 [UCRL-78546 (1976)\}.

Nineteenth Anmual Meeting of the Division of Plasma Physics of the American Physical Sociely. Atlanta, Georgia, November 7.11, 1077 .

D. V. Anderson. M. E. Rensink, and R. F. Post. "R.uversed Field Vlasov Equilibria and Orbils in 2D axisymmetric "2X" Configuritions" [UCRL-79844 (19i7)].

O. A. Anderson. Jr. and P, Poulsen, "A High-Current Deuterium lon Source for Neutral Beams" [UCRL$79882(1977)]$.

D. P. Alkinsun and :M. O. Calderon. "LN2 Liners for 2XIIB" [UCRL-79755 (1977)|.

D. P. Atkinson and M. O. Calderon. "The Vacuum Systern for the Tandem Mirror Experiment" [UCRL. $79750(1977)]$.

H. L. Berk. Y. Matsuda, T. D. Rognlien, and J. J. Stewart, "Stabiliza lion Mechanisms for Mirror Quasilinear Code" [UCRL-79853 (1977)].

R. J. Briggs, J.Clark, T. J. Fessenden, and E. J. Lauer, "Interpretution of Net Current Measurement in REB Experiments" [UCRL-79932 (1977)].

M. O. Caldron, F. F. K. Chen, and B. S. Denhoy, "Mechanical Design for TMX Injector System" |UCRL. $79753(1977)]$.

G. A. Carlson, W. C. Condit, R. S. Devoto, J. D. Hanson, and W. Neef, "Parameter Studies of FRM Reaclor" [UCRL-79956 (1977)].

F. W. Chambers, "Current Multiplication due to the Nonlinear Evolution of the Beam Plasma Interaction" [UCRL-79887 (1977)].

J. Clurk. T. J. Fessenden, and E. J. Liuer, "Observation of the Resistive Hose Instability With A 15 ka REB" [UCRL-79930 (1977)].

J. F. Clauser, "A Non-Perturbing Mugnetic Field 'Poinl' Measurement Technique" [UCRL-79831 (1977)].

B. I. Cohen. W. C. Condit, J. A. Byers, and T. A. Brengle, "Particle Simulation of Mirror Plasma With Quadrupole Magnetic Field and Electron Dynamics" [UCRL-79841 (1977)].

W. C. Condit, J.A. Byers, J. D. Hanson, and B. I. Cohen, "Simulation of Magneto Sonic Waves and Current Cancellation" [UCRL-79955 (1977)].

D. L. Correll, Jr, D. V. Anderson, and A, L. Hunt, "2XIIB Plasma Diamagnetism" [UCRL-79840 (1977)].

W. F. Cummins, Jr. and C. P. Parrish, "Efficient Processing Methods for Large CTR Dala Bases" [UCRL79836 (1977)].

T. A. Cutler, R. H. Cohen, and M. E, Rensink, "Ambipolas Potential-Aided Mirror Confinement" [UCRL.79846 (1977)].

R, S. Devoto, "Computation of :SIMGA'Y; for Neutral-Beam Injection" [UCRL-79872 (1977)].

T. J. Fessenden, R. J. Briggs, J.Clark. E. J. Lauer, and E. P. Lee, "Propagation of a $15 \mathrm{kA}$ REB in an Insula- 
tion Drift Chamber" [UCRL-7993I (1977)].

T. K. Fowler. "The New Face of the Mirror Fusion Program" [UCRL.79833 (1977)].

R. P. Freis, J. A. Byers, R. M. Glaser, T. B. Kaiser, S. Rompel. and T. C. Simonen. "Computer Calculations of Field Reversed 2XIIB Mirror Configurations" [(UCRL-79845 (1977)].

R. E. Hester, R. J. Briggs, T. J. Ressenden, and E. J. Liuer. "Observations of Current Multiplication in Relativistic Electron Beam-Plasma Interaction" [UCRL-79933 (1977)].

J. R. Hiskes and A. M. Karo, "Negative lon Yields From Protons und Hydrogen Atoms Backscalttered l runt Cesium-Coated Surfaces" [UCRL-79848 (1977)].

A. L. Hunt and B. G. Logan, "Neutron Emission Measurements for the 2XIIB Plismai" JUCRL.798.38 (1977)].

T. B. Kaiser, "Simulation of the Spatial Diffusion of Test Particles in a Magnetized Plasma Induced by Wealh Elecirostatic Turbulence" [UC'RL-79839 (1977)].

E. J. Lauer, R, J. Briggs, T. J. Fessenden, R. E. Hester, and E. P. Lee, "Measurements of Hose Instability of the Astron Relativistic Electron Beam" [UCRL-79929 (1977)].

E. P. Lee, "Stabilization of the Resistive Hose Mode of a Pulsed Relitivistic Electron Beim" [UCRL-79928 (1977)].

B. G. Logan, "Steady State Aipha Fractions in DT and DD Tandem Mirror Reactors" [UCRI.-79727 (1977)].

Y. Matsuda and H. L. Berk, "Monte Carlo Approach for Neutral Purticles in a Mirror Machinc" (UCRL. 79851 (1977)].

M. C. McCoy, J. Killeen, A. A. Mirin, M. E. Rensink, and D. Shumaker, "Fokker-Planck-Transparl Model of Non-Circular Axisymmetric Devices" [UCRL-79891 (1977)].

B. McNamara, B. Char, and R. J. Fateman, "Super Convergent Adiabatic Invariants with Rcionim Denominators by Lie Transforms" [UCRL-79843 (1977)].

R. W. Moir, "Electrostatic End-Plugging of Open-Ended Configurations" [UCRL-7989.3 (1977)].

R. W. Moir, "The Tandem Mirror Reactor" [UCRL-79907 (1977)].

T.J. Orzechowski, O. A. Anderson, Jr., D. H. Birdsall, E. B. Hooper, Jr.. P. Poulsen, R. I., Spocrlcin, and R. J. Turnbull. "Production of High Energy Negative lon Beams Lising Double Charge t Tuhange" [CCRL. 79885 (1977)].

J. E. Osher, "A Streaming Plasma lon Source for 2XIIB Stabilization" [LCRL.7987) (19771].

L. D. Pearlstein and I, Freiberg, "Finite Larmor Radius Effects on Weak MHD Instabilities" [CC RI . F) (1977)].

R. F. Post, "Field-Reversed Equilibria Created By Neutral Beam Injection-A Theoreticil Model" [l 'CRI. 79821 (1977)].

P. Poulsen, "A Sireaming Plasma Source for MFTF" [UCRL-7988 i (1977).

D. S. Prono and R. J. Briggs, "Intense Pulsed Ion Neutral Source" [UCR1.79897 (1977)].

M. E. Rensink, "One-Dimensionai Rigid Rotor Modei for Field Reversil in 2XIIB" [L CRL.79\$:U (1977)|.

T. D. Rognlien, T. A. Brengle, and T. A. Cutler, "Characteristics of Stabilizing Warm Plasma A Wial Flow in Mirror Machines" [UCRL-79842 (1977)].

J. W. Shearer, "Mirror Plasma Startup by Neulral Beam Healing of Dense Targets" (C (CRL.748:2? (1977)].

T. C. Simonen, J. F. Clauser, and R. K. Goodman. "Power Balance in 2XIIB Field Reversil Lxperinemes" [UCRL-79874 (1977)].

A. C. Smith, Jr., "Pulsed D.Hey Fusion Plasma Burns" [UCRL-79912 (1977)].

B. W. Stallard, A. M. Frank, and J, W. Shearer, "A Faraday Rolation Diagnostic for Magnetic litid Measurements in 2XIIB" [UCRL-79835 (1977)].

J. J. Stewart and H. L. Berk, "DCLC Marginal Stability in Quasilinear Code" [LCRL.79"4t' (1977)].

S. R. Thomas, "TMX, A New Facility" [UCRL-79754 (1977)].

S. R. Thomas, T. H. Batzer, M. O. Calderon, R. H. Hawkins, and R. J. Nagel, "A L.arge Rectangular Bellows Valve" [UCRL-79751 (1977)].

R. J. Tumbull, E. B. Hooper, Jr, O. A. Anderson, Jr., D. V. Anderson, and P. A. Willmann, "Stability of a Negative lon Beam" JUCRL.79883 (1977)]. 
W. C. Turner, "Field Reversal Experiments in 2XIIB" [UCRL-79868 (1977)].

D. C. Watson and D. E. Baldwin, "Finite-Length Stabilization of the Alfven-lon-Cyclotron (AIC) Mode: The Differential Equation Approach" [UCRL-79852 (1977)].

American Physical Saciery Meeting, Chicago, Illinois, Febraary 7-10, 1977.

B. G. Logan, "The Tandem Mirror Reactor" [UCRL-78762 (1977)].

Amterican Physical Society 1977 March Meeting, San Diego, Califomia, March 21-24, 1977.

J. R. Hiskes, A. M. Karo, and M. A. Gardner, "Mechanism for Negative-Hydrogen-Ion Production on Alkali Coated Surfaces" [UCRL.78956 (1976)].

American Physical Society Spring Meering. Washington, D.C., April 25-28, 1977

B. G. Logan, "Prospects for a DD Tandem Mirror Reactor" [UCRL-79047 (1977)].

1977 Annual Meeting on Theoretical Aspects of Controlled Thermonuclear Research, San Diego. California. Ma) 4-6, 1977, Sponsored jointly by General Alomic and Science Applications, Inc.

D. V. Anderson, M. E. Rensink, and W. C. Turner, "Equilibrium Models for Field Reversal for 2XIIB Parameters" [UCRL-79371 (1977)].

H. L. Berk, T. D. Rognlien, and J. J. Stewart, "Quasilinear Simulation of Mirror Machines"

J. A. Byers and R. P. Fieis, "Computer Simulation of Field Reversed Mirror Configurations with the Superlayer Code"

F. W. Chambers and E. P. Lee, "Unstable Modes of a Fully Pinched Relativistic Electron Beam in a Plasma [UCRL-79378 (1977)].

B. I. Cahen. J. A. Byers, W. C. Condit, and J. D. Hanson, "Hybrid Simulations of Quasineutral Phenomena in Magnelized Plasma."

R. H. Cohen, M. E. Rensink, and A. A. Mirin, "Tandem Mirror Confinement Studies."

B. I. Cohen und W. M. Tang, "2D Nonlinear Saturation of the Rapped-Ion by Mode Coupling,"

D. Culver, "Magnetohydrodynamic Instability of Straight Axis Mirror Quadrupole Wells with Steep Radial Pressure Gradients,"

T. A, Cutler and D. Kershaw, "The First Fully Implicit 2-D Fokker-Planck Solver Using ICCG Algorithm" [UCRL-79372 (1977)].

R. R. Dominguez and H. L. Berk, "Variational Method for a Cylindrical Plasma."

J. R. Hiskes, A. M. Karo, and M. A. Gardner, "Negative lon Yields From Hydrogen Atom Bombardment of Cosium-Couted Surfaces."

T, B. Kaiser, "A Technique for Monte Carlo Simulation of Velocity Diffusion in Two Dimensions."

T. B. Kiliser, 'Monte Carlo Simulation of a Quasilinear Transport Model For Mirror Plasmas."

B. G. Logan, "The Tandem Mirror Concept" [UCRL.79276 (1977)].

Y. Maisuda, H. L. Berk, and J. J. Stewar, "Quasilinear Model of a Mirror Plasma With Radial Transport."

L. D. Pearlstein and N. Maron, "Stability Boundaries for Loss-Cone Modes."

R. F. Post, "On Field Reversal Via Neutral Injection" [UCRL-79387 (1977)].

M. E. Rensink, R. H. Cohen, T. A. Cutler, and A. A. Mirin. "Particle Confinement by Ambipolar Potentials in Mirror Machines."

T. D. Rognlien, T. A. Brengle, and T. A. Cutler, "Computer Model of Gas Feed Experiments in Mirror Machines" [UCRL-79370 (1977)].

J. W. Sheurer. "Electron Energy and Space Charge Calculations in Reflex Diodes" [UCRL-792277 (1977)).

G. G. Tull, J. Killeen, and M. E. Rensink, "A Steady State Guiding-Center Model for the Counterstreaming lon Torus (CIT)" [UCRL-79383 (I977)].

D. C. Watsun and D. E Baldwin, "Alfvén-Ion Cyclotron Instability in the Central Cell of TMX," 
Seventh Symposium on Engineering Problesins of Fusion Research, Instimue of Electrical and Electronics Engineers, Knoxville, Temmessee, Oclober 25-28. 1977 [Published in Proceedings of ... (1977)].

K. Aaland, "Dense Plasma Focus (D.P.F.) Capacitor Bank-Systems Design." p. I55 [UCRL.79738 (1977)]. W, L. Barr, J. N, Doggett, G. W. Hamillu. J. D. Kinney, and R. W. Moir, "Engineering of Bcirm Direc: Conversion for a 120-kV 10MW Ion Beam," p. 308 [UCRL-79718 (1977)].

A. K. Chargin, M. O. Calderon, and G. E. Vogtlin, "System Design for the New TMX Machine," p. 649 [UCRL-79749 (1977)].

F. F. K. Chen, A, K. Chargin, B. S. Denhoy, and A. F. Waugt, "Designing for the Mignetic Ficld Requirements of the Tandem Mirror Experiment," p. 649 [UCR L-79743 (1977)].

D. N. Cornish, D. W. Deis, and J. P. Zbasnik, "Cold Pressure.Welded Joints in Large Multifilantentary NhTi Superconductors," p. 1266 [UCRL-79723 (1977); CONF 77109-41].

K. R. De Vore. "Design of an Eight Magawalt Series Regulator," p. 110 [UCRL-79594 (1977)].

J. H. Fink and L. A. Biagi, "A Long Life Cathode For the Berkeley Type lon Source." p. 1398 [CCRL-7970ई (1977)].

R. E. Hinkle, M. O. Calderon, A. K. Chargin, F. F. K. Chen, B. S. Denhoy, A. R. Harvey, J. A. Horvulh, and J. R. Reed, "TMX Magnels-Mechanical Design," p. 846 [UCRL-79752 (1977)].

G. A. Leavilt, "Tradeoffs in Capacitor Bank Design," p. 1764 [UCRL-79686 (1977)].

G. A. Leavitt, "A 40 kV, 25 ms Neutral Beam Power Supply for TMX." p. 1093 [UCRL.79687 (1977)|.

D. S. Mendell. "A Versatile Real-Time Interferometer Phase Detection Diagnosties System Using High Speed Digital Techniques," p. 1246 [UCRL-79613 (1977)].

R. W. Moir, T. J. Dolan, and W. L. Barr, "Design of Electrostatic End-Plugged Plasma Conlinement Device," p. I 38 [UCRL-79880 (1977)].

A. W. Molvik, K. H. Berkner, W. S. Cooper, T. J. Duffy, K. W. Ehlers, J. H. Fink, ind D. Garner, "Compact $80 \mathrm{keV}$ Neutral Beam Modulc," p. 295 [UCRL-79682 (1977)].

W. K. Mortensen, "A Microcomputer-Based Pellet Trajectory Guidance System." p. 1219 [UCRL-79685 (1977)]

G. G. North, "Design and Test of a $40 \mathrm{kV}, 80 \mathrm{amp}, 10 \mathrm{msec}$ Neutral Bum Power Supply Series Switch Regulator System." p.1096 [UCRL-79673 (1977)].

E. F. Oberst. "Analysis of Threephase Power Supply Systrms Using Computer Aided Desigu l'rograms:." p. 494 [UCRL-79611 (1977)].

G. G. Pollock, "Automation of Multiple Neutral Beam Injector Controls Al LLL." p. 1209 [UCRL.79640 (1977)]

P. Poulsen, O. A. Anderson, Jr., E. B. Hooper, Jr., T. J. Orzechowski, and R. J. Turnbull. "'Negative Beam Gentration, Transport and Acceleration," p. 1408 [UCRL-79728 (1977)].

W. A. Reass, "Programmable, Regulated 15 V, 10,000 A Neutral Beam Filament Supply." p. 1100 [UCRL79639 (1977)].

J. P. Richter, "Fiber Optic Telemetry System For LLL High Voltage Test Stand," p. 397 [UCRL-79688 (1977)].

G. T. Santamaria, "A New Generation of Arc and Arc Filament Power Supplies For Pulsed Neutral Beams." p. 1138 \{UCRL-79683 (1977)\}.

M. E. Smith, "The High Voltage Test Stand at Livermore," p. 1105 [UCRL-79614 (1977)].

A. F. Waugh, "Fast Scan Beam Profi $f$

International Conference on Plasma Science, Instilute of Electrical and Electronics Engineers. Troy. New York. May 23-25. 1977.

W. L. Barr, R, W. Moir, and G, W. Hamilion, "Experimental Results of Beam Direct Conversion" [UCRL$79041(1977)]$.

W. C. Condit, G. A. Carlson, R. S. Devoto, J. D. Hanson, and W. Neef, "Ficld-Reversed Mirrors as Fusion Power Reactors" [UCRL-79054 (1977)].

A. H. Futch, Jr., "A Frequency Stabilized $2 \mathrm{~mm}$ Microwave Interferometer" [UCRL-79118 (1977)]. 
G. W. Hamilton, W. L. P.arr, and R. W. Moir, "Beam Direct Conversion For Fusion Injection at Energies Above $100 \mathrm{keV}, "$ [UCRL-79095 Abstract (1977)].

B. G. Logan, "DT and DD Tanden Mirror Reactors," [UCRL-79048 (1977)].

Symposium on Production and Neutralization of Negative-Hydrogen Ions and Beams, Brookhaven National Lahoratory. Upton. New York, September 26-30, 1977 [Published in Proceedings of . . (1977)].

D. A. Anderson, R. and E. B. Hooper, Jr., "Plasma Production and Flow in Negative Ion Beams," p. 205 [UCRL-80099 (1977)].

J. H. Fink. "Evaluation of Beam Line Components for Use in a Large Neutral Beam Injector," p. 290 [UCRL-79570 (1977)].

J. H. Fink and G. W. Hamilton, "Efficient Production of Neutral Beams by Photo-Detachment of Negative lons," p. 185 [UCRL-79927 (1977)].

J. R. Hiskes and A. M. Karo, "Formation Processes and Secondary Emission Coefficient for $\mathbf{H}$ Neg Production on Alka]i-Coated Surfaces" [UCRL-80098 (1977)].

E. B. Hooper, Jr., D. A. Anderson, Jc, T. J. Orzechowski, and P. Poulsen, "Sixty keV D Neg Beams Using Double Charge-Exchange System" [UCRL-80102 (1977)].

R. J. Turnbull and E. B. Hooper, Jr., "Stability of Space-Charge Neutralized Beams" [UCRL-80103 (1977)].

Intrgy. Research and Development Administraxion Injormation Meeting on Acceleratnr Breeding, Brookhaven Salional Laboratory. Uipton. New York, January 18-19. 1977.

W. Heckrotte. "Nuclear Processes Involved in Electronuclear Breeding" [UCRL-79152 (1977)].

C. M. YiIn Atta. "A Brief History of the MTA Project," [UCRL-7915] (1977)].

Sctund Imternational Topical Conference on High Power Electron and Ion Bean Rescarch and Tecimolog)', Cornell L'niversity. Ithaca, New York, October 3-5. 1977 |Published in Proceedings of . . . (1977)].

R. J. Briggs. J. Clark, T. J. Fessenden, R. E. Hester, and E. J. Lauer, "Transport of Self-Focused Relativistic Electron Beams," p. 319 [UCRL-79958 (1977)].

E. P. Lee, F. W. Chambers, L. L. Lodestro, and S. S. Yu, "Stable Propagation of an Electron Beam in Gas," p. 38 ] [UCRL-79886 (1977)].

D. S. Prono, H. Ishizuka, and R. J. Briggs, "Intense Pulsed lon Neutral Soutce (IPINS)," p. I4,5 [UCRL$79965(1977)]$.

1977 Cryogenic Engineering Conference, Cryogenic Engineuring Conference Board, Boudder, Coloraúo, A ugust 2-5. 1977 [Published in Proceedings of . . (1977)].

D. W. Deis. D. G. Hirzel, A. R. Rosdahl, D. R, Roach, H. S. Freynjk Jr., and J, P. Zbasnik, "Evaluation of Large Multiflament $\mathrm{Nb}_{3} \mathrm{Sn}$ Conductors with a New 12-Tesla Tensile Test Apparatus" [UCRL-79|92 (1977)].

H. S. Freynik, Jr., D. R. Roach, D. W. Deis, and D. G. Hirzel, "Evaluation of Metal Foil Strain Gauges for Cryogenic Applications in High Magnelic Fields" [UCRL-79202 (1977)].

L.C. Pillenger, "Large-Scale Cryopumping for Controlled Fusion" [UCRL-79381 (1977); CONF 770801-16].

Accelerator Tedmology Conference, Lawrence Livermore Laboratory, Jamuary 25.27. 1977 [Published in Proceedings uf... (1977)].

R. J. Briggs, Scientific Editor, distributed by Naval Surface Weapons Center, Marylund [Rept, NSWC-177].

Conimuing Educalion Program, Lawrente Livermore Laboratory; September 1977 [Published as Eight Videotaped Lectures for ... (1977),

B. McNamura, "Magnetic Fusion Energy." 
Twenty-Fifth Remole Systems Technology Division (RSTD) Conference, San Francisca, Califomia, Novenher 27 through December 2, 1977.

W. Neef, "Remote Servicing Fęatures of Two New Mirror Fusion Reactors" [UCRL-79420 (1977)].

Electric Power Research Instimue Execuive Seminar on Fusion, San Francisca. California. Octoher 1 1.13. 1977.

T. K. Fowler, "Fusion Devices" [UCRL-80060 (1977)].

American Nuclear Society Conference, New York City, Jume 12-16, 1977.

W. Neef, "Mechanical Design Aspects of A Tandem Mirror Fusion Reactor" [UCRL-79434 (1977)].

Institute of Electrical and Electronics Engineers, Power Engineering Sociery Meeting. Special Techuical Sersion on Engineering Aspects of Fusion Power Generation, New Yark City, Januar]' 30-February 4, 1977 [Published in Special Publication of... (1937)].

J. H. Fink, "Efficient, High-Power, High-Energy Neutral Beams for Mirror Fusion Reactor" [UCRL-78895 (1976)].

Elecsric Power Research Insiliture Review Meeting on Advanced Fuel Fusion, Chicago. Ilinois, Jime 27-29, 1977.

A. S. Blum and R. W. Moir, "Direci Energy Conversion and Neutral Beam Injection for Catalyzed D and D He Tokamak Reactors" [UCRL-79642 (1977)].

Particle Accelerator Confercence, Chicago, Ilimois, March 16-18, 1977.

D. Culver, V. K. Neil, and R. K. Cooper, "Beam Break-up Instability in Linear Accelerators" [UCRL-78767 (1977].

1977 National Heat Transfer Conference, Salt Lake City. Litah. August 15-17. 1977.

D. J. Bender and M. A. Hoffman, "A Two.Phase Flow Coaling For Fusion Reactor Blankets" [UCRL -78892 (1977)].

The Training Course in Controlled Thermonuclear Research. Argonne Center for Educatiosal Affairs, Argomme National Laboralory, Argotme. Ilinois, May 26, 1977.

D. J. Bender, "A Review of Mirror Fusion Reactor Designs" [UCRL-79433 (1977)].

Workshop on Fusion Fueling. Princeton Plasma Physics Laboralory, Princeton, Nell Jersety. Furmher 1-3. 1977 [Published in Proceedings of ... (1977)].

J. H. Fink, "Fueling with Neutral Beams," p. 27 [UCRL-80065 (1977): CONF 77ILi2-3].

Electric Power Research Institule Review: Meeting on Adranced Fuel Fusion, Liniversity of Illinois at LrhanaChanjpagne Fusion Studies Laboralory. June 27.28, 1977 [Published in Proceedings of... (1977)].

B. G. Logan, "Prospects for a DD Tandem Mirtor" [UCRL-79641 (1977)].

Intemational Topical Conference on Synchrotron Radiation and Runoway Electrons in Tokumaks, L'nirersity of Maryland, College Park, Marylund, January 17-19, 1977.

E. J. Lauer, "Conditions for Producing a Relativistic Electron Beam in a Tokamak" [UCRL-78852 (I5 77)].

Rensselaer Polyteclmic Institute Seminar, Troy, Nent York, July 5-6, 1977.

R. W. Hornady, "The TMX Conceptual Design" [UCRL-79618 (1977)].

International Conference on Low-Energy lon Beams, Salfor, England, September 5.8, 1977.

J. E. Osher, "The Role of Space Charge in Beam Transpor" [UCKL-79311 (1977)]. 
*C. Christophilos Imernational Sunmer School and Conference in Plasma Physics, Spetses, Greece, July 20 30. 1977 (Published in Proceedings of ... (1977)].

R. J. Briggs. F. W. Chambers, J. Clark, T. J. Fessenden, R. E. Hester, E. J. Lauer, E. P. Lee, and L. L. Lodestro, "Current Multiplication in Relativistic Beam-Plasma Interaction Experiments" [UCRL-79729 (1977)\}.

B. G. Logan. "2XIIR Field Reversal Experiments and Tandem Mirrors," p. 36 [UCRL.79488 (1977)].

The Collegi mu Thipartical and Computational Plasma Physics, International Cenure for Theoretical Physics. Trieste, Lally', March 22-A pril 9. 1977 [Published in Proceedings of... (1977)].

J. A. Byers, B. I. Cohen. W. C. Condit, and I. D. Hanson, "Hybrid Simulations of Quasineutral Phenomena in Magnelized Plasma" [UCRL-80009 (1977)].

Third Imernasional IKIEV/ Conference on Plasma Theory. International Centre for Theorefical Physics, Trieste. Itali!. A pril 5-9. 1977.

J. A. Byers, B. I. Cohen, W. C. Condit. and T. B. Kaiser, "Computer Simulation of Magnetic Field Riversal in Mirror Machines" [UCRL-79164 (1977)].

M. E. Rensink. "Tandem Mirror Studies at Lawrence Livermore Laboratory" [UCRL-79252 (1977)].

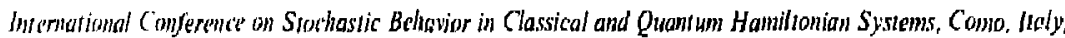
Jume 20-24, 1977 [Published in Proceedings of... (1977)].

G. R. Smith. "Numerical Study of Particle Molion in Two Waves" [UCRL-80121 (1977)].

Summer College on Plysics and Comemporary Needs, Pakistan Alomic Energy Commission. Narhiagali. Pakirtan. Jume 20-suly P, 1977.

B. McNamara, "Magnetic Fusion Energy" JUCRL-79600 (1977)].

Intermational Atomic Energy' Agency Sixth Conference on Plasma Physics and Conorolled Nuclear Fusion, Berchrosgaden, Gertualy. October 6-13. 1976.

D. V. Anderson, J. Boyd, J. Byers, R. Cohen, T. Cutler, L. Hall, B. MeNamara, R. Post, and M. Rensink, "Theory of Mirror Machines at High Beta" [UCRL-78123 Summary (1976)].

H, L. Berk, D. Baldwin, R. Cohen, T. Cutler, L, LoDestro, N. Maron, D, Pearlstein, T. Rognlien, J. Stewart, and D. Watson, "Theoretical Explanation of Present Mirror Experiments and Linear Stability of Larger Scaled Machines" [UCRL-78125 (1976)].

F. Coensgen, J. Clauser. D. Correll, W. Cummins, ., Gormezano, B. Logan, A. Molvik, W. Nexsen, T. Simonen, B. Stallard, and W. Turner, "2XIIB Plasma Confinement Experiments" [UCRL-78121 (1976)].

T. K. Fowler and B. G. Logan, "The Tandem Mirror Reactor" [UCRL-78740 (I976)].

R. W. Moir, W. L. Barr, D. J. Bender, R. J. Burleigh, G. A. Carlson, R. S. Devoro, J. N. Doggett, J. H. Fink, G. W. Hamilton. J. D. Lee, M. E. Rensink, C. E. Taylor, and R. W. Werner, "Mirror Reactor Studies" [UCRL-78122 (1976)].

W. M. Tang, J. C. Adam, B. I. Cohen, E. A. Frieman, J A. Krommes, G. Rewoldt, M. '' Rusenbluth, D. W. Ross, P. J. Catto, K. T. Tsang, and J. D. Callen, "Linear and Nonlinear Theory of Trapped-Particle Instabilities."

International Sympasiun on Plasma Wall Imeraction, Juelich. Germany. October 18-22, 1976 [Published in Proceedings of ... (1976)].

T. C. Simonen, J. F. Cliaser, F. H. Coensgen, W. F. Cumemins, Jr., C. , rmezana, B. G. Logan, A. W. Molvik, W. E. Nexsen, B. W. Stallard, and W. C. Turner, "Plasma wall Interactions in the 2XIIB Magnetic Mirror Experiment," p. 63 [UCRL.78516 (1976)].

B. W. Stallard, F. Coensgen, W. Cummings, C. Gormezano, B. Logan, A. Molvik, W. Nexsen, T. Simonen, and W. Tumer, "Plasma Wall Charge Exchange interactions in the 2XIIB Magnetic Mirror Experiment," p. 63 [UCRL-7874I (1976)]. 
Twelfth Intemarional Conference on Phenomena in Ionized Gases, International Union of Pure and Applied Physics, Eas! Berlin, East Germany, September 12.17. 1977.

B. W. Stallard and R. S. Devolo, "Computation of Plasma Build-up in Mirror Machines" [UCRL-79399 $(1977)\}$.

US/USSR Worksiop on Hybrid Reactor Design, Moscow, USSR, March 14-April 2, 1977.

D. J. Bender, "A Review of the Mirror Hybrid Reactor" [UCRL-79548 (1977)].

Negative-Ion Workshop, State Committee on Atomic Energy, Moscow, USSR, May 29.Junc 10. 1977.

J. R. Hiskes and A. M. Karo, "Negative Inn Yields From Protons and Hydrogen Atoms Buckscaltered from Cesium-Coated Surfaces" [UCRL-79512 (1977)].

Sixth International Conference on Magner Technoiogy. Electrotechmical Institute, Slovak A catkm! of Sciences. Bratislava. Czechoslovakia, Auguss 29-Spetember 2. 1977.

D. N. Cornish, D. W. Deis, A. R. Harvey, D. G. Hirzel, J. E. Johnson, R. L. Leber, R. L. Nelson, and J. P. Zbasnik, "Development Work on Superconducting Coils for a Large Mirror Fusion Test Facility (MFTF)" [UCRL-78891 (1977)].

D. W. Deis, D. N. Cornish, A. R. Rosdahl, and D. G. Hirzel, "Mechanical Strain of Large. Multifilament $\mathrm{Nb}_{3} \mathrm{Sn}$ Conductors for Fusion Magnets" [UCRL-78890 (1977)].

Eighth Eurnpean Conference on Contralled Fusion, European Physical Sociely. CEDON C'mgress Cenure, Prague, Czechoslovakia. September 19-23. 1977.

F. H. Coensgen, "Mirror Machine Program in the U.S." [UCRL-79870 (1977)].

R. W. Devnlo, G. A. Carlson, W. C. Condit, and J. D. Hanson, "Parameters of a Field-Reversed Mirror Reactor" 'UCKi 79507 (1977)].

\section{Publications}

\section{Joumal Articles}

Bulletin of the American Physical Sociery

R. H. Cohen and J. H. Foote, "Nonadiabaticity in a Flat-Bottomed Magnetic Well," 22. 1065 (1977).

J. H. Fonte, "Drift-Surface Calculations for the Tandem Mirror Experiment and the Mirror Fusion Test Facility," 22, '144 (1977).

A. W. Molvik, J. F. Clauser, D. L. Correll, Jr., J. H. Foote, R. K. Goodman, W. E. Nexsen. and W. C. Turner, "Stabilizing Plasma Stream Measurements," 22, 1144 (1977).

\section{Comments on Plasma Physics and Controlled Fusion}

D. E. Baldwin, "Energy Confinement in Mirror Plasmas," 2 (6), 173 (1977).

H. L. Berk, T. D. Rognlien, and J. J. Stewart, "R. F. Bursting in Quasilinear Theory/Pulsation of Turbulence in Quasilinear Theory," 3 (4), 95 (1977).

T. K. Fowler, B. G. Logan, "The Tandem Mirror Reactor," 2 (6), 167 (1977),

Journal of Applied Physics

E. B. Hooper, Jr., and P. A. Willmann, "Angular Scattering in Charge-Exchanging Beams: Implications for Neutral Beam Formation Via Negative Ions," 48 (3), 1041 (1977).

\section{Nuclear Engineering International}

R. F. Post, "Magnelic Mirror Fusion Research, " 22 (263), 59 (1977). 


\section{Nuclear Fusion}

B. I. Cohen, J. ^. Krommes, W. M. Tang, and M. N. Rosenbluth, "Nonlinear Saturation of the Dissipative Trapped-ion Mode by Mode Coupling," 16, 971 (1976).

R. P. Freis, C. W. Hartman. J. Killeen, A. A. Mirin, and M. F. Uman, "Calculations of Combined Steltarator-Multipole Toroidal Magnetic Field Configurations." 17 (2), 281 (1977).

L. S. Hall, "Electron Dynamics and the Enhancement of Q in Mirror Magnetic Walls," 4, 681 (1977).

\section{Plasma Phisics}

D. E, Baldwin and C, J. Watson. "Magnetized Plasma Kinetic Theory-ll Derivation of the Rosenbluth Potenlials for a Uniform Magnetized Plasma," 19, 517 (1977).

\section{Physical Revien leellers}

I. A. Byers, "Computer Simulation of Field Reversul in Mirror Machines," 39 (23), 1476 (1977).

B. G. Logun, J. F. Cluuser, F. H. Coensgen, D. L. Correll, W. F. Cummins, A. W. Molvik, W. E. Nexsen, T. C. Simonen. B. W. Stallard, and W. C. Turner, "High-Beta, Gas-Stabilized, Mirror-Conlined Plasma," 37 (22). 1468 (1976).

W. C. Turner. F. J. Powers, and T. C. Simonen, "Properties of Electrostatic Ion Cyclotron Waves in a Mirror Machinc," 39. $1078(1977)$

\section{Phi!sics of Filuids}

H. L. Burk, and I.. D. Pcarlstein, "Plasnla Return Currents in a Magnetic Field," 19 (11), 1831 (1976).

H. I.. Burk and M. I. Gerver, "Warm Plasma Stabilization of Drift Cone Mode at Finite Beta," 19 (10), 1646 (1976).

F. W. Chambers and A. Bers, "Purametric Interactions in an Inhomogeneous Medium of Finite Extent with Abrupt Boundarits." 20, 466 (1977).

B. I. Cohen and A. N. Kaufman, "Nonlinear Plasma Waves Excited Near Resonance," 20, 1113 (1977).

Revisu of Scrienific Insiruments

R. K. Goodman and A. L. Hunt, “Ammonia-Pellet Generation System for the Baseball II-Target Plasma Experimenl," 48 (2). 176 (1977).

Review of Modern Plysics

D. E. Baldwin. "End-Loss Processes from Mirror Machines," 49 (2), 317 (1977).

Transactions of the American Nuclear Society

D. J. Bender and J, D, Lee, "Fuel Design Considerations for the Mirror Hybrid Reaclor," 27, 341 (1977).

D. J. Bender, J. D. Lee, W. Neef, R. S. Devolo, T. R. Galloway, W. L. Dexter, M. A. Hoffman, J. H. Fink, K. R, Schultz, R. Rao, S. Rao, D. Culver, and W. E. Kastenberg, "A Reference Mirror Hybrid FusionFission Reactor Design," 26, 55 (1977).

G. A. Curlson, "Parametric Design Study of Tandem Mirror Fusion Reactors," 26, 43 (1977).

W. C. Condit, "Second-Generation Design Calculations of the Field-Reversed Mirror Reactor-Summary." 27, 90 (1977).

W. Neef, "Mechanical Structure of the Mirror Hybrid Reactor Power Plant," 27, 68 (1977).

\section{Zeitschriff fuer Naturforschumg (Journal for Natural Science)}

G. Bertschinger, K. H. Finken, and R. S. Hornady, "Schlicren Measurements of a High Density Z-Pinch," $31 \mathrm{~A}, 1318$ (1976). 


\section{Preprints for Journals}

Fizika Plasmy (Plasula Physics)

T, K, Fowler and R. F. Post, "The U.S. Mirror Fusion Program," by Lawrence Livermore Laboratory as UCRL.79532 (1977),

\section{IEEE Transactions on Plasma Science}

J. H. Fink. "Arc Snubbers for Very Large Steady State, Neutral Beam Injectors as Required by Mirror Reactors," published by Lawrence Livermore Laboratory as UCRL-79024 (1977).

J. H. Fink, W. R. Baker, and H, M. Owren, "Analysis and A pplication of a Transformer Core, Arc Snubber," published by Lawrence Liver nore Laboratory as UCRL-79016 (1977).

Journal de Physique (Physics Joumal)

W. C. Turner, "Electrostatic Jon Cyclotron Fluctuations and Ion Energy in a Mirror Machine," published by Lawrence Livermore Laboratory as UCRL-79334 (1977).

\section{Joumal of ripplied Physics}

K. D. Marx, C. J. Eggens, and R. F. Post, "Particle Distributions and Early Phases of lonization in Proposed Convergent Neutral Beam Experiments," pubiished by Lawrence Livermore Laboratory as UCRL-79156. (1977).

\section{Journal of Computational Physics}

J. A. Byers, B. I. Cohen. W. C. Condit, and J. D. Hanson, "Hybrid Simulations of Quasineutral Phenomena in Magnetized Plasma," published by Lawrence Livermore Laboratory as UCRL.79437 (1977).

\section{Nuclear Fusion}

W. L. Barr, R. W. Moir, and J. D. Kinney, "Experimental Results on Direct Energy Conversion for Mirror Fusion Reaclors," published by Lawrence Livermore Labol ntory as UCRL-78966 (1977).

R. S. Devoto and J. D. Hanson, "Computation of Properties of a Field-Reversed Mirror Reactor," published by Lawsence Livermore Laboratory as UCRL-80220 (1977).

J. H. Fink, W. L. Barr, and G. W. Hamilton, "A Study of Efficient High-Power, High-Energy Neulral Beams Cor the Reference Mitror Reactor," published by Lawrence Livermore Laboratory as UCRL-79205 (1977).

B. McNamata, "Report on Trieste College on Theoretical and Computational Plasma Physics," published by Lawrence Livermore Laboratory as UCRL-79460 (1977).

\section{Ply sics of Fluids}

R. Cohen. G. Rowlands, and J. Foote. "Nonadiabaticity in Mirror Machines," published by Lawrence Livermore Laboratory as UCRL-78889 (1976).

R. S. Devoto, U. H. Bauder, J. Cailleteau, and E. Shires, "Air Transport Coefficients From Electric Arc Measurements," published by Lawrence Livermore Laboratory as UCRL-79249 (1977).

R. R. Dominguez and H. L. Berk, "Stability of Interchange Modes in a Hot Eleclron Plasma," published by Lawrence Livermore Laboratory as UCRL-79268 (1977).

T. B. Kaiser, "Velocity Diffusion of Test Particles in Magnetized Plasma Due to Electrostatic Turbulence," published by Lawrence Livermore Laboratory as UCRL-80090 (1977).

E. J. Lauer, E. P. Lee, R. J. Briggs, and T. J. Fessenden, "Measurements of Hose Instability of a Relativistic Electron Beam," published by Lawrence Livermore Laboratory as UCRL-80039 (1977).

E. P. Lee, "Resistive Hose Instability of a Beam with the Bennett Probile," published by Lawrence Livermore Laboratory as UCRL-79913 (19i7). 


\section{Reports}

W, L, Barr, G. A. Carlson, W, L, Dexter, J, N. Dogget, J. H. Fink, G. W. Hamilton, J. D. Lee, B. G. Logan, W. Nee, M. A. Peterson, M. E. Rensink, and R. W. Moir, Preliminary Design of the Tandem Mirror Reactor, UCRL.52:502 (1977).

D. J. Bender and G. A. Carlson, System Model for Anolysis of the Mirror Fusion-Fission Reacior, UCRi$52293(1977)$.

T. A. Cutler, L. D. Pearistein, and M. E. Rensink, Errata Sheet for Computation of the Bounce Average Code, UCRL-\$2233 (1977).

C. C. Damm, J. H. Foote, A. H. Futch, Jr., R. K. Goodman, R. S. Hornady, J. E. Osher, and G. D. Porter, Sireaming-Plasma Meastremerts in the Baseball II-T Mirror Experiment UCRL-52279 (1977)

D. W. Deis and D. N. Comish, Superconducting Magnet Developmen Program A unual Repori: July 1975 $\therefore$.t. Mgh September 1976 UCRL-50031.76 (1977).

R. S. Devoto, Update of Plasma Parameters for a Mirror FERF. UCRL-52203 (1977).

J. Fink, W. Barr, and G. Hamilton, A Study of Efficient High-Power High-Energy Neutral Beams for the Reference Mirror Reactor, UCRL-52173 (1976).

J. H. Fink and G. W. Hamilton, A Neutral Beam Injector for the Tandem Mirror Fusion Reactor Delivering 147 $M W$ of $1.2 \mathrm{MeV}$, UCRL-52280 (1977).

A. H. Futch, Jr., A 2-mm Microwave Interferometer, UCRL-52245 (1977).

M. A. Harrison, C. K. McGregor, and L. Goulieb, Mognetic Fusion Energy Anmual Report July 1975 through September 1976, UCRL-50002-76 (1976)

V. N. Karpenko, Mirror Experimental Facility Project Management Plan, UCRL-52213 (1977).

G. D. Poner, R. H. Bulmer, F. H. Coensgen, W. F. Cunimins, Jr., R. S. Hornady, and R. R. Stone, The Effect of Extended Pulse Length on the Mirror Fusion Test Facility (MFTF), UCRL-52294 (1977).

B. W. STullard and M. E. Rensink, Neutral Bema Current Ragyirements for MX, UCRL-52205 (1977).

Proposal

F. H. Coensgen and C. C. DAmm, TMX Major Project Proposal and TMX Administrative Plan, LLL Prop$148(1977)$. 